\title{
THE ROLE OF LEADERSHIP IN PROMOTING AND SUPPORTING THE BASIC ENGLISH CURRICULUM DESIGN AND DELIVERY AT TWO VIETNAMESE UNIVERSITIES
}

by

TRAN THI BICH THUY

A thesis

submitted to the Victoria University of Wellington in fulfilment of the requirements for the degree of Doctor of Philosophy in Education

Victoria University of Wellington

2015 


\begin{abstract}
The purpose of this research study was to explore the role of leadership in supporting the Basic English curriculum design and delivery at two selected Vietnamese non-language major universities specialising in Finance and Accounting. Studies on academic leadership and distributed leadership in higher education are well documented in Western literature (Bolden, Gosling, O’Brien, Peters and Haslam, 2012; Bryman, 2007; Cardno, 2012); however leadership in higher education is largely under-researched in developing countries like Vietnam. Moreover, curriculum design impacts on the wellbeing and effectiveness of higher education (Barnett \& Coate, 2005). Leadership is necessary to effect change (Oliver \& Huyn, 2010) and therefore potentially to impact on curriculum design and delivery. The role of leadership in making the Basic English curriculum more relevant for graduate students and ensuring that they are better prepared for the workplace is of particular interest in the Vietnamese university context.

This qualitatively-focused case study design, with a small quantitative component, guided by an interpretivist/ constructivist theoretical framework aimed to explore how academic leaders promote the Basic English curriculum design and delivery in the Vietnamese university context. Data were collected through in-depth individual interviews with senior academic leaders and company directors, focus group interviews with English as a foreign language (EFL) lecturers, observations of a curriculum meeting, and an online survey by graduates from the two selected universities. The study employed thematic data analysis techniques. Research shows that the curriculum framework in Vietnamese universities promulgated by the Ministry of Education and Training (MoET) results in heavy workloads for academic staff (Gropello, Thomas, Yemenez, Chchibber, \& Adams, 2008; Van, 2011). This negatively affects their wellbeing and may reduce their effectiveness as teachers and researchers.
\end{abstract}


The findings from the study provided evidence that leadership practices in Vietnam were influenced by Confucian values. It also showed that the personal barriers academic leaders and EFL lecturers face vary according to gender. However, academic leadership in Vietnamese higher education contexts in this study reveals a mixture of distributed and collaborative leadership in curriculum design and delivery which can provide insights for other Vietnamese universities. It also revealed that senior leaders and EFL lecturers appear to work collaboratively to solve the issue of curriculum design and delivery.

The findings have implications for policy development and practice. Suggestions made by employers and graduates to institutional leaders, curriculum developers and lecturers are to consider redesigning the curriculum to have a more communicative focus and more oral practice to ensure graduates are better prepared for work. The study has brought insights for senior leaders on how to create successful collaboration with their colleagues and partners in curriculum design and renewal and provided guidance on the enhancement of educational leadership practices in the two chosen universities. The results of this study have contributed to closing the current gaps in understanding how leadership at all levels in higher education impact on curriculum design and delivery. This study will be useful not only in the Vietnamese context but also in other countries where English is taught as a second or foreign language. 


\section{ACKNOWLEDGEMENTS}

During my PhD journey in Wellington, New Zealand, I had the chance to meet a lot of fantastic people that inspired me, believed in my ideas and in different ways supported me throughout this journey. This thesis would not have been completed without the support of the people whom I thank below.

I would like to express my deepest thanks to my supervisors: Dr Kate Thornton, my primary supervisor, and Associate Professor Catherine Manathunga, my secondary supervisor. Both of them, I believe, are the most wonderful supervisors for their valuable direction, keen insight, informative orientation and warm encouragement throughout this project. Their enthusiasm and encouraging attitudes were sparkling in such a way that it helped to make my research a fun task to fulfil. I am indebted to them for their inestimable support, and for believing in my ability to pursue this study especially in its most critical and challenging moments.

I would like to thank all the research participants in my study for their trust and giving so generously of their time to contribute to the rich sources of data. Without their enthusiastic help, this thesis would not been completed. I would further extend my special thanks to the Boards of Rectors at the two universities, in Vietnam, during my data collection. My deep gratitude also extends to the Ministry of Finance and Ministry of Education and Training, in Vietnam and to all my colleagues at my workplace back home for their continuous support and encouragement.

I am grateful to the staff at Victoria University of Wellington for their encouragement and support. My heartfelt thanks go to Professor Neil Quigley, former Provost, Dr Liz Jones, Director of the Centre for Academic Development, Dr Le Nguyen and Chris Mahoney at the School of Linguistics and Applied Language Studies for their support and encouragement. I also wish to extend my sincere gratitude to the staff at the Faculty of Graduate 
Research and Faculty of Education and for providing a stimulating, supportive, friendly, and professional research and academic environment especially Associate Professor David Crabbe, Dean; Professor Carmen Dalli and Dr Sue Cherrington, Associate Deans. Special thanks also go to the administration team at the Faculty of Education for their help and support.

I especially owe profound gratitude to the New Zealand Scholarship Programme, NZAID for granting me a doctoral scholarship to pursue this study. I also thank the Faculty of Education at Victoria University of Wellington and NZAID for providing me with grants to carry out data collection in Vietnam and to attend and present at international conferences.

I am especially indebted to the staff at the Student Learning, particularly to $\mathrm{Dr}$ Xiaodan Gao for her input which helped make this piece of writing more coherent and cohesive; Dennis Dawson for his help with statistical analysis; Kirsten Reid for her advice on my oral presentation skills. Special thanks go to my NZAID coordinators: Julia Harrison, Linsell Richards and Catherine Guo for their enthusiastic help and support. I am indebted to Helen Barnard, part-time NZAID academic tutor for her encouragement, friendship and enthusiastic help during my PhD journey. My gratitude also goes to Helen Barnard and Hamish Clayton for proofreading my thesis.

My thanks also go to my officemates Siti, Abdul, Phuong, Sudatip, Steve, Angela, Raewyn, Syerina, Sukuna, Tina, Hana, Tinh, Shoba, Hue, Tien, Huong, Ha, Ribut, Wei, John, Josta, Sean, Barathi and Niusila at 31 Campbell Street, Karori campus for their friendship, encouragement and sharing which has filled my time in Wellington with beautiful and unforgettable memories and other friends for their input in the PhD monthly cohort group with Dr Liz Jones, Dr Linda Hogg, and Dr Brenda Service. I also thank all my Vietnamese friends in Wellington as well as my old friends and students in Vietnam for their friendship, encouragement and support.

Finally, I would also like to extend my sincere thanks to all my family members and relatives. My sincere thanks go to my parents, mother-in-law and husband for their love, support and invaluable time bringing up and 
taking good care of my son, Le Minh Huan while I was on study leave in New Zealand. I am especially indebted to my son for his sympathy, love and energy to learn well in the past three years that I was abroad and could not give him daily care and encouragement. However, frequent Skype meetings minimise the geographical distance between New Zealand and Vietnam and these also enabled me to see and encourage my son in his study especially his English learning. Consequently, I would like to delicate this work to my parents, mother-in-law, husband, son and siblings, who have been always supported me to pursue this PhD journey with boundless love and sympathy. 


\section{ABBREVIATIONS}

Vietnamese Non- Language Major Universities: VNLUs

MoET: Ministry of Education and Training

HEls: Higher education institutions

HERA:Higher Education Reform Agenda

MoHA: Ministry of Home Affairs

MoF: Ministry of Finance

MoPI: Ministry of Planning and Investment Ministry of Home Affairs

MoST: Ministry of Science and Technology

ASEAN: Association of South East Asian Nations

AEC: Asian Economic Community

CEFR: Common European Frames of References for languages

IELTS: International English Language Testing System

FPT: Financing and Promoting Technology

QS: Quacquarelli Symonds

EFL: English as a foreign language

TESOL: Teaching English to speakers of other languages

TOEIC: Test of English as international communication

TOEFL: Test of English as a foreign language

OS: Online survey

Early childhood education: ECE

The University of Economics in Ho Chi Minh City: UEH

Information Technology: IT 


\section{TABLE OF CONTENTS}

ABSTRACT

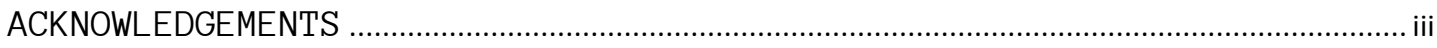

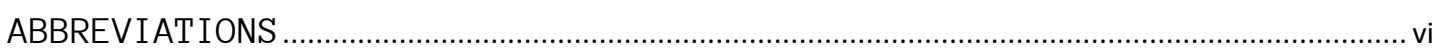

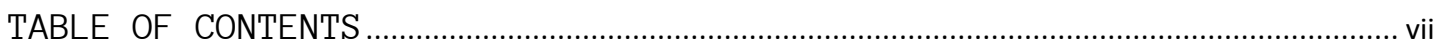

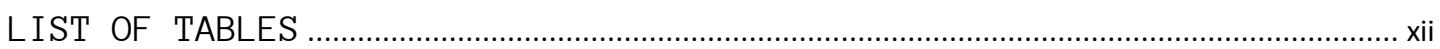

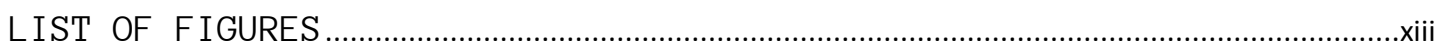

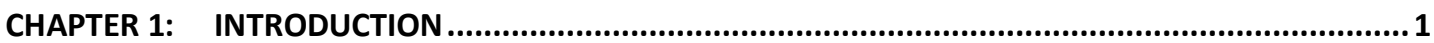

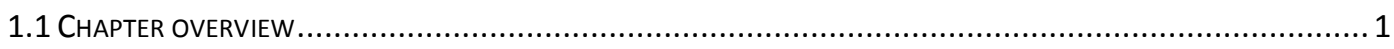

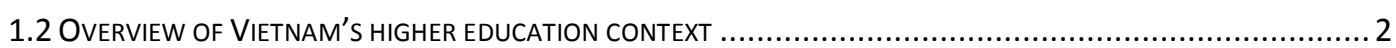

1.2.1 Lack of autonomy and mismatches in Vietnamese laws ............................................... 3

1.2.2 Lack of qualified staff and their English language competence ....................................... 6

1.2.3 An ineffective curriculum and the lack of skill focus for students................................... 8

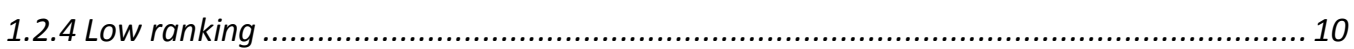

1.2.5 The situation of the teaching and of learning English at VNLUS .................................. 11

1.2.6 The Basic English curriculum design and delivery in this study ................................... 14

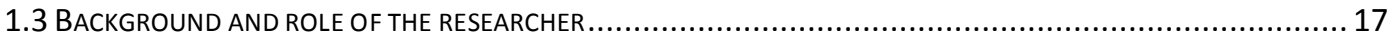

1.4. Educational leaderShiP ReSEARCh IN THE VIeTNAMESE CONTEXT ............................................... 19

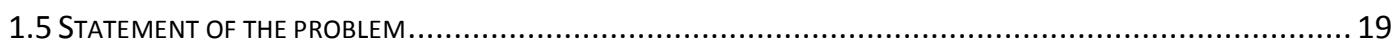

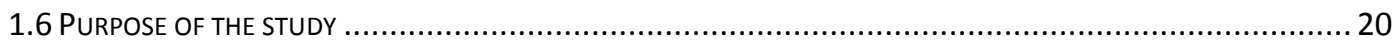

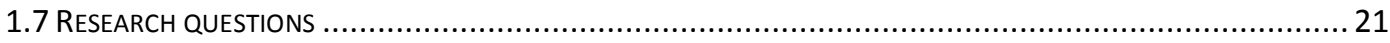

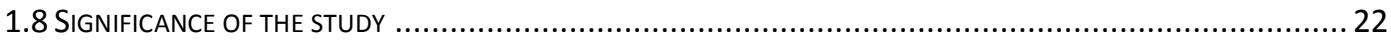

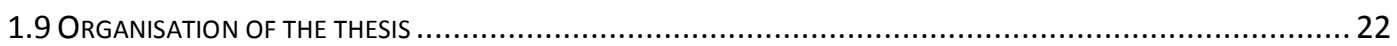

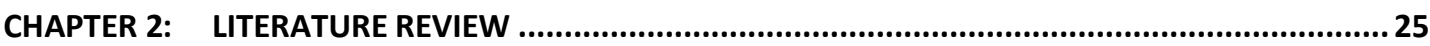

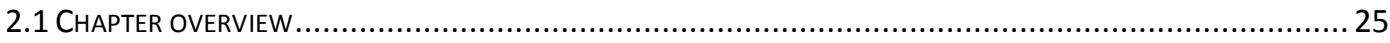

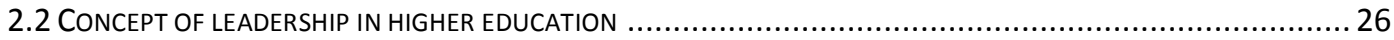

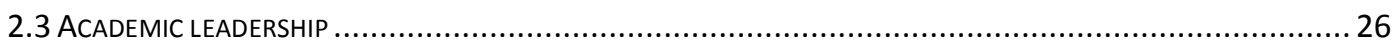

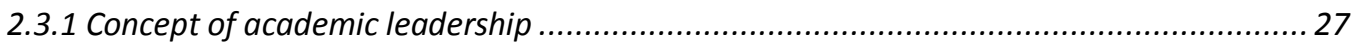

2.3.2 Relevant studies on key features of academic leadership ...................................... 30

2.3.3 Academic leadership and student learning outcomes.......................................... 34

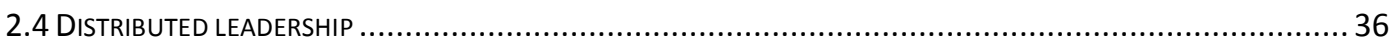

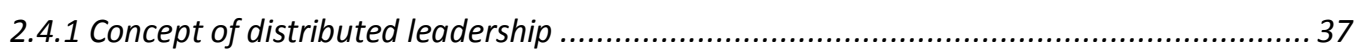

2.4.2 Key features of distributed leadership in higher education ..................................... 41

2.4.3 Supporting distributed leadership ............................................................... 42 


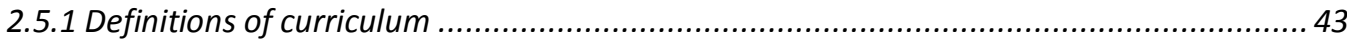

2.5.2 English language curriculum design and delivery ............................................. 45

2.5.3 Definitions of curriculum leadership....................................................................... 48

2.5.4 The importance of curriculum leadership ............................................................... 49

2.6 THE ROLE OF ACADEMIC LEADERS AT DIFFERENT LEVELS IN HIGHER EDUCATION .................................... 50

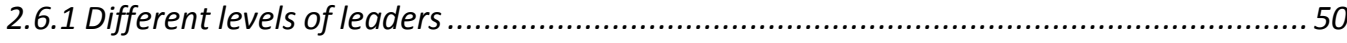

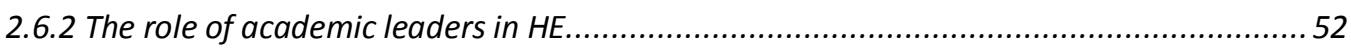

2.6.3 The role of academic dean ................................................................................ 54

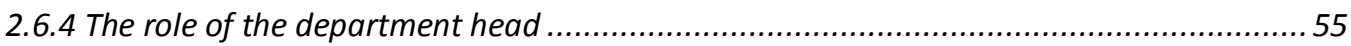

2.6.5 The role of subject coordinator (course coordinator) .............................................57

2.7 CHANGES IN UNIVERSITY CONTEXT AFFECTING LEADERSHIP CAPACITY IN HIGHER EDUCATION ......................60

2.8 FACTORS IMPACTING ON LEADERSHIP APPROACHES IN HIGHER EDUCATION ........................................6 62

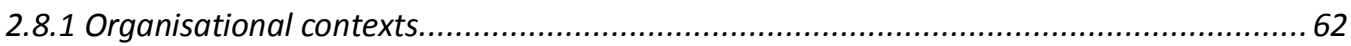

2.8.2 Expectations of leaders in higher education ........................................................ 62

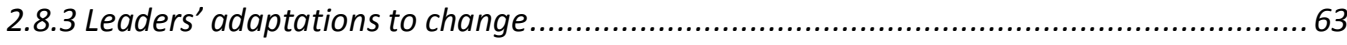

2.9 IMPACTS OF VIETNAMESE CULTURAL AND POLITICAL FACTORS ON ACADEMIC LEADERSHIP.......................... 65

2.9.1 Cultural and political factors impacts on academic leadership .....................................65

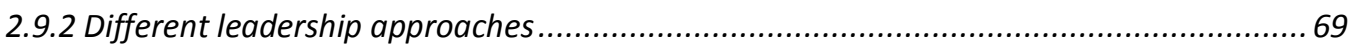

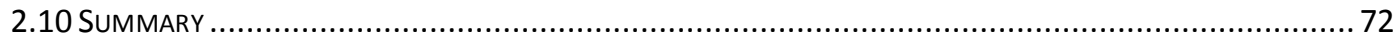

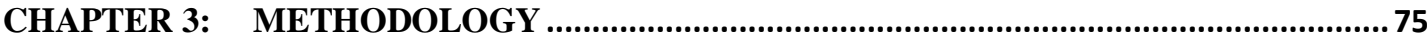

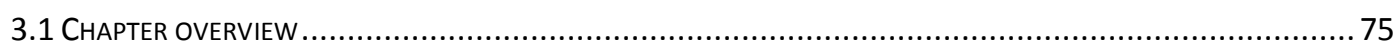

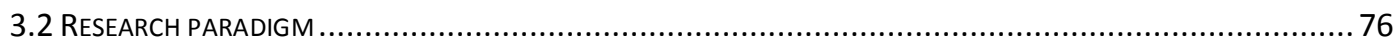

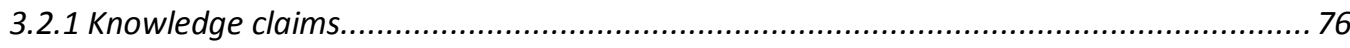

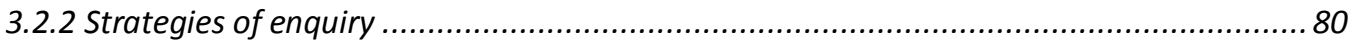

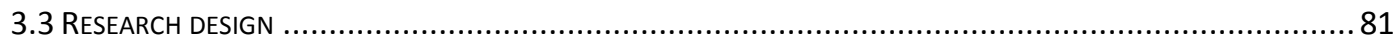

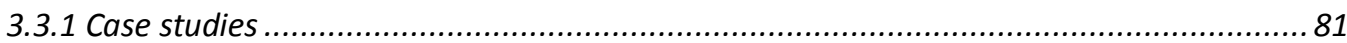

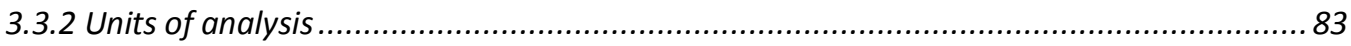

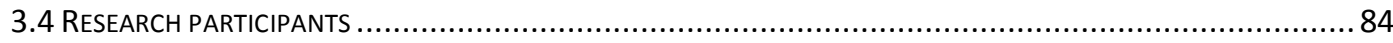

3.4.1 Criteria for selecting research site ................................................................ 84

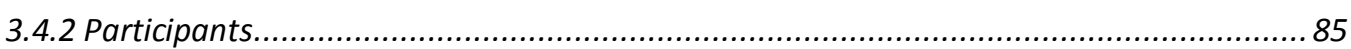

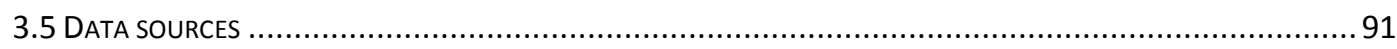

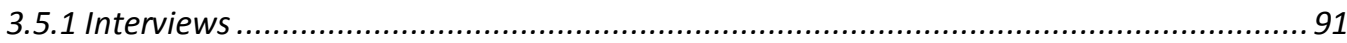

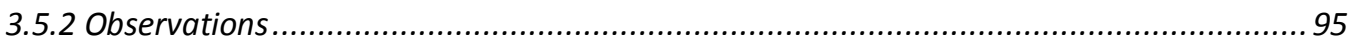

3.5.3 Online questionnaire .................................................................................... 96

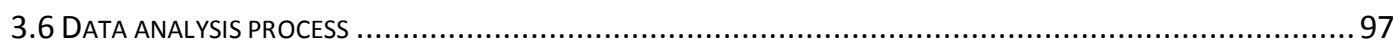




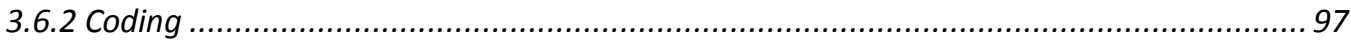

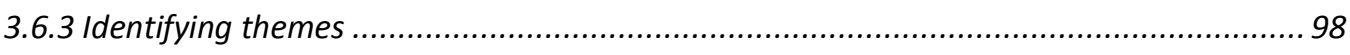

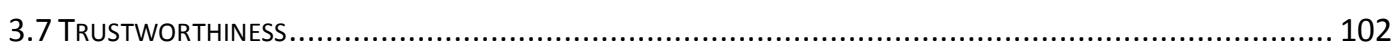

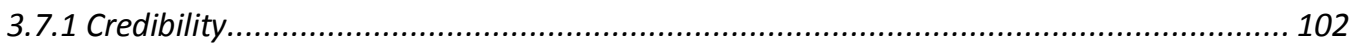

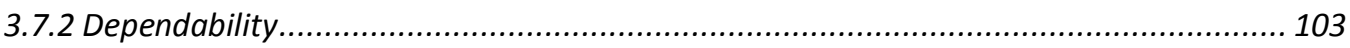

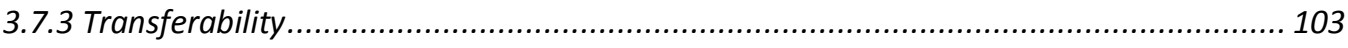

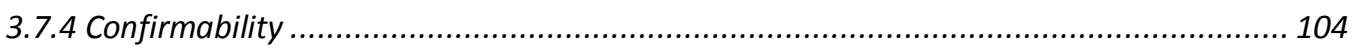

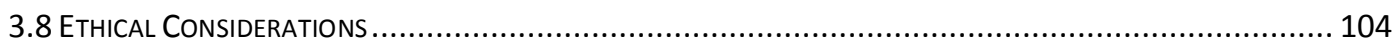

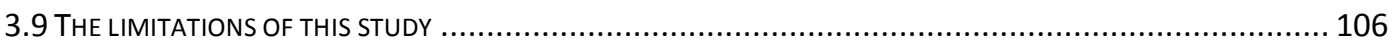

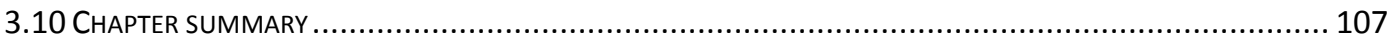

CHAPTER 4: SENIOR LEADERS' PERSPECTIVES ON CURRICULUM ISSUES .................................. 109

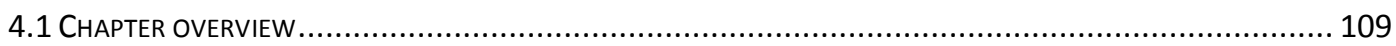

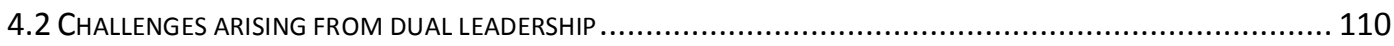

4.2.1 Discrepancies and unclear regulations from the two ministries ................................ 110

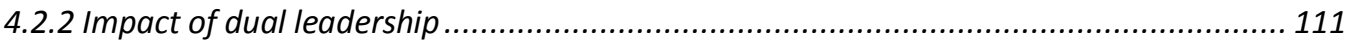

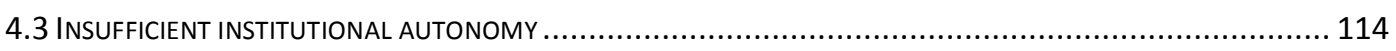

4.3.1 Limited power ................................................................................. 114

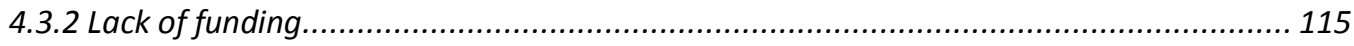

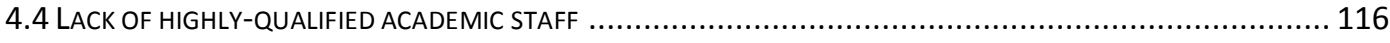

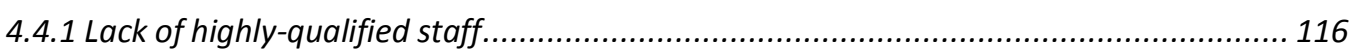

4.4.2 Limited professional knowledge and English ..................................................... 117

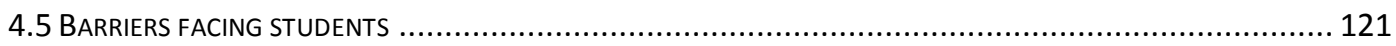

4.5.1 The requirements of the labour market...................................................... 121

4.5.2 To meet the requirements of global integration ................................................ 122

4.5.3 Students' limited English competence ......................................................... 123

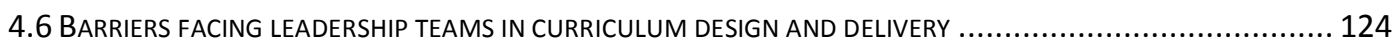

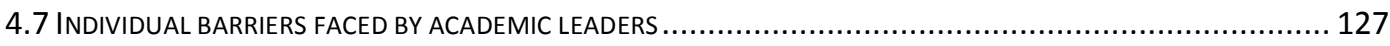

4.8 EFFORTS TO OVERCOME CHALLENGES IN CURRICULUM DESIGN AND DELIVERY ................................... 128

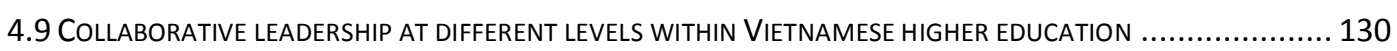

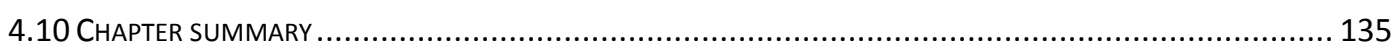

CHAPTER 5: EFL LECTURERS' PERSPECTIVES ON CURRICULUM DESIGN AND DELIVERY............. 137

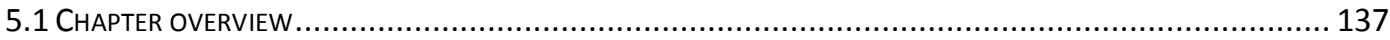

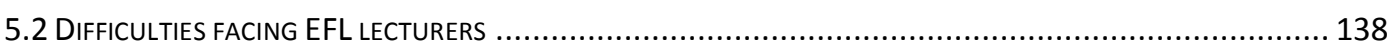

5.2.1 Students' different levels of English competence ................................................... 138 
5.2.2 Large classes 139

5.3 Challenges facing EFL leCturers IN THE BASIC ENGLISH CURRICULUM DESIGN AND DELIVERY ............... 140

5.3.1 Time constraints in doing research and improving qualifications ............................ 141

5.3.2 Insufficient support from the university and the ministries ..................................... 143

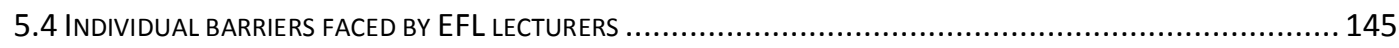

5.5 EFL LECTURERS' COLLABORATION IN CURRICULUM DESIGN AND DELIVERY ...................................... 146

5.6 SENIOR LEADERS' ROLES IN CURRICULUM DESIGN AND DELIVERY ........................................... 147

5.7 EFL LECTURERS' RECOMMENDATIONS TO THE LEADERSHIP TEAMS AND THE MINISTRIES ........................... 147

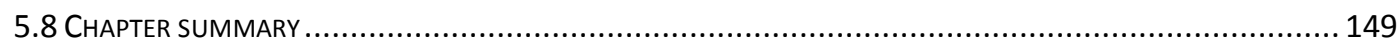

\section{CHAPTER 6: EMPLOYERS' AND GRADUATES' PERSPECTIVES OF THE BASIC ENGLISH CURRICULUM} .151

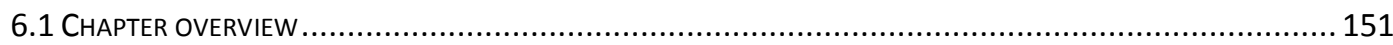

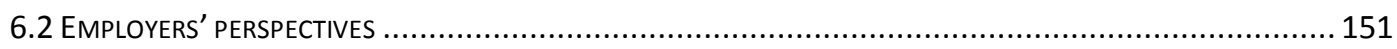

6.2.1 Barriers faced by new employees in the workplace............................................. 152

6.2.2 Encouragement in improving language skills and professional development offered by

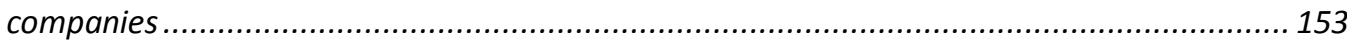

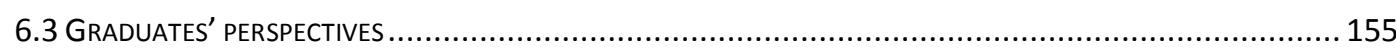

6.3.1 Graduates' perspectives on the relevance of the Basic English curriculum at work........ 156

6.3.2 Graduates' perspectives on the flexibility of the structure of Basic English curriculum... 158

6.3.3 Graduates' perspectives on the appropriateness of time allocation .......................... 159

6.3.4 Graduates' perspectives on lecturers' teaching and assessment ................................ 161

6.3.5 Graduates' perspectives on difficulties in working with senior colleagues ..................... 162

6.3.6 Graduates' perspectives on their communication difficulties ................................... 163

6.4 EMPLOYERS' AND GRADUATES' PERSPECTIVES ON THE EFFECTIVENESS OF THE BASIC ENGLISH CURRICULUM .... 164

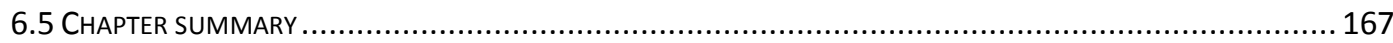

\section{CHAPTER 7: THE IMPACT OF LEADERSHIP ON THE EFFECTIVENESS OF THE BASIC ENGLISH}

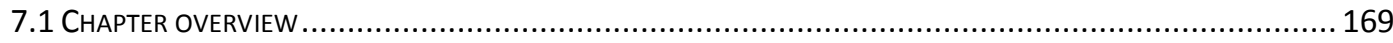

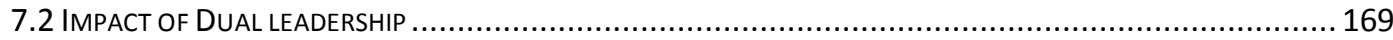

7.2.1 Dual leadership and the resulting lack of autonomy............................................ 170

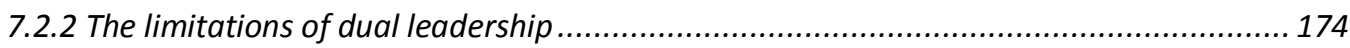

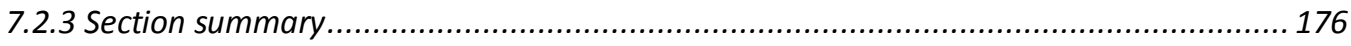

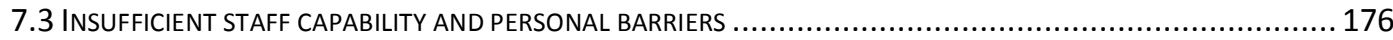

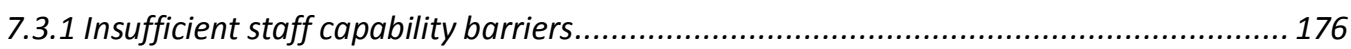

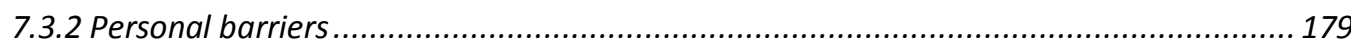


7.3.3 Section summary

7.4 CollaboratiVE LEADERSHIP AT DIFFERENT LEVELS WITHIN THE TWO UNIVERSITIES................................ 183

7.4.1 Building relational trust with colleagues and partners......................................... 183

7.4.2 The role of collaborative leadership ...................................................................... 187

7.4.3 EFL lecturers' collaboration in curriculum design and delivery .................................. 189

7.4.4 Positive factors enhancing collaborative leadership ............................................ 191

7.5 SYNTHESIS OF THE UNIVERSITY LEADERS' PERSPECTIVES ON THE EFFECTIVENESS OF THE BASIC ENGLISH

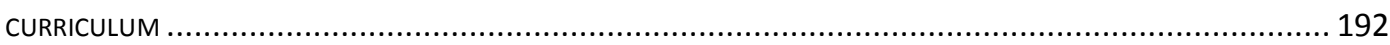

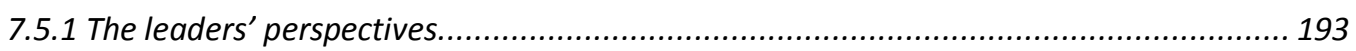

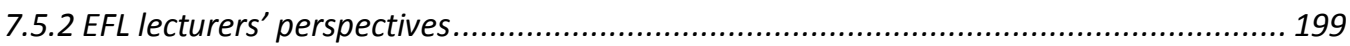

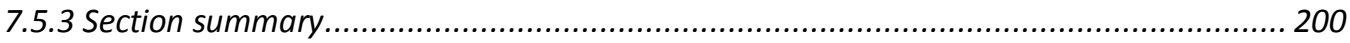

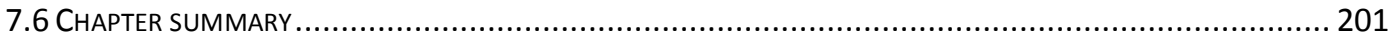

CHAPTER 8: $\quad$ RESEARCH IMPLICATIONS AND CONCLUSION................................................... 203

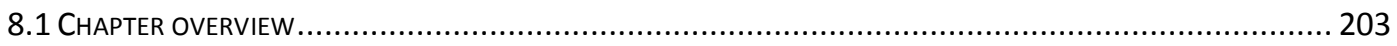

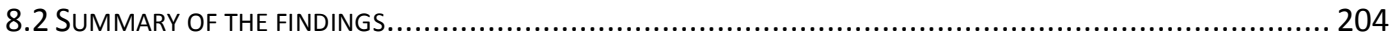

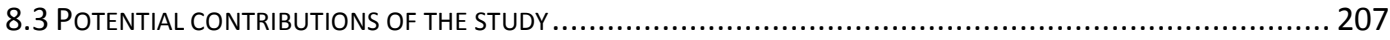

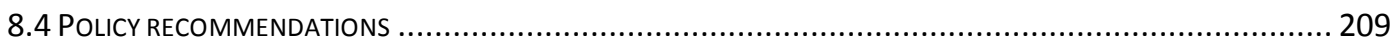

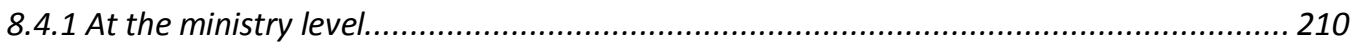

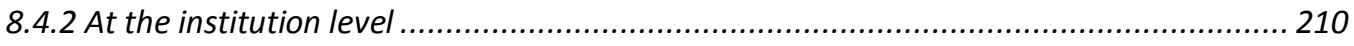

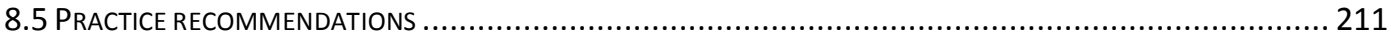

8.5.1 For university leaders ..................................................................................... 212

8.5.2 For curriculum developers ............................................................................. 213

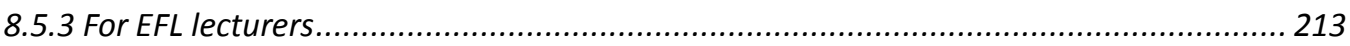

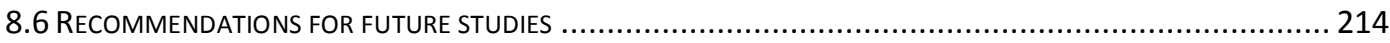

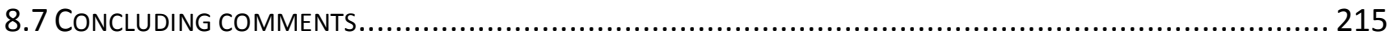

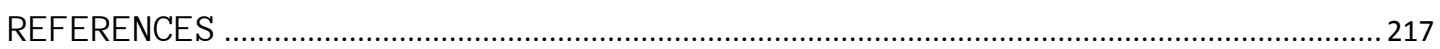

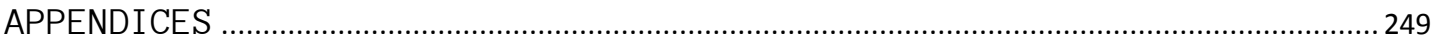




\section{LIST OF TABLES}

Table 1.1: Mismatches between articles of the Higher Education Law 2012 ..5 Table 1.2: Correlation among international equivalent tests (Pearson

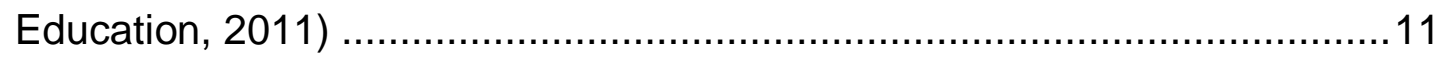

Table 3.1: Summary of the methodological approach taken in the current

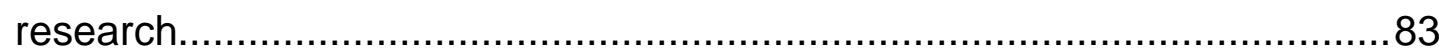

Table 3.2: Profile of academic leaders at University One ..............................86

Table 3.3: Profile of academic leaders at University Two .............................87

Table 3.4: Profile of EFL lecturers from the two universities..........................88

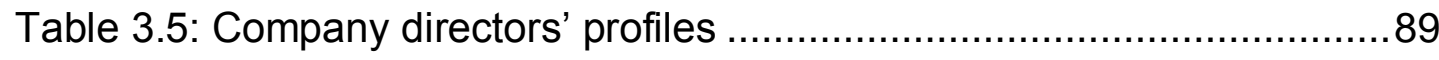

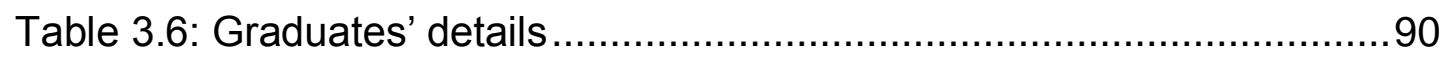

Table 3.7: Data collection timeline at University One..................................90

Table 3.8: Data collection timeline at University Two....................................91

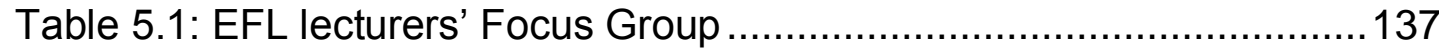

Table 7.1: Rankings of Vietnam National universities Adapted from (QS top

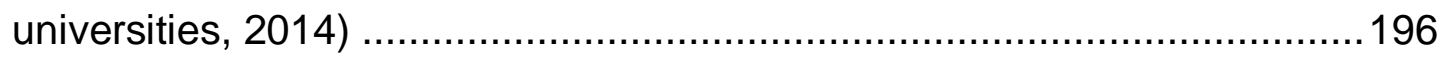




\section{LIST OF FIGURES}

Figure 1.1: Teaching and Learning English at HEls based on Van (2011) .. 13 Figure 2.1: Academic leadership, academic management and self-leadership (Bolden et al., 2012). 28

Figure 2.2: Dimensions of a curriculum adapted from Richards (2013, p.7) 46 Figure 2.3: The 'Authority over teaching' model adapted from Scott et al. (2008) 51

Figure 2.4: The influence/impact on teaching and learning' model adapted from Scott et al. (2008). 52

Figure 3.1: The convergent design adapted from Creswell and Plano Clark (2011) 83

Figure 3.2: The proposed model in the Vietnamese university context........ 85

Figure 3.3: Examples of coding.......................................................... 98

Figure 3.4: Data analysis framework based on Creswell (2014, p. 197) ...... 99

Figure 3.5: The procedure of research adapted from Creswell and Plano Clark (2011, pp. 79-80) 101

Figure 6.1: Relevance of the Basic English curriculum to practical work ... 157

Figure 6.2: Flexibility of the structure of the Basic English curriculum 159

Figure 6.3: Appropriateness of time allocated to theory/practice 160

Figure 6.4: Graduates' satisfaction with the lecturers' teaching and assessment. 161

Figure 6.5: Challenges involved in working with senior colleagues 162

Figure 6.6: Graduates' difficulties in communicating with customers 163

Figure 7.1: Dual leadership of the two universities 174

Figure 7.2: Barriers affecting the two leadership teams 182

Figure 7.3: Factors enhancing collaborative leadership. 192

Figure 7.4: Causes and effects of the Basic English curriculum 201 



\section{Chapter 1: INTRODUCTION}

\subsection{Chapter overview}

Studies on academic leadership and distributed leadership in higher education are well documented in Western literature (Bolden, Gosling, O'Brien, Peters, \& Haslam, 2012; Bryman, 2007; Cardno, 2012); however leadership in higher education is largely under-researched in developing countries like Vietnam. Leadership in Western universities is complex with contradictory patterns of aspirations for distributed leadership within a traditionally hierarchical structure. Little is known about how leadership is enacted in Vietnamese universities. This study was located within the research area of leadership, focusing on aspects of leadership in higher education including academic leadership, distributed leadership, leadership of curriculum design and delivery and the role of educational leaders at different levels in curriculum design and delivery. This study focuses on exploring the role of leadership in innovating the Basic English curriculum design and delivery at the two selected Vietnamese non-language major universities specialising in Finance and Accounting. For the purposes of this study, in the subsequent sections and subsections, it is necessary to refer to the two selected Vietnamese non-language major universities as VNLUs.

This introductory chapter aims to set the context for this study and provide an overview of the research study. The chapter begins by laying the background for the study by providing some brief information on the Vietnamese higher education context and the situation of teaching and of learning English at the tertiary level in general and at the two universities in particular. Following this is a brief discussion of the methodology and the background and role of the researcher. This is followed by a general statement of the problem. The rationale for this study is stated before the purpose of the study and the research questions are outlined. The chapter concludes by outlining the organisation of the thesis. 


\subsection{Overview of Vietnam's higher education context}

Vietnam is an agricultural and developing nation in South East Asia with a population of over 90 million. It is a socialist republic led by the Communist Party. The education sector in Vietnam is controlled by the Ministry of Education and Training (MoET). This control was granted in the Education Law (1998, revised 2005), which assigned MoET the responsibility for all education and training and supervision of the Departments of Education and Training in the 64 cities and provinces in the country. Therefore, MoET is both powerful and influential because it is responsible for planning and directing Vietnam's higher education system (Sarvi, Dhirathiti, Medrano, \& Banta, 2012). MoET has the power, for example, to approve the establishment of new higher education institutions (HEls), closing programmes, and approving HEls' regulations, as well as curriculum development and materials production. The educational systems of Vietnam in general, and in higher education in particular, have changed substantially over the last two decades.

The Higher Education Reform Agenda (HERA) 2006-2020 in Vietnam has built on the changing education environment which has seen spectacular growth in the number of public, semi-public and private HEls (Runckel, 2009). Among the changes in higher education are the founding of many new universities and colleges in all parts of the country and the expansion of existing institutions. There were 101 universities and colleges in the country in 1987 compared with 419 in 2011 (General Statistics Office of Vietnam, 2011). However, despite the growth in educational institutions there are issues with the quality of education these institutions offer. This was highlighted at the 11th Vietnamese Communist Party Congress in 2011, where the Party emphasised that the quality of education and training did not meet the requirements of development. Shortcomings in the Vietnamese higher education sector have been identified. The following sub-sections present the challenges in Vietnamese higher education including lack of 
autonomy, the lack of qualified staff and issues with their language competence and the low ranking of universities in global ranking lists.

\subsubsection{Lack of autonomy and mismatches in Vietnamese laws}

The term 'Autonomy' first appeared in the Law of Education 2005 (Anh, 2014). Autonomy may take a variety of forms. According to the United Nations Educational, Scientific and Cultural Organisation (2014), university autonomy is the freedom and authority enjoyed by universities and institutions of higher education to play their role and contribute to societal development within the framework provided by public authorities. Institutional autonomy implies the freedom for an institution to run its own affairs without the direct control or influence of the government. The influence exercised by the government may be based on legislative measures. On the other hand, institutional autonomy is perceived by Varghese and Martin (2014) as appointive authority, particularly in cases where staff are not employed as civil servants. Financial autonomy, however, has been granted in recent reforms primarily due to the inability of the public sector to support an expanding higher education sector. A further form of autonomy is administrative authority, which plays an important role in facilitating faster implementation of decisions. As Vietnam is a hierarchical country, therefore it is necessary to take the idea of academic autonomy and authority relations between MoET and universities into consideration. One of the factors affecting Vietnamese higher education is the lack of autonomy, particularly the mismatches and conflicts between Education Law 2005 and the Law of Higher Education as regards the claim of autonomy (Anh, 2014).

In the higher education sector, the Vietnamese government has the highest authority over tertiary education, including over private sector providers (Hung, 2012). Government authority is exercised through ministries with various regulatory responsibilities. There are five ministries which have regulatory responsibilities to the Vietnamese higher education sector, namely the MoET, the Ministry of Finance (MoF), the Ministry of Home Affairs (MoHA), the Ministry of Planning and Investment (MoPI), and the Ministry of 
Science and Technology (MoST) (Hayden \& Thiep, 2007). These ministries are also called line ministries and they provide advice to the government about the tertiary education sector including national policies and targets, financial plans, labour force plans, and governance protocols. Based on the suggestions from these ministries, the government decides on "the intended growth of the educational system, the appropriate balance of capital and recurrent expenditure, the extent of the application of a user pays principle, and the required levels of integration between the tertiary education sector and other sectors of the economy" (Hayden \& Thiep, 2010, p.19). The role of the State was also addressed in Article 14 of this 2005 law, namely to "implement the decentralisation of educational management; and to increase the autonomy and accountability of educational institutions". Nevertheless, this term was mentioned without any explanation of what autonomy means, or when and how the State will increase autonomy within HEls. Until 2012, when the Law of Higher Education was promulgated, the entire article 32 focused on autonomy in terms of governance, academic, and finance as follows:

- Higher education institutions are autonomous in major activities related to their organisation and personnel, finance and infrastructure, training and research, and quality assurance. Higher education institutions can be granted a higher degree of autonomy based on their capacity, ranking, and accreditation results.

- HEls which show they are no longer capable of being autonomous, or which violate the law while exercising their autonomy, and will be sanctioned according to the law.

It could be interpreted that autonomy is thus granted as a legal right, but not a favour from MoET. Since the introduction of the law of higher education there have been actual and obvious improvements in terms of academic autonomy. For instance, improvements on student admissions appeared in Article 34 and Article 36: 


\section{Article 34. Admission quota and organising the admission}

b) HEls autonomously decide their admission quota, are responsible for publicising their quota, the quality of their programmes, and the conditions to assure quality of educational activities in their institutions.

\section{Article 36. Curriculum and course books}

d) HEls are autonomous and held accountable in establishing, examining, and issuing programme curricula for all levels of training - associate, bachelor's, master's, and doctoral;

However, several mismatches and conflicts in the law can be easily seen in the following table contrasting Article 33 and Article 34.

Table 1.1: Mismatches between articles of the Higher Education Law 2012

\begin{tabular}{|l|l|}
\hline Article 33 - New course offerings & Article 34-Student admissions \\
\hline The Minister of Education issues & Higher education institutions \\
specific regulations concerning the & autonomously decide their admission \\
conditions, sequence, procedures to & quota, are responsible for publicising \\
offer or cancel new degree courses & their quota, the quality of their \\
at associate, bachelor, master, or & programmes, and the conditions to \\
doctoral degrees; decides whether & assure quality of educational activities \\
to allow or cancel new course & in their institutions. \\
offerings at the aforesaid levels. & \\
\hline
\end{tabular}

Another example of mismatch in law is on degree certificates, e.g. Article 38:

HEIs create the master copy and print their own degree certificates and award them to their graduates; and make public all information about degree awards on their websites.

But right below this, the same article stipulates:

MoET issues regulations concerning the design of degree certificates; the printing, awarding and revoking of degrees; regulates the responsibility and authority to grant degrees of Vietnamese HEls in joint degrees with foreign partners; regulates the 
responsibility of HEls with Foreign Direct investors (FDIs) in awarding degrees in Vietnam; sign agreements with international organisations concerning degree equivalency and recognition; and regulates the sequence and procedures for recognising foreign degrees held by Vietnamese.

Therefore, no significant changes have happened in terms of financial autonomy and governance in the law (Anh, 2014). Admission quotas, admission organisation, curriculum frames etc. are tightly controlled with very detailed regulations by MoET. Therefore, autonomy in Vietnamese higher education appears to be curtailed.

\subsubsection{Lack of qualified staff and their English language competence}

Another weakness is the shortage of teaching staff (Runckel, 2009). Runckel's observation is supported by Government statistics as follows: in the 2007-2008 academic year there were 1,055,078 teachers for all levels of education. Currently, Vietnam has a shortage of about 40,000 teachers including 20,000 university lecturers (MoET, 2009). When talking about problems of higher education in Vietnam, Hung (2012) points out that lecturers in HEls are poorly remunerated and many are not supported to do research. Too few qualified academics in higher education results in high teaching loads. Moreover, due to poor pay conditions (due to a salary and incentive system stipulated by the government through the national system of salary managed by MoHA (Huong, 2012; Sarvi et al., 2012), lecturers have to do many extra jobs to support their family. As a result, research is not a high priority for many Vietnamese academics. Over the past 29 years of reform, Vietnam has developed a centralised national education system, but within this, there is allowance for a wide range of tertiary providers and some different types of programmes. Nevertheless, tertiary education still has inadequacies and weaknesses in comparison to the requirements or standards of countries in the industrialised, modernised and internationally integrated world.

Further, a comparatively large number of staff are not professionally qualified or experienced in many disciplines including foreign languages and information technology. Deputy Minister of Education and Training, Nguyen 
Vinh Hien, admitted this while speaking about improving teaching generally and specifically English language teaching at a conference in Hanoi in 2012. He said the biggest problem in English language training in Vietnam was the scarcity of good quality teachers. Moreover, the deficiency of teachers' qualifications and experience was included in a statement by a researcher who noted that there were few visionary educational leaders and a shortage of well-trained and qualified faculty teachers and educational administrators (Phuong \& Berg, 2010).

Acknowledging the shortcomings in education and training, the Communist Party has instituted decrees or resolutions to innovate Education and Training fundamentally and radically (Anh, 2012). In the same year, the Higher Education Law 2012 appeared to be bringing some solutions to address the shortcomings in the higher education sector. One of the solutions is seen in the National Foreign Languages 2020 Project (Nhan, 2008) under Decision No 1400-QD-TTg, signed by the Prime Minister on September 30th, 2008, approving the project on foreign language teaching and learning in the national education system for 2008-2020. Since then, there have been many positive changes in foreign language teaching and learning from primary to the higher education sector. One of these initiatives, as part of the Project, is that English teachers at public universities will undergo a test to ensure they are qualified. The required level is C2 according to Common European Frames of References for languages (CEFR) for tertiary lecturers who teach English-major students whereas the requirement is $\mathrm{C} 1$ for teachers who teach non-English major students, which is equivalent to a band score of 6.5-7.0 with the International English Language Testing System (IELTS) for tertiary lecturers. The test would not be a problem for those teaching talented or English-major students, at universities, as these students have supportive backgrounds and some experience with English. However, it might be difficult for many teachers in universities teaching English as a non-major subject and for teachers at universities located in rural areas with few English competence and teaching aids. Since the National Languages 2020 Project was instituted, many 
teachers in underprivileged schools have felt nervous about their scores in the CEFR test as the results will affect their future careers (Vietnam News Agency, 2012a). Because of this, there may be doubt as to how well they can teach students so that students will then apply what they have learned when they come to the workplace.

A former manager of the Project, Nguyen Ngoc Hung, said the test could be modelled on those from international institutions, such as Cambridge and Oxford universities, or from eight prestigious universities nationwide licensed by MoET, including Hanoi University, Vietnam National University, and Ho Chi Minh City University for Teacher Training. Hung said the test will help departments of education and training to assess the quality of English teachers and then, based on the results, local authorities can make adequate plans to train and foster teachers. It was also decided that localities will give under-qualified teachers two years to improve their skills. However, how effective such strategies are in providing training courses for teachers remains to be seen.

\subsubsection{An ineffective curriculum and the lack of skill focus for students}

Developing curricula can transform an ordinary school into an institution of excellence (Wiles, 2009). A number of scholars discuss the significance of curricula in higher education (Barnett \& Coate, 2005; Wolf \& Hughes, 2007). Barnett and Coate (2005), with Barnett and Coate arguing that despite its significance little attention has been given to it. They express a sense of urgency in their viewpoint that higher education curricula must be a key topic under consideration for "the well-being and effectiveness of higher education" (p.7). The curricula framework used by universities in Vietnam is decreed by the MOET and is associated with heavy workloads for academic staff (Canh \& Barnard, 2009; Huong, 2012; Van 2011). Although there is evidence that curriculum and teaching methods are slowly improving, there is a lack of a skills focus and so graduates entering the workforce are seen as having inadequate skills in team and other group work, and in critical thinking (Anh, 2010; Gropello et al., 2008; Mai, 2015). 
Another issue concerning Vietnamese universities is noted by Hung (2007) who stated in an interview with a Viet Bao newspaper reporter that the greatest failure of Vietnamese universities is that only a small number of highly qualified students are proficient in the requirements of the global economy. He also argues that, similar to high school level, universities do not prepare students in important skills such as communication, creativity, leadership and personal style due to the curricula, teaching methods and organisational and administrative systems being inflexible and not adequate to meet the present situation. The narrowness of curricula has led to weaknesses in the quality and efficiency of training. As discussed earlier, curricula at tertiary level does not produce well-rounded graduates. The main reason for this is that their education is still very theoretical and formal.

One outcome of this didactic approach is that Vietnamese students are passive and used to listening and writing (Le, 2005). Other effects of this approach are that students learn the lecturer's materials, but not how to criticise or create things for themselves, nor do they gain problem solving skills. These deficiencies mean graduates are not work ready and a significant percentage of companies need to retrain them (Anh, 2010; Gropello et al., 2008). Hung (2007) notes significant statistics in relation to this and states that every year, in Vietnam about 150,000 students graduate from universities/colleges. However, only $5 \%$ to $10 \%$ of the best students with good communication skills and English language competence find jobs with a salary of approximately $\$$ US500 per month. These positions are usually in foreign companies. The others cannot find jobs, or have jobs with very low incomes. It is evident, with such low percentages of successful employment, that students cannot meet the requirements of the labour market or the social and economic needs of each region. A contributing factor to this situation is the lack of a skills focus in the English curriculum. The lack of a skills focus may also be a contributing factor to the low position of Vietnamese universities in global ranking lists (Huong, 2012; Ly et al, 2014). Accordingly, in this chapter the situation of teaching Basic English in Vietnamese universities is discussed. 


\subsubsection{Low ranking}

Rankings are established to favour American-European universities that have a very long history. By contrast, the rankings of Vietnamese universities are very low in the world. Given the above-mentioned factors (lack of autonomy and mismatches in the higher education laws, and lack of qualified staff with low English language competence and poor pay conditions), the low rankings of Vietnamese universities in the world are not surprising (Huong, 2012; Sarvi et al, 2014).

Further evidence of issues of quality within Vietnamese universities is marked by their status in the world university rankings. The Financing and Promoting Technology (FPT) University has become the first to be awarded three stars by British Quacquarelli Symonds (QS) Stars, one of the leading global university rating systems (Trinh, 2012). The government's awareness of the many problems facing universities is evident in a statement by the Deputy Prime Minister and Ex-Minister of Education and Training, Nguyen Thien Nhan, who said the quality of higher education in Vietnam remains low and drastic measures are required to improve it (MoET, 2009). Similarly, Professor Tran Hong Quan, the former Vietnamese Minister of Education and Training, confirmed that the quality of education has not met the demands of society due to old-fashioned educational thought especially managerial thought (Quan, 2010). The Vietnamese Emeritus Professor Nguyen, a Belgian-resident now, acknowledged in 2012 the limitations of the outdated philosophies of education and strongly recommended that Vietnam should immediately remove the conservative educational leadership and radically revise the human resource requirements for these positions. D. Hung (2012) also added that Vietnam should appoint staff based on their ideas rather than their curriculum vitae and contact with senior leaders. 


\subsubsection{The situation of the teaching and of learning English at VNLUs The importance of English for VNLU graduates}

English has gained the predominant role in the foreign language teaching programme at Vietnamese universities since the 'Doi Moi-economic policy reform' in 1986 (Van, 2008). One of the reasons for the popularity of English lies in Vietnam's establishment of diplomatic relationships with 180 countries, and economic and trade ties with 230 countries and territories in the world (Vietnam News Agency, 2012c). Vietnamese people in general and Vietnamese students in particular are aware of its importance as an official international language to access information and meet the needs of the labour market in in terms of the processes of modernisation, industrialisation, integration, and globalisation. Therefore, English provides the Vietnamese with more opportunity to improve their study, work, and living conditions. Vietnamese students are required to be able to communicate in English fluently enough to apply for jobs in both the domestic and international labour markets, and in the sectors that provide high-paying jobs.

With regard to the importance of English before graduation as well as embarking on employment opportunities, students are expected to use English at the pre-intermediate level which is equivalent to B1-CEFR after finishing the English credits course prior to their graduation ceremony (Hien, 2014). This regulation is stipulated in the National Foreign Languages Project 2020 (Nhan, 2008). Students can alternatively sit for other international equivalent tests of English and send the certificate to their universities before their graduation. The following table shows the correlations among these tests.

Table 1.2: Correlation among international equivalent tests (Pearson

\section{Education, 2011)}

\begin{tabular}{|l|l|l|l|l|l|}
\hline Level & CEFR & TOEIC & $\begin{array}{l}\text { TOEFL } \\
\text { IBT }\end{array}$ & $\begin{array}{l}\text { TOEFL } \\
\text { PBT }\end{array}$ & IELTS \\
\hline $\begin{array}{l}\text { Low intermediate } \\
\text { to intermediate }\end{array}$ & A2- B1 & $\begin{array}{l}545- \\
615\end{array}$ & $53-64$ & $477-510$ & $\begin{array}{l}4.5- \\
5.0\end{array}$ \\
\hline
\end{tabular}


In the domestic labour market, apart from good skills, one important requirement to work in a foreign company or a joint venture is English proficiency, especially for positions like executive assistants, bank clerks, accountants or auditors and so on. These employees are required to do research, attend meetings, and do other clerical office work in which English is indispensable in daily communication. Therefore, English language proficiency is a crucial requirement for the national human capital in the context of globalisation and internationalisation as well as in today's competitive world of work (Ly et al., 2014; Tuyet, 2013a).

In reality, Vietnamese graduates' inability to communicate in English has been open to criticism. According to Anh and Tho (2014), there are about 40 training providers including $24 \mathrm{HEls}$ which offer Finance-Banking training across Vietnam. Every year there are about 11,000 graduates with Bachelors in Finance-Banking. Among this large amount of graduates, only a few students are employed by banks in Vietnam because many of them lack English communication skills as well as critical thinking and soft skills (Hoan, 2014). Accordingly, a lack of English proficiency may have lowered the competitiveness of Vietnamese graduates compared with that of citizens from neighbouring countries who will arrive in Vietnam to find jobs when the ASEAN economic community (AEC) comes into being at the end of 2015, transforming ASEAN into a region with free movement of goods, services, investment, skilled labour, and freer flow of capital (Minh, 2014).

\section{Teaching and learning English at VNLUs}

When studying foreign languages in general, and English in particular, a combination of the skills of reading, writing, listening and speaking are involved. The limited attention given to these skills was noted by the Deputy Minister of Education and Training, Nguyen Vinh Hien, who indicated that teachers have been focusing on grammar instead of other skills (Vietnam News Agency, 2012a). In Vietnam's higher education, English is taught nationally as a discipline and as a subject (Van, 2011). In the former category, students study English as their major to gain a Bachelor of Arts 
(BA), a Master of Arts (MA) or a doctoral degree in English so that they can become teachers, interpreters or researchers in English linguistics or in English language teaching. In the latter category, English is a compulsory subject taught across the entire higher education system at VNLUs. Students study 14/140 credit hours. Ten percent of the total English credit hours of an undergraduate programme is divided into two parts, Basic English and Academic English, according to MoET's regulations. Moreover, some tertiary universities select a set of imported English textbooks and mandate a number of units for teaching Basic English within the amount of time stipulated by MoET whereas other institutions design their own programmes. Different universities take a different view on what to teach. Therefore, this creates diversity on the one hand but confusion on the other. Normally, each institution in the aforementioned latter category teaches their students Basic English and then Academic English for their students' own major. The following figure illustrates the situation of teaching and learning English at HEls.

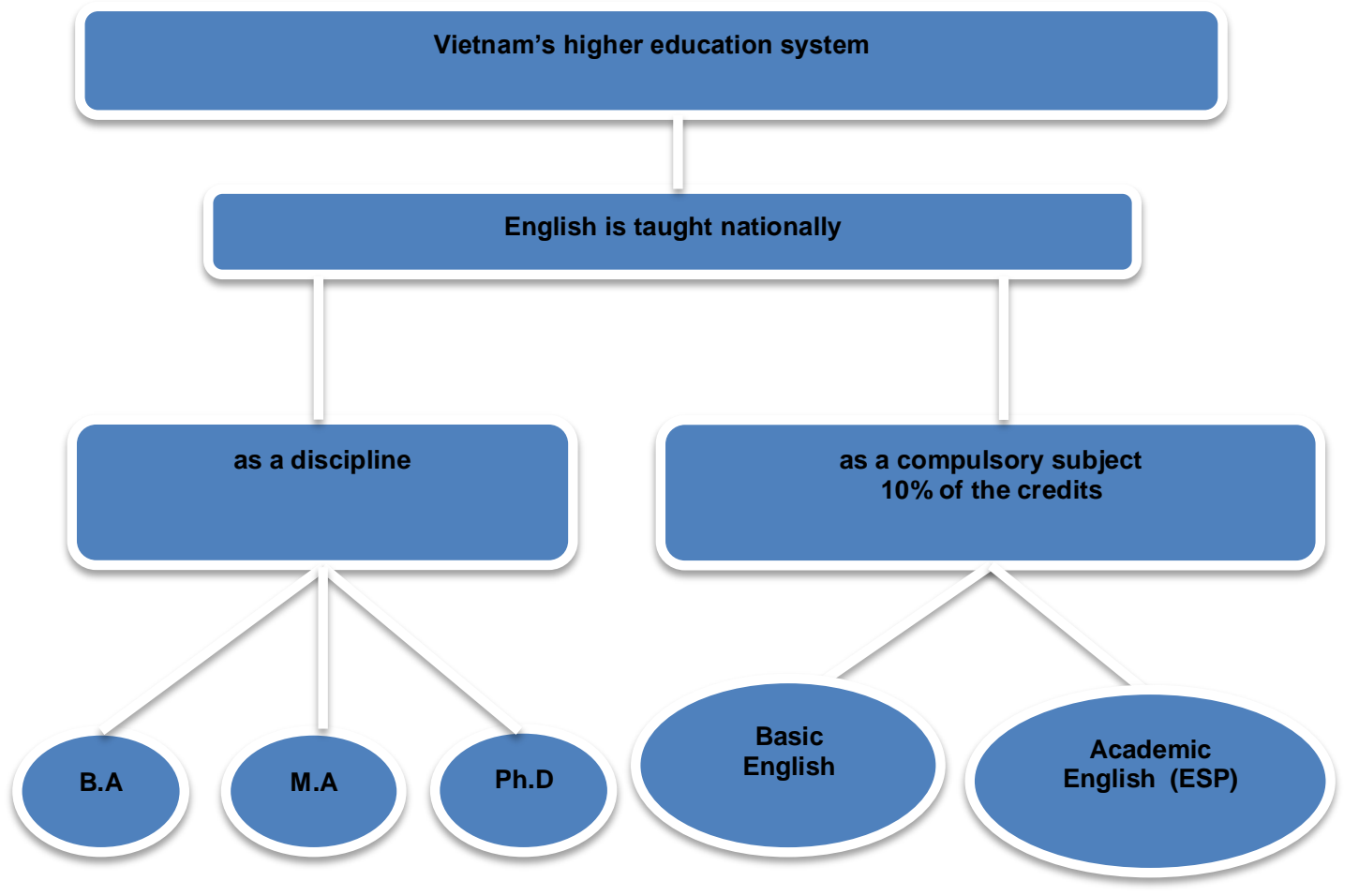

Figure 1.1: Teaching and Learning English at HEls based on Van (2011) 
Moreover, tertiary English language education is held accountable for the poor outcomes for students because little attention is given to the development of communicative competence overall (Ly, 2010). There are several reasons which badly affected the effectiveness of teaching and learning English at VNLUs resulting in graduates' lack of English language competence. These are as follows:

- low English levels of the majority students when entering university (Van, 2007)

- large class size (Van, 2008)

- lack of authentic context for language study (Huong, 2010)

- traditional focus on instruction rather than interactive teaching approaches (Tuyet, 2013a)

- English test design is problematic, being designed to recheck the grammar and structures students learnt in the programme (H.Van, 2008)

Despite a great deal of effort and investment which is put into teaching and learning English at tertiary level in Vietnam, the English competence of the majority of university students and graduates is quite modest as they do not appear to be confident with their English speaking skills (Tuyet, 2013b). The need to improve English language teaching and learning has become one of the most important tasks at VNLUs in general, and at the two selected universities in this study in particular. This is vital in order to help students better prepare for the social and labour market demands in this globalised era as well as in the process of higher education reform in Vietnam. Therefore, it is necessary that policies are put in place to encourage and help Vietnamese students to achieve high levels of communicative ability to be well-prepared for the workplace.

\subsubsection{The Basic English curriculum design and delivery in this study}

English is one of the compulsory foreign languages subjects for non-major language programmes at the two Vietnamese universities selected for this study. As mentioned earlier, in section 1.2, a curriculum frame has been 
constructed, specifying that foreign languages are taught with 10 credits accounting for $10 \%$ of the total credits of an undergraduate programme (MoET, 2003a). However, after completing the 10 credits in the first and second years of study, graduates' English competence is very limited (Gropello et al., 2008). It is questionable as to whether students can use their English in the workplace and for communication, as Decision No 1400/QDTTg (Nhan, 2008) required. In order to see the effectiveness of the Basic English curriculum at Vietnamese universities, it is necessary that policies are put in place to encourage and help Vietnamese students achieve high levels of communicative ability and thus be well-prepared for the workplace.

At the two research sites, the English credits are spread across three terms. Basic English is included in each of the first two terms, and then in the third term students study English for specific purposes in their own discipline, such as Finance or Accounting and so on. The current Basic English curriculum taught at the two universities has been adapted from the textbook 'Business Basics' by David Grant and Robert McLarty (2004) and is included as Appendix A. Appendix B sets out who is involved in curriculum design and delivery at the two universities.

At the ministerial level, MoET stipulates the curriculum framework whereas MoF provides resources for the universities. At the university level, the Rector sets direction on curriculum when he chairs the Council of Scientific Research through the curriculum meeting. The direction is forwarded to the Vice-Rector of Teaching and Learning before being passed onto the Department of Scientific Research. It is then sent to the discipline faculty to invite Dean/ Associate-Dean and some EFL lecturers for their participation in the design process. The discipline faculty submits the curriculum back to the Department of Scientific Research by the deadline and it is then sent to external reviewers. Once the Department of Scientific Research gets feedback from the reviewers, the documents are sent to the discipline faculty for making amendments. The curriculum is then sent back to the Department of Scientific Research to forward to the Vice-Rector of Teaching and Learning to manage/oversee the development process and the curriculum 
meeting of the Council of Scientific Research will be organised and chaired by the Rector to discuss and receive other members' suggestions related to the curriculum design. The Rector will have the final say on that curriculum and then it will be delivered to students. Finally, the process will be reported to the ministries. Although the curriculum emphasises four language skills, examinations are based on only two skills, reading and writing, while the other two skills, listening and speaking, are not formally assessed. Therefore, the communicative competence in English of the Vietnamese workforce has not met the requirements of the employers (Anh, 2010) and this, to a large measure, can be attributed to the design and delivery of the English curriculum.

Consequently, an urgent task for Vietnamese tertiary education in general, and at the two universities in this study, is to innovate curriculum and teaching methods because one of the features of the curriculum framework, instituted by MoET, is quite heavy teaching workloads for academic staff (Gropello et al., 2008; Van, 2011). To address these shortcomings, the Minister of the MoET hosted a workshop to discuss innovation for Vietnam's higher education sector in Hanoi in 2012. The workshop considered the current situation and explored possible solutions. It was determined that transforming Vietnam's higher education should begin at the basics, be thorough, and that it should also be emphasised that it has only just begun (Anh, 2012). It was also determined that finding solutions to Vietnam's higher education issues should be decisive and directed to meeting the demands of global integration. Further, the development of new curriculum with teaching/learning innovations and a reconsideration of the exam focus will also enhance the quality of education (Tuyet, 2013a). Another innovation which the Deputy Minister of Education and Training, Tran Quang Quy, emphasised, was that Vietnam should draw up national training standards, increase links between schools and the business sector, promote English language training and standardise syllabi at tertiary education level (Huu, 2012). The above-mentioned solutions to the challenges facing Vietnamese tertiary education tend to focus on training courses for teachers and changes 
in foreign language teaching. However, one area that has not been considered in respect of these problems is the role of leadership in curriculum issues, and how effective leadership might instigate changes for a more efficient and successful education system; one which understands and reflects that higher education is considered to have the responsibility to provide students with professional knowledge and skills, and to help students satisfy the demands of the employment market (Hung, 2012).

\subsection{Background and role of the researcher}

I grew up in Quang Ngai, a province in the Middle region of Vietnam. One personal motivation for carrying out this study is because during my school years I was involved in leadership roles, namely, as the class monitor or vicemonitor. These experiences made me think about leadership. After graduation from university, I applied for a post as an EFL teacher at The Secondary School of Finance and Accounting where I have worked for over sixteen years as a teacher and the last seven years as a subject coordinator. My school has been upgraded twice over 39 years to become a university. Witnessing some leadership challenges at work I realised that educational leadership in higher education is a crucial issue, but it has not been a priority and has been under-researched in Vietnam. These observations urged me to think deeply about the relationship between leadership and curriculum issues and how leadership was practised at my workplace. The above-mentioned problems inspired me to carry out this study to investigate the role of leadership in promoting the Basic English curriculum design at two selected Vietnamese university institutions.

Moreover, another motivation for this thesis is that there are only a small number of highly-qualified people to meet these burgeoning needs. Leaders in the Vietnamese government and many researchers have identified many shortcomings. Shin and Harman (2009) reveal that Vietnam's higher education in the $21^{\text {st }}$ century faces major shortcomings in its governance systems, curricula, mission focus, external relations, research, and financing. Top Vietnamese officials, including Prime Minister Nguyen Tan Dung, 
perceive shortcomings facing Vietnam's educational system which are inhibiting the country from developing its and economic infrastructure. The US-Vietnam Education Task Force was created by a Memorandum of Understanding signed at the United States Department of State on June 25, 2008 by James K. Glassman, Under Secretary for Public Diplomacy and Public Affairs, US Department of State, and Pham Vu Luan, Vice-Minister of MoET, at that time, of the Socialist Republic of Vietnam (Mikhalak \& Luan, 2009). The Task Force was charged with producing a set of recommendations to both governments in 2009 with a view to strengthening US-Vietnamese higher education cooperation in general, and specifically in three key areas:

- Encourage more and deeper linkages and joint programmes between American and Vietnamese universities;

- Increase the number of Vietnamese studying at American universities and colleges, especially $\mathrm{PhD}$ students; and

- Promote educational programmes designed to help Vietnamese students acquire the skills needed in Vietnam's modernising economy.

However, the report also revealed that Vietnam's crisis in its education systems at all levels may jeopardise its pursuit of economic progress and global integration. The report also added today's failed education system resulted from a conservative and largely unqualified hierarchy of educators. The above-mentioned problems inspired me to carry out this study to investigate the role of leadership in promoting the Basic English curriculum design at two selected Vietnamese university institutions.

This study is a qualitatively-focused case study with a small quantitative component. Therefore, the first singular personal pronoun ' $l$ ' will be used in the subsequent chapters instead of the more formal way of addressing 'the researcher' to denote a person who carries out this investigation. Qualitative researchers are described as the main instrument for data collection and analysis (Merriam, 2002). In the qualitative research, I acted as the interviewer in the face-to-face as well as focus group interviews. 


\subsection{Educational leadership research in the Vietnamese context}

Educational leadership is a field which has attracted the attention of many researchers internationally (Bryman, 2007; Cardno, 2012; Fullan, 2007). Moreover, in Teddlie and Reynolds' (2000) research, the close relationship between high-quality educational leadership and an institution's achievements was noted. Educational leadership in Vietnam, especially at tertiary level, has however received little attention. This view is supported by further studies which found that there are only a few studies about educational leadership in Vietnamese higher education: Phuong and Berg (2010); Ngan (2011); Dung (2012) and Lan (2012). These scholars also noted that most universities lack institutional autonomy and accountability.

Women in leadership positions were the topic of a study by Ngan (2011) who examined the significant impact culture has on women's leadership in higher education. A further study by Dung (2012) on educational leadership examined how middle management learnt leadership on-the-job and how they perceive effective and sustainable leadership. Another study by Lan (2012) examines the perspectives of Vietnamese mid-level women leaders in four selected HEls in the Mekong Delta about their leadership experiences. Lan's (2012) study shows that disparity between gender equality policies and gender practices were typical throughout in Vietnam. These three studies mainly focus on the impact of cultural dimensions on mid-level female leaders in higher education, not top-level leaders, in relation to their leadership practices in solving curriculum issues.

\subsection{Statement of the problem}

The scarcity of scholarly work has hindered the development of educational leadership in Vietnam. Other studies have also looked at leadership and found in recent years Vietnam's higher education system has faced challenges and lacked in-depth leadership experience and skills within university institutions (Fry, 2009; Hayden \& Thiep, 2007; Valley \& Wilkinson, 2009). For example, Hayden and Thiep (2007) identified problems facing the Vietnamese tertiary education system, including severely constrained 
management process due to numerous regulatory controls, a lack of depth in leadership experience and skills within institutions, poorly developed articulation arrangements within the system, poorly prepared graduates as regards a range of skills and capacities, high staff-student ratio (about 1:30), traditional teaching methods, and a slow-moving and bureaucratic process of programme renewal.

Leadership is pivotal to effect change (Oliver \& Hyun, 2010) therefore leadership has the potential to improve the delivery of the Basic English curriculum to ensure students can communicate effectively in English in the workplace. The role of leadership is to ensure the Basic English curriculum is more relevant and useful for graduate students. This is of particular importance in the Vietnamese university context. There have been no systemic studies of the role of leadership in promoting the Basic English curriculum design and delivery in the higher education context in Vietnam. Consequently, I decided this needs to be deeply explored and addressed so leaders will be more active in continuously implementing the curriculum and diversifying methods of teaching and learning in order to meet the demands of the economic and social situation in Vietnam from now until 2020.

Accordingly, the unanimity between my interests as mentioned earlier and the scarcity of research in terms of educational leadership relating to curriculum issues in the Vietnamese higher education context has urged me to do research in educational leadership.

\subsection{Purpose of the study}

The main purpose of this study is to explore the role of leadership in promoting the Basic English curriculum design and delivery in Vietnam's higher education sector.

In pursuit of this, I have attempted to discover the relationship between leadership at different levels and curriculum issues. The key research objectives were as follows: 
1. To explore and critically analyse leadership roles in the Basic English curriculum design and delivery at different levels in the two selected universities in Vietnam.

2. To identify perceptions of academic leaders regarding their roles in promoting and supporting the Basic English curriculum design and delivery.

3. To examine employers' and graduates' perceptions about the effectiveness of the Basic English curriculum and delivery.

4. To suggest solutions to overcome challenges and provide guidance to enhance educational leadership practices in the two selected universities.

\subsection{Research questions}

In this study, the main research question under investigation was:

What is the role of leadership in promoting and supporting the effectiveness of the Basic English curriculum design and delivery at two selected Vietnamese universities?

The following sub-questions helped answer the research question:

1. What levels of leaders are involved in the Basic English curriculum design and delivery?

2. In what ways do collaborative leadership practices positively impact on the Basic English curriculum design and delivery?

3. What are the barriers affecting the leadership roles of academic leaders?

4. How do academic leaders promote the Basic English curriculum delivery?

In order to supplement the qualitative data gathered to answer the main question, it is helpful to know whether leadership is effective in the Basic English curriculum design and delivery or not, and therefore the following sub-question (5) will examine the perspectives of different stakeholders such as university leaders, EFL lecturers, employers and graduates about the effectiveness of the Basic English curriculum at the two selected universities: 
5. What are the perspectives of the stakeholders about the effectiveness of the Basic English curriculum design and delivery?

\subsection{Significance of the study}

This thesis makes a significant contribution to the literature on cultural and political system impacts on educational leadership at Vietnamese universities. Firstly, this study is helpful for the two institutions being researched, as the findings contribute to the current gaps in understanding how leadership at all levels in higher education impact on curriculum design and delivery. Further, it offers insights into the significance of leadership practices and their effects on improving the quality of educational leadership practices in Vietnamese universities and other countries' higher education. The study also points out the barriers affecting the leadership roles of participants in order to develop solutions or make changes. The findings reveal how, within Vietnam's higher education context, the cultural and political system impacts on educational leadership at all universities and the two in the study, in particular. Secondly, the findings and recommendations are relevant and may be useful to other Vietnamese tertiary institutions. Thirdly, the findings will contribute to the theoretical and methodological innovations in the Vietnamese context and may also be valuable to other countries teaching the Basic English curriculum as a second language.

Finally, this study hopes to attract more public attention to educational leadership in Vietnam, especially in areas of effective leadership regarding curriculum design and delivery. More importantly, studies of leadership in the area of curriculum design in universities are relatively recent, in many countries, so this study adds to, and expands on, the existing literature on educational leadership in universities.

\subsection{Organisation of the thesis}

The thesis consists of eight chapters. Chapter One is the introductory chapter which has outlined the context of the research in which I present my personal interest as EFL lecturer, which led to my interest in the topic of the study. The chapter then discussed the purpose and the significance of the study. The 
rationale for this thesis is the scarcity of research in leadership relating to curriculum issues in the Vietnamese higher education context.

Chapter Two presents a review of relevant literature focusing on key international literature about aspects of leadership in higher education including academic leadership, distributed leadership, and the role of educational leaders at different levels in curriculum design and delivery as the theoretical framework for the study. The chapter also discusses the impacts of the Vietnamese social and cultural context on academic leadership.

Chapter Three presents the research methods that I employed to conduct this study. The research methods are located within a qualitative-focused case study approach. The methods used are underpinned by a constructivist view because this view acknowledges multiple realities that are constructed by the participants and myself as a researcher. The data is collected by a series of semi-structured in-depth interviews with academic leaders and company directors, focus groups interviews with EFL lecturers and observations of the curriculum meeting. I then argue why a quantitative aspect is appropriate to address the research question and I also describe the instruments used in the qualitative method and the online survey used as a quantitative method. Finally, trustworthiness and ethical issues are addressed.

Chapter Four, Chapter Five and Chapter Six report the findings from different data sources in assisting to answer the central research question. Chapter Four reports on the findings of the data collected and analysed from the views and perspectives of all senior academic leaders involved in curriculum design and delivery at the two selected universities while chapter Five presents the data from the focus group interviews with EFL lecturers about their participation in curriculum design and delivery. Chapter Six reports on the data from the semi-structured interviews with employers and the data of an online survey by graduates about the effectiveness of the Basic English curriculum at the two universities. This information will be helpful for 
university leaders who look, in their decision-making and leadership practice, to solve curriculum issues.

Chapters Seven discusses its findings with respect to leadership in curriculum design and delivery. The qualitative data and the data from the online survey are analysed and discussed to answer the research questions which were raised in Chapter One and in Chapter Three in light of the literature review in Chapter Two.

Chapter Eight is the conclusion which summarises the main findings of the thesis, discussing potential contributions in terms of theory, policy and practice. It also addresses the thesis' limitations and proposes future research directions and, finally, offers a concluding comment with my personal reflection.

In order to understand the ways different levels of leaders participate in curriculum design and delivery issues, key literature on leadership in higher education including academic leadership, distributed leadership need to be explored in the next chapter. 


\section{Chapter 2: LITERATURE REVIEW}

\subsection{Chapter overview}

Leadership in higher education is an under-researched field especially in developing countries. The distinctive nature of leadership in higher education has been rigorously debated and there is a lack of consensus in the field about what it actually involves. A number of influential studies which have examined leadership in higher education (Bolden et al., 2012; Bryman, 2007; Scott, Coates, \& Anderson, 2008) provide a foundation for my study and will be discussed in this chapter. My study focuses on the role of leadership in promoting and supporting the curriculum design and delivery issues which have not yet been explored in the Vietnamese context. In this chapter, I will situate the current study within the key international literature which focuses on aspects of leadership in higher education including academic leadership, distributed leadership, leadership of curriculum design and delivery and the role of educational leaders at different levels in curriculum design and delivery. I organise my review in this way for the following reasons:

- Studies on academic leadership and distributed leadership in higher education are well documented in Western literature; however leadership in higher education is largely under-researched in Vietnam.

- Leadership in Western universities is complex with contradictory aspirations for distributed leadership within a traditionally hierarchical structure. Little is known about how leadership is enacted in Vietnamese universities.

- Several key factors such as organisational contexts, social pressures, leaders' capabilities and investment in leadership development affect leadership in higher education. However, how these factors have impacted on academic leadership in Vietnam's higher education context is unknown. 


\subsection{Concept of leadership in higher education}

Leadership has been a research topic for many years yet it remains an "essentially contested concept" (Grint, 2005, p.17). Studies of leadership normally concentrate on individuals who have very high positions within organisations such as chief executive officers in businesses, leaders of government agencies, and politicians. The model of school leadership for many years was focused on authority, power, structures, job descriptions, targets and performance management (O'Donoghue \& Clarke, 2010). However, in today's rapidly changing and complex world, the idea of leadership being the sole responsibility of a single individual is no longer accepted. In the higher education context, leadership arises from "the interactive process of sense making and creation of meaning that is continuously engaged in by organisational members" (Middlehurst, 1993, p.36). Moreover, Bolden, Petrov, and Gosling (2008) argue that, although leadership is one of the least understood phenomena known to human kind, it is essential for change to occur, such as that sought in higher education. For the aims of this study I have selected a recent definition of leadership by Cleveland-Innes and Sangra (2010). These authors define leadership as: "a set of characteristics and behaviours that together enable organisations, and the individuals in them, to create optimal organisational conditions for realising organisational goals" ( $p .235)$.

\subsection{Academic leadership}

This section sets out to define the concept of academic leadership that will be used for this study and then explores the connection between academic leadership and curriculum issues in order to enhance students' learning outcomes.

Nowadays, governments of many countries are demanding greater accountability and transparency from institutions of higher education. In developing countries like Vietnam greater accountability is demanded because "there is a general lack of accountability from individual institutions and schools; reporting to MoET and through MoET to the nation absolves them from the responsibility of accountability for their own actions" (Phuong \& 
Berg, 2010, p.7). Jones, Lefoe, Harvey and Ryland (2012) argue that higher education needs new models of leadership to harness the skills and abilities of its knowledge-based workforce. The following sub-sections give a brief review of previous research into academic leadership and the focus of the current research.

\subsubsection{Concept of academic leadership}

A number of authors from a range of countries have discussed the concept of academic leadership such as Bolden et al. (2012); Cardno (2012); Ramsden (1998); and Scott et al. (2008). These previous studies reveal academic leadership as a complex concept. This section examines and analyses the work of various authors on this topic as this term 'academic leadership' has a range of meanings.

Ramsden (1998) conducted a study in an Australian university context and points out several key characteristics such as leadership in teaching, leadership in research, strategic vision and networking, collaborative and motivational leadership and interpersonal skills that influence effective academic leadership. He posits that academic leadership is applied to all levels of an organisation, from strategy-making to teaching by affirming "academic leadership is both identical to leadership in organisations, and idiosyncratic to university environments" (p.123). He considers academic leaders as academically-inclined and concerned with academic business whereas Scott et al. (2008) conducted their study in an Australian context and view academic leaders as learning leaders. Cardno (2012) carried out her study in New Zealand and argues that there is negligible literature which discusses the concept of academic leadership in higher education in relation to improving student learning outcomes in comparison to research conducted in the school context. Accordingly, Cardno uses the term academic leadership to refer to the "leadership of curriculum and learning in the tertiary sector" (p.27). 
Bolden et al. (2012) in a study involving 350 academics from 23 universities in the UK and a number of other higher education providers found a high degree of consistency in perspectives on, and experiences of, academic leadership. They define academic leadership as "a process through which academic values and identities are constructed, promoted and maintained" (p.2). Bolden et al. further distinguish academic leadership from academic management (See Figure 2.1).

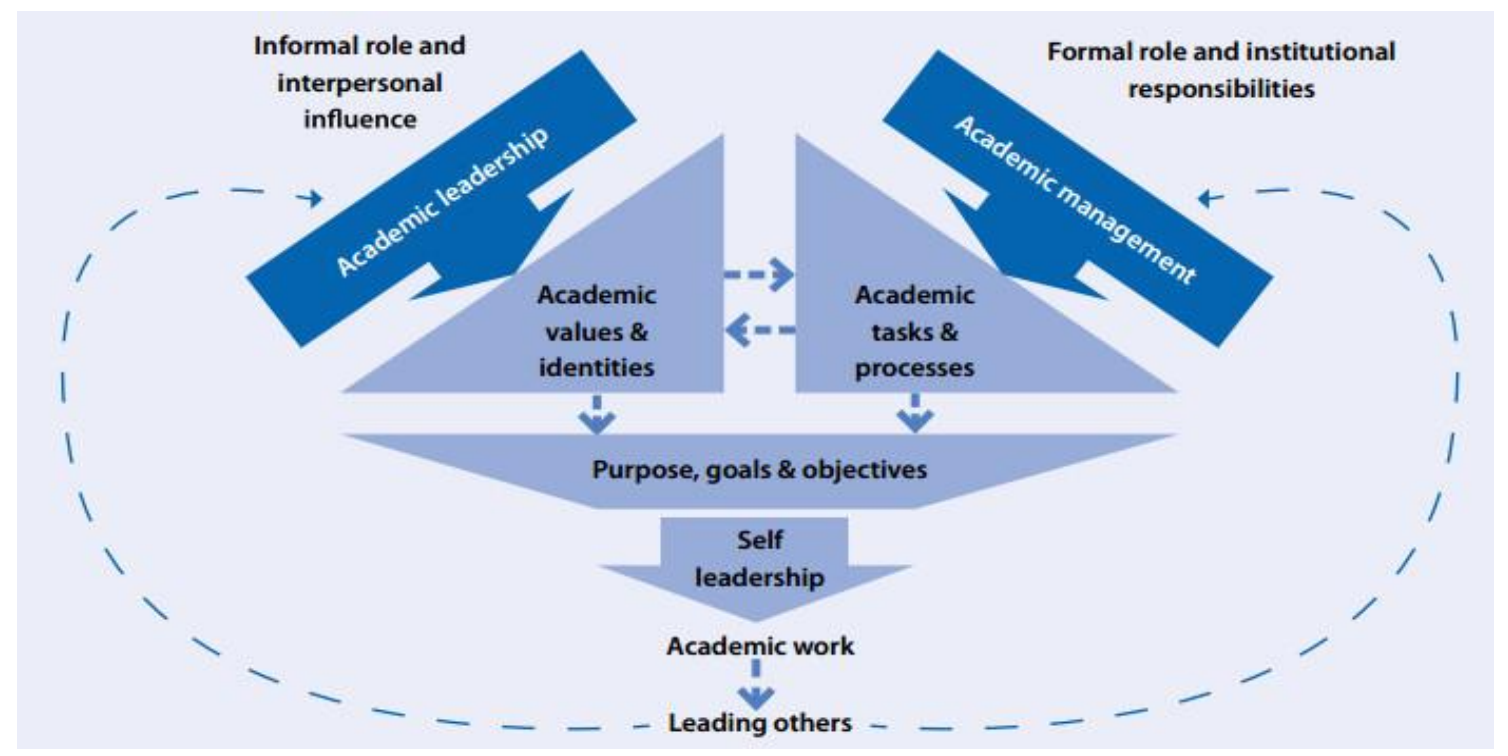

Figure 2.1: Academic leadership, academic management and selfleadership (Bolden et al., 2012)

When considering the relationship between academic management, academic leadership, and self-leadership, Bolden et al. (2012) imply that academic management and academic leadership are not necessarily provided by the same people or processes and address difference issues. Bolden et al. suggest that academic leadership "is conceived more broadly and is most significant in terms of its impact upon academic values and identities" whereas academic management "tends to have an institutional focus and is used in order to frame academic tasks and processes such as allocation of workload, performance monitoring and assessment and provision and distribution" (p.35). They draw the attention to the fact that academic leadership and academic management are likely to be understood as "important by an individual academic to the extent to which they facilitate 
his/her ability to work as an autonomous professional and ...lead others." (p.36). According to these authors, academic work is likely to be conceived of as 'self-leadership' for those who have achieved a certain level of 'professionalism'. Moreover, they also link 'self-leadership' with 'the result in the individual exerting a leadership influence on others' (p.36) and so the cycle continues. The processes outlined by Bolden and his colleagues in figure 2.1 show that each plays a different role in creating direction, alignment and commitment with universities. Accordingly, they link 'academic management' with 'alignment'; 'academic leadership' with 'commitment' and self-leadership with 'direction'. These three elements of 'alignment, commitment and direction' resonate with the leadership tripod of direction, alignment and commitment towards a more interactive ontology of leadership by Drath, McCauley, Palus, Van, O'Connor and McGuire's (2008). They claim to challenge the current 'leadership tripod'- leaders, followers and shared goals. Bolden et al. further conclude that "academic staff also exercise leadership through the activities of teaching and learning" (p11). Although the literature is based in Western context, it is useful when considering the Vietnamese university context. In the integration of industrialisation and globalisation and exposure to international universities' leadership systems through conferences, seminars and publication, these concepts of academic leadership, academic management and self-leadership may become relevant and universally adapted by Vietnamese universities.

The literature discussed above suggests that academic leadership activity focuses on student learning and curriculum design. Bolden et al. (2012) and Cardno (2012) view academic leadership as being central to the teaching and learning process. Consequently, it is interesting to combine part of Bolden et al.'s (2012) definition of academic leadership with that of Cardno (2012). Hence, academic leadership with emphasis on exercising leadership through the teaching and learning activities and its relationship in curriculum and learning will be the focus of this study. 


\subsubsection{Relevant studies on key features of academic leadership}

Several studies have examined features of academic leadership in teaching and learning. These studies cover key areas for academic development such as Marshall's (2006) theory for developing leadership in teaching and learning, modes of academic operations, key characteristics of fostering a supportive and collaborative environment, facilitating participation in decisionmaking and protecting staff autonomy for successful leadership in higher education.

A two-tier approach to the development of leadership in learning and teaching which addresses individuals' needs to develop their leadership capacity has been described by Marshall (2006). Marshall's research on the issues of developing learning and teaching leadership in higher education succinctly traces the development of leadership theory from the early perceptions of 'traits' of leadership through to 'transformational leadership' and Social Exchange Theory. In this study, Marshall describes the 'contingency perspective' of leadership as a process as much about "developing the organisation as it is of developing the professional knowledge and skills of those called to leadership positions" (p.3). In the Social Exchange Theory, leaders are encouraged "to use their knowledge, skill, abilities, networks and resources to satisfy followers' expectations and then inspire followers to transcend their own interests for the good of the organisation" (p.3). Therefore, in the context of learning and teaching, leadership should be an active engagement with learning and teaching processes and goals in a community of practice. Marshall's model simultaneously develops an organisational culture that facilitates and rewards a complex, multi-faceted conceptualisation of learning and teaching and professional leadership. The challenges that learning and teaching leaders encounter have been identified by Marshall as essentially establishing a direction, developing plans and strategies to implement the direction, making meaning of the plans and strategies and thereby allowing others to participate, monitoring and evaluating processes and taking corrective action where necessary. There are eight basic areas in which professional development would be appropriate for individuals, namely their discipline, learning and teaching, leading and working in teaching and learning teams, managing teaching and 
learning development projects, leading and managing an organisational subject, and social and personal interactions.

Further, Marshall (2006) follows identification of the basic areas for individual development with a framework for academic development for individuals that includes learning, teaching, evaluation, curriculum, managing, strategic development and working in teams. Marshall's study points out challenges leaders face in leading teaching and learning process. He also points out several essential areas which are necessary for developing leadership capacity in order to enhance teaching and learning. Accordingly, Marshall's theory appears to be very useful as it focuses on leadership that places teaching and learning at the centre in the higher education sector.

According to McDonald et al. (2010), any discussion of leadership in learning and teaching contexts needs to be grounded in an understanding of the variety of roles and workloads that academics might be expected to encounter. Marshall (2006)'s study contributes substantially to the leadership of teaching in the higher education context because it calls for research and development that reveals the breadth and complexity of leadership in learning and teaching, and assists in developing the organisational environment supporting learning and teaching. Marshall's study is very relevant because it points out several critical principles guiding the development of leadership capacity for learning and teaching in higher education such as: developing an active community of scholars working to resolve obstacles or dilemmas; focusing on developing the capability of all those involved in planning, implementing, or evaluating learning and teaching and/ or the organisational environment in which learning and teaching occurs; and ensuring routines and systemic opportunities are offered as part of each institution's professional learning programme for staff, at appropriate times and in appropriate ways, to meet the changing career development needs of staff. As mentioned earlier, this study is also carried out in a Western context. Consequently, Marshall's study about the development of leadership for teaching and learning in higher education could be useful in the Vietnamese higher education context for the wellbeing of HEls. 


\section{Key features of academic leadership in teaching and learning}

Other studies also highlight the relationship of academic leadership to teaching and learning. Leaders' attributes and capabilities in teaching and learning examined below may be considered as key characteristics for succuessful leadership. One feature of academic leadership relates to leaders' attributes in teaching and learning. Debowski and Blake's (2004) study reviews the teaching leadership responsibilities of various academics in Australian universities. They argue that academic roles need to be clearly defined and supported more specifically in order to better develop different leadership roles. Debowski and Blake conclude that academic leaders of teaching and learning require the general attributes noted as being important for many leadership roles - for example, the ability to develop a collaborative and supportive culture and to provide opportunities to share knowledge between colleagues. However, they suggest that the following capabilities and competencies specific to learning and teaching are also necessary:

- A strong commitment to pedagogy, and an understanding that course design and curriculum development should be driven by a strong grasp of how learning occurs and the effects of different forms of teaching on student learning;

- A sound awareness of the university, faculty and school, and teaching and learning policies;

- Knowledge of the curriculum areas and factors which need to be considered when designing relevant and effective curricula;

- The ability to evaluate and review courses and programmes;

- The capacity to analyse and evaluate curriculum content for relevance, suitability, currency and uniqueness;

- An understanding of student needs and learning styles; and

- Ongoing development of new teaching strategies (such as flexible learning). 
However, Debowski and Blake (2004) found that leadership development for learning and teaching in universities is generally not well recognised, understood or supported. Therefore, they conclude that academic leadership is critical to the wellbeing of universities and recommend further development.

Another feature of academic leadership in teaching and learning relates to leaders' responsibilities and challenges in teaching and learning. Bryman's (2007) work investigates leadership researchers about their experiences in leading teaching and learning. According to Bryman, it is evident that, to date, leaders in learning and teaching:

...must juggle, along with their more traditional individual academic aspirations for subject expertise, management of a more diverse subject cohort, increasing pressure to align their academic interest with strategic institutional priorities as well as a capacity to oversee and accommodate the non-traditional and diverse learning aspirations of their students (p.11).

Bryman (2007) not only points out several challenges for leaders of teaching and learning but also emphasises the importance of human interpersonal and management skills. Bryman's study found similar attributes to those of Debowski and Blake's (2004) such as consideration, treating academic staff fairly and with integrity, being trustworthy and having personal integrity, acting as a role model/having credibility, and creating a positive collegial work atmosphere in the department. These attributes are highly valued in academic leadership (Bryman, 2007). He also explores fostering a supportive and collaborative environment, facilitating participation in decision making and protecting staff autonomy, and concludes that they are considered as key characteristics for successful leadership in higher education.

Similarly, Marshall, Orrell, Cameron, Bonsanquet and Thomas (2011) examine the conceptions of academics regarding the nature of 'leading' and 'managing' learning and teaching in six Australian universities. They identify three key responsibilities of leaders and managers of learning and teaching, these are: "developing institutional, faculty and departmental cultures where 
learning and teaching is valued, rewarded, prioritised and developed... developing teachers and teaching practice itself... developing and maintaining collaborative and collegial cultures in which teamwork becomes a key leadership and management strategy" (Marshall et al., 2011, p.88). Marshall et al. further explain that these leaders need to operate in four domains in which the quality of education needs to be developed curriculum, staff, student, and organisational enablers - and through three levels of leadership and management responsibility for learning and teaching: the macro-level, which includes the whole of the institute; the meso-level, which denotes the faculty, school or department; and the micro-level, pertaining to the course or programme teaching level.

The studies referred to so far explored aspects of leadership of teaching and learning including academic leaders' responsibilities, capabilities, and attributes in HEls. However, these studies were conducted in Western contexts. Little is known about these aspects of leadership in teaching and learning in the contexts of Vietnamese HEls. Such aspects of leadership need to be taken into consideration in the context of Vietnamese higher education in order to enhance teaching and learning because Vietnamese universities target teaching quality as a strategic priority in increasingly turbulent times (Trong, 2013).

\subsubsection{Academic leadership and student learning outcomes}

A number of authors have argued that academic leadership impacts on student learning outcomes. The relationship between academic leadership and the quality of student learning is discussed by Knight and Trowler (2001). They conducted a series of 26 interviews with 24 appointees in two Canadian and eight English universities in 1997/98. They posit that one way to develop cultures that are conducive to high quality teaching and learning is academic leadership of a collaborative nature. They also argue that improvement in teaching and learning is dependent on changes in departmental culture. They conclude that desirable change is most likely to be achieved in collective and collaborative ways. 
In a similar vein, the work of Gardiner (2002) who explores how academic leadership impacts directly on student learning, posits that leaders in higher education need to develop management and leadership skills in order to ensure high-quality learning experiences for students. In addition, academic leaders need to translate mission statements into practice through clearly articulated goals and objectives which describe intended outcomes for each programme. Further, Gardiner (2002) recommends that an academic leader should actively provide a high-quality programme of assessment; balance curriculum and academic advice for students; ensure the active involvement of students in all their study components; create an engaged and supportive campus environment; and provide support and development for staff.

Moreover, the impact of academic leadership on students' learning outcomes can be direct and indirect. Academic leadership has a direct impact on students' learning outcomes as mentioned above in Gardiner's work while Scott et al. (2008) point out that academic leadership practised at a number of levels in both direct and indirect ways. The less senior levels of academic leadership could be described as middle-level leadership or middle management. Their study involved 513 learning and teaching leaders from 20 Australian universities, occupying roles from Deputy Vice-Chancellor to Head of Programme. Nearly 500 leaders attended the national forum and workshops on the results, along with an additional 100 leaders at the international review workshops. In Scott et al.'s (2008) investigation, the practice that academic leadership generally took a very eclectic view was confirmed.

The findings from Scott et al. (2008) identify a number of areas of focus in academic leadership, including policy formation, managing relationships, working with challenging staff, involvement in various aspects of planning and attending meetings. Interestingly, Scott et al. also discuss the use of 'academic leadership' when they refer to an academic leader as 'a learning and teaching leader'. Scott et al. further suggest that in order to overcome the problem of leadership succession, it is necessary to provide tailored and sufficient development to support academic leaders in their specific roles. 
While Gardiner (2002) and Scott et al. (2008) claim that academic leadership is related to student learning outcomes, Joyce and O'Boyle (2013) argue that leadership should be kept at the centre by focusing on developing leadership skills for staff in order to allow them to be both innovative and creative in the programmes they design and deliver. These authors conclude that higher education staff need to "view themselves as leaders not because they are exceptional or senior but because they recognise what needs to be done and can work collaboratively with others to do it" (p.13). They further advise HEls to encourage staff at all levels to come together to work on real challenges and opportunities.

These studies emphasise that there is a strong connection between academic leadership and students' learning outcomes. The concepts of academic leadership and its key features as defined above play an important role in the teaching and learning process. Academic leadership and its connection with students' learning outcomes need to be considered in order to enhance teaching and learning. However, all these studies like those discussed previously by Bryman, Debowski and Blake, and Marshall refer to specifically Western higher education contexts. Many key aspects outlined above (such as leaders' challenges and basic areas for professional development and leadership skills) are relevant to this study because little is known about the implementation of such key features of academic leadership, and their impact on improved student learning outcomes, in Vietnamese higher education.

\subsection{Distributed leadership}

Some literature on academic leadership focuses on the ways people work collaboratively. The following section will explore the concept of distributed leadership and its key features in the higher education sector. The notion of distributed leadership was first used in the field of social psychology in the early 1950s and remerged in the early 1990s in organisation theory and then education (Gronn, 2002). Distributed leadership is a practice that spreads leadership over a number of people who work cooperatively and 
interdependently to achieve the purpose of their group (Thornton, 2010, p.1). The definition of distributed leadership, developed in the context of selfmanaging teams, refers to multiple leaders seeking and taking responsibility for different leadership functions and assuming complementary roles (Barry, 1991). This view is premised on the notion that "leadership is a collection of roles and behaviours that can be split apart, shared, rotated, and used sequentially or concomitantly" (Barry, 1991, p.34). Distributed leadership is recognised as an emergent leadership concept relevant to the culture of the education sector from primary to secondary and higher education (Jones et al., 2012). Distributed leadership has been studied to a greater extent in the school sector in Western literature. Key theories in the school sector view distributed leadership as crucial in teaching and learning. Much of the literature acknowledges the work of leadership at all levels drawing on distributed leadership theory (Bolden, 2011; Gosling et al., 2009; Harris, 2008).

\subsubsection{Concept of distributed leadership}

Bennett, Crawford, and Cartwright (2003); Chang (2011); and Spillane (2005) see distributed leadership as a synonym of 'shared leadership', 'team leadership' and 'collaborative leadership'. Although all the terms support the viewpoint that leadership should not simply focus on a single person (MacBeath, Oduro, \& Waterhouse, 2004), they are different in several aspects. Avolio, Walumbwa, and Weber (2009) argue shared leadership, collective leadership, and distributed leadership are used interchangeably in research literature, while team leadership is commonly viewed as a slightly different stream of research. Shared leadership means leadership practice as a team-level phenomenon in which multiple individuals enact behaviours rather than solely by those enacted at the top or by those in formal leadership roles (Avolio et al., 2009).

Conger and Pearce (2003) define shared leadership as "a dynamic, interactive influence process among individuals in groups for which the objective is to lead one another to the achievement of group or organisational goals or both" (p.1). Conger and Pearce added, "This influence process often 
involves peer, or lateral, influence and at other times involves upward or downward hierarchical influence" (p.1). Shared leadership means leadership practice as a team-level phenomenon in which multiple individuals enact behaviours rather than solely by those enacted at the top or by those in formal leadership roles (Avolio et al., 2009). Likewise, Kocolowski (2010) considers shared leadership as "a relational, collaborative leadership process or phenomenon involving teams or groups that mutually influence one another and collectively share duties and responsibilities otherwise relegated to a single, central leader" ( $p .24)$ while teams often work better when leadership is shared (Carson, Tesluk, \& Marrone, 2007). In short, shared leadership can be operationally defined as a dynamic, collaborative process (Conger \& Pearce, 2003) whereby influence is distributed (Carson et al., 2007) amongst a plurality of networked individuals, often referred to as "teams, for the purpose of achieving beneficial outcomes for the organization" (Kocolowski, 2010).

Similar to shared leadership in terms of group work activity, Bennett et al. (2003) also view distributed leadership as "a group activity that works through and within relationships, rather than individual action" (p.3). On the other hand, distributed leadership occurs in both formal and informal forms. Harris (2008) defines distributed leadership as "a collection of roles and behaviours that can be split apart, shared, rotated and used sequentially or concomitantly, [which] means that any one time, multiple leaders can exist in a team, with each leader assuming a complementary leadership role" (p.174). However, it should be noted that distributed leadership does not simply mean sharing tasks among individuals who perform assigned and separate organisational responsibilities; rather it involves dynamic interactions between multiple leaders and followers (Timperley, 2005). It has been suggested that leadership is distributed to both employees holding formal positions and those who have the ability to lead certain activities (Bell \& Baker, 1997; Harris, 2009). For the purposes of this study, the term 'distributed leadership' is used as leadership is distributed to both employees holding formal positions and those who have the ability to lead certain 
activities (Harris, 2009; MacBeath et al., 2004). The following sub-section will discuss distributed leadership in the higher education sector.

\section{Distributed leadership in higher education sector}

A number of studies have discussed the concept of distributed leadership in higher education. Ramsden (1998) posits "leadership in universities should be everyone from the Vice-Chancellor to the casual car parking attendant, leadership is to do with how people relate to each other" (p.4). Ramsden's idea has led to the development of more shared, distributed approaches to leadership for the education sector, particularly in higher education in the UK

and Australia (Bolden et al., 2009; Bolden, 2011; Jones et al., 2012). Some other researchers, namely Bijandi, Nazari, Pourrajab, and Mahdinezhad (2011); Middlehurst (1993); and Knight and Trowler (2001) share the same view when they conclude that leadership in universities is widely distributed.

Bolden et al.'s (2008) study showed that leadership in higher education was widely distributed through people, structures and networks but that the actual forms of leadership were better described as hybrid in terms of nature as they comprised both individualistic and collective approaches. In this respect, Bolden et al. share a similar view with Gronn (2009) about distributed leadership as a hybrid concept. The extension of distributed leadership into the higher education sector in the UK and Australia is being explored as a new 'architecture for leadership'.

In a study done by Gosling, Bolden, and Petrov (2009), the rhetorical function of distributed leadership was examined. Gosling et al. argue that distributed leadership has limited usefulness as a descriptive device as they found little evidence of what was actually occurring in higher education and could be described as distributed leadership. In addition, they examine the usefulness of distributed leadership as a descriptive, corrective, empowering or rhetorical device. However, they do believe it could be useful as a rhetorical device insofar as it provides a way of moving away from leadership that is centred on personal traits and behaviours. They, like others, put a caveat on 
this last point, saying it could "distract from the systemic degradation of academic autonomy and creeping managerialism" (p.308).

Gosling et al. (2009) identify two dialectics at work in the professional lives of higher education managers: the first is to do with the constantly contested exercise of authority and the second with the emergent and reflexive identity work that is intrinsic to taking on managerial roles. Jones, Harvey and Lefoe (2014) shares a similar view with Gosling et al. when they consider 'new managerialism' as changes to the governance and management of HEls. Similarly, Jones, Harvey, Lefoe and Ryland's (2014) research explores commonalities in distributed leadership processes. Their paper focuses on the reflections of participants in projects designed to use distributed leadership to build leadership capacity in learning and teaching in Australian higher education. They conclude that rather than replacing the traditional focus on individual leaders, distributed leadership links individual leaders and experts in collaborative activities.

Brungardt (1998) claims that collaborative leadership works best in postsecondary and higher education because it models what effective teachers do to help students learn. Moreover, Humphreys (2013) argues that "many individual faculty members and academic administrators have been creating new classroom practices and curricula models specifically to advance the skill of teamwork and collaboration in today's college students" (p.1). However, little attention has been paid to date to how teamwork is applied in HEls. Consequently, Humphreys claims that more effective and widespread collaborative leadership is an urgent need because "collaborative leadership can help to increase the efficency with which we maintain the quality of operations and can develop more effective ways to actually educate a far wide proportion of the society to meet the twenty-first century demands." (Humphreys, 2013, p.3)

For the purpose of this study, the term 'collaborative leadership' will be used interchangebly with 'distributed leadership' because it can also help to enhance students' outcomes. However, in using the term, it is understood by 
the researcher to incorporate Jones et al.'s (2014) concept of participation of individual leaders and experts in collaborative activities and Humphreys' view of working together to participate in collaborative decision making.

\subsubsection{Key features of distributed leadership in higher education}

One of the key features of distributed leadership relates to collaborative and collegial action. Jones, Lefoe, Harvey, and Ryland (2012) support the adoption of contextualised distributed leadership approaches which focus on collaborative and collegial action. They argue that higher education needs new models of leadership to harness the skills and abilities of its knowledgebased workforce. Likewise, Jones, Hadgraft, Harvey, Lefoe, and Ryland (2014) posit the relationship of distributed leadership to teaching and learning and view it as:

A leadership approach in which collaborative working is undertaken between individuals who trust and respect each other's contribution... through shared and active engagement, distributed leadership can result in the development of leadership capacity to sustain improvements in teaching and learning. (p.23)

Another key feature of distributed leadership is the way it is distributed. Distinctions between 'vertical' and 'horizontal' leadership are made by researchers within the field of distributed leadership. One of the important studies on distributed leadership in UK education was that of Bolden et al. (2009) who revealed two views of distributed leadership, 'devolved' (topdown) and 'emergent' (bottom-up.) The devolved approach was put forward by formal leaders as the way they conceived distributed leadership. For them leadership was distributed when they delegated functions and responsibilities (particularly budgets). This emergent view of distributed leadership was observed among research activities where individual academics developed their research interests and led these developments without direction from the formal leadership of their institutions. Thus Bolden et al. (2009) argue that distributed leadership which emphasises collective leadership and 
responsibility does not adequately describe distributed leadership as the majority of leaders believe it to be practised.

\subsubsection{Supporting distributed leadership}

In order to support distributed leadership, leaders need to be aware of leadership development. The need for distributed leadership (Bolden, 2011) and what has been termed post-heroic leadership (Fletcher, 2004; Sinclair, 2007 ) is also seen to be of critical importance, and there is an emphasis on the need for relationship-building skills. Bolden (2011) highlights a range of factors, such as power and influence, organisational boundaries and context, and ethics and diversity which are significant in the enactment of leadership but which are not yet adequately addressed by distributed leadership theory. A recent study by Hempsall (2014) focuses on senior leadership development thinking, programmes and practices. Hempsall's (2014) work provides a descriptive examination of 29 participants who were selected on the basis of reputation in research and/or leadership practice and included participants from across US, UK and Australia HEls, research institutes and professional agencies who were asked about their perspectives on leadership development and leadership work. The participants in this study from the nine sites in the high education sector overwhelmingly agreed that there remains a significant need for an approach to build effective and efficient leadership capacity which embodies a deeper appreciation of what it means to lead and engage in leadership work that transcends traditional heroic and bureaucratic models of leadership (Fletcher, 2004; Sinclair, 2007). This study focuses on interviewing experienced individuals who have demonstrated scholarship in leadership development and research and/or leadership practice in the higher education sector, in particular to explore their understanding of the critical challenges facing leaders in this context. There was a strong sense that traditional leadership skills were no longer as effective and that leaders needed to develop additional skills to be able to meet the challenges they face. This view is also supported by Fullan and Scott (2009) in their book, Turnaround Leadership. Fullan and Scott argue the need for change in higher education, and provide a detailed new agenda 
that uses 'change knowledge' to guide learning (p. 43). They posit that higher education has not approached leadership in an effective way and therefore institutions need to change from within using specific leadership capabilities. They lay out a new agenda for leadership in the way of viewing leadership and how leaders act because of the importance of understanding organisational dynamics, and of their powerful influence on students and their futures, for the university academy and for the larger society.

The literature discussed emphasises the importance of, and challenges for, higher education, in developing new approaches to leadership that are "more shared, distributed and relational" (Davis \& Jones, 2014, p.368). This requires an even greater change in mindset by academic leaders. Whether leadership in higher education in Vietnam is distributed effectively is currently under-researched. Accordingly, it was explored in this study.

\subsection{Leadership of curriculum design and delivery}

In this section, the review will focus on the literature of curriculum, curriculum design and the role of curriculum leadership in connection with the issues of Basic English curriculum design and delivery at the two selected universities.

\subsubsection{Definitions of curriculum}

There are many definitions and interpretations of curriculum. Henderson and Hawthorne (2000) define curriculum as "a plan for a pedagogical journey toward the good life, or students' actual classroom engagement with ideas and ways of knowing..."; but "depending on national, state, and local policy, it may also be understood as a course of study, a syllabus, or a group of text books or tests" (p.3). On the other hand, Bell and Baker (1997) claim that curriculum can have multiple layers of meaning which may "differ from the official or the teacher-intended curriculum" (Bell \& Baker, 1997, p.3). Bell and Baker depict many layers such as the planned, taught, learned, assessed and hidden curricula. These layers further explained as follows:

- The 'planned' curriculum is what the teacher plans and intends to happen 
- The 'taught' is what actually happens during the course of the lesson as it is influenced by the students' ideas, questions and needs.

- The 'learned' curriculum is what the students actually take away with them, which may or may not be the taught curriculum.

- The 'assessed' curriculum is that which the teacher assesses which does not necessarily reflect all that the students have learnt,

- and the hidden curriculum is the "...implicit and unintended learning which may occur"

(Bell \& Baker, 1997, p.2).

\section{Curriculum in higher education}

There is a dearth of research informing curriculum theory and practice within higher education (Hicks, 2007). Therefore, the term 'curriculum' has limited currency in higher education (Hicks, 2007, Short, 2002). Hicks (2007) defines "curriculum as a proxy to mean either the content of a programme of study, for example science curriculum or the issue addressed within a stand-alone unit of study" (as cited in D'Agostino and O'Brien, 2010, p.5). In a similar vein, D'Agostino and O'Brien (2010), suggest that "curriculum in tertiary education is poorly theorised and... in the absence of theoretically anchored principles and programmatic approaches to curriculum design or review, individual academics may undertake their curricular tasks by seeking a fit with their research interests" (p.3). Therefore, curriculum leadership plays an important role in the design, delivery, and evaluation within a degree programme (D'Agostino \& O'Brien, 2010).

The majority of research on curriculum development and leadership draws from school contexts. Several authors have argued this school-based literature has limited relevance to university settings because of the following reasons:

- The disciplinary settings in which university curriculum is located (Neumann, Parry, \& Becher, 2002; Parker, 2003);

- The variation in purpose and function of university programmes (Short, 2002); 
- The emphasis in higher education on the development of independent, critically-minded graduates capable of making significant contributions to society (Barnett, 1997).

The following aspects of this curriculum literature is relevant in this study as Gaff and Ratcliff (1997) claim that "the vision of what is a curriculum is heavily shaped by disciplinary values, educational philosophy, the diversity or homogeneity of students enrolled, and the social and institutional context" (p.5). Accordingly, it can be said that the context, content and design of the curriculum which universities/ colleges offered to their students are relevant. Ramsden (1998) argues that the higher education sector could learn from corporate approaches to leadership because the tertiary sector is highly analogous to other organisations in the need to deliver effective performance to a variety of customers within a highly dynamic context. Along these lines, the role of the university leader has received considerable attention (Gibbs, 2005, Knight \& Trowler, 2001) whereas the specific role of the curriculum leader is relatively unexamined (Marshall, 2006). Therefore, the following sections will address some of the literature about English curriculum design, curriculum leadership, and the characteristics of curriculum leaders from the school sector which may be relevant in higher education contexts.

\subsubsection{English language curriculum design and delivery}

Curriculum design in language teaching can be understood as both 'a kind of writing' and a kind of 'writing process', thus language curriculum design is widely applicable for ESL/EFL language education courses around the world (Nation \& Macalister, 2010). Supporting this view, Wiggins and McTighe (2006) argues that curriculum in language teaching consists of many components including input, output, methodology and outcomes.

Curriculum takes content (from external standards and local goals) and shapes it into a plan for how to conduct effective teaching and learning. It is thus more than a list of topics and lists of key facts and skills (the "input"). It is a map of how to achieve the "outputs" of 
desired student performance, in which appropriate learning activities and assessments are suggested to make it more likely that students achieve the desired results (Wiggins \& McTighe, 2006, p.6).

In a similar vein, Richards' (2013) study examines the assumptions and practices underlying different curriculum design strategies. Today, desired learning outputs or outcomes are often described in terms of objectives or in terms of performance, competencies or skills. For the purposes of this study, the recent definition of curriculum by Richards is adopted to refer to "the overall plan or design for a course and how the content for a course is transformed into a blueprint for teaching and learning which enables the desired learning outcomes to be achieved." (p.7). In terms of language teaching, 'Input' is suggested by Richards to refer to the linguistic content of a course. Therefore, it is assumed before teaching a language, we need to decide what linguistic content to teach. 'Process' relates to how teaching is carried out and constitutes the domain of methodology in language teaching. 'Methodology' encompasses the types of learning activities, procedures and techniques that are employed by teachers when they teach and the principles that underlie the design of the activities and exercises in their textbooks and teaching resources. 'Output' refers to learning outcomes focusing on what learners are able to do as the result of a period of instruction (Richards, 2013). The following figure summarises the components of curriculum and their relationship.

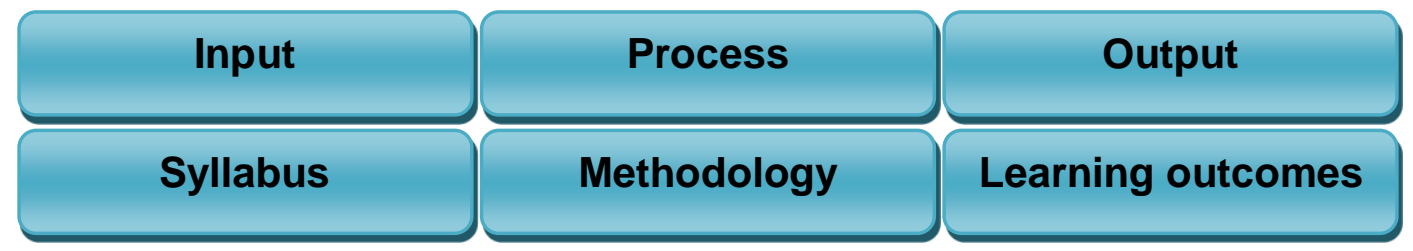

Figure 2.2: Dimensions of a curriculum adapted from Richards (2013, p.7)

English language teaching (ELT) curriculum design has seen several changes over time, especially with the changing views on the educational 
ideologies and philosophies in the western world (Ali, 2010). According to Nunan (1988a), a curriculum is associated with the planning, implementation and evaluation of a language course. There are several approaches to language curriculum design. Richards (2013) argues that curriculum development in language teaching can start from input, process or output. His statement implies that each starting point reflects different assumptions depending on both the ways and the outcomes of teaching and learning. Therefore, forward design, according to Richards, starts with syllabus planning, moves to methodology, and is followed by assessment of learning outcomes. Central design begins with classroom processes and methodology. Backward design starts from a specification of learning outcomes and decisions on methodology and syllabus are developed from the learning outcomes.

In language teaching, forward planning is an option when the aims of learning are understood in very general terms such as in courses in general English where goals may be described in such terms as 'proficiency in language use across a wide range of daily situations', or 'communicative ability in the four language skills'. Curriculum planning in these cases involves operationalising the notions of general English, or intermediate level English in terms of units that can be used as the basis for planning, teaching and assessment. This is the approach that was adopted by the Council of Europe as early as the 1970s. At present, Vietnam's higher education system is following the CEFR as mentioned earlier in section 1.2, therefore, forward design seems logical with the two universities in this study in dealing with their Basic English curriculum. For the purposes of this study, the term Basic English curriculum, in the study, is interpreted as the overall design for the Basic English course which is translated into the classroom via teaching approaches, learning activities and practices based on the curriculum frames of the Vietnamese national tertiary curriculum.

In reference to the context of the two VNLUs in this study, in terms of English language curriculum design, different universities take a different view on 
what to teach (Van, 2011). Some universities select a set of imported English textbooks which have no contextual relevance and mandate a number of units for teaching Basic English within the amount of time stipulated by MoET whereas other institutions design their own programmes. In order to see the relationship between curriculum leadership in curriculum design and delivery, it is necessary to discuss definitions of curriculum leadership, curriculum design in language teaching and its connection with the Basic English curriculum at the two universities.

\subsubsection{Definitions of curriculum leadership}

Fidler (1997) describes curriculum leadership as a concept which implies "that the head teacher has an impact on the professional work of the school, including the teaching and learning which goes on in the classrooms" (p.30). He presents two points of view from which instructional leadership can be considered. Instructional leadership by definition is strongly focused on the quality of instruction, however it attends to the underlying features of the school's organisational effectiveness such as routines, good appointments, solving problems as well as the quality of teaching (Bendikson, Robinson \& Hattie, 2012). One view takes a functional approach while the other represents a process approach. The functional approach involves leaders in defining the school mission, managing curriculum and instruction, supervising teaching, monitoring student progress and promoting an instructional climate. However, Fidler considers the process approach important as he suggests leadership comes from the way the tasks in the functional approach are achieved rather than achievement.

Jefferies (2000) identifies how characteristics of curriculum leaders in different leadership positions influence the practices and activities of others when displaying in their different roles. These characteristics include:

- have a sense of purpose and a clearly defined mission or direction

- involve people as much as possible in the change process and promote continual monitoring and review of programmes and practices 
- use effective interpersonal skills and establish climates that build consensus, empower others and promote open and clear communication patterns.

- motivate colleagues to attain goals and encourage discussion, collaboration, shared decision-making and problem solving and are also concerned with curriculum implementation

- help teachers to better understand the philosophies and intent of curriculum documents, provide assistance in implementing curriculum and resource materials, and model appropriate behaviours and practices in curriculum delivery.

(Jefferies, 2000, p.139)

These characteristics of curriculum leadership are very relevant to curriculum design and delivery because they can enhance leadership of curriculum issues. Whether they are applicable or hold true in the Vietnamese higher education context is under-researched. The next section explains the importance of curriculum leadership.

\subsubsection{The importance of curriculum leadership}

Sparks and Hirsh (1997) claim that curriculum leadership is needed because the purpose of schooling is to "...adequately prepare students for life in a world that is becoming increasingly complex" (p.96). Sergiovanni (1996, p.184) suggests that leadership must be viewed as one important part of the web of moral obligations that administrators, teachers, parents, and even students must accept. One part of this obligation is to share in the responsibility for exercising leadership. The other part is to share in the responsibility for ensuring that leadership, whatever its source, is successful. In this redefinition, teachers continue to be responsible for providing leadership in classrooms. Similarly, administrators, parents, and teachers must accept responsibility together for the provision and the success of leadership. One way to promote this ongoing professional development might be through the use of curriculum leaders. 
It has been suggested that leaders are people who engender a sense of purpose, influencing people towards achieving goals and making improvements in their practice, and that curriculum is translated from the national statements (Jefferies, 2000). While much of the literature focuses on principals as leaders, a number of authors (Bush, 2003; Firestone \& Wilson, 1985; Leithwood \& Poplin, 1992) identify the characteristics of successful and effective leaders, and utilise this knowledge in developing and implementing curriculum documents and resources. This, Jefferies continues, might help to better meet and respond to the changing needs of students, teachers and schools and points out that there are many other people within the educational setting who have leadership responsibilities. Consequently, D'Agostino and O'Brien (2010) suggest curriculum decisions from stakeholders such as students, staff, potential employers of graduates, professional bodies, teaching and learning committees, directors of studies, discipline heads and other schools would ensure better student outcomes. The role of leadership in promoting the Basic English curriculum design and delivery at the two VNSUs is of particular interest and needs to be examined. The next section will deal with the role of leaders at different levels of higher education.

\subsection{The role of academic leaders at different levels in higher education}

Leadership in higher education can be very hierarchical. There are strictly defined roles such as vice-chancellors, deputy-vice chancellors, pro-vicechancellors, etc. However, because academics are skilled professionals they all have the capacity to contribute to leadership. Therefore, it is relevant, in the context of this study, to look at the role of academic leaders at different levels in higher education and distributed leadership.

\subsubsection{Different levels of leaders}

The achievements of a university institution usually result from the contribution and cooperation of academic leaders at different levels and staff ranging from the most powerful leader, the vice-chancellor, and then the deputy vice-chancellor, down through levels of deans, heads of department, 
course coordinators, lecturers and so on. As mentioned earlier in section 2.3.3, some of these levels of leadership could be referred to middle leadership. From a practitioner's perspective, McMaster (2014) argues "the role of administrative leaders in universities is largely to coordinate processes and to ensure that one activity articulates readily with the next" ( $p .433)$. This requires individuals to work together to achieve common goals both within and between departments. Accordingly, this section discusses the role of academic leaders across university institutions. However, this review will focus on the role of educational leaders, course coordinators and heads of department as they may best correspond to the context of Vietnamese higher education regarding to curriculum design and delivery issues.

In Scott et al.'s (2008) examination of the most extensive roles and capabilities required of teaching and learning leaders in Australian higher education, it was found that a traditional view of academic leadership positions would show a standard hierarchical pyramid with the Vice-Chancellor at the pinnacle of the organisation and the subject coordinator on the lowest rung (Figure 2.3).

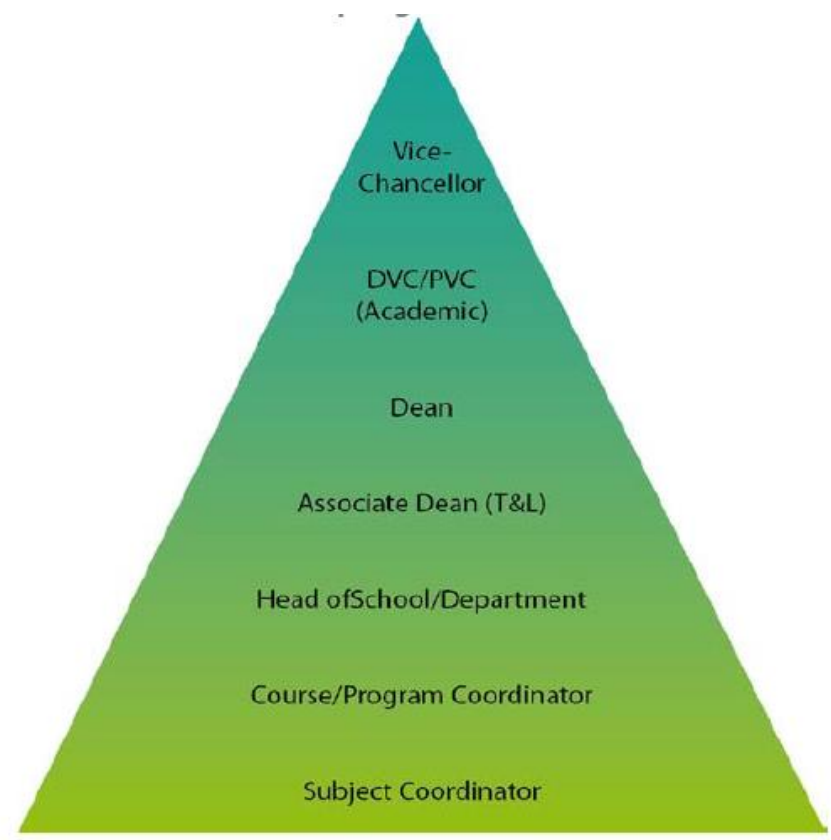

Authority over teaching and learning

Figure 2.3: The 'Authority over teaching' model adapted from Scott et al. (2008) 
In order to give the desired prominence to the role of subject coordinator, an inverted management pyramid is described in figure 2.4 .

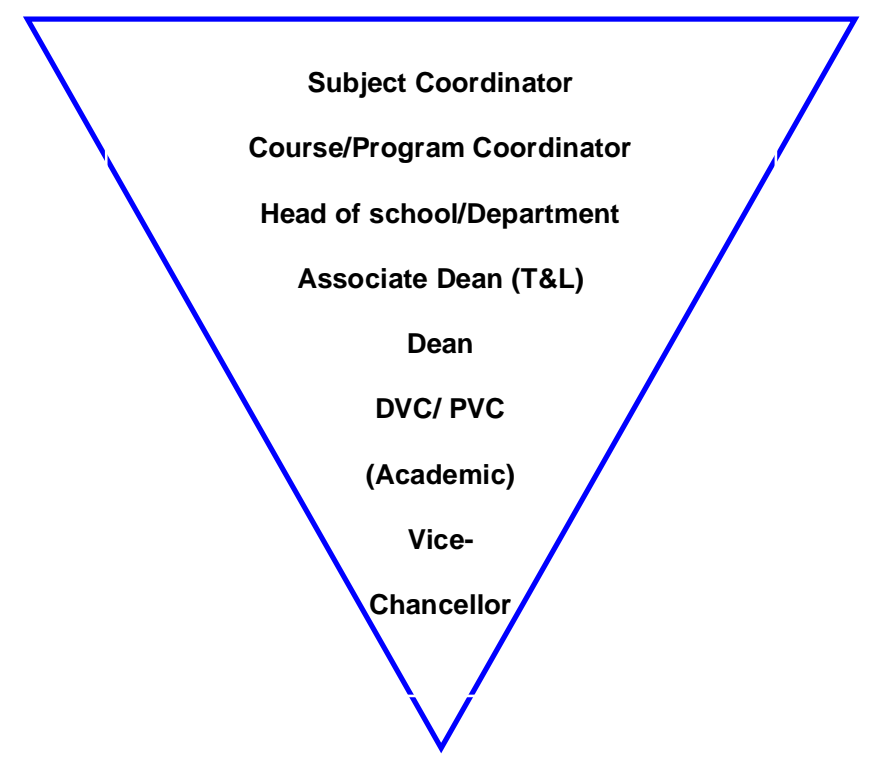

Figure 2.4: The influence/impact on teaching and learning' model adapted from Scott et al. (2008)

The inverted-pyramid figure highlights the ways in which higher levels of positional leadership should see their role and performance as supporting, and being contingent on, the lower but now symbolically higher positioned leadership roles. In reality, it can be argued that teaching and learning performance, development and innovation is strongly, and possibly ultimately, driven and carried by those in subject teams and subject leadership positions. Figure 2.4, which was developed by Scott et al. (2008), appears to be consistent with the Vietnamese university context. Hence, for the purpose of this study the framework is adapted to reflect Vietnamese higher education.

\subsubsection{The role of academic leaders in HE}

There is an overlap between the roles of academic leaders and educational leaders. According to Somalingam and Shanthakumari (2013), an academic leader is defined as "an academic member of staff who are teaching or administrating academic programs and having primary responsibility for the (re)design, delivery, monitoring and review of one or more educational 
programs of study (course) within a higher education institution" (p.82) while Heikkila and Lonka (2006) use the term 'educational leader' as the leader who is accountable for ensuring that effective teaching and learning occur in a learning community. Regarding the role of an educational leader in teaching and learning in higher education, Bijandi, Nazari, Pourijab and Mahdinezhad (2011) argue that the ability of a leader to connect with others in the organisation and gain their cooperation in working collaboratively towards the organisation's goals and objectives is the key to being effective. In this section, the educational leaders involved are referred to as senior leaders of teaching and learning in universities.

The role of educational leaders and their impact on teaching and learning process in universities is emphasised by Bijandi et al. (2011). Bijandi et al. also mention studies by Blackwell (2003); Burton and Dowling (2005); McKenzie, Gow, and Schwietzer (2004) which support some new elements impacting on the culture of teaching and learning. Moreover, Dinham (2005) and Nahavandi (2012) agree that where we find good universities we will find good leaders. Other scholars, namely Jackson and Lund (2000); and Montez, Wolverton, and Gmelch (2003), claim it is very difficult to construct a description of university leadership which goes beyond common heuristics grounded in everyday practice, as we know little about university leadership and the ways in which university leaders develop and sustain conditions and processes for improving teaching and learning. Interestingly, a number of recent studies' findings (Cleveland-Innes \& Sangra, 2010; Eddy, 2003; Heikkila \& Lonka, 2006; Knight \& Trowler, 2001) demonstrate that the understanding of leadership in academic organisations, at least among scholars, may be undergoing a paradigmatic shift, from a rational perspective toward a cultural and symbolic perspective.

The aim of Bolden et al.'s (2009) study was to develop ideas about how leadership could be enhanced through the encouragement of collective behaviour. They address this through five themes: structural approaches to leadership; individual motivation; collective leadership; context of higher education; and leadership development (Bolden et al., 2009). The study 
focus on leaders in formal positions but Bolden et al. believe its findings to be more generalisable to individuals in informal positions, as they concluded that bottom-up and horizontal leadership play important roles in universities. They also recognise that formal leaders often depend on informal leaders and informal leaders are often the formal leaders of the future. They identify that a significant aspect of university leadership is found in the committee structure; often decisions are made by consensus and leaders of such committees need to be 'authorised' to speak for the group. They further state that any leadership development plans must acknowledge the changing context of an institution. For example, they believe there has been a significant shift from the collegial style of working into a more corporate style in the UK higher education. They identify a need for leadership development to move from a generic focus to one specific to the needs of the different roles found in universities.

From some of these studies (Bijandi et al., 2011; Fullan, 2006; McCaffery, 2010; Reiss, 2007), it can be concluded that the knowledge and skills an educational leader needs to support and enhance teaching and learning processes in higher education include focusing on others; being flexible, creative and up to date; listening actively and comprehensively to academics and students; using different techniques and offering skills that lead to learning; and showing respect and "love" (Bijandi et al., 2011, p.338) to academics and students. "Love" is an unusual term to use in an area where emotional words are not usually used. However, in this context of study, it is understood as consideration to, and collegiality with, academics and students.

\subsubsection{The role of academic dean}

Academic deans are defined as the chief academic officers of their divisions (Wood, 2004) while their duties and responsibilities are varied (Thrash, 2012). Deans have the ability to control information, accumulate and allocate resources, and access the performance of their faculty and staff with the 
university hierarchy (Wood, 2004). They must act as managers as well as leaders (Thrash, 2012). Some of the responsibilities of deans are:

- to cultivate and maintain the quality of academic programmes in their divisions (Jackson, 2004);

- to plan, organise and control, and set goals for the organisation (Gmelch, 2004);

- to have an array of leadership and interpersonal skills (Sypawka, 2008); and

- to be cultural representatives of their colleges, good communicators, skilled managers, forward-looking planners, and advocates for the university with an ability to manage change (Del Favero, 2006a).

Finally, the type and style of leadership employed by academic deans plays a major role in the successful completion of their duties and the overall success of their academic units (Del Favero, 2006a). Therefore, the role of academic dean is crucial to the success of HEls.

\subsubsection{The role of the department head}

The role of the head of department in tertiary education is also important. Bryman (2007) considers leadership in higher education, particularly in relation to heads of departments, and investigates the literature around the styles or approaches to leadership that were associated with effective leadership in higher education. He also comments that there is considerable anecdotal reflection and research on what leaders do but "remarkably little systemic research on what aspects of leader behaviour makes them effective leaders" (2007, pp.693-694). He notes that this view is consistent with that of other authors such as Harris, Martin, and Agnew (2004) who suggest treating academic staff fairly and with integrity; being trustworthy, and having personal integrity themselves. These suggestions were applied in Bryman's (2007) work. Bryman argues:

One of the most striking aspects of the literature on academic work is the degree that academic staff relish a collegial climate with the implication that an important aspect of leadership effectiveness is the degree to which the head of department is able to foster such collegiality (pp.701-2). 
Leadership with a sense of shared social and academic values between the leader and their followers is expressed by "allowing the opportunity to participate in key decisions/encouraging open communication" (Bryman, 2007, p.697). This collation of items or expectations of leaders from the literature does suggest that academics believe leadership is important for academic effectiveness (Bryman, 2007). Nevertheless, as his review includes assessment of leader effectiveness in relation to research orientations as well as learning and teaching, it is not clear whether this claim would be made so strongly in respect of leadership in the more specifically learning and teaching context of course coordination.

The role of the department head, to which Bryman (2007) specifically directs his literature review, may perhaps be more managerial in nature and less 'at the coalface' of teaching and learning than that of the course coordinator. He further suggests that the encouragement of participation in decision making is one aspect of leader behaviour that is especially significant in universities because of the "striking intensity with which the literature suggests that leaders are more effective if they promote this" (p.706). However, he has significant reservations about the relevance of traditional notions of leadership in the academic context where individuals are intrinsically motivated by their work and suggests that this is an area for further study. He emphasises that what can actually occur is that leadership may have adverse effects rather than positive ones. He also notes that the call for accountability in universities "has arisen largely because of a lack of trust and confidence in professionalism that can act as a substitute for leadership" (p.707).

The role of department head is also mentioned by Smith (2005). His study investigates two case studies of leadership and management in two British universities, one a chartered university and one a statutory university. He interviewed the heads of the two departments and members of the staff who have leadership and/or management roles. He found that there is striking difference in the culture and organisational structures and different approaches to leadership and management of the two departments. For example, in the chartered university, department heads are elected for fixed terms whereas heads in the statutory have permanent and fullime jobs. In the chartered university, the head is responsible for research and teaching in 
his/her department. In contrast, in the statutory, the head is responsible for research, but unofficially, as research is considered a lower priority than teaching. From the two studies above, focusing on the role of department head, research and teaching should have equal attention and department leadership is crucial for academic effectiveness.

\subsubsection{The role of subject coordinator (course coordinator)}

Subject coordinators are defined as those who are responsible for managing and leading the constituent subject components of a course or programme of study; for example, the organisational, administrative, curricula, teaching and learning, and overall quality of a subject (McDonald et al., 2010). Subject coordinators are also distinguished from senior staff as they have formal leadership responsibility for course/programme-wide curriculum development and delivery. McDonald et al. proposed that these largely informal roles require formal recognition and training to provide a strong foundation and a base for further leadership capacity building. Evidence suggests that subject coordinators require specific skills and competencies to be effective in their role and that there are few resources available to assist in role interpretation and professional development to build leadership capacity. Subject coordinators are responsible for "managing and leading the constituent subject components of a course or program of study; for example, the organisational, administrative, curricula, teaching and learning, and overall quality of a subject" (McDonald et al., 2010, p.2). The subject is usually part of a sequence of subjects in a programme or course.

In a study by Percy, Scoufis, Parry, Goody, Hicks, and MacDonald (2008), it was suggested the role of subject coordinator is also changing with the increasing casualisation of university staffing. Similarly, Cohen, Bunker, and Ellis (2007) emphasised that the subject coordinator's role encompasses administrative and academic duties. However, the qualifications required for the position are often unclear, and there is little or no training for the position. Cohen et al. (2007) suggest: 
Subject coordinators require diverse skills and knowledge in order to effectively fulfil their duties which include designing curriculum, supporting the sessional academic staff, working collaboratively with their colleagues, teaching and supporting students. (p.3)

Subject coordinators, therefore, have a further responsibility to engage broadly with students in order to understand their issues and responses to the challenge of academia in the relevant subject area/s and be able to provide related learning and teaching leadership to staff within the unit (Kennedy, 1995). Further, in an increasingly interdisciplinary context, an additional level of expertise is required to manage or interact effectively with the diverse perspectives and contributions of the subject coordinator's team. In a review of the literature on effective leadership in higher education, Bryman (2007) suggests that the impact of different disciplinary contexts on leadership expectations, style and effectiveness has so far received only limited research attention.

According to McDonald et al. (2010), in the current learning and teaching environment, some team members may form part of a casual industry pool that may potentially bring enriching cutting-edge ideas and practical or 'real world' issues to the learning and teaching environment. They also suggest it might be expected that such interaction would inform or stimulate the subject coordinator's own management practices, learning and teaching, and research initiatives. Therefore, a subject coordinator as discussed above would be likely to be well equipped to recognise and act positively in response to individual team members' contributions while constantly weighing the input in terms of its relevance to the coherence of the subject activity, goals and strategic directions (McDonald et al., 2010). Ladyshewsky and Jones (2007) suggest that universities must consider leadership development within the course coordinator role, given the coordinator's pivotal leadership role in ensuring course quality. Ladyshewsky and Jones' research positions subject coordinators as academic leaders and key players in the quality process: 
Course coordinators are key players in the quality process because of their leadership role in managing, developing and running university courses. The decisions and actions they take have a large influence on student performance, feedback, learning outcomes and overall course quality (p.83).

Clearly, subject coordinators play an important role in the leadership of teaching and learning. A subject coordinator is equivalent to the role of a course coordinator or a programme coordinator at each university (McDonald et al., 2010, p.2). Accordingly, the term 'subject coordinator' and 'course coordinator' can be used interchangeably. However, in the context of my study, the use of the term 'course coordinator' is preferred because of their contribution and indispensable role in improving the quality of teaching and learning at university.

In brief, section 2.6 has discussed the roles of different leaders involved in curriculum design and delivery issues in Western contexts. Whether the roles of different leaders in dealing with curriculum design and delivery issues in Western context are applicable or hold true in the context of Vietnamese higher education is under-researched and will be investigated in this study. Leadership also operates at different levels and comes from different places. Therefore dual leadership seems to be relevant here.

\section{Dual leadership}

The term 'dual leadership' has been discussed in business and non-profit organisation literature (Fosberg \& Nelson, 1999; Gottfridsson, 2013; Vidyarthi, Erdogan, Anand, \& Liden, 2014; Voogt, 2006). Dual leadership can refer to a corporate organisation having different people as chief executive officer (CEO) and chairman (Fosberg \& Nelson, 1999). Dual leadership is also applied to describe two leaders with equal rank (Voogt, 2006) which could be called a joint leadership (Gottfridsson, 2013). Moreoever, Vidyarthi et al. use concept of 'dual leadership' to describe 'a situation where multiple leaders supervise an employee' (Vidyarthi et al., 2014, p.1). Their concept is tightly woven into the leader-member exchange theory, since multi leaders 
mean multiplied dyads and relationships. Several studies of the Vietnamese higher education context [see Gropello et al. (2008); Ly et al. (2014); and Sarvi et al. (2012)] agree that the MoET and line ministries have control over universities in terms of management decisions. Apart from the two national universities that are largely autonomous under the supervision of the office of the Prime Minister, all universities must follow MoET guidelines governing admissions, curriculum design and organisation of instruction including organisation of degrees, grading, teaching methods. Similarly, public universities must follow rules on budgeting, spending and personnel management. These structures may be seen as examples of dual leadership even though the term 'dual leadership' is not specifically used. This term could be applicable to all aspects of the relationships the universities have with multiple ministries.

\subsection{Changes in university context affecting leadership capacity in higher education}

The higher education setting has changed greatly in the last two decades (Bryman, 2007). For example, there have been substantial changes in the higher education sector globally in response to factors such as expansion, internationalisation, research funding, student fees and government policy (Bolden et al., 2012). Specifically, changes in both global and national contexts in recent years have substantially impacted on the way universities operate. These include changing the nature and expectations of academic work and creating the need to build the leadership capacity of academics and staff to operate in this changing environment. Further, the subsequent demand for skilled workers for the 'knowledge economy' has challenged the notion of a university as an elite institution, and government, employers and others have put pressure on higher education providers to produce' human capital' to meet social needs (Marginson \& Sawir, 2006; Middlehurst \& Woodfield, 2007). Nowadays, students and their families who increasingly bear the cost of their education might demand flexibility, quality teaching, more feedback and better facilities. Consequently, academic leadership is critical in higher education as it impacts on the quality of 
student learning (Ramsden, Prosser, Trigwell, \& Martin, 2007). Changes pointed out by Scott et al. (2008) include:

opening up access and a resulting diversified student body, changes in funding, pressure to generate new sources of income, rapid growth in the higher education export market, growing competition, the challenge of maintaining standards with the changing nature of the student cohort and the changing characteristics of a new generation of students. (pp.29-39)

A major challenge to academic territory and the independence of universities is perceived in "structuring curriculum around external needs and demands rather than securing resources for a department or school" (Coaldrake \& Stedman, 1999, p.5). Currie and Vidovich (2009) also note that academic work is increasingly located within the complex interplay between global, national and local contexts. It is clear that Vietnam's higher education also faces similar changes in funding, student fees, pressure to generate income, government policy as mentioned by Scott et al. (2008) and Bolden et al. (2012). However, other changes like rapid growth in the higher education export market and the changing characteristics of a new generation of students are less relevant in the Vietnamese university context.

McDonald et al. (2010) affirm that academics working at the coalface are affected by contextual changes occurring in the world outside higher education, including the effect of technology which enables people to share ideas and work collaboratively across the globe. Mayes, Morrison, Mellar, Bullen, and Oliver (2009) emphasise that this "signals a fundamental change in the way young people learn, although the change is more likely to be cultural rather than cognitive" (p.4). As a result, this has put the normally conservative higher education environment under considerable pressure from society to change "to become more accountable, more efficient and effective, and more relevant and responsive, while providing greater and more equitable access" (Reushle, McDonald, \& Postle, 2009, p.61). Nowadays, universities operate in competitive, internationalised, dynamic environments (Hotho, Goldrick, \& Work, 2008), increasing the focus on the need to develop strategic capability at all levels 
(Brown, 2004). Due to both the changing global and national context, it is essential for universities to build their leadership capacity to operate in this changing world.

\subsection{Factors impacting on leadership approaches in higher education}

Leadership in higher education, is "not a simple process... rather, it is a complex, multifaceted process that must focus on the development of individuals as well as the organisational contexts in which they are called to operate" (Marshall, 2006, p.5). There are a number of factors which affect effective leadership approaches in higher education. These are, organisational contexts, expectations of leaders, and leaders' adaptations to change.

\subsubsection{Organisational contexts}

Middlehurst, Goreham, and Woodfield (2009) debate whether there is something distinctive about leadership in higher education in comparison to other organisations. They conclude there is no singular aspect which sets it apart from other organisations; however, they feel there are some characteristics that have greater emphasis in higher education compared to other entities such as its decentralised nature and the culture of autonomy and collegiality. They also point to the possible tensions between "those who wish to preserve the privilege and power of the bureaucratic class from those who hope to build less structured and less tightly managed organisations" (Middlehurst et al., 2009, p.329). In a recent article discussing the two concepts, 'leadership' and 'management', Middlehurst (2012) argues that the context in which universities operate is dynamic with a variety of changes needed to sustain or enhance institutional performance and competiveness. Therefore, universities should pay much attention to effective leadership.

\subsubsection{Expectations of leaders in higher education}

Bryman (2007) in his review of literature on ways to determine effective leadership competencies in higher education found that because the literature lacked a consistent way of using key terms it was impossible to form a cumulative view of what effective leadership is. He asked leadership 
researchers to give their views on leadership and what this means for a leadership competency framework. He reported that participants were sceptical about competency frameworks as they ignored contextual factors and there was a feeling that any leadership framework which ignored context was ineffective (Bryman, 2007). There was also a strong feeling among the participants in this study that higher education provided a unique context for leadership which meant that leadership approaches used outside of higher education often did not work within higher education. The participants felt this was particularly due to academics being first loyal to their discipline and then to their institutions. Bryman also argues that academics are by their very nature critical and need to be told why they need to do something rather than simply being told to do it. However, he states that a number of characteristics were identified for good leaders including, trustworthiness, integrity, consultative approaches and tackling problems.

Bryman (2007) believes that a leader needs to create an environment "for academics and others to fulfil their potential and interest in their work" (2009, p.66). Similar to Middlehurst et al. (2009), he believes that "higher education institutions are not as distinctive" (p.66) as sometimes thought, but again it is the intensity of what is expected of academic leadership that sets it apart from other types of leadership. For example, he believes university employees want their leaders to ensure autonomy, consult, foster collegiality and fight for them with senior managers. It is this last point that, for Bryman (2007), distinguishes middle managers or leaders in higher education from those in other organisations. Further, leaders' capabilities which adapt to changes are also pertinent to the discussion of leadership.

\subsubsection{Leaders' adaptations to change}

In the increasingly-pressured and changing contexts of HEls, leaders need to develop their capabilities to adapt to change. Scott et al. (2008) argue that higher education in Australia has been the subject of a range of broad social pressures to change and this has generated the need for institutions and leaders to be 'change capable'. Thus, leaders not only need to be good 
managers but also lead their institutions in new directions by engaging people in the process and reshaping the operating context of their institutions. They do this by encouraging staff to adapt to change and guide them on how to do make the necessary changes through ensuring effective and supportive learning environments. Scott et al. believe that leaders themselves need support to enable such changes to occur and they prefer role-specific, practice-based, peer-supported and self-managed learning to more formal and generic workshop learning.

Leadership capability is another factor impacting on leadership approaches. A study undertaken by Bolden, Petrov, and Gosling (2008a), examined the forces acting on higher education and how leaders have responded to them. They centre their argument on the notion that leading implies learning. Thus, they focus on the capabilities of leaders and how they can be developed. They consider, as a result of this lack of understanding, leadership is often subject to "a somewhat individualistic and management approach" (Bolden et al., 2008b, p.359). This approach, they believe, causes tensions between individual and collective performance, centralised and decentralised control, and economic and social aims. The result of these tensions is that leadership in higher education is multi-layered and multifaceted, and that agency and structures interact at the group level through social capital and identity. They further suggest that although leadership is widely distributed across universities, individual leaders play a critical role. Thus, they suggest a hybrid model of collective and individual leadership.

Similarly, Burgoyne, Mackness, and Williams (2009) in their baseline study of leadership in higher education investigate the national UK higher education investment in leadership development. Their study addressed several questions:

- Does such investment work?

- What institutional performance is improved by the investments?

- How are careers influenced and does leadership development fit into the notion of learning organisations? 
- What conditions are required to improve capabilities?

- What are the leadership capabilities that are supposed to be improved?

Their study focused on developing capacity for future roles and supporting people in preparing for new roles. Their research indicated that higher education has made significant progress with leadership development in recent years. Their study also implied that a new vision for leadership development is needed so that leaders at all levels can focus on creating a work climate which motivates staff to perform at their best and provide training and coaching to help intact leadership teams as well as the individual leaders to work more efficiently.

\subsection{Impacts of Vietnamese cultural and political factors on academic leadership}

In this section, the cultural and political characteristics of Vietnam and its impacts on different leadership approaches, namely heroic leadership and distributed leadership, dual leadership and some key concepts on the literature of Vietnamese leadership in the higher education context are addressed.

\subsubsection{Cultural and political factors impacts on academic leadership}

Vietnamese indigenous culture still maintains its core values even though it has been influenced by Confucianism since the country was invaded and ruled by the Chinese (Hang, 2011). Later, Communist ideologies and Western values came into contact with Vietnamese culture, but their influences have been adapted in a different way. Communist ideologies help to reinforce Vietnamese cultural values as the Vietnamese government has always devoted a lot of effort in maintaining the community spirit of the common Vietnamese people, especially Vietnamese youth, via education and other means. For example, Constitution of the Socialist Republic of Vietnam 1992 stipulates that "the State applies a policy of equality, solidarity and mutual support among the various communities" therefore, moral education lessons at all levels emphasises teaching the love of community to 
students (Education Law, 1998, revised 2005). The Education Law states that a socialist citizen "knows how to live and work for the harmony and benefits of the community" (Doan, 2005, p. 455). Therefore, the core values of Vietnamese culture, including, community culture, solidarity and mutual support are still maintained (Hang, 2008). Tran (2006) stated that the development and values of Vietnamese culture are influenced and shaped by the living conditions which have led to an economy based on water-based rice-crop agriculture. Vietnamese people have to collaborate/cooperate with one another to protect their crops. Moreover, Vietnamese need to pay special attention to the many interrelated factors that may impact on crop yields. These features of the economy shape the features of Vietnam's social organisation, leading to a high degree of collectivism/community spirit, an emotion-based lifestyle, and high adaptability to various situations and changes (Hang, 2011). Accordingly, Vietnamese always try to be in harmony with nature, and with the community.

Although cultural dimensions have been mainly been studied in terms of cross-cultural research on leadership, they are relevant to educational leadership as they offer useful research tools for analysis (Dimmock \& Walker, 2005). Cultural dimensions can also be used as a lens which helps to understand the cultural characteristics of Vietnamese society. In Vietnam, socio-cultural and political characteristics play a crucial role in the education system due to Chinese influence. One of the most striking consequences of the Chinese domination of Vietnam has been the impact of Confucianism on Vietnamese culture, especially in terms of hierarchy and power distance (Ngan, 2011). According to Northouse (2007), power distance means the degree to which members of a group expect and agree that power should be shared unequally.

Due to the strong influence of the Chinese Confucian philosophy, Vietnamese society became "a highly bureaucratic and hierarchical structure in which age and seniority is accorded with wisdom and considered as an important indicator of one's social status" (Ngan, 2011, p.8). Vietnam's society therefore tends to accept the fact that a high power distance is a 
fundamental characteristic of an orderly structure (House, Hanges, Javidan, Dorfman, \& Gupta, 2004; Northouse, 2013). Recently, Northouse (2013) described a leader in the Confucian Asian countries as self-protective, teamoriented and humanly-oriented. According to Northouse (2013), this type of leader does not invite others to be involved in goal setting or decision making. Because of the power distance existence in Confucian Asia countries, a leader "works and cares about others but uses status and position to make independent decisions without the inputs of others" (p.398). Power distance usually creates inequality between people based on power, authority, prestige, status, wealth and material possessions

\section{Impact of culture on women's leadership}

Another noticeable Confucian influence on Vietnamese culture is observed in the status of women. In a study by $\mathrm{Ha}$ (2001), women's positions in Vietnamese society were found to be heavily influenced by Confucian ideology which considers women as inferior to men. In addition to this low status, Vietnamese women are also expected to conform to the femininity norms of the "heavenly mandate" (Hang, 2008, p.19) which involve giving birth, breast feeding, educating children, taking good care of the family and husband's elderly relatives and many other unpaid jobs in parallel to their fulltime professional job.

There have been some Vietnamese research studies on how cultural dimensions impact on women's leadership in higher education. Ngan's (2011) study examined how culture impacts on women's leadership in higher education. She interviewed six female participants; five of the six were Heads of Departments/ Divisions at a technical university and the other a teacher. Drawing on the experiences of these six women leaders, her study explored how culture shaped the way women led, as well as their beliefs and perceptions about leadership in higher education in Vietnam. The findings indicated that both the indigenous and organisational culture substantially influenced the female participants' exercising their leadership and consequently contributed to the poor representation of women in senior 
positions. Ngan's study indicated that to promote women's progress and their representation in leadership positions, cultural change is necessary. However, it is difficult to change the traditional culture in countries such as Vietnam and China.

Another study by Lan (2012) examined Vietnamese mid-level women leaders in four selected higher education institutions in the Mekong Delta regarding their leadership experiences. Lan's (2012) study shows that disparity between gender equality policies and gender practices were typical throughout Vietnam. Moreover, it revealed the impact of the cultural contexts of Vietnam on women's professional and personal lives and the influences of the culture of gender on their leadership development process. A further case study by Dung (2012), also in the Mekong Delta, explores developing middle leadership as discussed earlier in section 2.3.3 in a Vietnamese university and the perceptions and practices affecting these. In Dung's study five females and five males with a wide range of ages and professional experiences were selected from different units across the university to explore how middle leaders have learnt professionally in their leadership learning and their perceptions of effective leadership and sustainable leadership.

The three studies mentioned above mainly focus on the impact of cultural dimensions on mid-level female leaders in higher education, but not senior leaders. These female leaders were found to face some challenges in their leadership work. No existing literature in Vietnam examines the impact of culture on academic leadership in relation to curriculum design and delivery in higher education. Because of the impact of culture on leadership, it is expected that these cultural values and dimensions influence academic leadership which is the reason why this study will provide insights into understanding the role of leadership in promoting and supporting the curriculum design and delivery in Vietnamese higher education contexts. 


\subsubsection{Different leadership approaches}

Nahavandi (2012) who researched cross cultural perspectives on leadership pointed out that different leadership approaches can influence organisational performance or effectiveness. This idea is further supported by Mahdinezhad, Suandi, Silong, and Omar's (2013) research which found effective leadership has a role in the better performance and growth of higher learning organisations. A number of leadership models and approaches have been addressed in this literature including dual leadership which has not been explored in the literature in the Vietnamese context. Accordingly, it may be appropriate to link 'dual leadership' to the leadership of line ministries and MoET in Vietnamese universities. Therefore, dual leadership in the context of this study can be defined as the leadership of two different ministries over the universities. A number of leadership approaches have been addressed in this literature. However, this section will examine the most relevant models for Vietnamese higher education: heroic leadership and distributed leadership.

\section{Heroic leadership in Vietnamese higher education}

The heroic leadership approach is built on the claim that leadership is about strong individuals with superior qualities as leaders, and others as less able passive objects who have no choice but follow their leaders (Koivunen, 2007). However, Cohen (2013) argues that this leadership style is the art of influencing others to achieve their personal best and maximise performance in accomplishing any task, objective, or project while putting their needs and those of the mission above their own. Heroic leadership depends on the belief that the organisation's success is shaped by the leaders' personal characteristics and attributes alone, and that individuals, as heroes, can make a difference, can change things and make things better. Accordingly, this model emphasises formality and opportunities for exercising leadership in accordance with hierarchical and structural positions (Oduro, 2004). With all these features, heroic leadership plays a significant role in transitional or developing societies where its features could meet the needs of both leaders and followers (Burns, 2010). Moreover, Dung's (2012) point of view is that 
heroic leadership has been widely practised in Vietnam as it suits the existing notion of power distance and the hierarchical thinking of this country. She suggests that heroic leadership is commonly practised in developing countries that are power-led and heavily hierarchical such as Vietnam. However, because of the increasing changes in universities' contexts, HEls need to improve the leadership and management and challenge this reliance on the heroic leadership model. The distributed leadership practice from Western literature can offer insights into the questions of whether this model hold true or is applicable in the context of Vietnam.

\section{Distributed leadership in Vietnamese higher education}

Although distributed leadership is well-documented in Western higher education contexts, it is rarely explored in Vietnamese higher education contexts. One study by $\mathrm{Du}$ (2013) which investigates distributed leadership in the Vietnamese school sector, examined the relationships of distributed leadership, demographic factors and teachers' organisational commitment. However, it is unclear whether distributed leadership in the Vietnamese school sector is similar to that of the higher education sector. As discussed earlier, Dung's (2012) study focuses on examining participants' leadership experiences in one university in the Mekong Delta. Her study suggests that distributed leadership is a desirable model for Vietnamese education system rather than using the 'topdown' approach of leading. In order to support the idea that leadership in higher education is distributed as mentioned in section 2.4 by many foreign scholars, it is necessary to explore whether academic leaders face any challenges if this leadership is practised in Vietnamese HEls to improve their practice within the prevailing social-political hierarchical system of the Vietnamese collective society and can it be a an effective leadership in Vietnamese higher education contexts?

Distributed leadership also emphasises collectivism. As discussed earlier, collectivism plays an important role in the Vietnamese society therefore it is useful to consider the relationship between distributed leadership and collectivism. Elmoore (2000) confirmed in her study that it is necessary to distribute 
responsibility for leadership among roles in the organisation and to work hard at creating a common culture or sets of values, symbols and rituals in order to perform complex tasks in a knowledge-intensive enterprise like the teaching and learning process. An analytic framework was used in a study by Bolden et al. (2009), in which they further affirmed that distributed leadership emphasises collectivism rather than individualism. Interestingly, in research by Knight and Trowler (2001) into department-level cultures and the improvement of teaching and learning, it was argued that leadership practices and working cultures at department level could modify the impact of possibly negative structural changes in the higher education system and enhance the development of deeper teaching and learning practices. They propose that:

If better departmental leadership is to be seen as the key to improving approaches to teaching and student learning by facilitating collaboration, then the role of the head, or chair, of department needs reworking and this will require improved leadership and management training for department heads. New approaches to training require new thinking in staff and educational development units, which will also have much more to do in supporting faculty working on teams to address current problem.

(Knight \& Trowler, 2001, p.88)

Knight and Trowler (2001) pointed out that activity systems at the departmental level are the central place for change in approaches to teaching and learning practices. It can be said that distributed leadership is beneficial and has a positive influence on organisational as well as teaching and learning performance. Mahdinezhad et al.'s (2013) research asserted that transformational and transactional leadership approaches can assist in the development of leadership capability of both leaders and enhance their performance and commitment. Mahdinezhad et al. further suggested a leader should take on the style of leadership that fits the setting in which the followers and leaders interact. Therefore, it is useful to see which of these leadership approaches works best in Vietnamese HE contexts. Moreover, the examination of the concept of distributed leadership is appropriate for my 
study because it provides a desirable and effective model to help academic leaders to improve leadership practice and teaching and learning approaches in the Vietnamese university context especially with the increasing changes in these contexts.

\subsection{Summary}

This literature review has discussed a number of different aspects of leadership in higher education related to this study. First, key concepts including leadership, academic leadership and distributed leadership that underpin the study have been clarified. Second, the argument that academic leadership is crucial in higher education because it impacts on teaching and learning was highlighted. Third, the hierarchical model of leadership in higher education was presented, with an analysis of different leaders involved in curriculum design and delivery issues. Next, several factors which affect leadership approaches in higher education, such as organisational contexts, expectations of leaders, leaders' capabilities and adaptation to change, were examined. The cultural and political contexts of Vietnam and different leadership approaches in Vietnamese higher education contexts were discussed. This review has provided a literature base and comprehensive background insights to further understand different leadership approaches in higher education.

Further, this review identifies a gap in the literature. This includes: how academic leadership and distributed leadership develop in the context of the Vietnamese higher education sector; the impact of dual leadership; the scarcity of research in terms of distributed leadership and academic leadership relating to curricula issues in the Vietnamese higher education context; the leadership of teaching and learning to affect better student learning outcomes in Vietnamese tertiary education; and the influence of Confucian ideological and cultural values on leadership practices in curriculum issues in HEls. This study will help us understand academic leadership in Vietnam, however some features of this study may be relevant to other Asian and non-Western contexts. So far, no research has addressed 
the role of academic leaders at different levels in curriculum design and delivery in Vietnamese HEls. Therefore, this thesis will provide insights into this neglected area. The following chapter presents the methodological approach in this research and details the research design. 



\section{Chapter 3: METHODOLOGY}

\subsection{Chapter overview}

This chapter aims to fully explain the methodology to justify its suitability in order to investigate the leadership of curriculum design and delivery at the two Vietnamese universities. The chapter is divided into five parts. First, I will present the research approaches including research paradigms and strategies of inquiry which demonstrate the choice of qualitative-focused case study design with a small quantitative component as the research methodology. Second, I will discuss the research design used in this study, which involves a case study design and units of analysis. Third, the chapter provides a detailed account of the procedures for data collection, and explains the methods for managing and analysing the data. The fourth section will look into issues of trustworthiness. Finally, this chapter deals with the consideration of ethical issues.

The study sought to investigate the role of leadership in promoting and supporting the Basic English curriculum design in two Vietnamese universities through the central question:

- What is the role of leadership in promoting and supporting the Basic English curriculum design and delivery at two selected Vietnamese universities?

In particular, it focused on what levels of leaders are involved, perspectives of academic leaders on their roles and practices, how collaborative leadership practices positively impact on the Basic English curriculum design and delivery, views on the barriers and enablers of the Basic English curriculum design and delivery and the perspectives of the stakeholders about the effectiveness of the Basic English curriculum. The following subquestions helped answer the research question:

1. What levels of leaders are involved in the Basic English curriculum design and delivery? 
2. In what ways do collaborative leadership practices positively impact on the Basic English curriculum design and delivery?

3. What are the barriers affecting the leadership roles of academic leaders?

4. How do academic leaders promote the Basic English curriculum delivery?

5. What are the perspectives of the stakeholders about the effectiveness of the Basic English curriculum design and delivery?

\subsection{Research paradigm}

According to Cohen, Manion and Morrison (2007), researchers need to understand elements of epistemology, ontology, and methodology in developing a framework for conducting research. Therefore, the combination of the three elements affects the direction of a study. Creswell (2003) poses the three following questions which he believes are important in research design:

1. What knowledge claims are made by the researchers?

2. What strategies of inquiry will inform the procedures?

3. What methods of data collection and analysis will be used? (p.5)

Each of the above questions was taken into consideration when forming the framework for this study.

\subsubsection{Knowledge claims}

Creswell (2003) argues that knowledge claims include both theories of knowledge and theoretical perspectives or paradigms. In the work of Cohen et al. (2007) on research methods in education, knowledge claims are defined as contentions about the nature and forms of knowledge and how it can be acquired and communicated. Denzin and Lincoln (2000) view paradigms as a combination of the ontological, epistemological and methodological premises of a researcher which guides their actions. Moreover, research is guided by beliefs and feelings about the world and 
how it should be understood (Denzin \& Lincoln, 2005). The research paradigm not only focuses on how a study should be conducted, but also raises issues about the focus of a study and approaches to interpreting the data (Bryman, 1988). Accordingly, the research paradigm is important as a guideline for enquiry.

As stated previously, this research is placed within the interpretivist/ constructivist paradigm. In this study, both terms "Interpretivist/constructivist" approaches to research are used for the following reasons: they

- have the intention of understanding "the world of human experience" (Cohen \& Manion, 1994, p.36).

- imply that "reality is socially constructed" (Mertens, 2005, p.12).

- do not generally begin with a theory...rather they "generate or inductively develop a theory or pattern of meanings" (Creswell, 2003, p.9) throughout the research process.

- assume that the meaning of experiences and events are constructed by individuals, and therefore people construct the realities in which they participate (Charmaz, 2006).

- tend to rely upon the "participants' views of the situation being studied" (Creswell, 2003, p.8) and recognises the impact on the research of participants' own background and experiences (Mackenzie \& Knipe, 2006, p.3).

- are most likely to rely on qualitative data collection methods and analysis...Quantitative data may be utilised in a way, which supports or expands upon qualitative data and effectively deepens the description (Mackenzie \& Knipe, 2006, p.3).

From this stance, this study aimed to elicit and understand how research participants constructed the realities and shared meanings around the phenomenon of interests namely the role of leadership in curriculum design and delivery in this study. Therefore, the decision of approaching this research study from a constructivist perspective was largely based on my epistemological stance. Based on my experience, I recognised the role of 
leadership as a context-specific phenomenon that has different meanings for those involved. In this approach, I, as the researcher, would play an active part in constructing the interpretation of the data gathered. To promote a constructivist perspective, I therefore elected to draw predominantly from Stake's work on case studies $(1995,2005,2006)$ which recognise multiple perspectives and my role in constructing interpretations of the role of leadership in promoting the Basic English curriculum design and delivery at the two selected Vietnamese universities.

The interpretivist paradigm appears to fit my research study. The interpretive paradigm emphasises the need for both in-depth research and my personal involvement as a researcher. The interpretive paradigm also seeks to understand the 'subjectivity' of human actions, tested through understanding people's perspectives. In the interpretivist paradigm, the world is understood through individuals and theory comes after the research. The interpretivist research paradigm is consistent with my study as I am concerned with the meaning that people bring to leadership situations in universities and which they use to understand their work. I argue that using the interpretivist/constructivist research approach can help me to achieve the most trustworthy findings about the leadership roles and experiences of academic leaders at the two selected universities in Vietnam.

The ontological perspective accounts for the nature of reality and its characteristics. Different researchers embrace different realities, as do the individuals being studied and the readers of a qualitative study (Creswell, 2012). In this study, I investigated the role of academic leaders with the intent of reporting these multiple realities. Evidence of multiple realities in this research came from semi-structured interviews and recorded observation of curriculum meetings. Each participant is likely to have had a different interpretation based on their perspectives and experiences of practical work (ontological assumptions). Participants' interpretations collectively create multiple realities that enhance my understanding of their leadership roles in 
innovating curriculum design and delivery in the Vietnamese university context.

The epistemological perspective enables me, as a researcher, to get as close as possible to the participants being studied by understanding their beliefs about the nature of knowledge (Briggs, Coleman, \& Morrison, 2012). This view refers to how knowledge is known through the subjective experience of the participants. The role of academic leaders at different levels of two selected Vietnamese universities was explored. This study was conducted in the field where participants work. The researcher and participants interacted to construct the understanding and the interpretation of the leadership role of each participant in the natural setting. Researchers including myself assume that knowledge is constructed within participants' minds and knowledge is "subjective, personal, and unique" (Cohen et al., 2007, p. 7). Consequently, these contexts are very crucial for understanding the thoughts of participants.

The axiological perspective refers to the role of values in a study. The researcher puts himself/ herself in the study and admits the value laden nature of the study and actively reports values and biases as well as the value laden nature of information gathered from the field (Creswell, 2012). I therefore situate myself in this study as a leader in the data collection in a Vietnamese university field with an interest in exploring the role of leadership in promoting and supporting the Basic English curriculum design and delivery. My values are my views on interpreting and discussing the data collected at the two research sites. Furthermore, the axiology also refers to ethics because every study with human participants, qualitative or nonqualitative, requires prior approval from an institutional review board (Yin, 2011, p. 44).

In a discussion of theoretical knowledge claims by Cohen et al. (2007, p. 33), three paradigms are compared: normative, interpretive and critical. The normative paradigm focuses on 'objectivity' and the research 'conducted from outside' whereas critical theory pays attention to issues of power among societies, groups and individuals and participant researchers. Instead of 
adopting these paradigms I have adopted the interpretive paradigm because it helps me to understand the interpretations academic leaders placed on their leadership in the two VNLUs. The views of participants are significant as their thoughts and perceptions were the foundation and focus of data collection and analysis.

\subsubsection{Strategies of enquiry}

I have chosen qualitative-focused enquiry for this study because this approach can help to compare different stakeholders' perspectives drawn from primarily qualitative and supplementary quantitative data (Creswell, 2014). According to Denzin and Lincoln (2005), strategies of enquiry are defined as "a bundle of skills, assumptions and practices that the researcher employs as he or she moves from the paradigm to the empirical world" (p.25). Strategies of enquiry can be divided into qualitative, quantitative or mixed methods. Mixed method approaches use both qualitative and quantitative approaches. Creswell (2012) suggests that mixed methods are particularly valuable when the researcher is making pragmatic claims. Pragmatic claims focus on the outcomes of the research, namely actions, situations and consequences of the enquiry and solutions to the problems.

The methods employed in this study are primarily qualitative with a small quantitative component. These methods help solicit information and gather data that provide answers to the research questions. The qualitative case study approach described by Stake $(2000 ; 2005 ; 2006)$, falls within the interpretive/constructivist paradigm. Stake's case studies explicitly seek out the multiple perspectives of those involved in the case aiming to gather collectively agreed upon and diverse notions of what occurred. In this instance, the ontological belief is that reality is local and specifically constructed. Therefore, this study sought out the multiple perspectives of senior leaders and EFL lecturers in the case study to gather their perceptions and different interpretations of leadership at tertiary level in Vietnamese contexts. Knowledge is constructed by gaining the information directly from participants involved in leadership roles. A qualitative case study design was 
chosen to promote the richness, depth and complexity drawn from multiple events that helped me understand the phenomenon of interest (Anaf, Drummond, \& Sheppard, 2007; Stake, 2000).

A qualitative research approach enables me as a researcher to understand the nature of academic leaders' roles in two Vietnamese universities. The smaller quantitative part deals with supplementary data that help to explore graduates' perceptions of the current Basic English curriculum in two selected universities in Vietnam. The statistics are descriptive in a way that complements the qualitative aspects of the data as they are expected to provide insights for curriculum designers and leaders so that they can give useful suggestions for the future leadership, implementation and delivery of the Basic English curriculum. Both the qualitative-focused method and a small quantitative component help develop a deeper understanding of the live experience of academic leaders in the Vietnamese university context.

\subsection{Research design}

This section presents and justifies the reasons why this study chose case study design and unit of analysis.

\subsubsection{Case studies}

This study adopted an interpretivist/constructivist case study approach with two units of analysis at the two selected Vietnamese universities as mentioned in section 1.2.6 for the following reasons. Case research involves the in-depth study of a bounded system, such as a process, an activity, an event, a program or multiple individuals (Creswell, 2012). Stake (1995, 2000, 2005) identifies three main types of case study: intrinsic, instrumental and collective. An intrinsic case study is used to explore the case itself as it focuses on the particulars of one specific phenomenon rather than seeking generalisations, with the interest arising from the particulars and potentially rare or unique aspects of the case (Stake, 2005). In this study, I have chosen an intrinsic case study approach because it enables me to understand how leadership of curriculum design and delivery operates at two selected Vietnamese universities. An instrumental case study (Stake, 1995, 2000) 
explores phenomena beyond the immediate particularities of the situation examined and ollective case studies focus on groups of individual studies to gain a fuller picture.

Case research fits within both positivist/post-positivist and interpretivist/ constructivist paradigms (Lauckner, Paterson, \& Krupa, 2012) and therefore may use quantitative and/or qualitative approaches (Stake, 2005, 2008). Case study also "involve[s] systematically gathering enough information about a particular person, social setting, event, or group to permit the researcher to effectively understand how it operates or functions" (Berg, 2004, p. 251). Case studies are believed to lead to better understanding, perhaps better theorising, about a larger collection of cases (Stake, 2000). Accordingly, it is appropriate for this study because the research focus is on contemporary, the role of leadership in promoting the curriculum design and delivery, rather than historical events (Yin, 1994). Moreover, with a period of six months for data collection, the case study design was the best choice to deal with time limitations. Finally, the case study design allowed me to gain an in-depth understanding from in-depth information and retain holistic and meaningful characteristics of real-life events (Berg, 2004; Yin, 2009), and understanding of the role of leadership in the Vietnamese higher education contexts.

This research used a case study design (Creswell, 2012; Yin, 2011) to produce descriptions and explanations of leadership practices. 


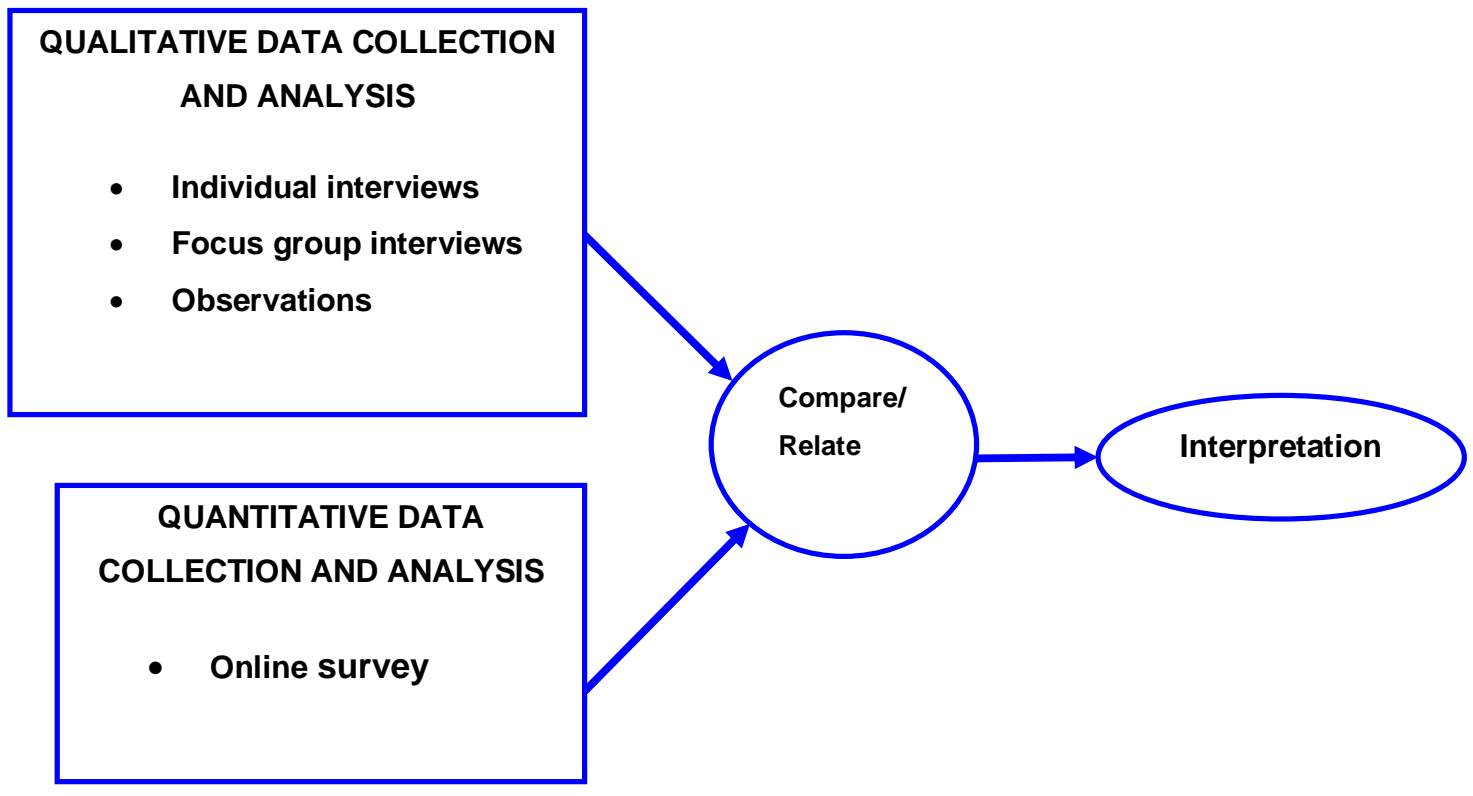

Figure 3.1: The convergent design adapted from Creswell and Plano Clark (2011)

The following table summarises all the methodological characteristics of this current research including the research approach according to the research paradigm, strategy of inquiry, methodology and methods of data collection.

Table 3.1: Summary of the methodological approach taken in the current research

\begin{tabular}{|l|l|}
\hline \multicolumn{1}{|c|}{ Elements } & \multicolumn{1}{|c|}{ Current research } \\
\hline Research paradigm & Interpretivist/ Constructivist \\
\hline Research methodology & $\begin{array}{l}\text { Qualitatively-focused intrinsic case-study including a small } \\
\text { quantitative component }\end{array}$ \\
\hline Data collection & $\begin{array}{l}\text { Face-to-face interviews, focus group interviews, } \\
\text { observations, online survey }\end{array}$ \\
\hline
\end{tabular}

\subsubsection{Units of analysis}

In this study, two units of analysis were chosen in order to have more data to compare as one unit may be unusual and may not provide enough data. Each university is considered as a unit of analysis which includes academic 
leaders, two groups of EFL lecturers, and groups of graduates as a unit of analysis. This is based on Stake's (2005) study which found that the unit of analysis involves defining the boundaries of the case and selecting the issues or phenomena to emphasise.

\subsection{Research participants}

This section discusses the criteria used to choose the research site and research participants for this study.

\subsubsection{Criteria for selecting research site}

The criteria for selecting the two cases are based on university type and location. The two universities are public universities which specialise in training Bachelors of Finance, Accounting and Banking under the control of MoF in Vietnam. Public universities are selected over private universities because most lecturers in state-run universities are employed predominantly full-time, whereas private schools can employ part-time teachers. The fulltime teachers have more commitment to the university's activities and are directly influenced by leadership practice. In terms of location, one of the universities is located in the middle region of Vietnam and is near where I lived and worked before going on study leave in New Zealand. Time was limited and therefore selecting an accessible university was necessary to save time and costs. The other university is in a big city in the North of Vietnam. Moreover, the universities are accessible thanks to the existing good relationships which I have already had with some of the academic leaders in both universities.

As mentioned earlier in section 3.3, this study is overwhelmingly a qualitative method with a small quantitative component. The qualitative research process is emergent because it is conducted in a natural setting (Creswell, 2008). First of all, after receiving the approval for this research granted by the Human Ethics Committee of the Faculty of Education at Victoria University of Wellington, I sent a letter to the Rectors of the two selected universities in my study to ask for the permission to collect data at their universities (See Appendix C). Subsequently, the Rector of each university was invited to a 
briefing which explained the rationale, aims, research questions and methodology of the study, I provided them the information sheet (See Appendix D) and asked for their consent (See Appendix E) for their personal agreement to participate in the study. Next, I contacted other academic leaders to invite them to participate in this study and then mailed them a similarly-designed information sheet as the one sent to the two Rectors (See Appendix D) and a consent form (See Appendix F). Meetings were arranged to discuss the project after receiving their voluntary agreement to participate in my study. After that, a similar process was applied to access EFL lecturers, company directors and participants of the curriculum observations.

\subsubsection{Participants}

Referring back to Scott et al.'s (2008) model (See section 2.6.1), here are the relevant participants that are involved in the curriculum design and delivery. Within Vietnamese higher education, other terms, such as Rector and Vice-Rector, are preferred to those of Vice-Chancellor or Deputy Vice-Chancellor (See figure 3.2).

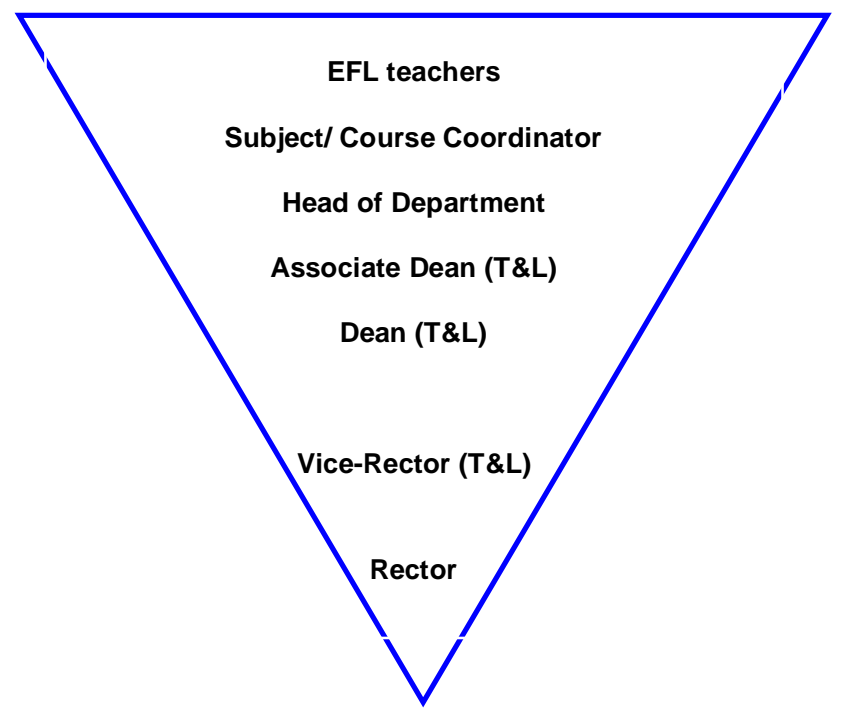

Figure 3.2: The proposed model in the Vietnamese university context 


\section{Criteria for selecting participants}

The following basic criteria were applied for the selection of participants. In the following sub-sections, justification of criteria, who were chosen and the numbers of participants are presented.

\section{Academic leaders participating in individual interviews}

This selection criterion is based on the belief that a less experienced leader may not be a rich-information participant. Academic leaders of at least two years of leadership experience were selected. Moreover, gender is also a cultural factor affecting leadership roles (Northouse, 2013). Therefore, the gender of the participants was also taken into consideration to ensure that at least one female leader was chosen from each of the two selected universities (See tables $3.2 \&$ 3.3).

Table 3.2: Profile of academic leaders at University One

\begin{tabular}{|l|l|l|c|l|c|}
\hline $\begin{array}{l}\text { University } \\
\text { One }\end{array}$ & $\begin{array}{l}\text { Pseudo- } \\
\text { nyms }\end{array}$ & $\begin{array}{l}\text { Gender, } \\
\text { Position }\end{array}$ & Qualifications & Responsibilities & $\begin{array}{l}\text { Years in } \\
\text { current } \\
\text { position }\end{array}$ \\
\hline $\begin{array}{l}\text { Academic } \\
\text { leader 1 }\end{array}$ & $\begin{array}{l}\text { R1, } \\
\text { Interview }\end{array}$ & $\begin{array}{l}\text { Male(M), } \\
\text { Rector }\end{array}$ & PhD & $\begin{array}{l}\text { All activities relate to } \\
\text { personnel, teaching, } \\
\text { learning, research, funding } \\
\text { and development }\end{array}$ & 5 \\
\hline $\begin{array}{l}\text { Academic } \\
\text { leader 2 }\end{array}$ & $\begin{array}{l}\text { VR1, } \\
\text { Interview }\end{array}$ & M, Vice-Rector & PhD & $\begin{array}{l}\text { All activities relate to } \\
\text { teaching and learning }\end{array}$ & 5 \\
\hline $\begin{array}{l}\text { Academic } \\
\text { leader 3 }\end{array}$ & $\begin{array}{l}\text { HT1 } \\
\text { Interview }\end{array}$ & $\begin{array}{l}\text { M, Head of } \\
\text { Training Dept. }\end{array}$ & M.Eco & Activities relate to training & 5 \\
\hline $\begin{array}{l}\text { Academic } \\
\text { leader 4 }\end{array}$ & $\begin{array}{l}\text { HSR1 } \\
\text { Interview }\end{array}$ & $\begin{array}{l}\text { M, Head of SR } \\
\text { Dept. }\end{array}$ & PhD & $\begin{array}{l}\text { Activities relate to } \\
\text { scientific research and } \\
\text { international relations }\end{array}$ & 6 \\
\hline $\begin{array}{l}\text { Academic } \\
\text { leader 5 }\end{array}$ & $\begin{array}{l}\text { DSR1 } \\
\text { Interview }\end{array}$ & $\begin{array}{l}\text { F, Deputy- } \\
\text { head of SR } \\
\text { Dept.( } \\
\text { scientific } \\
\text { research) }\end{array}$ & M.Eco & $\begin{array}{l}\text { Assistant to the head to } \\
\text { process activities relating } \\
\text { to scientific research and } \\
\text { international relations }\end{array}$ & 4 \\
\hline $\begin{array}{l}\text { Academic } \\
\text { leader 6 }\end{array}$ & $\begin{array}{l}\text { DFL1 } \\
\text { Interview } \\
\text { Dept. } \\
\text { Foreign of FL } \\
\text { languages) }\end{array}$ & M.A & $\begin{array}{l}\text { Activities relate to } \\
\text { teaching-learning and } \\
\text { scientific research }\end{array}$ & 6 \\
\hline
\end{tabular}

Similar criteria were applied to select academic leaders at University Two (See table 3.3) 
Table 3.3: Profile of academic leaders at University Two

\begin{tabular}{|c|c|c|c|c|c|}
\hline $\begin{array}{l}\text { University } \\
\text { Two }\end{array}$ & Pseudonyms & $\begin{array}{l}\text { Gender, } \\
\text { Position }\end{array}$ & Qualifications & Responsibilities & $\begin{array}{l}\text { Time in } \\
\text { current } \\
\text { position }\end{array}$ \\
\hline $\begin{array}{l}\text { Academic } \\
\text { leader } 1\end{array}$ & R2, Interview & M, Rector & PhD & $\begin{array}{l}\text { All activities relate to } \\
\text { personnel, teaching, } \\
\text { learning, research, funding } \\
\text { and development }\end{array}$ & 9 \\
\hline $\begin{array}{l}\text { Academic } \\
\text { leader } 2\end{array}$ & VR2, Interview & $\begin{array}{l}\text { M, } \\
\text { Assoc Prof. } \\
\text { Vice-Rector }\end{array}$ & PhD & $\begin{array}{l}\text { All activities relate to } \\
\text { teaching and learning }\end{array}$ & 3 \\
\hline $\begin{array}{l}\text { Academic } \\
\text { leader } 3\end{array}$ & $\begin{array}{l}\text { DHT2 } \\
\text { Interview }\end{array}$ & $\begin{array}{l}\text { F, } \\
\text { Deputy Head } \\
\text { of Training } \\
\text { Dept. }\end{array}$ & $\mathrm{PhD}$ & $\begin{array}{l}\text { Activities relate to scientific } \\
\text { research and international } \\
\text { relations }\end{array}$ & 4 \\
\hline $\begin{array}{l}\text { Academic } \\
\text { leader } 4\end{array}$ & $\begin{array}{l}\text { HSR2 } \\
\text { Interview }\end{array}$ & $\begin{array}{l}\text { F, } \\
\text { Head of SR } \\
\text { Dept. }\end{array}$ & M.Eco & $\begin{array}{l}\text { Assistant to the head to } \\
\text { process activities relating to } \\
\text { scientific research and } \\
\text { international relations }\end{array}$ & 6 \\
\hline $\begin{array}{l}\text { Academic } \\
\text { leader } 5\end{array}$ & $\begin{array}{l}\text { DFL2 } \\
\text { Interview }\end{array}$ & $\begin{array}{l}\text { M, Dean of } \\
\text { FL Dept }\end{array}$ & M.A & $\begin{array}{l}\text { Activities relate to teaching- } \\
\text { learning and scientific } \\
\text { research }\end{array}$ & 7 \\
\hline
\end{tabular}

\section{EFL lecturers participating in focus-group interviews (FGI)}

EFL Lecturers who have worked for at least two years were selected. In the Vietnamese education system, they have to go through a one-year period of probation when they are recruited to begin their teaching career. In terms of gender, both female and male teachers were selected. In terms of age, both younger and more mature lecturers were selected. In the sections and subsections which follow, different Vietnamese names for flowers and seasons were used in order to preserve the participants' identities. I used the abbreviation beginning with name, university (U1/U2), focus group interview (FGI). For example, lecturer Hoa who taught English at University one is named HoaU1, FGI. Table 3.4 shows the profiles of the EFL lecturers who were willing to participate in the study. 
Table 3.4: Profile of EFL lecturers from the two universities

\begin{tabular}{|l|l|c|c|c|}
\hline $\begin{array}{l}\text { University } \\
\text { One/Two }\end{array}$ & Pseudonyms & Gender & Qualifications & $\begin{array}{c}\text { Teaching } \\
\text { experience }\end{array}$ \\
\hline Lecturer 1 & Hoa U1, FGI & F & M.A & 18 \\
\hline Lecturer 2 & Mai U1, FGI & F & M.A & 12 \\
\hline Lecturer 3 & Lan U1, FGl & F & M.A & 7 \\
\hline Lecturer 4 & Cuc U1, FGl & F & M.A & 6 \\
\hline Lecturer 5 & Truc U1, FGI & F & M.A & 3 \\
\hline Lecturer 6 & Mua U2, FGI & F & M.A & 20 \\
\hline Lecturer 7 & Xuan U2, FGl & F & M.A & 15 \\
\hline Lecturer 8 & Ha U2, FGI & F & M.A & 9 \\
\hline Lecturer 9 & Thu U2, FGI & M & M.A & 22 \\
\hline Lecturer 10 & Dong U2, FGl & F & M.A & 7 \\
\hline
\end{tabular}

\section{Company directors participating in individual interviews}

The directors were selected according to their location and the majors of the graduates they employed. I chose 3 companies which are located in my hometown so that travelling cost was minimised. The other three companies are located in the North near the location of University two to save time and cost when collecting data. Companies that recruit graduates with Bachelors in Finance (Banking or Accounting) from the two selected universities were chosen and a similar permission letter to conduct research was sent to directors of these companies (Appendix C). Company directors who had at least two years of working experience in their incumbency were selected and then shortlisted based on the principle 'first replied, first served' within each category of discipline such as Finance, Accounting and Banking (See table 3.5). The gender of director participants was also taken into consideration to ensure that at least one female director was included. Based on the above- 
mentioned principles and criteria, these six selected companies were among the outstanding companies that recruited a large number of graduates from the two universities. In the sections and sub-sections which follow, different Vietnamese names for wealth and prosperity were used in order to conceal the participants' identities (See Table 3.5).

Table 3.5: Company directors' profiles

\begin{tabular}{|l|l|l|l|}
\hline $\begin{array}{l}\text { Company } \\
\text { directors }\end{array}$ & Pseudonyms & Gender & Types of company \\
\hline Director 1 & Thanh, Interview & $\mathrm{M}$ & Finance consultancy services \\
\hline Director 2 & Cong, Interview & $\mathrm{F}$ & Bank \\
\hline Director 3 & Giau, Interview & $\mathrm{M}$ & Accounting consultancy services \\
\hline Director 4 & Sang, Interview & $\mathrm{M}$ & Bank \\
\hline Director 5 & Phu, Interview & $\mathrm{M}$ & Accounting consultancy services \\
\hline Director 6 & Quy, Interview & $\mathrm{F}$ & Finance consultancy services \\
\hline
\end{tabular}

\section{Participants of curriculum meeting observation}

Some academic leaders and EFL teachers who satisfied the requirements of the individual and focus group interviews were chosen. Before the curriculum meeting, I contacted the chairman and asked for permission to attend the meeting (Appendix L). After his approval, I sent all the participants, before the meeting, an email with an information sheet (Appendix D) to explain my research and invite them to participate in my study. After getting the participants' agreement to participate, I asked them to sign a consent form (See Appendix M) and return it to me.

\section{Graduate students to complete the online survey}

Graduates who received Bachelors in Finance, Accounting or Banking from the two selected universities at least two years ago and are now working in companies were chosen to complete the online survey. Both male and female graduates were selected. After sending out the survey with greetings attached (See Table 3.6) to 100 graduates from each university, I received 
54 responses from University one and 48 responses from University two.

Table 3.6 shows graduate students' profiles.

Table 3.6: Graduates' details

\begin{tabular}{|l|l|l|l|l|l|l|l|l|}
\hline University & \multicolumn{3}{|c|}{ Age } & \multicolumn{2}{c|}{ Gender } & \multicolumn{4}{c|}{ Major } & Number responding \\
\cline { 2 - 9 } & $22-26$ & $27-31$ & M & F & Finance & Banking & Accounting & \\
\hline U1 & 52 & 2 & 21 & 33 & 7 & 9 & 38 & 54 \\
\hline U2 & 45 & 3 & 19 & 29 & 9 & 8 & 31 & 48 \\
\hline
\end{tabular}

\subsubsection{Data collection process}

In order to collect data for this study, I followed the standard ethical procedures in terms of gaining access to participants and obtaining their informed consent to conduct individual interviews, focus group interviews and curriculum meeting observations and an online survey.

Data collection was conducted from March 2013 until August 2013. After getting access to the two research sites and permission from both university rectors to conduct the research in their universities as mentioned in Appendix $B$, the data collection was divided into two periods which are shown in the two tables below.

\section{Table 3.7: Data collection timeline at University One}

\begin{tabular}{|l|l|}
\hline \multicolumn{1}{|c|}{ Date } & \multicolumn{1}{c|}{ Data collection activities at University One } \\
\hline $\begin{array}{l}\text { March } 1^{\text {st }} 2013 \text { - } \\
\text { March } 4^{\text {th }} 2013\end{array}$ & $\begin{array}{l}\text { - Approached the two universities and got permission from } \\
\text { the Rector }\end{array}$ \\
\hline March $5^{\text {th }} 2013$ - & - Approached the Heads of related departments and Deans to ask \\
& for their permission and an invitation to participate in the research \\
& - Invited EFL teachers to participate in this study. \\
& - Conducted individual interviews with academic leaders \\
& - Conducted a focus group interview with EFL lecturers \\
& - Attempted to transcribe as much as possible between \\
& data collection sessions \\
& - Planed observation schedules with the chairman to \\
& observe the curriculum meeting. \\
& - Asked for graduates' emails to invite them to participate in \\
& the online survey \\
& - Received consent from graduates and launched the survey. \\
& - Arranged meetings with company directors to invite them to \\
& participate \\
\end{tabular}


The process of data collection at the second case university benefited from the experience I gained during fieldwork at the first university. The following table shows the timeline for fieldwork at University Two.

\section{Table 3.8: Data collection timeline at University Two}

\begin{tabular}{|c|c|}
\hline Date & Data collection activities at University Two \\
\hline $\begin{array}{l}\text { May 21st } 2013- \\
\text { August } 12^{\text {th }} 2013\end{array}$ & $\begin{array}{l}\text { - Approached the Heads of related departments and Deans to ask } \\
\text { for their permission and an invitation to participate in the research } \\
\text { - Invited EFL teachers to participate in this study. } \\
\text { - Conducted individual interviews with academic leaders } \\
\text { - Conducted a focus group interview with EFL lecturers } \\
\text { - Attempted to transcribe as much as possible between } \\
\text { data collection sessions } \\
\text { - Planed observation schedules with the chairman to } \\
\text { observe the curriculum meeting. } \\
\text { - Asked for graduates' emails to invite them to participate in } \\
\text { the online survey } \\
\text { - Received consent from graduates and launched the survey. } \\
\text { - Arranged meetings with company directors to invite them to } \\
\text { participate }\end{array}$ \\
\hline
\end{tabular}

\subsection{Data sources}

As is consistent with case study design (Stake, 1995; Yin, 2003), data collection methods in this study included: interviews (including both in-depth semi-structured individual and focus group interviews), observations and an online survey. This section discusses, the four tools for data collection in this case study: semi-structured interviews with senior leaders and company directors, focus group interviews with some of the EFL teachers, observation of scientific meetings related to curriculum discussion, and the questionnaires distributed to graduates. Each of the following sub-sections will describe the data collection from the field, the justification and the actual collection process.

\subsubsection{Interviews}

Two types of interviews were conducted: semi-structured and focus group interviews. The purpose of interviewing is not just to relay facts but rather to obtain participants' analyses of what they believe happened (Gubrium \& Holstein, 2002) and how they interpret the situation. The focus of interviewing 
was on assessing and representing the participants' world so that their voices were acknowledged and analysed. Walliman (2001) suggests that all interview participants (including interviewers) create believable accounts of their words. In this way participants may be viewed as "meaning makers" (Gubrium \& Holstein, 2002, p. 83). A study of interviewing by Fontana and Frey (2005) affirms that the most common form of interviewing includes faceto-face spoken exchange. According to Fontana and Frey, when two or more participants are involved in the interview process their interactions lead to "the creation of collaborative effort" (p.695). Interview studies are a strategy used by researchers either on their own or as part of another strategy such as a case study (Briggs et al., 2012). A successful interview is reliant on the relationship established between the researcher and participant (Woolner, Thomas, Todd, \& Cummings, 2009). Trust is fundamental to ensure that what is reported is honest and true to their experience of the situation, and that the data collected is authentic. The respondents provided answers and gave accounts of their leadership roles in terms of their understanding of the settings in which they were located.

Each interview was audio-taped then transcribed verbatim and analysed. The recording allows for detailed and accurate transcription of data that cannot be obtained from memory and note-taking. The interviews were conducted in Vietnamese.

\section{Semi-structured interviews}

In conducting semi-structured interviews, participants received "a flexible and fluid structure, unlike structured interviews, which contain a structured sequence of questions to ensure flexibility in how and in what sequence questions are asked" (Mason, 2004, p. 102). The semi-structured interviews were conducted to obtain academic leaders' views of their roles, and challenges in their leadership practices. The interview protocol was divided into two sections (Section A and Section B). In Section A, senior leaders were asked questions about their background (position, gender, leadership experience, qualifications, etc.). In Section $B$, the interview questions were 
focussed on the senior leaders' perspectives of their roles, leadership practices, barriers and enablers in promoting curriculum design and delivery (See Appendix G).

All the interview sessions were recorded and later transcribed and translated into English. Before I could recruit the academic leaders to participate in the study, I talked to each of them. After the briefing session in which they were invited to participate, all of them received the information sheet and the consent form (as mentioned earlier in Appendices C, D, E \& F). The information sheet provided information about the aims of this study, research procedures, and the participants' roles. The consent form contained information for the participants' attention to ensure that they were aware that they had the right to participate or withdraw from the study at any stage of the research. I gave a few days for academic leaders to consider the invitation. After that, six of them replied to participate in my study as discussed in table 3.2.

At the second university, I did not wait until prospective participants replied to the invitation via emails because I learnt from the first case that they were busy and did not check emails frequently. Instead, after sending emails inviting prospective participants, I phoned them and invited them to participate in this study. This helped to shorten the timeframe for the second stage of fieldwork. The procedure of approaching the academic leaders at University Two was carried out similarly to that of University One. Six academic leaders agreed to participate. However, one female leader cancelled due to health problems (See table 3.3).

\section{Focus group interviews}

Creswell (2008) defines focus group interviews as "the process of collecting data through interviews with a group of people, typically four or six" (p. 226). Focus group interviews also help gain an understanding of the shared experiences of a group of people (Creswell, 2008). However, the limitation of focus group interviews is that the researcher may have some difficulties in taking notes because a considerable amount of information is generated 
through such interviews. The EFL lecturers were recruited based on the dean's recommendation. I approached the lecturers and explained the aims and their roles in a focus group interview.

They were given the opportunity to ask questions about the study before they received the information sheet and the consent form (Appendix $\mathrm{H}$ ) after the briefing sessions, each lecturer was given a week to make the decision whether s/he wanted to participate in this study. Five teachers gave consent to participate in the focus group interview of the study as discussed earlier in Table 3.4. The procedure for approaching and conducting focus group interviews with EFL lecturers at University Two was done similarly to that of University One. The focus group protocol was divided into two sections (Section A and Section B). In Section A, EFL lecturers were asked questions about their background (gender, teaching experience, responsibilities, etc.). In Section B, the focus group questions were focussed on their views about their participation and collaboration in the curriculum design and delivery process (See Appendix I). I acted as a facilitator of the focus groups, asking the questions one by one and allowing the lecturers to discuss these among themselves. I also extended the discussion by posing further questions I thought were important regarding any potentiality of curriculum design and delivery issues. In either case, they were encouraged to talk freely. Each session lasted for approximately one hour, and these sessions were audio recorded.

\section{Semi-structured interviews with company directors}

Procedures to conduct semi-structured interviews with company directors were similar to those applied to academic leaders. First, I sent an email to make an appointment with each company director. After receiving their agreement to participate, I sent them an information sheet and a consent form (See Appendix J). Two female and four male directors participated (Table 3.5).

The interview protocol was divided into two sections (Section A and Section B). In Section A, company directors were asked questions about their 
background (position, gender, working experience, types of company, etc.). In Section B, the interview questions were focussed on their perspectives about the effectiveness of the Basic English curriculum at the two universities (See Appendix K).

\subsubsection{Observations}

Observation methods are powerful tools for gathering 'live' data from naturally occurring social situations (Cohen et al., 2007, p. 396). Observations of curriculum meetings were chosen to gain more understanding and give a more complete picture of the role of academic leaders, as well as to allow for triangulation in the study. Observational techniques are much used in educational research, either on their own or to complement other strategies (Briggs et al., 2012). Therefore, observation is a tool to record participants' actions that cannot be captured through interviews or questionnaires. The observation in this study aimed at recording the direct experience of the curriculum activities which were actively occurring.

In Vietnamese universities, meetings about curriculum, training activities and scientific research issues are normally called 'scientific research meetings'. The observations of academic leaders' and EFL lecturers' behaviour in specific scientific research meetings were audio-recorded. Furthermore, data was obtained from in-depth interviews with leaders about their leadership practices. All of these observational data were used to reflect the curriculum processes of the two selected universities. They allowed the researcher to grasp the motivations, intentions, beliefs and views of the individuals who participated in specific scientific research meetings. The timing for observations depended on events in each case. In this study, I conducted direct observations by asking permission to attend the meetings and acted as an observer who just watched and recorded what happened in a meeting without interfering or taking part in what's going on (Johnson \& Christensen, 2008). One observation took place at the first university because all participants were happy to participate and signed the consent form (See Appendix M). The observation session lasted for more than an hour. Through 
the observation, I observed ways senior leaders and EFL teachers engaged in curriculum design and delivery issues. Their actions in the meeting were recorded through the observation meeting. All the transcripts from the observation at University One were sent back to the participants by email for verification to ensure the accuracy of data a few weeks after the observation. The plan to observe the second meeting was cancelled due to objections from several lecturers because they were planning a trip to Singapore for a short training course in a few weeks.

\subsubsection{Online questionnaire}

The online questionnaire enabled me to explore the graduates' perceptions about the current curriculum used to teach in the two universities as the results of the questionnaire offered suggestions to academic leaders for a more efficient Basic English curriculum design and delivery. Online surveys as a data collection method in research are used as they are a fast and inexpensive way of gathering data (Couper, 2000; Dillman, 2007). I followed the constructing procedures described by Cohen et al. (2007) related to direct statements that elicit responses in Likert-style response format with a five-point scale, ranging from 1 (strongly disagree) to 5 (strongly agree). An online survey of five-point rating scale of 14 questions was designed using Qualtrics online survey software to elicit graduates' perceptions about the effectiveness of the current Basic English curriculum taught at the two universities. Perceptions of each construct were elicited with two or more statements, which allowed for checking the internal consistency of the responses as well as eliciting their perceptions of specific factors. Space was also provided to elicit further comments on or explanations of each statement, for the purpose of clarification.

After getting the approval from the Ethics Committee of Victoria University of Wellington, the questionnaire was then trialled for readability with four individuals, including two volunteer graduates and two experienced teachers of English before embarking on the online survey of graduates. The sample targeted 100 graduates which is about ten percent of the graduates from 
each selected university so as to represent a reliable sample for data analysis. I contacted the department of student affairs at each selected university and they sent me the list of emails without the graduates' names attached. After that I emailed graduates to invite them to join the survey. For those who agreed to join the survey, I directly sent them an electronic questionnaire via email as mentioned in Appendix N. The following section discusses the data analysis process.

\subsection{Data analysis process}

The first stage of the analysis involved the preparation of the raw data, transcription of audio-tapes made during interviews with the leaders, and focus group interviews. The transcripts were prepared with relevant information from the field notes which was recorded. Non-audible factors such as the participants' gestures and actions were also noted. The second stage of data analysis is about coding and thematic analysis.

\subsubsection{Transcribing and translating}

After conducting individual interviews with academic leaders and company directors, focus group interviews with EFL lecturers and one observation of a curriculum meeting at University One, I transcribed all the data and sent the transcriptions to the participants for verification of accuracy. However, no participant replied that they needed changing. To ensure that the translation was accurate, I signed a contract with a lecturer of English who has a good command of English and Vietnamese to translate the document for me (See Appendix O). I used pseudonyms for participants before sending all the transcripts to the translator to maintain confidentiality of participants. After she finished translating, the translated versions were returned to me for crosschecking.

\subsubsection{Coding}

There are many approaches to analysing data including thematic analysis, content analysis, and semiotic analysis. However, the most popular strategy is thematic analysis (Boyatzis, 1998; Braun \& Clarke, 2006; Mutch, 2005). According to Braun and Clarke (2006), thematic analysis involves a six- 
phase process where movement is back and forth as needed, throughout the phases. In analysing the data, I identified categories and themes across the data sources (the interviews, the meeting observations, and the documents). The data were then coded based on the categories. First of all, I read the data carefully, took notes and highlighted ideas for coding. Secondly, I coded interesting aspects of the data systematically and meaningfully (Braun \& Clarke, 2006; Tuckett, 2005) by writing notes on the texts being analysed, and highlighting potential items to mark interesting features of the data. In developing the categories and coding regarding the purposes and aims of doing this study, long statements from the initial interviews were reduced into phrases that contained a few words that I called 'coding'. For example, in the first interview question, academic leaders were asked to explain their leadership practices. Those answers were grouped together at coding and later grouped into similar categories. Figure 3.3 shows an example of the process of coding related to academic leaders' views in curriculum issues that emerged from the interviews.

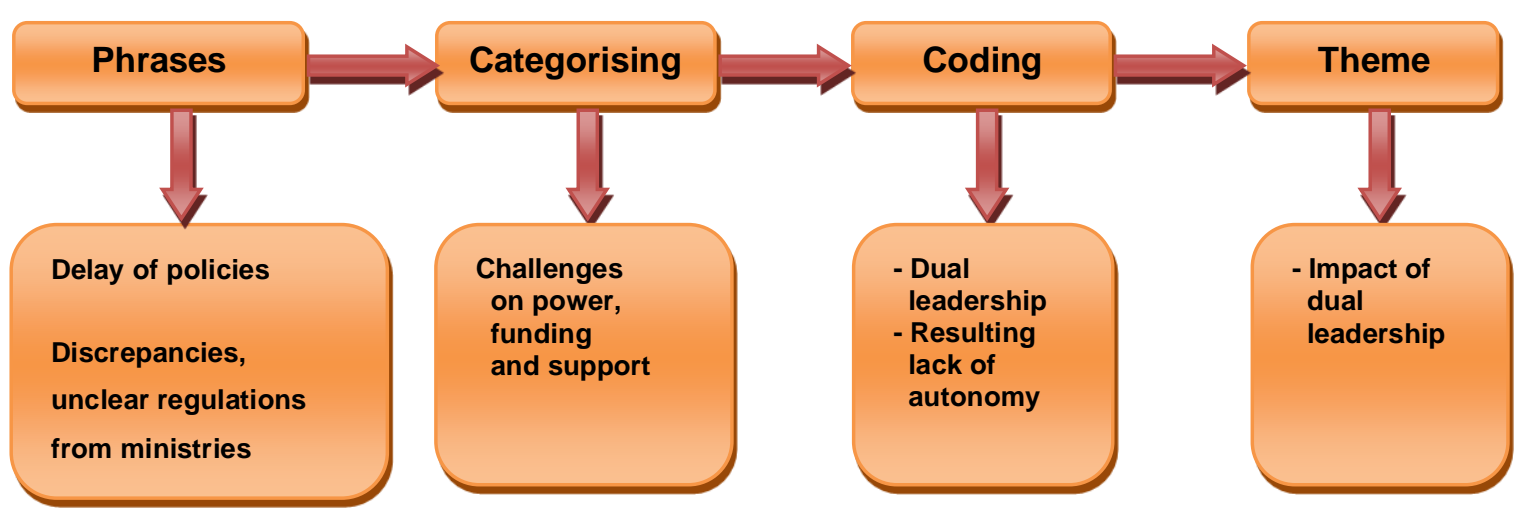

Figure 3.3: Examples of coding

\subsubsection{Identifying themes}

After coding, I continued to analyse data but at a wider level to identify themes and classified different codes into potential themes. Interestingly, there were some codes that failed to fit in any of the main themes. I then put them into a 'miscellaneous theme' because they might be helpful later (Braun 
\& Clarke, 2006). I reviewed the themes and checked if the themes worked in relation to the coded extracts and also in relation to the entire set of data before working on a thematic map of the analysis (Braun \& Clarke, 2006). I then considered how each theme related to the research questions and to each other. Creswell's (2014) flow chart (Figure 3.4) was followed as a framework in analysing the data.

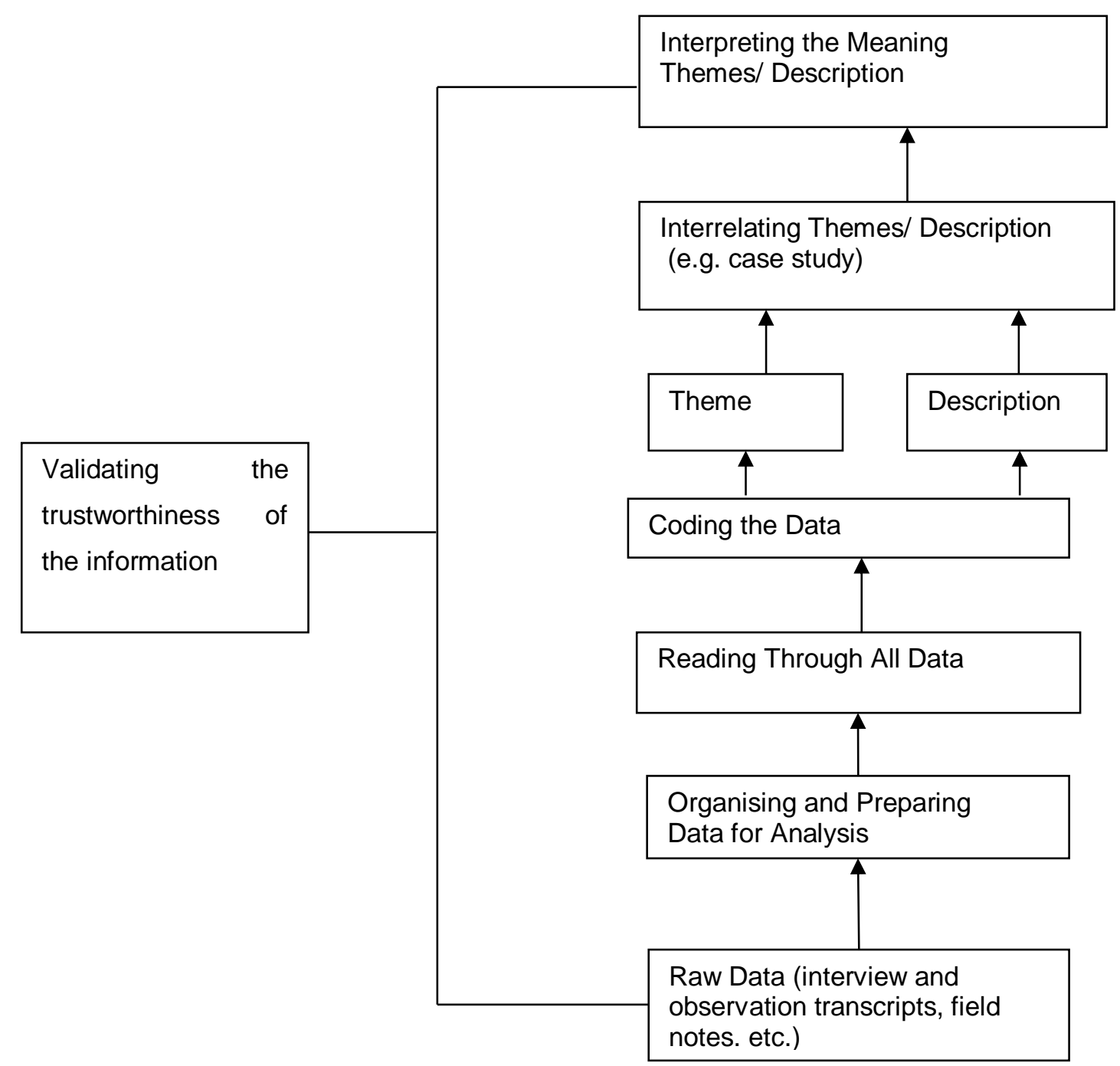

Figure 3.4: Data analysis framework based on Creswell (2014, p. 197) 


\subsubsection{Thematic analysis}

This study has applied thematic data analysis because thematic headings were chosen that were concise, meaningful and directly related to the content of the theme (Braun \& Clarke, 2006). The thematic analysis was presented concisely, coherently, logically and interestingly with vivid examples or extracts that clearly demonstrate the main points. Importantly, the report needs to go "beyond description of the data" (Braun \& Clarke, 2006, p. 93) and present an argument related to the research questions. Therefore, thematic analysis was undoubtedly the best choice of data analysis to achieve credibility in my study because of its clear and elaborate steps (Creswell, 2014). Themes were identified as patterns that emerged from the data. Theories and generalisations were compared with the existing literature. The interpretation of the role of leadership has been developed through the combination of detailed descriptions of academic leaders' actions, thinking, and practices; teachers' perspectives and views on curriculum design and delivery; and my view about curriculum design and delivery issues.

In this study, at first, I analysed the data from each university separately. Many similar themes came across from the two universities, therefore I grouped these themes together and then highlighted and distinguished the different characteristics which arose from the two universities. Cross case analysis was then employed to examine differences and similarities to answer the research questions (Yin, 2009). This process helped me to describe in detail complex real-life situations that cannot be captured through a survey study (Yin, 2009). Based on detailed descriptions of case studies, explanations of phenomena were generated. The numerical data of the questionnaires were analysed by counting frequencies of the scales reported by the participants to obtain the pattern of graduates' perceptions of the effectiveness of the Basic English curriculum. Any further comments provided in the questionnaire were examined to further explain and give supplementary information to address the research questions. 
Creswell and Plano Clark (2011) suggest the separate analysis of the two databases in the convergent model before bringing them together. Therefore, in order to combine the data analysis, I employed the convergent model (Creswell, 2014; Creswell \& Plano Clark, 2011) by analysing the two sources of data separately and then bringing them together as shown in Figure 3.5.

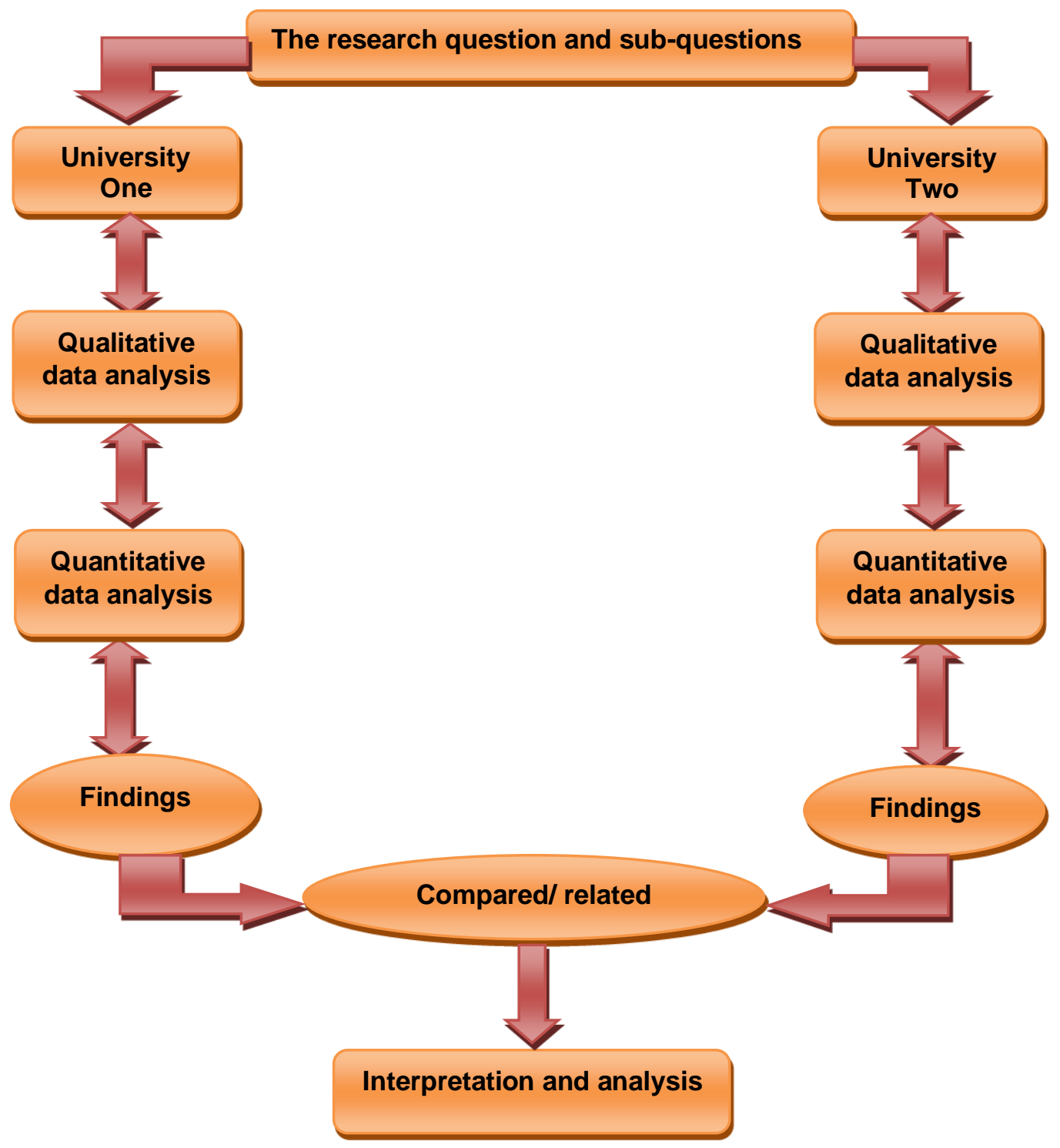

Figure 3.5: The procedure of research adapted from Creswell and Plano Clark (2011, pp. 79-80) 


\subsection{Trustworthiness}

Lincoln and Guba (1985) posit that trustworthiness of a research study is important to evaluating its worth. Trustworthiness involves establishing credibility, transferability, dependability and confirmability. All the issues related to trustworthiness will be discussed in this section.

\subsubsection{Credibility}

Credibility is a match between the researcher's interpretation and the interpretations of the participants who provide data. There are different ways to produce a credible study. Cohen et al. (2007) suggest triangulation, participants' validation, and prolonged engagement with participants as approaches to increase the credibility of qualitative research. Participants' validation is gained through re-checking to ensure the researcher transcribes the participants' words accurately. As mentioned earlier, after transcribing interview and observation data, I sent the transcripts to all the research participants for verification by email but no participants chose to correct them. In the coding process, in the first sample, I co-coded with one of my supervisors and then I continued to code the subsequent data because I was aware that when processing the multiple-case study analysis, the coding process might affect the reliability because of its subjectivity (Mukherji \& Albon, 2010, p. 231).

Triangulation was conducted by mixing data and methods to obtain diverse viewpoints about the topic and avoid misinterpretations of the findings (Stake, 2006). Each data source has strengths and drawbacks. For instance, interview participants or graduates may not be willing to answer all the questions in either the interviews or the questionnaire due to their limited time, or they do not wish to reveal the information for their well-being or they do not see the benefits they will gain from responding to the questions. These concerns made me select the multiple data source for this study as it provided a triangulation model, in which the weakness of one method will be the strength of another method, to ensure the trustworthiness of the research (Creswell \& Plano Clark, 2011; Yin, 2009). By collecting data from different 
sources such as semi-structured and focus group interviews, an observation, and an online survey, I could minimise the weaknesses of a single data source (Patton, 2002).

\subsubsection{Dependability}

Dependability refers to the consistency of the interpretation of the data (Cohen et al., 2007). The information helps readers to understand the interpretations as well as to ensure the process of inquiry is "logical, traceable, and documented" (Schwandt, 2007, p. 299). Patton (2002) also identified dependability ("a systematic process systematically followed," p. 546) and triangulation ("capturing and respecting multiple perspectives," p. 546) as important components of quality. Therefore, I reported the participants' background, the context of the study, and the research procedure in detail. The information helped readers to retrieve the evidence written in the report.

\subsubsection{Transferability}

Transferability shows that the findings have applicability in other contexts. Lincoln and Guba (1985) argue that transferability can be achieved when the context of the original study is found to be similar to that of a proposed study. Therefore, I, as a researcher, described the context of this research study in as much detail as possible so that others can compare their proposed contexts and find similarities. However, this comparison should be made by those in other contexts rather than by the researcher(s) (Lincoln \& Guba, 1985).

In order to achieve transferability, I provided a thick and detailed description of my research site, participants, and research procedures (see section 3.4). Given that the research participants in this study work in non-language major universities within the Vietnamese social and cultural context, it is possible that the study's findings might be relevant to other non-language major universities in Vietnam as suggested in section 3.2.2. This study is designed to enhance understandings of academic leadership in the Vietnamese higher education context, however some features of this study (for instance the 
influence of Confucian ideological and cultural values on leadership practices in curriculum issues in HEls) may be relevant to other Asian and nonWestern contexts.

\subsubsection{Confirmability}

Confirmability is "fidelity to real-life, context and situation-specificity, authenticity, comprehensiveness, detail, honest, depth of response and meaningfulness to participants" (Cohen et al., 2007, p. 149). In order to increase the confirmability, I carefully examined and triangulated the data from different participants and from different sources. Unpredicted things may happen and can affect an initial plan as researchers approach research sites (Creswell, 2008). Therefore, I applied an audit trail procedure to track and record the changes that may occur throughout the research process and the rationale for the changes. I also continuously checked the findings and interpretations against the interview transcripts and kept a research diary in which I noted any changes to the codes and their definitions, as well as the themes.

\subsection{Ethical Considerations}

Victoria University of Wellington places a high priority on the ethical conduct of research. Therefore, this study strictly abided by the requirements of the Faculty of Education's Human Ethics Committee. All ethical considerations and concerns for this study were documented, lodged and approved through the Human Ethics Committee before gaining access to participants, obtaining their consent, and collecting data. I addressed the key ethical and legal issues to protect the participants' rights and mine. Throughout the research project, I was fully aware of any potential risks that the research may cause to the participants, so every step was taken to minimise such risks. Apart from explaining to the participants in detail the aims of this study, the activities involved, and the time they might have to spend on the research, all the participants were guaranteed that their identity was kept confidential.

To conduct a study in the Vietnamese public universities, I had to get written permission from Rectors of the two selected universities. Rectors, academic 
leaders, some of EFL teachers and graduate students from the two selected universities received an information sheet and a consent form because I am aware of sensitive issues and potential conflicts of interest with academic leaders who are in higher positions and teaching staff whose responsibility is to oversee the curriculum design and delivery activities. I also made it clear and explicit to the participants that any information from interviews and other sources of data were not transferred to any other third parties, and that the purpose of collecting such data was for research only. The information sheet provided information about the aims of this study, research procedures, and the participants' roles. The consent form contained information for the participants' attention before they choose to participate in this study. I also sought consent from six company directors as well as 100 graduate students from each university for their voluntary participation in this study.

My study involved interpersonal interaction and therefore I need to "respect the participants and the sites for research" (Creswell, 2009, p. 89). Gaining the written agreement of individuals in authority was needed to access participants and research sites. An informed consent form together with a information sheet had been designed for participants to sign before the study. Creswell (2009) also emphasises that an ethical issue may arise unless there is reciprocity between the researcher and the participants. Consequently, both the researcher and participants can benefit from the study as discussed in section 1.5 of the first chapter. As my topic is about leadership, a topic of some considerable sensitivity in Vietnam, I observed principles of confidentiality very strictly. Only the graduates who participated in the online survey were anonymous and all other participants were given pseudonyms. I ensured that all the information and data provided by the participants were kept confidential and only accessible to me and my supervisors. I have to maintain the security, privacy, and confidentiality of the participants' details. Anonymity also applies to the universities where this study was conducted. Permission was sought from the participants to record the interviews and the observation of curriculum meetings. Furthermore, I clearly explained the rule of confidentiality to the participants, so that they could freely answer my 
questions without fear of professional reprisals. In presenting my findings at conferences and to my supervisors, I also employed procedures to keep the confidentiality of my participants. No real names were used in any publications and presentations. The academic leaders were anonymised as indicated in tables 3.2 and 3.3 and pseudonyms were used in tables 3.4 and 3.5 instead of EFL lecturers' and company directors' real names. University identity was also protected: they were identified as University One and Two.

In addition, I also anticipated some of the issues that may arise during data analysis and interpretation including how to protect the anonymity of individuals, roles and incidents, a reasonable time to keep the analysed data and who owns these data (Creswell, 2009). Storing data also strictly followed the guidelines by the Faculty of Education's Human Ethics Committee, Victoria University of Wellington. During the process of data collection, I made duplicate copies of each data file to make sure that I would not lose them through technical problems. The data from each 'sub-case' (semistructured interview with an academic leader) were allocated together to make up one 'case' folder. A much larger folder was established to represent the overall 'case' (i.e., the group). Another folder was made to include group data (i.e. semi-structured interviews, focus group interviews, an observation) to be analysed separately. Duplicate copies of these folders were made and stored in a lockable cabinet in my office.

\subsection{The limitations of this study}

This study has several limitations. Some can be minimised and others were beyond my control. The limitation of the research design needs to be acknowledged. First, this study applied interpretive case studies which are small-scale and specific to particular cases and cannot be generalised to larger populations of universities in Vietnam as well as many other countries in the world. Researchers using these methodologies can present these case studies in ways that the reader is then able to recognise elements of their own experience and draw valuable lessons from them (Yin, 2009). Given that the case study was small, it is difficult to make generalisations across other 
contexts. However, as can be seen in 3.7, the replication of this study is possible by the detailed description of the research site, participants, and research procedures (see also 3.4). It is, however, up to other researchers to make comparisons.

Other possible limitations included: the participants might have felt uncomfortable during the observation of curriculum meetings. They might have realised that their actions were being observed which may affect their actual practices. The participants might assume that their responses were evaluated during the interviews. I did remind academic leaders that their responses are for the purposes of this study and will not be used for promotion or performance evaluations. Some of the EFL lecturers were also told that their responses in focus group interviews were not for the assessment purposes that affect their performance and participation in curriculum design and delivery.

\subsection{Chapter summary}

This chapter has provided a detailed account of the research methodology used in this study. The selection of a qualitative-focused intrinsic case study design including a small quantitative component; the use of individual and focus group interviews, observations and an online questionnaire as the data sources have been justified in the discussion of the interpretivist /constructivist research paradigm I have selected. Methods of data collection and analysis, trustworthiness and ethical issues have also been taken into consideration.

The finding chapters are presented in chapters Four, Five and Six. 



\section{Chapter 4: SENIOR LEADERS' PERSPECTIVES ON CURRICULUM ISSUES}

\subsection{Chapter overview}

This chapter reports on the findings of the data collected and discusses these with reference to relevant literature. Senior leaders at the two universities selected for the present study were asked the following overaching research question:

- What is the role of leadership in promoting and supporting the effectiveness of the Basic English curriculum design and delivery in two selected Vietnamese universities?

The views and perspectives of different people at different leadership levels, including Rectors, Vice-Rectors, Managers, Deputy-Managers, Deans and Vice-Deans of some related departments involved in the Basic English curriculum design and delivery from both universities will be discussed in this chapter. In the sections and sub-sections that follow, a coding system will be used to ensure the confidentiality of the participants' identities. The data will be presented according to themes that emerge from the interviews with academic leaders. Section 1 explores the challenges facing the leadership teams of both universities as a result of the dual leadership of MoET and MoF; section 2 analyses insufficient institutional autonomy in Vietnamese higher education; section 3 reports on the lack of highly-qualified academic staff skilled in professional knowledge and English competence; section 4 deals with the barriers students face in meeting the requirements of the labour market in Vietnam as well as global economic integration; section 5 focuses on barriers faced by academic leaders in curriculum design and delivery; section 6 introduces individual barriers facing leadership teams; section 7 relates to efforts made by academic leaders to overcome challenges; and the last section, section 8 addresses collaborative leadership at different levels in terms of curriculum design and delivery. 
As mentioned earlier, the academic leaders at different levels of leadership in this study were identified in tables 3.2 and 3.3.

\subsection{Challenges arising from dual leadership}

The interview data revealed a number of challenges facing academic leaders. This section discusses the ambiguity in regulations between (and unclear regulations administered by) the two ministries (MoET and MoF) that direct the universities. Complications arising from a lack of consultation with the universities are also presented.

\subsubsection{Discrepancies and unclear regulations from the two ministries}

The data recorded discrepancies in legal documents (such as decrees or circulars) from the two governing bodies. Due to certain sensitivities in respect of this, some leaders only provided their general views and refused to give particular examples.

An illustration of the concern for the discrepancies at ministry level is provided in a response given by the Rector of University One, who commented:

Some universities in Vietnam are governmentally authorised by MoET, but owned by another governing body. That has an adverse impact; in other words, that is a barrier. (Interview, R1)

This response indicated the Rector's dissatisfaction that many universities in Vietnam are not only supervised by their own ministry but also by MoET. The control from the two ministries has brought disadvantages in managing the university activities. Due to some delicate reasons, the Rector only provided his general view and refused to give a particular example.

The negative impact of dual leadership is also mentioned by the Manager of the Training Department:

Sometimes, the ministries have contradictory directions so universities find it difficult to follow. (Interview, DMT1) 
It can be inferred from the data that there is a discrepancy between the roles of the two ministries. This problem might be related to a lack of a necessary exchange of views between the two ministries before giving directions to universities, directions, for instance, on financial and training matters. For example, at present, the State sets tuition fees for all regular fulltime tertiary programmes (Hayden \& Thiep, 2007). Many academic leaders have complained about the tuition fee problem. For instance, the Rector of University Two was convinced that:

The leadership in the university depends greatly on the directors of the ministries' directions, for instance governing ministries' decisions. (Interview, R2)

He seemed to imply that he felt challenged by the control of the two ministries. Similarly, the Dean of the Foreign Languages Faculty from University Two was adamant when he stated:

The biggest challenge is a lack of consensus in directions from the Ministries. ...There are several leaders who remain conservative and have no mastery in the subjects' characteristics and teaching situations of various levels. (Interview, DF2)

Some of the reasons for inconsistencies between the ministries may be because of unrealistic instructions, as, for instance, in the regulations stipulated in the national university entrance exam from the two governing bodies. This data shows that both universities' leadership teams are challenged when working under dual governmental instructions.

\subsubsection{Impact of dual leadership}

Dual leadership has had a number of impacts. One impact can be seen in the response made by the Vice-Rector of University One when he indicated that the difficulties his university has encountered are due to its position in Central Vietnam, approximately $1,000 \mathrm{~km}$ away from the ministries: 
The university is under the functional ministry, MoF. However, we are also administered by MoET. Therefore, many official texts and policies take excessive amount of time or are done slowly. (Interview, VR1)

It can also be inferred from the data that some regulations and policies stipulated by the administrative agencies, namely MoET and MoF, are difficult to follow. For instance, the Joint-Circular 20/2014 which guides the implementation of some articles of Decree No. 49/2010 / ND-CP dated May 14,2010 , pertaining to the exemption or reduction of tuition fees for students in educational institutions of the national education system may affect sources of revenue for HEls (Phi, Mai \& Ga, 2014). The Joint-Circular stipulates that students who are from poor households or those of marginalised ethnic minority groups are subject to free tuition, and that students whose parents have occupational accidents or occupational diseases are subject to a $50 \%$ fee reduction at HEls subject to the Prime Minister's approval in each period. Accordingly, the more these students enrol in a given university, the less funds the university will have. This will eventually lead to inadequate sources of revenue to spend on updating teaching materials and facilities.

In a similar vein, regulations on transitioning full-time training in college to university, as stipulated by MoET, are confusing to the universities (Quyen, 2013). For example, after finishing a three-year full-time training course in finance at a junior college, a student who wants to get a university degree has to sit the university entrance examination with those who have just finished grade 12 at high school. After passing the university entrance examination, this college graduate student will spend one and a half years at university to get a university degree. This regulation from MoET has had an adverse effect on college students because they seem to forget all the basic mathematics, physics and/ or chemistry knowledge that they had learnt in high school a few years before and when they passed the national high school graduation tests. This shows the difficulties transitioning from fulltime junior colleges to universities not only for students but also the universities in Vietnam. 
The manager of the Training Department in University One added:

The fact that the university is authorised by MoF, but governmentally managed by MOET also brings about complexity and trouble in the progress of carrying out work. (Interview, MT1)

It can be interpreted from his statement that his university finds it difficult in executing regulations from MoET, as, for example, in the university entrance examination task.

In addition to this, the Rector from University Two shrugged his shoulders when he indicated:

Our university leadership remains limited by a closed and less selfcontrolled mechanism. For example, regarding personnel organisational tasks mainly depends on governing ministries; or, similar to funding, it depends on the State budget for State-owned universities. (Interview, R2)

From his body language, Rector Two expressed his annoyance regarding the impact of dual leadership on his university.

The data suggest that academic teams from the two universities in this study agree that they find it challenging working under the control of two governing bodies. Leaders' statements directly indicate that dual leadership of the two universities has some drawbacks. As mentioned earlier, in section 1.2.6, the two selected institutions in this research study are under MoF, however, they are also under the control of MoET. The reason for this adverse impact is that although MoET in many ways plays the leading role in education in Vietnam, there are several HEls in Vietnam that are under other line ministries or government agencies. According to the Education Law 2005, high-ranking leaders at universities in Vietnam have to follow the guidance of their governing body. Some ministries have their own universities and colleges for example, the Ministry of Culture and Information has eight and MoF has five. Therefore, all the universities which are namely under the control of the MoF and MoET face some difficulties when they follow directions of both ministries. As a result, the rectors of some of public-sector 
institutions report to whichever ministry controls their university or college (Hayden \& Thiep, 2007). Nevertheless, they also have to send reports to MoET about their university's activities. This operating mechanism is one of the main reasons explaining the negative impact of dual leadership on the development of the tertiary education sector in Vietnam.

Dual leadership impacts on universities' management and operation, therefore the next theme will address the issue of institutional autonomy.

\subsection{Insufficient institutional autonomy}

The second theme emerging from the data is the insufficient institutional autonomy in Vietnam's higher education as discussed earlier in section 1.2. This theme can be linked to limited power and lack of funding from the ministries.

\subsubsection{Limited power}

Vietnam's Higher Education Law which gives HEls autonomy to carry out their activities took effect on 1 January 2013 (Hung, 2012). Despite this, according to participants in this study, institutional autonomy in the tertiary education sector is not sufficient. An example of this insufficiency is given by the Rector of University One, who stated:

The barrier that impacts on the leadership roles of a university leader ...is the current autonomy regime which greatly affects the execution and management of the universities' rectors, especially public universities and colleges in Vietnam at present. (Interview, R1)

It can be inferred from the Rector's reply that autonomy at tertiary level in Vietnam is still problematic; universities have limited autonomy as their activities are still under the surveillance of MoET. Rector One's comment showed this point more clearly:

The tuition fee structure is a barrier to the generation of income to ensure the requirements of improving the staff's proficiency, building material facilities, renewing the curriculum, purchasing equipment, 
applying IT for the university's excellent training activities. (Interview, R1)

His comment highlighted the shortcomings in policies such as those related to fees, and how universities lack the financial resources to upgrade the infrastructure and services to support teaching and to educate students for the developing economy, and for global integration.

\subsubsection{Lack of funding}

Vietnamese public universities are supported with financial aid from the government and each university leader is in charge of using government funding on appropriate spending aims. However, the power given to university leaders by their own governing ministry as well as MoET does not result in actual autonomy.

An example of this lack of funding can be seen in Rector Two's reply to my question. Shrugging his shoulders, Rector Two said:

Autonomy has not been real power yet. (Interview, R2)

According to him, when state-owned universities want to recruit new teaching staff, for example, they have to seek a quota from their own ministry. Moreover, the procedures stipulated by the ministries seem complicated. The reason for Rector Two's frustration may be explained by the problems of institutional autonomy in Vietnam's higher education: universities are theoretically conferred full autonomy whereas in reality they are given limited power.

It has been suggested in the literature that the culture of centralised planning and bureaucratic decision-making is deeply rooted across most areas of the public education sector in Vietnam (Hayden \& Thiep, 2007). Since the 1986 'Doi Moi' policy, the whole education system from early childhood education (ECE) to higher education has undergone remarkable reforms, but it has continued to be controlled by the central government, headed by MoET and some related ministries. Consequently, attempts to achieve greater efficiency and effectiveness in HEls by the central government have ostensibly 
conferred autonomy in both decision-making and the use of funds to HEls, but in fact the government retains control. This is consistent with the socialist orientation of higher education and of the deployment of the sector within a framework of centralised national economic management (Thinh and Phuong, 2010). The directive on tuition fees by the State means that HEls in Vietnam have little institutional autonomy at present. This is an obvious obstacle to the execution and leadership of a university. As a result, it can be said that slow policy development, inappropriateness and the tuition fee structure can prevent tertiary institutions from upgrading their infrastructure and teaching facilities to serve the learners' needs. Currently, the Vietnamese government is developing regulations for the financial structure to align it to the new higher education law 2012.

In conclusion, a common theme which has emerged from the interviews with senior leaders in these two universities is that the difficulties they face in carrying out their jobs which are made more difficult and inefficient because of the lack of institutional autonomy. Interestingly, there is a close link between the first two themes. The correlation between dual leadership and insufficient institutional autonomy is significant because the first two themes are viewed as barriers faced by the leadership teams in carrying out their tasks.

\subsection{Lack of highly-qualified academic staff}

As discussed earlier, autonomy at the two selected universities is not true autonomy. This leads to difficulties in recruiting teaching staff and improving their qualifications.

\subsubsection{Lack of highly-qualified staff}

This sub-section deals with the issue of academic staff lacking in quantity and quality with regard to their qualifications and experience at the tertiary level. This can be seen in the reflection of the Vice-Rector of University Two:

...the training scale continues to rapidly increase overwhelming our teaching capacity. We have few professionally and pedagogically highly-qualified lecturers, and especially lack leading experts. This is a 
problem affecting the quality of training management of our university. (Interview, VR2)

This Vice-Rector expressed his concern about the lack of teaching staff as the number of students who choose to pursue economic majors is increasing because students think that it may be easy for them to find jobs after graduation.

\subsubsection{Limited professional knowledge and English}

Academic leaders from the two universities shared their anxiety about the lack of teaching staff. Moreover, they are also worried about their professional knowledge and English competence. Rector One emphasised:

For the requirement of integration to be met, EFL lecturers' specialised proficiency is a very big barrier to the leadership of activities in the university. (Interview, R1)

Rector One expressed his desire to build an advanced curriculum which will be taught in English in his university in the near future. Nonetheless, it is at present unfeasible due to many of the staff's poor English competence. In addition, some other academic leaders from University One also have commented on the professional knowledge and English ability of their academics. For example:

The human resources I have mentioned here have definite limitations: the university's lecturers are not good in terms of their professional knowledge, foreign language proficiency, and abilities to apply IT in teaching. We are trying to reduce this setback. (Interview, VR1)

Currently, at University One, lecturers teaching specialised subjects know very little English. Moreover, EFL lecturers do not have many chances to study or attend workshops on English teaching methodology to improve their qualifications. Therefore, many lecturers do not meet the English competence framework based on CEFR stipulated in the National Foreign Languages Project 2020 as discussed in section 1.2. 
Similarly, the training department manager from University One made this point clearer:

The resources of the university such as teachers, reading rooms, books, teaching and learning facilities are not adequate. The staff's professional proficiency and experience in curriculum management and implementation is not equal, especially their English and IT skills do not meet the demands of the work. (Interview, MT1)

It can be seen from this quote that not only are the staff's qualifications limited but they are not good at English or IT as well. A possible explanation for this shortage of teaching staff is that lecturers spend a great deal of time teaching and do not have time to upgrade their professional knowledge and research skills (Clark, 2010).

The Dean of the Foreign Languages Faculty in University One also raised the concern about improving teaching methodology:

Many EFL lecturers in my faculty rarely have many opportunities to communicate with native English speakers or attend workshops in English language teaching to improve their professional knowledge. (Interview, DF1)

It can be inferred from the data that EFL lecturers have a strong desire to update their knowledge and teaching methods but lack opportunities to enhance their competence. Inadequate funding is another reason EFL teachers are unable to enhance their professional knowledge.

Another effect of the academic staff's limited professional knowledge and their English competence may prevent the university from designing advanced curricula. The Rector of University One said:

A lack of lecturers inhibits the designing of curriculum that are advanced in terms of their quantity, quality and professional structure and that properly involve the expertise of both lecturers and leaders. (Interview, R1) 
Despite the barriers to academic staff improving their professional knowledge and English language competence discussed above, staff are encouraged to pursue study to enable them to participate in developing advanced curricula to help students to be fully prepared to meet the demands of workplaces in Vietnam's changing world. This Rector's strong desire is to build advanced curriculum that must be taught in English. However, this is a huge challenge because:

Many lecturers cannot teach specialised subjects in foreign languages, namely English. (Interview, R1)

Academic leaders from University One mentioned the poor English language competence of their colleagues, while the leadership teams from University Two, although agreeing with this, focused on the importance of English in internationally cooperative programmes as expressed by a female leader of University Two:

The challenges I have recently coped with while solving the problems of the curriculum are teaching and learning foreign languages to meet the demand of the foreign languages cooperation programmes. Beside the lecturers and students, we need officials who are proficient in English and able to work in an international environment completely like the curriculum in the native countries. (Interview, MS2)

In recent years, many universities in Vietnam have widened relationships with many famous universities around the world, especially from Englishspeaking countries such as the US, the UK, Australia, New Zealand and Canada. This collaboration has been hindered, however, by the Vietnamese official's limited knowledge of English (Tuoitre, 2012). Thus, knowledge vital to meeting the demands of the country's economic growth and international integration has been slow in being implemented.

An illustration of this can be seen in the response of the Head of Scientific Research and International Relations Department from University One, who said: 
I can perform my job well because I have had more than 20 years of working experience; however, in terms of individual barriers, my really big problem is foreign language skills. (Interview, MS1)

This viewpoint is also expressed by one Dean from University Two:

The obstacle affecting the role of leadership is the fact that international integration requires leaders to be professionally competent, decisive and good at foreign languages. These virtues are not inborn. (Interview, MS2)

This academic leader emphasised the usefulness of English especially its importance in scientific research. Nevertheless, she expressed her worry about the fact that it is not easy for senior leaders to learn English. It has been suggested in the literature that older people find it more difficult to learn English or another language than younger ones and the success of learning English also depends on aptitude. Besides age, there are correlations between language aptitude, working memory capacity and language proficiency (Sáfar \& Komos, 2008). Moreover, according to Tuy (2007), Vietnam's higher education system is heavily influenced by the Soviet academic system, in which universities were mainly teaching institutions whereas research was conducted by research institutions. This is a reason why Vietnamese academics have had a poor publication record (Valley \& Wilkinson, 2009). To overcome this, the government is accordingly attempting to build some research-based universities. Another reason for poor publication is that senior leaders do not fully understand specific characteristics of English as a skill subject and thus pay much attention to specialised subjects such as finance and accounting and neglect fostering programmes for EFL lecturers. As a Faculty Dean from University Two commented:

Some superiors have little knowledge of the specific features of English subjects. Some of them are conservative, dogmatic and only offer vague instructions which could be considered the biggest barrier. 
Moreover, EFL lecturers have few opportunities of communicating with native speakers which is also a big barrier. (Interview, DF2)

It could be inferred from his response that many leaders and teaching staff from the two institutions have difficulty with English competence which prevents them from improving their qualifications to meet the needs of regional and global integration.

\subsection{Barriers facing students}

The fourth theme emerging from the data in this study can be linked to the barriers students face in meeting the requirements of the labour market in Vietnam and the requirements of global economic integration.

\subsubsection{The requirements of the labour market}

The labour market in Vietnam is lacking highly-qualified workers (Thanh, 2013), as discussed above. This is aggravated by graduate students' poor professional knowledge and low competence in the English language, resulting in them not meeting the expectations of the labour market. One of the reasons is that state-owned universities do not have enough practical resources for students. This shortage of teaching facilities is seen in the reflection of Vice-Rector at University Two:

Practicum is a bit limited as we lack funding to expand our campus and upgrade infrastructure. (Interview, VR2)

Another reason for failing to meet the requirements of the labour market is that the curriculum has not been updated to meet the society's needs in the changing labour market. This is illustrated by the Rector of University One's response:

One of the biggest challenges that we have faced in the progress of participating in designing and leading experts to design a curriculum in our university is the tasks of updating and assessing how the curriculum meet the society's needs especially the demands for economic development. (Interview, R1)

Likewise, another academic leader from University One mentioned: 
With the present situation of the university, it is clear that we have to choose subjects or determine whether those subjects belong to theory or practice when designing a curriculum. Our material facilities are not adequate at present and we need to design many practice modules. (Interview, MS1)

According to this academic leader's perspective, concentrating on theory means that there will be less emphasis on practical skills. Accordingly, the practical period will be inevitably very short. As a result, employability skills and practical workplace experience do not meet the requirements of the labour market. Another illustration regarding students' difficulty in efficient practice can be seen from the response of Vice-Rector Two:

I think the university is increasing its level of activity. This requires us to solve the contradictory situation that follows, between improving the quality of training and increasing the scale of expansion; you cannot expand overwhelmingly when you are also short of teaching staff and material facilities. (Interview, VR2)

The Vice-Rector of University Two expressed his concern about how to balance the student enrolment scale and the issue of improving training quality in his university. This problem may also be the challenge for other public universities as well. In brief, many senior leaders from both universities agree that students lack practical skills because their institutions lack adequate facilities and staff.

\subsubsection{To meet the requirements of global integration}

Students not only have difficulty in meeting the needs of the labour force but also the needs of global integration. An example of this is taken from the Faculty Dean of University One who indicated the challenges in integration because:

Vietnamese students are not good in language skills which prevent them from keeping up with other countries' advanced higher education systems. (Interview, DF1) 
Several leaders from University Two also expressed concerns regarding education integration with other advanced education systems in the region as well as the wider world.

\subsubsection{Students' limited English competence}

Participants in this study generally agreed that they were challenged not only by the demands of global economic integration but also by students' limited English competence. An example of this can be seen in the response provided by Rector One who said with a determined voice:

The impacts of natural, socio-economic conditions have influenced students' awareness of the importance of English learning. (Interview, R1)

His response indicated that low economic conditions prevent students from achieving better English learning outcomes as discussed in the context of study in section 1.2. In addition to this, the application of the tuition-fee reduction policy as discussed earlier in section 4.2.2 has led to more enrolments from rural areas in University One. As a result, the university will not have enough sources of revenue to use for upgrading, either infrastructure or buying facilities for teaching. An illustration of this is provided by Vice-Rector One:

Public universities in Vietnam have been restricted by tuition fee income which is regulated by the Government. Meanwhile, the university needs to invest more money in infrastructure and personnel to improve training quality to meet the current integration demand. The pressure ... for better training quality in public universities in Vietnam is a problem which needs a long time to be solved. (Interview, VR1)

Although University Two is located in a big city, it also has similar revenue constraints to University One as illustrated by an academic leader from University Two: 
The budget for upgrading training facilities and scientific research activities is very small. This will lead to the fact that professional practice for students is not sufficient. (Interview, DMT2)

This response revealed that the funding given by the State is not enough for universities to spend on expanding their campus, upgrading their infrastructure and training their staff in order to support training tasks. This academic leader's viewpoint also indicated that a lack of practical workplace experience hinders students from strengthening their professional development as well as their English capability.

Similarly, Rector One shared this viewpoint:

The present situation prevents the university from keeping up scientific research as well as curriculum innovations with other universities in the country and in the Region as well. (Interview, R1)

Consequently, better equipping students to meet the needs of society and global integration seems problematic due to the university's inadequate financial budget. These reasons may explain the ineffectiveness of the curriculum design for students and consequently may have led to the students' inability to meet the requirements of the labour market in Vietnamese society. The connected issue of lecturer quality will be addressed in the next sub-section.

\subsection{Barriers facing leadership teams in curriculum design and delivery}

Another theme evident from the data, and one which is closely linked with the previous ones, is barriers in designing curriculum. Rector One explained the difficulty that his university has:

Designing a proper curriculum which can meet social needs is challenging to follow as it is difficult to invite graduates, alumni as well as scientists specialised in finance-accounting to take part in building and evaluating the curriculum. The matter of building an appropriate curriculum for Vietnam's tertiary education might be solved if universities have full financial autonomy. (Interview, R1) 
One of the prerequisites for the university to design a better curriculum for students is that the university should have enough financial resources to pay their academics as well as external curriculum reviewers. However, the policies for encouraging academics and leading experts are not timely and supportive. Teachers have to teach long hours with low pay. That is why Professor Hoang Tuy, one of the Vietnamese well-known mathematicians and educators, argues that Vietnam will not have effective education without good teachers and appropriate curricula, but policies regarding teachers are archaic (Tuy, 2007). As a consequence, many scientists and leading experts are not passionate because they are poorly-paid. This can be illustrated from the response of the manager of Scientific Research and International Relations Department of University One:

Lecturers are a key force in the participation in scientific research activities, but they are not keen on doing research due to poor pay thus it is clear that the university's present scientific products are not highly-qualified. (Interview, MS1)

It seems possible that low research quality is due to inadequate and unequal rules and regulations on related scientific activities. Besides, the supervision, inspection, rewarding and disciplined tasks in doing research in the university have not been performed well and efficiently. This senior leader continued to point out the reason for not having better curriculum:

Funding for training is problematic because MoET stipulates a fixed tuition fee. The allocation of funding is not appropriate because universities have not been classified and ranked yet. (Interview, MS1)

It can be inferred from his response that the funding does not reflect the quality of the university. Every university is given the same amount of funding. His response also implied that if his university is at level one, it should get a larger amount of funding for curriculum design in comparison with a second rank university. Furthermore, reality shows that not many Vietnamese universities have been ranked in the Asian region and in the world as discussed in the previous section. 
University One has faced difficulties in building and evaluating curriculum as mentioned in this response from Rector One:

This is a huge challenge because it is very difficult to invite actual experts of the university's specialised fields (namely in the field of finance-accounting) to take part in designing and assessing the curriculum. This is a big problem for the university in the current conditions in the Central-Highlands in particular and in Vietnam in general. (Interview, R1)

There are several possible explanations of this leader's reflection. The economic conditions in the Central-Highlands of Vietnam are very poor in comparison with other areas in the country. Low salaries and unfavourable living and working conditions result in a brain drain because teachers cannot live on their basic salaries. Many teachers also complain they do not have time to improve their teaching skills because of time consuming unnecessary tasks namely preparing a myriad of academic documents which contain overlapping information (Vietnam News Agency, 2011). Moreover, many Vietnamese leading scientists do not want to work in small cities and decide to settle in big cities. As a result, University One faces challenges even though they have the strong desire to invite external reviewers to participate in curriculum design and delivery.

The Vice-Rector from University One also shared a similar comment:

From the curriculum for a major or a module, we have tried to invite wellinformed and experienced academics to design the curriculum. In my opinion, inviting curriculum design consultants is difficult and these ways have not been efficiently carried out in our university. (Interview, VR1)

It can be said that it is very difficult for University One to have their curriculum externally assessed due to tight funding in scientific activities. Similarly, ViceRector of University Two shares the difficulty in terms of curriculum design and delivery when he said:

Curriculum renewal in other universities as well as our university has encountered some difficulties. That is, for the curriculum to be 
renewed, it requires us to cut down old subjects, supplement new ones, which affects the arrangement of lecturing staff. What is more, when the new subjects are taught, who will teach them? (Interview, VR2)

His comment seemed to imply that he was anxious when assigning teaching staff when the university cuts down the amount of time allocated for old subjects. He also worried about the lack of highly-qualified lecturers and the time it would take to train staff to teach the new subject as they would need to be up-skilled in these. This is quite different in Western universities where academics are expected to be flexible about teaching new materials. As a result, the problem Vietnamese universities face in curriculum renewal is how to find the balance between reducing old subjects and adding new ones and how to assign jobs to staff that will be made redundant due to curriculum reform.

Another illustration can be seen from the Deputy-Manager from University One when she said:

In the recent years, the university has transferred to credit training, which has led to changes in the restructure of the curriculum and the management of syllabus and numerous problems. (Interview, DMT1)

It can be inferred from her reply that the transfer from academic year training to credit training stipulated by MoET in 2008 has brought about difficulties for universities.

\subsection{Individual barriers faced by academic leaders}

Many academic leaders face not only organisational barriers such as institutional autonomy and dual ministerial leadership but also individual barriers. Nonetheless, these barriers vary in terms of gender and age. Some of the male leaders indicated that they have encountered difficulties in language learning. An example of this is illustrated by the response of one of the department heads at University One: 
I think there are two big challenges. First, the scale has increased, along with the requirement that training quality be ceaselessly improved. Second, it is difficult and time-consuming for middle-aged people like me to improve language skills. (Interview, VR2)

This leader not only expresses his worry about how to improve training quality but also the difficulty he has had in learning English when he is middle-aged. Likewise, some male academic leaders from both universities also mentioned the difficulties they have in foreign language learning whereas no women mentioned language barrier issues in terms of their leadership roles.

For female leaders the issues were quite different. All four female leaders included in this study reported that they have dual responsibilities to fulfil: academic duties as well as housework and caring responsibilities in the home. One of the examples is as follows:

Along with my work at the university, I also have to fulfil my duties as a mother, a wife and a daughter-in-law in the family. I have to do domestic work and take care of the children. A variety of housework takes time and partially hinders me in my leadership role. (Interview, DF1)

A possible explanation for these female leaders' comments may have something to do with the ways Vietnamese women are socialised to be gentle and magnanimous and take on these dual responsibilities. The data show that these gendered, individual barriers prevent female academic leaders from enhancing their professional development as well as performing their leadership roles.

\subsection{Efforts to overcome challenges in curriculum design and delivery}

Another key theme emerging from the data concerns efforts made by the two universities to overcome difficulties such as limited financial budget, shortages of highly-qualified staff and poor infrastructure. 
One solution that leaders as well as teaching staff at both universities have come up with is to bring workplace preparation to their university so that students can spend their probation period at their institutions. This may be a creative idea from the two tertiary institutions due to the economic crisis in the world as well as in Vietnam in recent years (Varghese, 2009). If the university has its own practical workplace, it will help save time, money and increase workplace preparation efficiency. This probation period may be useful for students to apply practical knowledge and skill in the workplace later. For example, Rector One had the idea of 'bringing reality to their university' efficiently by building a practical lab based on the model of an accounting workplace for their students:

We want to help students improve practical work experience. That's why we have built professional practical labs. (Interview, R1)

The experience of attracting local experts' experience built up leadership experience for him during his leadership journey as he mentioned:

The experience is closely following and taking advantage of the guidance of MoF and of MoET as well as local experts and scientists with seasoned experience in the specialised field, mainly officials of Finance, Treasury, Customs Departments, or leaders of the People Committee of the district and the province. (Interview, R1)

Likewise, University Two collaborates with internal and external specialists to compose and to assess curriculum for training implementation in the university:

When we carry out updating or designing the curriculum for a new major, we invite not only the university's leaders, scientists, highly experienced lectures but also experts in our training majors who are working in companies, have a lot of practical experience and clearly know about how the university's training products will satisfy the society's demand. (Interview, VR2)

From his response, it could be inferred that curriculum design may require a large number of professional experts working in teams. This process of 
working collaboratively in designing curriculum is indicated in the response of a Department Manager in University One:

Collective staff and faculty unanimously support and show their determination to overcome the difficulties of implementation, especially the teachers, who were very active in adjusting teaching methods, measures to strengthen student learning service. (Interview, MT1)

Although the two universities have certain difficulties in terms of funding, infrastructure, lecturers, and curriculum design, the leadership teams are very knowledgeable and try to get consensus from their colleagues and followers so that they work together to serve training needs.

\subsection{Collaborative leadership at different levels within Vietnamese higher education}

Although academic leaders at the two universities face a lot of organisational and individual barriers in carrying out their responsibilities and roles, both leadership teams have made efforts to design better curriculum to serve their students. The final theme relates to collaborative leadership at different levels within the Vietnamese higher education in curriculum design and delivery.

Rector One's subordinate shared a similar experience to his superior:

I have established relations with other universities region-wide and nation-wide as well. Thanks to these good relations, the collaboration, experience sharing, and support between the university and other universities have brought about many advantages for the university. (Interview, VR1)

Likewise, some academic leaders from University Two support collaboration in designing curriculum. This collaboration can be illustrated in the following example:

When a curriculum is designed, there is always a council in which I am the president who puts forward guidelines and orientations so that we can design the curriculum for every specific major. Based on designed curriculum, they will be sent to the faculties and departments for 
feedbacks, and then the council will host a meeting and I will make a final decision on those curricula. (Interview, R2)

Rector Two explained the procedures that his university uses in designing curricula. In order to have a good curriculum, they send it to internal and external reviewers to assess. As the head of the university, he is the one with full responsibility to finalise the curriculum.

In reality, the tasks are shared among the leaders of the university through coordination and collaboration, simultaneously we have our own independent points of view. I think that leaders should be good listeners to their colleagues and experts, to be able to cooperate in design and write the curriculum to satisfy their requirements. (Interview, MS2)

The data show that senior leaders at the two universities in this study are very experienced and knowledgeable because they have long-standing commitments to their universities and they are trying to build relationships with their colleagues as well as with other partners. For example, some of the respondents at both universities shared their views of not having been properly prepared for their leadership roles in advance. They have had a lot of preparation in how to execute and manage training activities in the field of Finance-Accounting but it can be inferred from the senior leaders' responses that they gain the leadership experience while they are on the job.

The Rector of University One views himself as a very good listener who respects to his superiors' thoughts and shares ideas, as he expressed in his response:

For me, I think things that make an impact on the leadership journey are as follows: Firstly, it requires me to be a good listener to my colleagues. Secondly, it requires me to mobilise local experts and scientists who have seasoned experience in the specialised field, mainly officials of Finance, Treasury, Customs Departments, or leaders of the People Committee of the district and the province. (Interview, R1) 
It could be drawn from the data that listening to colleagues' thoughts is valuable for leadership practice.

Other illustrative examples of sharing experience are evident in the responses of academic leaders from the two universities. For instance:

I have tried to learn from my colleagues, other leaders and former ones to gain knowledge and skills for my role as Vice-Rector in charge of the university's training activities. (Interview, VR2)

According to Vice-Rector One, a good leader knows how to share experience with his subordinates and employ them creatively by encouraging them to develop their abilities and skills for the purpose of serving the learners' needs:

... With my position of leadership, I collaborate with the faculties and departments to create the curriculum; recommend developing types of training, collaborative training activities. (Interview, DMT1)

Her response reveals that she works in groups with other colleagues across her university. Similarly, this view was also shared by the Rector of University Two who argued:

Before becoming a leader, first of all I was well prepared in terms of thinking, i.e. it is very necessary to learn about the former leaders' experience and that of my subordinates as well, and I did think how to convince and encourage all staff to mutually implement the political tasks set up by the university. (Interview, R2)

Rector Two put an emphasis on his way of leading his university. He was willing to learn from both his predecessors and his followers. Many of the academic leaders generally indicated that they have their direct role and responsibilities in curriculum design and delivery. For instance, Rector One showed his direct role by asserting:

In the university, I am a key person who directly takes part in designing and composing curricula for some majors in Finance- 
Accounting. I am also a pioneer of curriculum design and delivery to meet the manpower demands for the society. (Interview, R1)

The use of a word with metaphorical meaning like 'pioneer' conveys the message that he views himself as a creative person who has the idea of innovating the curriculum to meet the manpower demands for the society. In a similar vein, Vice-Rector One also expressed his role in participating in the activity of curriculum design and delivery by saying:

Curriculum design is done in the regime of a board. I will be usually the Vice-President of this scientific and research board. I have participated in curriculum design with the role of leading a group of experts to design the university's curriculum for each major as well as each module of a major. (Interview, VR1)

The way that his university works to build curricula can be inferred from his response. He also emphasised his crucial role in curriculum design as a Vice-Chairman of the Council of Scientific Research.

This view point was also shared by a Dean from University Two when he said:

I am the one who presides and takes the main responsibility to put forward ideas, plans, and curriculums and hold seminars to gather members' viewpoints and make the final decisions. (Interview, DF2)

Finally, leadership is shared across University Two because many senior leaders seem to trust their staff implicitly. An example for this is taken in the response of Rector One who said:

I encourage my colleagues to present and share ideas. I also assign tasks to Heads of Departments and Faculty Deans so that they are aware of their responsibilities for the benefits and development of the whole university. (Interview, R1)

A possible explanation for his viewpoint might be related to the idea of the collective spirit of Vietnamese people as it is consistent with Thang's (2013) study. In collective cultures, people's relationships are very close, they tend 
to be considerate and responsible for each other's wellbeing and especially emphasise loyalty and respect for members of the groups.

Similarly, the Vice-Rector Two and the faculty Dean share a similar view. They like listening to their staff's leadership ideas and highly evaluate the roles of the teaching staff. Typical illustrations included:

I have had many opportunities to gather and share with the university's staff, especially employing the lecturers' ideas for the university's strategic, long-term and short-term goals. We all know the role of the lecturers is extremely important in a university. (Interview, VR2)

I think it is advisable to be faithful, straight and outgoing in the interaction with colleagues and to care about common issues and members' interests to encourage and gain everyone's consensus. (Interview, DF2)

From these statements, it can be interpreted that both are interested in sharing responsibilities. It may be that the senior leaders benefit from the learning experience of their colleagues and that getting on well with them helps to gain the approval of the whole team. Through these responses, it can be implied that academic leaders from University One and University Two shared power and worked collaboratively in curriculum design and delivery. The leaders try to encourage their subordinates to participate in curriculum design, respect their ideas and then assign jobs for them.

The concept of collaborative leadership has been recently deployed not only in business but also in public policy and community organisations (Humfreys, 2013). The need to increase understanding of institutional goals and practices in higher education highlights even further the necessity for collaboration and the cross-sector communication it requires and enhances (Humphreys, 2013). The issue of collaborative leadership relates to the way in which academic leaders at different levels from both universities collaborate with each other to design curriculum for the purpose of developing more opportunities for graduate students to apply what they are 
learning in real-world settings and bringing them to higher levels of achievement in their future jobs. That is the reason why higher education demands more collaborative leadership in our current changing world. The Vietnamese proverb says that [Together we can change the world]. It represents the spirit of consolidation of the Vietnamese people. It has been suggested in the literature that collectivism affects the Vietnamese people's characteristics (Thang, 2013). In short, the data from this study show that collaborative leadership plays a crucial role in both universities because it is valued by the leadership teams in designing curriculum.

\subsection{Chapter summary}

This chapter provides a summary of the key themes that emerged from the interviews with academic leaders at the two selected universities in this research study. The first section discusses the challenges faced by the two universities caused by the dual leadership from two ministries. Following this is the issue of insufficient institutional autonomy. The third theme concerns the issue of lacking highly-qualified academic staff and their shortcomings in professional knowledge and English competence. The next theme addresses barriers that prevent students to meet the requirements of the labour market as well as the requirements of global economic integration. After that, difficulties in curriculum design in tertiary education are addressed. The other two themes evident from the interview data relate to the individual barriers faced by academic leaders and their efforts to build a better curriculum. Last but not least, the collaborative leadership across different levels in the universities regarding curriculum design and delivery is also addressed. These findings may contribute to explain the challenges that senior academic leaders face when they execute their roles in terms of curriculum design and delivery. In general, the findings aligned with those of previous research in the area. Nevertheless, there were several findings, in this study, which make additional contributions in such areas as dual and collaborative leadership, particularly, in the context of the Vietnamese higher education system which is influenced by cultural and historical aspects. Moreover, some of the findings indicated the issues which need further research namely, the issue 
of gender influence on collaborative leadership. The next chapter will discuss EFL lecturers' perspectives on the Basic English curriculum design and delivery at the two selected universities in Vietnam. 


\section{Chapter 5: EFL LECTURERS' PERSPECTIVES ON CURRICULUM DESIGN AND DELIVERY}

\subsection{Chapter overview}

This chapter reports on the findings of the data collected from the focus group interviews with EFL lecturers and discusses these with reference to relevant literature. It aims to help answer the central research question of this thesis:

- What is the role of leadership in promoting and supporting the effectiveness of the Basic English curriculum design and delivery in two selected Vietnamese universities?

The views and perspectives of EFL lecturers of the Faculty of Foreign Languages from both universities will be discussed in this chapter. As noted earlier, in the sections and sub-sections that follow, different Vietnamese names for flowers and seasons were used in order to preserve the participants' identities. I used the abbreviation beginning with name, University One/Two (i.e. Hoa, U1, FGI).

Table 5.1: EFL lecturers' Focus Group

\begin{tabular}{|l|l|l|l|l|}
\hline & University One & Name & University Two & Name \\
\cline { 2 - 5 } & Teacher 1 & Hoa, FGI & Teacher 1 & Mua, FGI \\
\cline { 2 - 5 } $\begin{array}{c}\text { Data source } \\
\text { (focus group } \\
\text { interviews) }\end{array}$ & Teacher 2 & Mai, FGI & Teacher 2 & Xuan, FGI \\
\cline { 2 - 6 } & Teacher 3 & Lan, FGI & Teacher 3 & Ha, FGI \\
\cline { 2 - 6 } & Teacher 4 & Cuc, FGI & Teacher 4 & Thu, FGI \\
\cline { 2 - 6 } & Teacher 5 & Truc, FGI & Teacher 5 & Dong, FGI \\
\hline
\end{tabular}

The data is presented according to themes which emerged from the focus group interviews with EFL lecturers. Section 1 discusses the teachers' difficulties when teaching large classes with students of different English 
competence; section 2 explores the challenges facing EFL lecturers from both universities because of the shortage of time to upgrade their qualifications and do research; section 3 deals with Individual barriers faced by EFL lecturers; section 4 discusses the endeavours to overcome challenges to collaboration in curriculum design and delivery; and the last section addresses EFL lecturers' suggestions to be put to the leadership teams in terms of curriculum design and delivery.

\subsection{Difficulties facing EFL lecturers}

The first theme from the focus group interviews is the many difficulties EFL lecturers face when they teach students with different English language levels in large-sized classes ranging from 45 to 60 students.

\subsubsection{Students' different levels of English competence}

EFL lecturers expressed their concern about students' varied levels of English competence in their classes. An example of this is seen in the statement from an EFL lecturer from University One, who said:

My students are from different provinces with a variety of English language input. Student from urban areas often have better English language skills than those from the mountainous and islands. (Mai, U1, FGI)

Her reply revealed that geographical distance has impact on students' English competence, maybe because those from rural and remote areas are disadvantaged by this isolation as they do not come into contact with the language, as many of their urban counterparts do and also because their teachers are less competent in English (Vietnam News Agency, 2012a).

Differences in English language knowledge between students from urban and remote areas was also highlighted by another EFL lecturer from University One who stressed students' attitudes to learning English, and noted confidence as a significant factor. 
Teaching English to a class with differing levels is indeed a challenge. The students with greater English competence feel bored while rural students find it challenging and are embarrassed by the superior knowledge of their urban peers. (Cuc, U1, FGI)

Her comment revealed that learners with advanced English ability find tasks in class easy while those with lower English competence are shy and too embarrassed to express their ideas. These students may be afraid of losing face in front of their urban peers. A possible explanation might be due to the shortcomings in the MoET's regulations in the English teaching for high school learners before they take the National High School Examination.

Though sharing a similar view with EFL lecturers from University One, one teacher from University Two specifically noted the placement test at the beginning of the new academic year:

Students are required to take the placement test...Those who get $A+$ score can continue the second module of the Basic English curriculum whereas those who get an $F$ score have to attend extra classes along with taking the first module of the examination. (Thu, U2, FGI)

Applying the placement test when the new school year starts is helpful, however, this classification has revealed some limitations. In this format students with $A+$ move to the next level, while those who get scores ranging from $\mathrm{D}$ to $\mathrm{B}+$ are randomly placed in the same class. This random arrangement causes difficulty for teachers because students with high English levels often feel bored when they study in the same class with lowerlevel ones. Further and importantly, higher level students are not challenged and the individual needs of lower level ones are not addressed. This is likely to contribute to some EFL teachers' difficulties in dealing with students' different English language skills.

\subsubsection{Large classes}

In Vietnam, due to the shortcomings in infrastructure at HEls, as reported in the previous chapter, universities have insufficient classrooms and 
auditoriums, therefore many students are put in very crowded rooms. An EFL teacher from University One highlights this:

Teaching large-sized classes is rather challenging. We find it hard to organise activities especially in speaking periods. (Mai, U1, FGI)

In the above comment Mai emphasised the challenges she faced when dealing with crowded classes especially as each period lasts only 45 minutes. As noted earlier there has been an explosion of student numbers resulting in over-crowded classes. A possible further explanation for the large class sizes and the high ratio between students and lecturer is the lack of funding for universities to extend their campuses. Another factor impacting on English language teaching is the practice of most EFL teachers concentrating on reading and writing resulting in few opportunities for students to practise speaking drills within a 45 minute period. Consequently, time limits hinder students from improving their communication and teamwork skills (Huyen, 2012).

A lecturer from University Two agrees:

The number of students in many classes varies from 50 to 60 because we are short of classrooms so it is challenging for teachers to carry out communicative activities. Moreover, time allotted for speaking and listening is also limited in the programme. (Dong, U2, FGI)

Dong expressed her preoccupation with the large classes which hinder the organisation of speaking and listening activities and the time limit for oral practice in the curriculum. This shortcoming results in students' weak communicative skills.

\subsection{Challenges facing EFL lecturers in the Basic English curriculum design and delivery}

The interview data reveals a number of challenges facing EFL lecturers. This second theme is about time constraints to do research and improve qualifications resulting from a lack of support from the universities. 


\subsubsection{Time constraints in doing research and improving qualifications}

One challenge faced by EFL lecturers is time constraints in doing research and enhancing their qualifications. An illustration of this is provided in a response given by an EFL lecturer from University One, who commented:

Currently, because there are few EFL lecturers in our faculty, we have to teach many periods a week. This results in less time for improving teaching methodology and doing research. Our faculty has sent requests to the university's leaders for more teachers. However, the recruitment process takes time and we also we have to wait and seek the ministry's permission. (Truc, U1, FGI)

Truc implied that teaching long hours made her very tired because her university lacks teachers of English. A potential reason for this view may be the complicated and lengthy process of recruitment in Vietnam's higher education sector as waiting for approval from the ministry, on the universities' selected candidates, takes an inordinate amount of time. Firstly, the university has to await the decision about quota from the MoF and then founds the Recruitment Council. After that, the Rector signs an announcement to advertise the positions. When the applications are received and scrutinised the Rector selects the successful candidates to go through the recruitment process which is long and gruelling. This process includes: meeting and talking to the personnel manager; being interviewed by the Recruitment Council; and facilitating a 45 minute teaching examination observed by the Recruitment Council. When the results of all the stages are in, the university Rector signs another announcement informing all the successful candidates. The university then completes the procedures to send to the MoF for approval. Normally, the whole recruitment process takes about three months. This complicated recruitment process may also delay the enhancement of the faculties. As a result, one of the reasons for EFL lecturers' excessive teaching loads is the shortage of lecturers exacerbated by the long and complicated recruitment process. 
Another teacher of English from University One expressed her view about the issue of the shortage of lecturers and the pressure this puts on the current lecturers:

Every year, each teacher in my faculty teaches about 350 hours. In the morning, after taking the children to school, I come to the university to teach all day. After taking the kids home in the afternoon, I often have to teach at our university's foreign language centre in the evening. Where is time left for research? (Lan, U1, FGI)

Her comment illustrated her overloaded teaching timetable and as a result she has little time for research and English language development. This results in few opportunities to produce quality research, consistent with Anh's (2009) research which found that Vietnamese academics have little time for research. This is very different from many developed countries, where university lecturers teach fewer hours and earn a good salary (Hiep, 2006). By contrast, Vietnamese teachers are poorly paid so they have to work extra time to get additional money to support their families. Having to do extra jobs also puts constraints on the time available to do research. A lecturer from University Two also shared her desire to study new teaching methods:

We want to improve our teaching methods to help students achieve English competence. Although we teach many hours, our monthly income is just around 6,000 Vietnam Dong [NZ\$340]. Also, it is difficult for us to improve our qualifications as we do not have much free time. (Ha, U2, FGl)

Although this lecturer has a strong desire to improve her qualifications to help students to improve their command of English and therefore be more competent in their future work, the time constraints restrict her ability to do this. Besides long hours teaching, she also has home and child-caring responsibilities. This prevents EFL teachers from enhancing their professional development and research capacity. 


\subsubsection{Insufficient support from the university and the ministries}

The second challenge is about insufficient support from the university because of the ministry's regulations. Illustrating this is the response of an EFL lecturer from University Two who lamented:

We lack materials such as scholarly journals when we do research. Sometimes, I find a very interesting article about teaching English but I cannot access it as it costs $\$ 39$, for instance. I cannot seek financial support from the university to access journals as we have a limited budget for research activities. (Thu, U2, FGI)

His response indicated that it is very difficult for teachers to do research as there is little financial support from the university and the ministries. Moreover, Vietnamese lecturers are not released from their teaching to do research unlike academics from other countries in the world. Vietnamese universities, excluding Vietnam National University, Hanoi and Vietnam National University in Ho Chi Minh City, do not have enough funding to purchase copyright from international scholarly journals; academics are unable to access and download them to pursue research. As discussed in the previous chapter, the budget for professional research, granted by the State, is inadequate. In Vietnamese universities, the time for research varies between 40 and 75 hours per year. The obligatory amount of time for research depends on the teacher's seniority and the institution in which she/he works (Phuong, 2005). If a lecturer has, for example, worked for four years or less, her/his research duty is 40 hours a year. For senior teachers, it can increase to 75 hours. If a teacher does not want to conduct research projects, these 40 or 75 hours are transferred to the teaching workload, which means these teachers have to teach longer hours to compensate for research hours.

A teacher of English from University Two shared this difficulty with her colleague from University One as follows:

Attending an international conference in TESOL is a dream of ours. Sometimes, going to national conferences organised in big cities in 
Vietnam is also difficult for us because of our university's lack of funding for conference leave. (Mai, U1, FGI)

This lecturer's argument demonstrated how funding shortages obstruct her desire to attend specialised professional development conferences relating to her expertise.

There is a consensus among the EFL lecturers, from both universities, that the heavy workload of teachers hinders them from carrying out research and improving their professional knowledge. This is consistent with Phuong's (2005) study about the low quality research practices among Vietnamese teachers of English. In order to improve their research capacity and professional development, appropriate funding and support should be available.

The support from the University One and the ministries is not sufficient for academic staff to pursue masters or do doctoral education. This lack of funding is expressed by an EFL teacher from University Two:

In order to obtain reputation, prestige, quality and enhance professional proficiency of lecturers in the university, the Board of Rectors has encouraged us to do MA or PhD research domestically and internationally. However, although the ministry and the university partially support our study expenses most of it we have to pay ourselves. Therefore, many of my colleagues are not very interested in studying for higher degrees. (Dong, U2, FGI)

Her comment revealed that financial support from MoF and her university for professional development or refresher courses is inadequate. In addition, this inability to access funding may make the teaching staff reluctant to do further research to enhance their teaching careers and professionalism. The result is that EFL teachers have substandard skills even though the National Foreign Language scheme 2020 has been implemented for several years (Vietnam News Agency, 2011). 


\subsection{Individual barriers faced by EFL lecturers}

As discussed, EFL lecturers face many common barriers in their professional lives but female teachers face barriers not encountered by their male counterparts. These are illustrated by a teacher of University One who said:

As a Vietnamese woman, besides teaching at university, I also spend time taking care of my children and doing housework. This prevents me from improving my teaching methodology and professional development. (Lan, U1, FGI)

Mai cited her home caring duties as the individual barriers which hinder her pursuing professional development. These combined with her busy teaching schedule, including preparation and marking take up all of her time. Most of the EFL lecturers in this research are females and they all agree they face certain difficulties as Vietnamese women. To further substantiate this, an EFL teacher from University Two indicated:

Vietnamese female lecturers are busy with teaching. When we come home we also work hard to fulfil our duties in the house as a mother, a wife, and a housewife. We are tired by bedtime and do not have the energy or the time for our professional research. (Mua, U2, FGI)

Her comment noted her dual responsibilities: a teacher and a housewife with child-caring duties all of which fill her days. Therefore, she cannot find time to improve her teaching methods and expertise. Due to the influence and permeation of Confucian ideology in Vietnam, as discussed in the previous chapter, Vietnamese women's Confucian roles and duties within the patriarchal family are to serve her husband and his family by maintaining the house and all it entails. Another Confucian duty is child bearing (Frenier \& Mancini, 1996). Despite the above barriers, EFL lecturers collaborate in curriculum design and delivery. 


\subsection{EFL lecturers' collaboration in curriculum design and delivery}

Another theme evident from the data, which is closely linked with the previous ones, is the efforts made by teachers of English to collaborate in curriculum design and delivery.

Although my question to the teachers invited their perspectives on both curriculum design and delivery, some significant comments are about design and most teachers focused their views on curriculum delivery. This is a reflection of a lecturer from University One:

My faculty often has meetings to evaluate the English curriculum and make amendments twice a year. When we come across some issues which are not appropriate during our teaching hours, we share with colleagues and the Dean to find solutions. (Mai, U1, FGI)

Mai's response indicated that she shares her ideas and cooperates with colleagues when any problem relating to the curriculum arises in teaching. EFL lecturers not only appear to collaborate with other colleagues in the English faculty but also with colleagues from other faculties and departments. This is illustrated by an English language teacher from University Two who shared her viewpoint on collaboration in curriculum design:

Collaboration in the university plays a very crucial role. Teachers in my department meet every semester to discuss the content of the curriculum. After obtaining a consensus, it is submitted to the university's Scientific Council for assessment and critique. Lastly, the university Rector, chairman of the curriculum meeting, will finalise what is to be taught. (Xuan, U2, FGI)

Xuan's comment explains what she believes about revising and collaboratively approving the content of the curriculum. Xuan's response illustrated the way she works in collaboration with her colleagues. She also mentioned the procedure in which the content of the curriculum is revised and approved. 


\subsection{Senior leaders' roles in curriculum design and delivery}

Another theme relates to the role of senior leaders in curriculum design and delivery. Senior leaders have the final say in curriculum design and delivery. An illustration of this is seen in the response of a teacher from University One, who said:

As you know, the Boards of Rectors, led by the Rector, decides and approves the curriculum. They have crucial role in curriculum issues. (Hoa, U1, FGI)

Hoa's reply revealed the decisive role of the leadership team at her university in curriculum design and delivery. Similarly an EFL lecturer from University Two commented:

The roles of the leadership team in the university, especially the Dean, and Vice-Dean of the Foreign Languages Faculty, are very important because they are the ones who determine the teaching content appropriate for the students' level of proficiency in the university. (Ha, U2, FGI)

Ha's response recognised the importance of the roles of senior academic leaders in curriculum design and delivery. Despite the leadership teams' established decision making roles, EFL lecturers had some suggestions to senior leaders at both universities about better curriculum design, improving the universities' training products and their facilities and these will be discussed in the next section.

\subsection{EFL lecturers' recommendations to the leadership teams and the ministries}

The last theme emerging from the focus group interviews with English language teachers concerns the suggestions they wish to send to the leadership teams at the two universities and their ministries. Some of the suggestions are about updating teaching facilities, redesigning the Basic English curriculum to teach as a skill subject and making more funding available for teachers' professional development, research and attending 
conferences and seminars. An example of these can be seen in the response of an English language teacher from University One who commented:

The leadership role of university leaders is very important in curriculum issues because it determines the teaching content and aligns it with students' proficiency levels. Moreover, the university should pay more attention to investing and upgrading teaching materials and facilities. (Lan, U1, FGI)

Lan's recommendations stressed the importance of the role of senior leaders in participating in curriculum issues. Further, she implied that the inadequacy of teaching facilities and resources resulted in poor quality teaching. Therefore, further investment in extending the campus, equipping new teaching materials and revising teaching materials should be a priority.

Another teacher from University One emphasised the importance of teaching English as a skill subject when proposing suggestions to the superior leaders:

Teaching English should be regarded as a skill subject. However, due to the curriculum framework stipulated by MoET, we actually teach reading and writing and hardly have time for speaking and listening. The university should accordingly invest in teaching resources, facilities and equipment to enable us to help students develop speaking and listening skills. (Hoa, U1, FGI)

Hoa's comment demonstrated that English is still taught at tertiary level as a compulsory subject whereas it should be an optional subject, with emphasis on speaking and listening. Her argument seemed to imply that the curriculum is still heavily biased towards writing and reading, consequently, more time for speaking and listening is necessary to help students develop their communicative competence.

An EFL teacher from University Two pointed out the need for more resources and collaboration with other universities. 
Firstly, we should reduce the number of students in an English class to 20. Secondly, the library should be well-equipped with a variety of English books to serve the English teaching and learning needs. And thirdly, universities which have foreign language faculties should organise cooperative activities with national and international universities and educational organisations to facilitate teachers' opportunities to exchange expertise and improve their teaching methodology. (Dong, U2, FGl)

Dong's reply indicated teachers and students are short of reference materials for enhancing their English knowledge. She also pointed out that English language teachers do not have many opportunities to access forums to learn and share expertise with domestic and international colleagues and experts in their majors. This inability to enhance and develop their professional knowledge prevents them from providing better quality education.

The EFL lecturers, from the two selected universities in this research, propose that the leadership teams and ministries give the suggestions offered above immediate attention to improve the quality of training so that Vietnamese universities can compete with other universities in the world in the near future.

\subsection{Chapter summary}

This chapter summarises the key themes which emerged from the interview data with EFL lecturers at the two selected universities in this research study. The first section discussed the teachers' difficulties when teaching large classes with students of different English competence. Section 2 pointed out the challenges facing EFL lecturers from both universities because of the shortage of time with which to upgrade their qualifications and do research; section 3 dealt with Individual barriers faced by EFL lecturers. Section 4 discussed the endeavours to overcome challenges to collaboration in curriculum design and delivery and the last section addressed their suggestions to be put to the leadership teams in terms of curriculum design and delivery. 
The findings from this chapter help explain the challenges EFL lecturers face when they execute their roles in terms of curriculum design and delivery. In general, the findings aligned with those of previous research in the area. Nevertheless, there were several findings that made additional contributions in such areas as collaborative leadership and the suggestions made to the leadership teams at the two universities.

The leadership teams claim to have listened to the perspectives of EFL lecturers regarding the effectiveness of the Basic English curriculum and indeed acknowledge their substance as they are aware of many of their graduates being either ineffectual at work or unable to gain employment because of their poor English. They are however unable to implement changes because of the lack of autonomy and funding as cited earlier. The views of the company directors and graduates about the effectiveness of the Basic English curriculum design and delivery are noted and discussed in the following chapter. 


\section{Chapter 6: EMPLOYERS' AND GRADUATES' PERSPECTIVES OF THE BASIC ENGLISH CURRICULUM}

\subsection{Chapter overview}

This chapter discusses the findings of the data collected from the semistructured interviews with employers and surveys of graduates and discusses these with reference to relevant literature in order to answer a particular aspect posed by one of the research questions in this study:

- What perspectives do stakeholders have about the effectiveness of the Basic English curriculum at the two selected universities?

The views and perspectives of company directors, who recruit graduate students from the two selected universities, will be reported in this chapter. As mentioned earlier in table 3.5, different Vietnamese names for addressing wealth and prosperity were used in order to conceal the participants' identities in the sections and sub-sections which follow.

The data is presented according to the issues emerged from the individual interviews with company directors. Section 1 discusses barriers faced by new employees according to their employers in the workplace. Section 2 explores skills which employers believe new employees need to develop; Section 3 deals with additional professional development offered to new employees by their companies, and the last section addresses the recommendations they wish to send to curriculum designers and leaders at both universities. The graduates' perspectives will be discussed later in this chapter.

\subsection{Employers' perspectives}

In this section, the data gained from interviews with company directors are presented. The semi-structured interviews reveal a number of barriers facing new employees in the workplace as well as the professional development offered by their companies. The following section will explore new employees' low competencies in the English language and their lack of soft skills in the workplace. 


\subsubsection{Barriers faced by new employees in the workplace}

\section{Weak English language competence}

This section reports on the employees' perspectives of the level of English language skills of new workers. Company directors expressed their concerns about new employees' English proficiency and communicative skills at work. An example of this is seen in a comment of a company director who recruited graduate students from University One:

Some of the new employees can speak English but many of them have only a limited ability speaking and listening in English. Because of this they are often shy when they communicate with Englishspeaking clients. However, their reading and writing skills are generally good. (Thanh, CD interview)

Thanh's comment revealed that new workers' English communicative skills are poor. In this employer's experience, new employees lack confidence when they speak to customers in English. This may hinder the quality of their work and the development of the company's long term relationships with its customers. If new staff are unable to work effectively with customers, they may be in danger of losing their jobs.

Similarly, a company director who employs graduates from University Two commented on the new students' poor English skills:

My new staff are not good at speaking English. I think, because they lack practice. Therefore, HEls should innovate their teaching methods instead of continuing the old-fashioned method of teaching grammar, vocabulary and translation. (Quy, CD interview)

Quy's commented highlights his complaint that oral skills are not paid much attention to; he also suggested HEls change their traditional way of teaching English. This might reflect dissatisfaction with the Basic English curriculum due to the English curriculum at tertiary level is still heavily focused on grammar, reading and writing rather than oral communication. 


\section{Lack of soft skills}

Company directors also complained about new workers' lack of soft skills. An illustration of this shortage is seen in the response of a company director who said:

New employees are also not good at soft skills and team work. Oh, every year, my company reserves part of our revenue to assist employees with extra professional training. (Thanh, $C D$ interview)

Thanh lamented the barriers new employees faced in the workplace. The necessary skills they learned from their university studies seemed insufficient and therefore they were ineffective at work. She also complained about her company invested money for training new staff to meet the skills required in the work environment.

Likewise, a company director who recruits graduate students from University Two revealed the low quality of new staff:

Some of the new employees do not know how to communicate with their colleagues. They look shy and lack of confidence when presenting their idea or taking to their managers so they need to be given extra training (Cong, $C D$ interview)

Cong's comment indicated that new employees are weak in presenting their ideas and communicating in the workplace. Accordingly, they need to spend time taking extra courses to have better conversations within the work environment.

\subsubsection{Encouragement in improving language skills and professional development offered by companies}

In order to encourage and help new employees to overcome the barriers they faced in the workplace, many companies often encourage them to improve their English language skills and give them financial and time assistance so that they can attend professional training courses. 


\section{Encouragement to improve their English language skills}

The data from the semi-structured interviews also shows the encouragement for new employees to improve their English language skills. This is seen in the response of another company director who has employed new graduates from University One:

I think they need to spend time practising speaking and listening. They should try to take advantage of every opportunity to speak English with foreigners to enhance their English proficiency. (Giau, $C D$ interview)

The data confirms that new employees are weak at speaking and listening in English. Because of this they are encouraged, by their employers, to invest time improving their verbal communication skills in English. Giau also advised his new employees to seek opportunities to practice speaking and listening with English-speaking people such as foreign business partners.

Another company director who has hired graduates from University Two shared this viewpoint:

Many students with Bachelor degrees have very poor English skills. They fail to understand what customers mean when they talk to them so they need to improve their verbal skills to meet the needs of the workplace. (Phu, CD interview)

In the above comment, Phu emphasised that new employees' poor listening and speaking in English skills result in misunderstandings with customers. As a result, new workers are encouraged to spend time and effort enhancing their communicative skills so they can respond effectively to the requirements of the workplace.

\section{Professional development offered by companies}

In order to encourage and support new employees to overcome the barriers they faced in the workplace, some companies have offered financial support and time to attend professional training courses. An example of helping new applicants in the workplace is seen in the response of a company director: 
My business annually provides financial assistance and time so that new staff can attend intensive English speaking courses and improve communicative skills. However, the new must try their best to improve themselves. (Quy, CD interview)

Quy's reply indicated that favourable support from the company is very helpful for new employees looking to improve necessary skills and thus quickly adapt to the work environment. Nevertheless, Quy also recommended the employees should be aware of their own professional development.

Supporting the idea of assisting new employees, a female director who hires graduates from University One commented that:

Vietnam will be joining the ASEAN Economic Community at the end of 2015 therefore money should be invested in new workers' education, such as learning which help them to acquire international English certificates. They will then help the company to promote trade with foreign business partners. (Thanh, $C D$ interview)

Her reply showed that giving supportive conditions for new employees will also be beneficial to the company's reputation and in promoting its business with other countries in the world. Moreover, company directions also expressed their suggestions to be put to university leaders and curriculum designers to revamp the curriculum to align with their companies' needs. These suggestions by employers will be addressed in detail in the discussion chapter.

The following section will address the graduates' perspectives on the effectiveness of the Basic English curriculum design and delivery.

\subsection{Graduates' perspectives}

This section discusses the findings from the online survey (OS) completed by graduates from the two selected universities. Not all questions from the OS are discussed in this section. However, the qualitative comments from the 
online questionnaires have been included as these provide insights into graduates' perceptions of the Basic English curriculum.

The responses show the students mostly agreed that the Basic English curriculum is effective, however many also offered constructive comments which will be discussed later. In particular, these include the recommendations offered by graduates to university leaders, curriculum developers and lecturers about redesigning curriculum to accommodate more communicative skills learning.

The first section discusses graduates' perspectives on the relevance of the Basic English curriculum to new graduates at work. The second section explores graduates' perspectives on the flexibility within the Basic English curriculum to facilitate student learning. Next, graduates' perspectives on the allocation of the credit hours for English instruction between theory and practice respectively at the two universities are explained. Following this is graduates' perspectives on their lecturers' teaching and the different forms of assessment. Graduates' perspectives on the challenges faced by new employees when they communicate with their senior colleagues and work supervisors are then presented, and the final section addresses graduates' perspectives on English speaking clients' misunderstandings because of their own low levels of English. The OS data revealed a number of barriers facing graduates as new employees. In this section, new employees' low competence in the English language and their need for the curriculum to include more practice in listening and speaking are discussed.

\subsubsection{Graduates' perspectives on the relevance of the Basic English curriculum at work}

As seen in figure 6.1 below, $17 \%$ of the graduates strongly agreed that the content of the Basic English curriculum is relevant to their work environment and $80 \%$ agreed with this. In contrast, $2 \%$ thought the content was not relevant and $1 \%$ did not offer an opinion. 


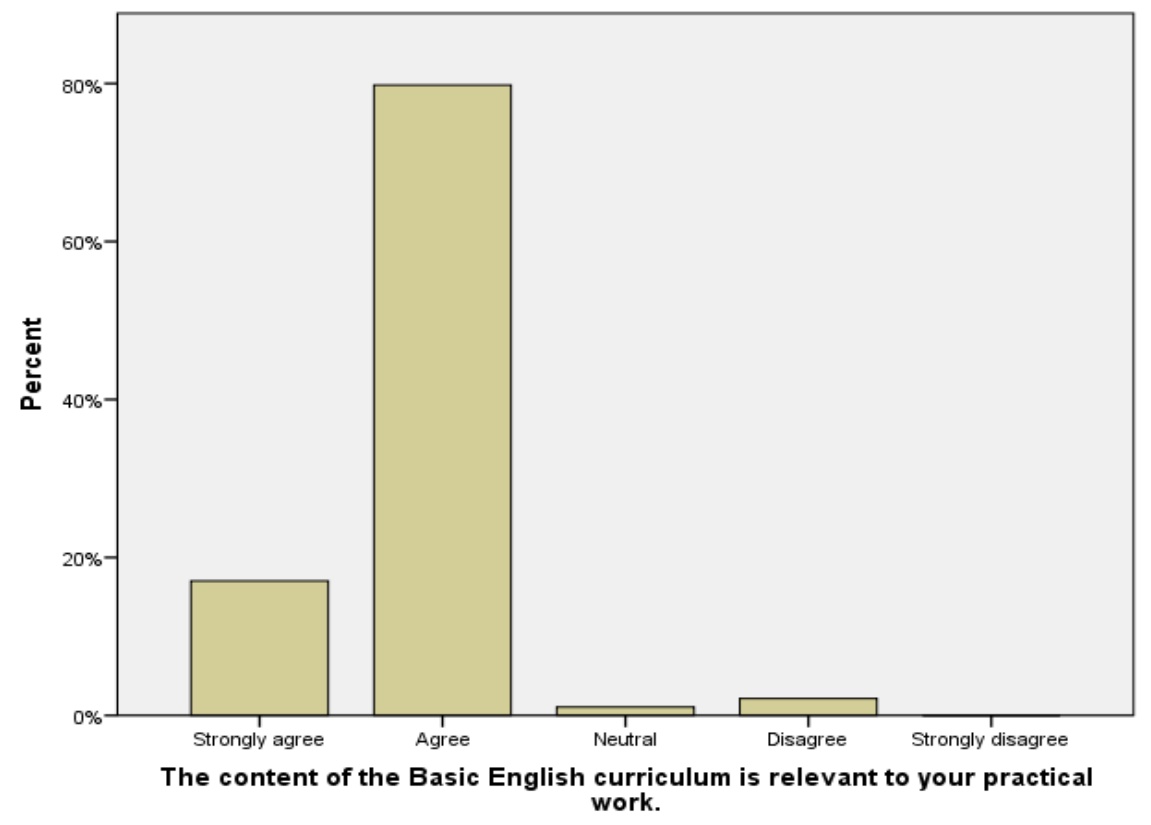

Figure 6.1: Relevance of the Basic English curriculum to practical work

However, the numbers which recorded 'strongly agree' and 'agree' may not accurately reflect the respondents' true opinions. This is because politeness is inherent in Vietnamese culture and consequently the participants may have felt compelled to answer as they did. Because the cultural context may have influenced the data, the comments could be more relevant than the percentages reported here. This feature may also be evident in this section and subsequent findings. The high level of agreement, as mentioned above is a reflection of an aspect of politeness in Vietnamese culture where the graduates wanted to express their politeness and respect to their lecturers (Long, 2013; Thang, 2013). This politeness may explain the disparity between the quantitative percentage and the strong qualitative comments as is seen in the feedback from two graduates from University One and one from University Two.

The two graduates from University One stated unambiguously:

The content of the curriculum needs to increase the periods of listening and speaking so graduates like me can apply what I learned when communicating at work. 
I don't think it is really practical for my work.

These perspectives indicate that the content is not balanced in terms of dividing the hours for each language skill, especially the lack of speaking drills for students to apply in workplace situations.

A graduate from University Two suggested applying authentic situations in the workplace in the curriculum:

I think it is necessary to embed a variety of real workplace situations in the lessons so students can see the relevance.

These graduates' comments indicated they would like more speaking and listening practice so they can communicate effectively in the workplace. This finding is supported by Huyen (2012) who found that new employees are not good at English communication skills. Therefore, a significant number of companies need to retrain new employees (Vietnam News Agency, 2013).

\subsubsection{Graduates' perspectives on the flexibility of the structure of Basic English curriculum}

As shown in figure 6.2 below, $12 \%$ of the graduates surveyed strongly agreed that the structure of the Basic English curriculum (in terms of listening, speaking, reading and writing) is sufficiently flexible to facilitate learning. Only $2 \%$ disagreed while $10 \%$ were hesitant and did not voice their opinions. Flexibility here can be understood as teachers combining aspects of the curriculum in their teaching periods, for example reading and writing, listening and speaking, speaking and writing, etc. The majority of the students (76 \%) expressed agreement about the flexibility of the structure of the Basic English curriculum and they also offered opinions relating to teachers facilitating more speaking and listening practice. 


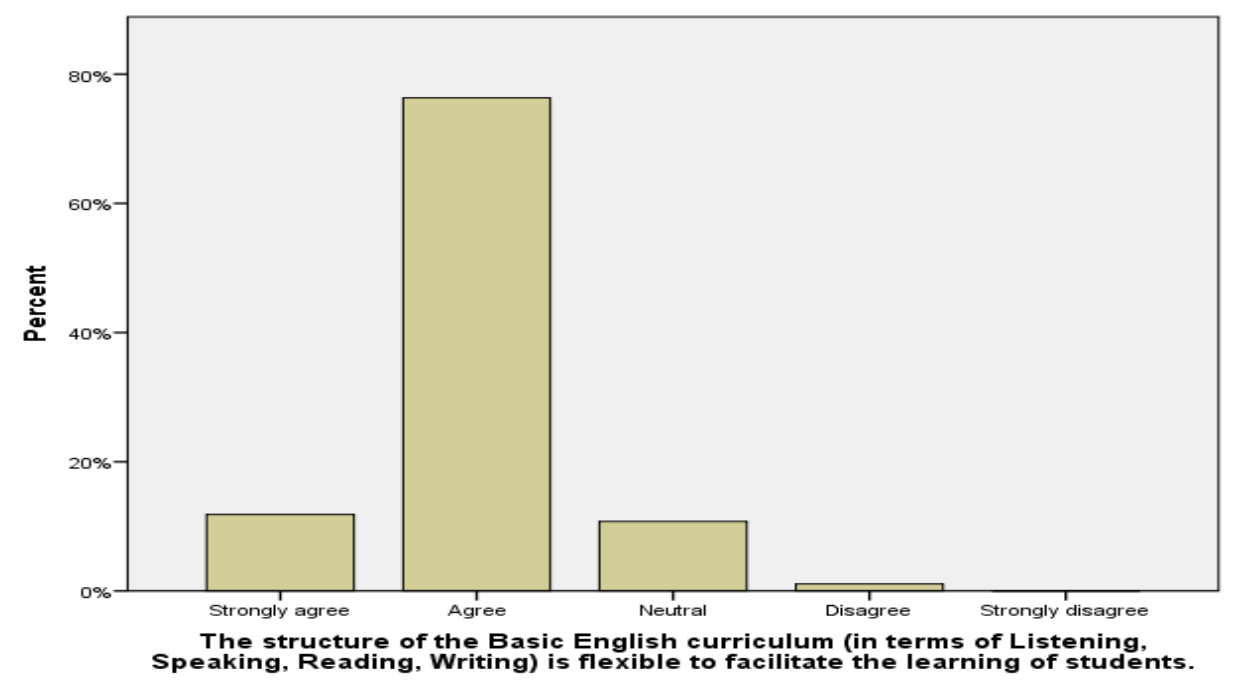

Figure 6.2: Flexibility of the structure of the Basic English curriculum

Their comments revealed that the curriculum still focuses on reading and writing while less attention is given to the other two communicative skills. As one graduate reflected:

The curriculum focuses on vocabulary, grammar, and writing while graduate need more oral skill in the workplace.

This comment indicates that the prominence given in the universities to the Basic English curriculum does not have an appropriate focus according to graduates. Perhaps the reason for this is that when they start work grammar is of less importance to them than speaking and listening and more practice in these skills would be of far greater value. Their lack of confidence is also reflected in the graduates not taking all the opportunities to talk with English speakers, including outside work. This finding correlates with Tuyet (2013b), who posited that students are too shy to speak to English speaking people when they have a chance to communicate.

\subsubsection{Graduates' perspectives on the appropriateness of time allocation}

Figure 6.3 shows 29 percent of graduates disagreed with the allocation of the credit hours between theory and practice. They consider the time allocation is inappropriate, $4 \%$ indicated their strong disagreement and $20 \%$ did not respond. Conversely, $17 \%$ of the students showed their strong agreement 
about the appropriateness of the credit hours between theory and practice and $30 \%$ agreed the allocation is appropriate. The percentage of graduates who agreed is similar to those who disagreed. In this context, theory means grammar and vocabulary and practice refers to speaking and listening.

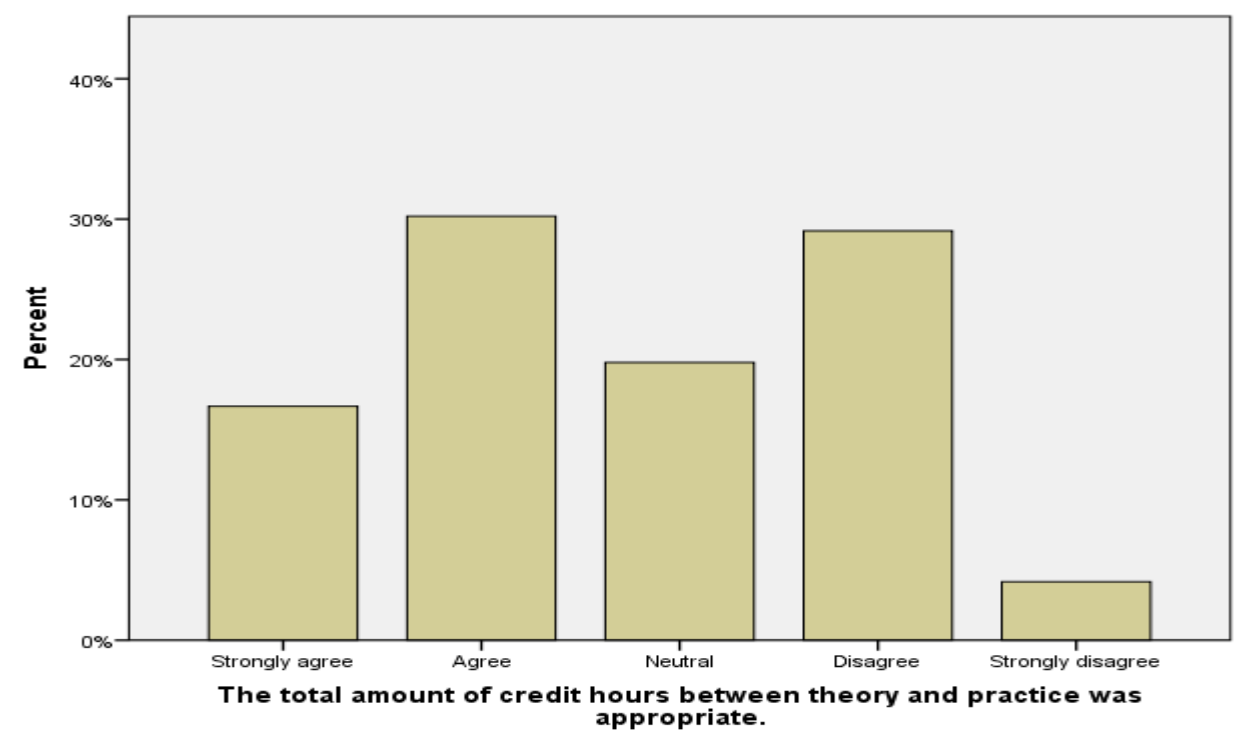

\section{Figure 6.3: Appropriateness of time allocated to theory/practice}

Graduate students expressed their views on the excessive theoretical content of the Basic English curriculum, saying fewer hours should be spent in this area as their priority is listening and speaking:

Practice should be given more prominence.

There are too many theoretical hours. Students need more oral drills. I think the curriculum is illogical because there are only a few practical hours.

From their comments, it can be seen that the graduates perceive that the Basic English curriculum at both universities is not balanced because the emphasis is on theory with only a few practice hours. In reference to this, they offered many constructive comments about the ineffectiveness of the curriculum as well as their legitimate aspiration of having more practice in listening and speaking English because of their need to communicate effectively in the work environment. Therefore, changes to the Basic English 
curriculum suggested by students are, one, that "The amount of listening hours should be increased and the amount of grammar should be reduced.", and two, that "More oral work situations should be included in the curriculum. Theory dominates."

\subsubsection{Graduates' perspectives on lecturers' teaching and assessment}

As shown in figure $6.4,27 \%$ of the students expressed their strong approval of their lecturers' teaching and different forms of assessment. 64\% were satisfied with their lecturers' teaching as opposed to the $3 \%$ who recorded their dissatisfaction, while none expressed their dissatisfaction strongly.

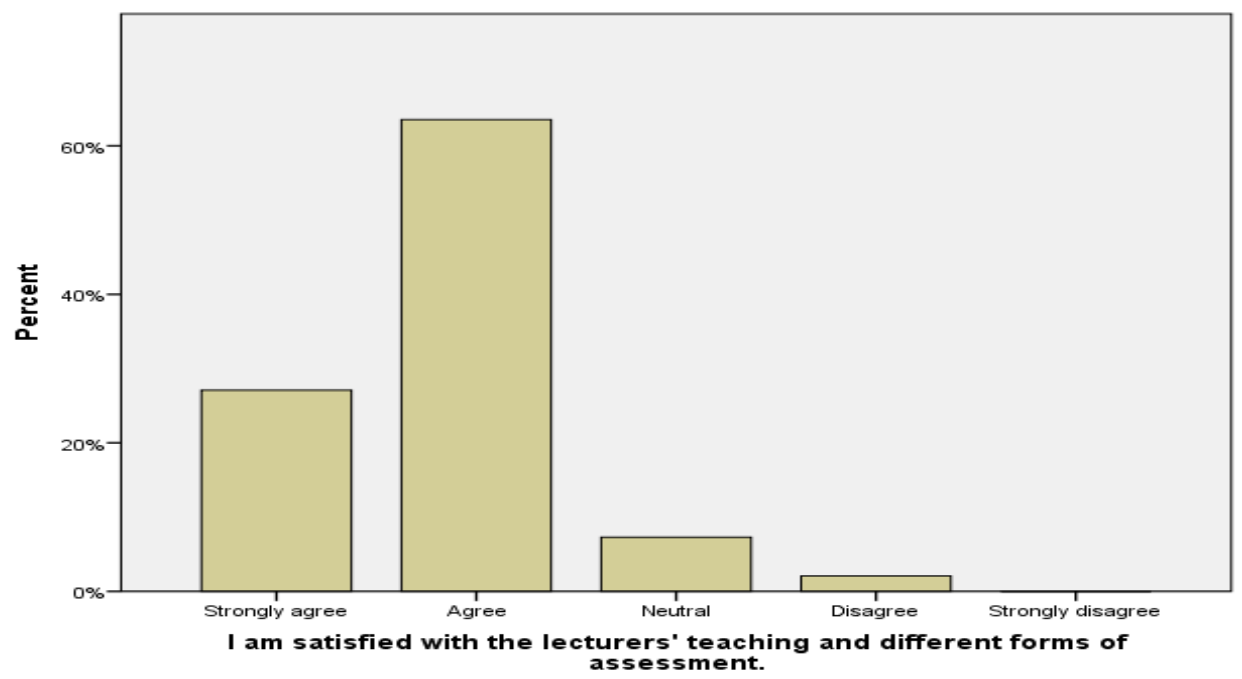

\section{Figure 6.4: Graduates' satisfaction with the lecturers' teaching and} assessment

Generally, the majority of the graduates indicated that they were pleased with their lecturers' teaching and assessments. The positive results here clearly outweigh the negative. As discussed, these positive results may refer more to the lecturers than the assessment results. A comment from one participant reflects this:

My teachers were very helpful.

Others however, included their dissatisfaction about the theoretical assessments: 
The teachers are very enthusiastic and kind but the content is heavy in theory so the assessment is also heavy in theory.

We are often assessed in written tests.

The comments from graduates revealed that they focus on theory and writing to pass the written tests while their oral communication skills will fade in the course of time even though they have four skills in the curriculum.

\subsubsection{Graduates' perspectives on difficulties in working with senior colleagues}

As seen in figure $6.5,11 \%$ of the students strongly agreed they face challenges communicating with their senior co-workers and work supervisors in English, $60 \%$ agreed and only $9 \%$ felt confident in this area.

One of the students expressed the reasons for his lack of confidence when speaking English:

I am often shy when I communicate in English because I am usually afraid of making mistakes.

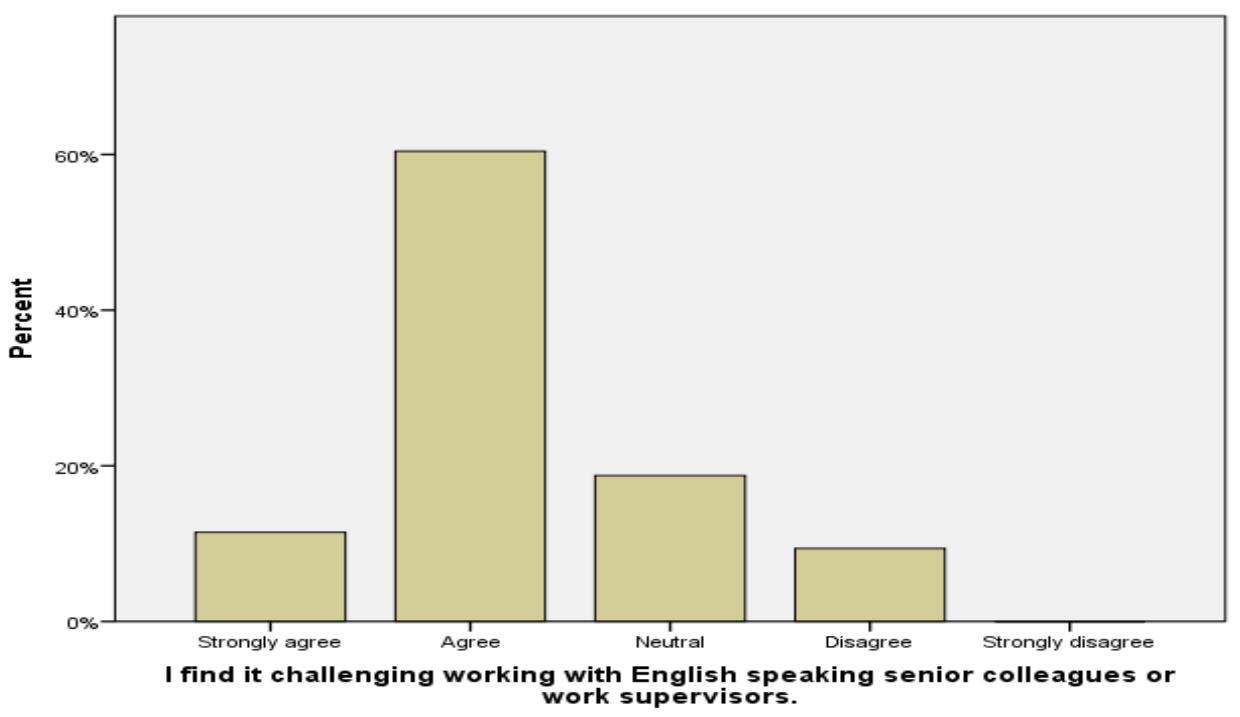

Figure 6.5: Challenges involved in working with senior colleagues 
Other reasons explained their lack of confidence as follows:

Many of my senior colleagues are very good at speaking English therefore I am not self-confident to communicate with them.

Some of my co-workers speak English like native speakers.

Students also made recommendations for the university. The first is to the university leaders suggesting they re-apportion the hours to allow more practice for English language instruction. To the curriculum developers they proposed the curriculum should be redesigned to accommodate more communicative skills. Further, they recommended the inclusion of oral assessments in examinations. These changes would help them to develop the English language competence needed in their workplaces.

\subsubsection{Graduates' perspectives on their communication difficulties}

As shown in figure 6.6 , the majority, $59 \%$ of graduates reported that their poor English skills often led to misunderstandings with their customers, while $9 \%$ strongly disagreed and $7 \%$ disagreed. As with most learners of a foreign language, the graduates may feel embarrassed because of their low English language competence. Furthermore, it is likely that the reasonably high neutral percentage could be another example of Vietnamese politeness and respect given to teachers.

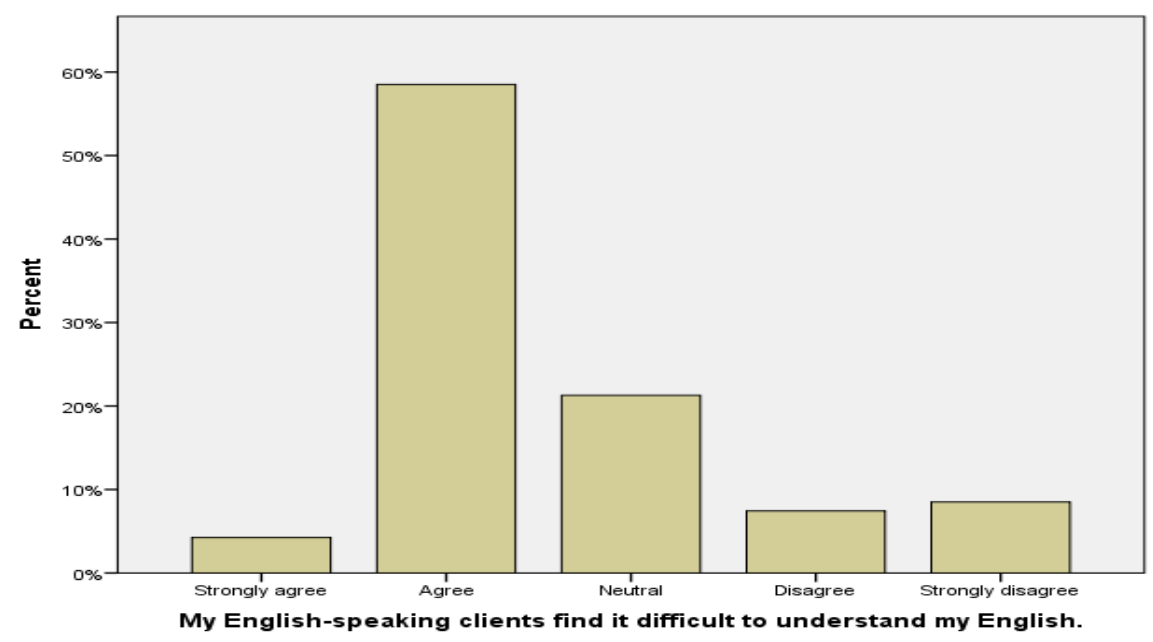

Figure 6.6: Graduates' difficulties in communicating with customers 
Some of the graduates made comments about their low English communicative skills when communicating with a variety of clients at work:

Some of my customers often speak English very fast like singing.

Their replies indicated that the speed and the variety of accents of Englishspeaking customers challenged them. Other graduates mentioned their difficulties in communicating with a variety of customers at work: "Customers who know English speak very fast so I find it difficult to understand what they mean." It could therefore be assumed that more practical lessons and being exposed to different accents would probably be of considerable assistance to them.

\subsection{Employers' and graduates' perspectives on the effectiveness of the Basic English curriculum}

In this section, the views of employers and graduates on the effectiveness of the Basic English curriculum design and delivery at the two universities are discussed.

The employers interviewed in this study as well as the respondents to the online survey of graduates seemed to agree on the challenges faced by new employees and on the reasons for these challenges. One of the reasons suggested is their lack of English language skills. The findings show graduates fail to communicate with their co-workers and supervisors in the workplace in English. Graduates' poor English skills were commented on by Dat, a company director employing graduates from University One who commented that new employees' English skills do not meet the company's needs because "they learned only grammar and reading at university. Their listening and speaking skills are not good so it is difficult for them to adapt quickly to their new jobs." Dat's statement implied he lamented the traditional strategies of teaching English reading and grammar at universities.

The heavy reliance on a traditional methodology for teaching English is largely due to the English curriculum at tertiary level focusing heavily on grammar, reading and writing rather than oral communication. Furthermore, 
the semester examinations at many universities and colleges in Vietnam nowadays are also written rather than oral tests (Toan, 2013). The curricula at HEls in Vietnam are still heavily focused on theory with a lack verbal communicative practice which is consistent with Canh and Barnard's (2009) study which revealed shortcomings in the English curriculum in Vietnam's education system. As a result, HEls are criticised for not producing quality graduates. This is also recognised by what Vu Duc Dam, Deputy Prime Minister, confirmed when he answered a Dantri reporter's question about the training quality in Vietnamese higher education system (Hung, 2013). Vu replied saying the Vietnamese higher education system has some weaknesses. He also added that according to a report he received, about 30 per cent of universities and junior college graduates cannot find employment. It could be extrapolated from this that the training quality in Vietnam's higher education institutions is unsatisfactory.

Another concern mentioned by employers is that they believe the new graduates have only superficial knowledge of their majors namely Finance, Banking and Accounting and also skills such as basic communication and oral presentation skills. Sang, a company director who hires graduate students from University Two reflected that "many graduate students, in my company, seem to be new in the work surroundings. They do not know how to work in groups and lack communication skills. Some of them do not even know how to talk to their managers". Sang's comment indicated that even though new employees have the professional knowledge, they are unable to apply it in the world of work.

Sang's comment revealed that his new office workers do not appear to understand work place verbal communication. As discussed earlier, there could be many reasons why graduates are not confident to communicate including a number of additional cultural reasons. In Vietnamese culture respect is shown to teachers and older people by not asking questions, offering differing points of view and/or participating in conversation unless asked (Long, 2013). Sang's reply reflected this when he indicated that graduates failed to have good conversations within the workplace. Poor soft 
skills were also commented by Masaki Yamashita, chairman of the Japan Business Association in Vietnam, when he spoke at a conference in October, 2012 in Ho Chi Minh City (Tuoitre, 2012). He stated that few new staff members know how to communicate with their line managers. He further added that graduates are well- equipped with academic knowledge but they fail to apply it to real situations. In addition to failing to apply the knowledge they learnt at university, Tran Thanh Liem, another conference participant from the Ho Chi Minh City branch of the state-owned power company Vietnam Electricity, complained that university graduates cannot work in groups but added they performed very well on individual assignments. Moreover, he commented when questioned by the Tuoitre reporter that, in his opinion, they have poor personal presentation and English speaking skills (Tuoitre, 2012).

Overall, in the employers' view, limited professional knowledge, English language and soft skills are three key challenges graduates face. In addition, graduates offered additional views on the challenges they face in communicating at work.

Graduates mentioned their difficulties in communicating with a variety of customers at work. For example, English-speaking customers speak very fast, thus, some graduates find it difficult to understand what their customers mean. Moreover, another graduate confessed: "Other customers speak with a variety of accents so we cannot catch their voices." As with most learners of a foreign language the graduates may feel ashamed of their low English language competence. The reason for their communicative challenges with clients may be because they have not invested enough time practising pronunciation, listening and speaking. One result of this is they are unfamiliar with the variety of accents of native English speakers and others with English as a second language.

In brief, this section discussed the key issues which emerged from the employees' perspectives on graduates' barriers in the workplace and 
graduates themselves also voiced similar comments to the employers about the challenges they face when dealing with customers.

\subsection{Chapter summary}

This chapter presented the key issues which emerged from the company directors' perspectives and the responses of graduates from both universities to the online questionnaires. The comments from company directors largely agree with the thoughts expressed by the graduates surveyed on the Basic English curriculum. These comments made by company directors may also be of concern for university leaders and curriculum developers, perhaps enough to motivate them overhauling their curriculum generally, including the Basic English curriculum. In turn this may help them to provide students with in-depth professional knowledge and English language skills, thus increasing the opportunities of their university-leavers finding jobs aligned to their majors. Further, graduates expressed their views on the excessive theoretical content of the Basic English curriculum, saying fewer hours should be spent in this area as their priority is listening and speaking. To this end, they emphasised practice in listening and speaking, in typical work situations, and also suggested that hours for this practice should be doubled.

The next chapter will discuss the leadership of the Basic English curriculum design and delivery. 



\section{Chapter 7: THE IMPACT OF LEADERSHIP ON THE EFFECTIVENESS OF THE BASIC ENGLISH CURRICULUM}

\subsection{Chapter overview}

The perspectives of different participants on the effectiveness of the Basic English curriculum were presented in chapters four, five and six and significant themes emerging from each research question were identified. The impact of leadership on the effectiveness of the Basic English curriculum will be discussed in this chapter and a synthesis of the views of employers and graduates discussed at the end of chapter 6 will be incorporated here to give recommendations for leaders. This chapter provides a detailed discussion and analysis of both dual and collaborative leadership within the two universities. As senior leaders and EFL lecturers are involved in leadership practices at different levels. it is necessary to look at how they collaborate to lead curriculum design. The findings will be discussed in relation to previous studies in the area of curriculum leadership, with special attention to those investigating curriculum design. Each of the following sections addresses one of the research questions investigated in this study and analyses the different perspectives of senior leaders, and EFL lecturers. The aim of this discussion is to bring together the findings from the research and the literature in addressing the research questions and outlining how this research study can contribute to the effectiveness of leadership of the Basic English curriculum design and delivery.

\subsection{Impact of Dual leadership}

This section addresses the first and second research questions, which are:

- Which different levels of leaders are involved in the Basic English curriculum design and delivery?

- What are the barriers affecting the leadership roles of academic leaders? 
The perspectives of all senior academic leaders, including Rectors, ViceRectors, Managers, Deputy-Managers, Deans and Vice-Deans of some related departments and the views of EFL lecturers involved in curriculum design and delivery from both universities will be discussed in this section. The study has found there are different levels of leaders involved in the Basic English curriculum design and delivery. These are the senior leaders and EFL lecturers and although their responsibilities differ they have similar viewpoints in some areas. Therefore, senior leaders and EFL lecturers practise leadership at their levels. In general, the data from senior leaders and EFL lecturers reveal that they participate in the process of designing and delivery the curriculum. The senior leaders are responsible at the macro-level and the EFL lecturers at the micro-level. However, the findings show that senior leaders are the ones who finalise and approve what is taught.

A significant divergence in the roles of the different participants is evident from the findings. These differences impact on what actually happens in the design and delivery of the Basic English curriculum. Specifically, senior leaders and EFL lecturers identified three distinct barriers which limit their involvement: organisational, staff capability, and personal barriers. The following section explores the organisational barriers which hinder the leaders. The staff capability and personal barriers will be addressed later in the chapter.

\subsubsection{Dual leadership and the resulting lack of autonomy}

Being under the control of both MoET and MoF puts the two universities in this study under dual leadership, and therefore, they lack autonomy. This is consistent with the findings of Anh (2014) whose research showed unclear role division between ministries and universities. In Cambodia and Vietnam, the governance of the higher education sector is shared among several line ministries due to the formerly strong influence of centrally planned systems in HE (Varghese \& Martin, 2014). Furthermore, dual leadership has resulted in a range of issues for universities to manage. The staff from the two universities found discrepancies in, and unclear regulations from, both 
ministries which hinder the university leaders from exercising power and responsibility.

However, the challenges of the academic leaders are different from those of the EFL lecturers mentioned at the beginning of this chapter. One barrier faced by the leadership team from University One, resulting from the dual leadership, is illustrated by a senior leader's comment that because of the distance of University One from Hanoi, many policies take excessive time to reach the university and be implemented.

This response indicates this leader is frustrated as he finds himself in a dilemma due to the dual leadership from the ministries and the ambiguity in laws and legal procedures regarding education. This frustration is further exacerbated by the many laws which affect education. These include the Law of Education, the Law of Budgeting, the Law of Government officials and the Law of Auditing, all of which contribute to the complex law system related to university autonomy (London, 2011). Although the Law of Education 2005 clearly defines concepts of autonomy, quality assurance, university governance and increased university autonomy, in practice autonomy is limited.

Limited institutional autonomy is the second cause of frustration for senior university leaders from the two universities. This lack of autonomy is in line with findings from Hayden (2012) who posited a nine-point plan of reform to help develop a globally integrated higher education system in Vietnam. His work revealed that public Vietnamese universities are generally unable to make their own decisions because MoET is responsible for promulgating regulations and legal documents for the higher education sector. Other line ministries duplicate this role. This duplication is also aggravated by the lack of consultation between the ministries which has resulted in ineffective management in Vietnamese universities. In contrast, Estermann and Nokkala (2009) point out significant differences in Europeans universities. They discuss the four dimensions of autonomy (organisational, financial, staffing and academic) on which European universities base their decisions to ensure 
their success. In comparison Vietnam's public universities rank poorly in terms of institutional autonomy (Hayden, 2012).

The restriction of institutional autonomy creates difficulties for the leaders in effectively implementing their responsibilities. With regard to this the Government developed the Resolution on Innovation in Higher Education 2010-2012 which suggests it is aware of the universities' dilemmas. This resolution advocated increasing autonomy and investment in infrastructure for higher education. Moreover, the Government also promulgated a resolution ${ }^{1}$ on fundamental and comprehensive renovation of Vietnam higher education for 2006-2020 (the HERA) as discussed earlier in chapter One.

Even though, the higher education law came into effect in January 2013, there has been considerable controversy about university autonomy as it is a pressing issue in higher education reform in Vietnam, as discussed earlier. This is evident in the comments of the senior leaders in this study who state that they 'lack autonomy at institutional level'. These views are supported by Vu Thi Phuong Anh, a member of the Association of Non-public Universities and a well-known expert on education management who stated that autonomy issues are not described fully in the new law to assist institutions to proactively run their operations on academic affairs as well as research and development activities (Anh, 2014). This corroborates the findings of previous work in addressing the governance reform in Vietnamese higher education (Hayden \& Thiep, 2007, Thinh \& Phuong, 2010; Varghese, 2009). Moreover, Varghese and Martin (2014) suggest that decentralisation can allow public universities more autonomy to achieve higher quality, relevance and access via Decree October 2002. In fact, the Vietnamese government has meant that the Decree October 2002 had already given public universities considerable financial autonomy to manage their own revenue and seek alternative revenue sources (See section 1.2). However, in reality, as mentioned by the senior leaders, the dual leadership means they do not have real autonomy.

\footnotetext{
${ }^{1}$ Resolution N0 14/2005/NQ-CP, dated 2 November 2005
} 
As mentioned earlier, the HERA proposes the elimination of line-ministry control and the development of a mechanism by which the ownership is moved from the State to the institution itself. This management strategy correlates with the findings of Gropello et al. (2008) who argue that this form of governance constrains Vietnamese higher education institutions. In contrast, many countries in the world, notably European countries, operate under governance structures and leadership which are strongly shaped by national legislative frameworks (Estermann \& Nokkala, 2009). However, the organisational and financial autonomy of European countries vary depending on the degree of high, medium high, medium low or low autonomous cluster to which each European country belongs (Estermann, Nokkala, \& Steinel, 2011).

As discussed in section 1.2, Vietnamese HEls are placed under numerous line ministries as well as central and decentralised government structures. Therefore, in terms of decentralised governance, Vietnam experiences a lack of coordination between national and regional levels regarding regulations for financial management (Varghese \& Martin, 2014). In further contrast, universities in the USA and the UK are given funding by their governments with more freedom to spend it as there is accountability. Although reforms in the Higher Educational Law 2012 in Vietnam imply that the autonomy has moved from the ministries to the institutions, in reality this is not the case. As reported in the findings, the Vice-Rector of University Two commented that his university has to send requests to the ministries to seek their approval, for example, in terms of staff recruitment, quota for student admission and monthly planning reports on proposed activities.

In brief, the two universities in this research are under the leadership of MoET. Figure 7.1 illustrates how their administration is under their lineministry, MoF, as mentioned in section 1.2 in the introduction chapter. Therefore, the impact of dual leadership can be summarised in the following chart. 


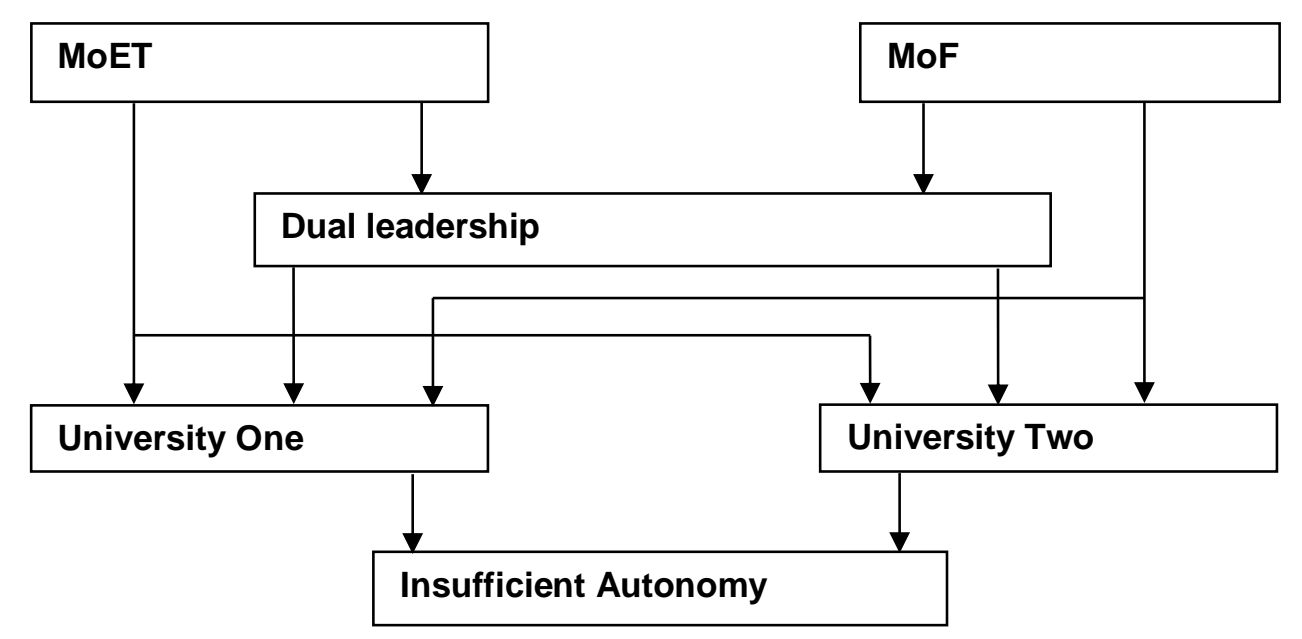

Figure 7.1: Dual leadership of the two universities

\subsubsection{The limitations of dual leadership}

Dual leadership has resulted in a lack of autonomy and as a consequence, university leaders have limited power to expand infrastructure, update teaching facilities and provide adequate support for lecturers to pursue professional development. The inadequate support to pursue professional development is illustrated by many EFL lecturers who complain about not having enough funding and support from the ministries and the university to up skill their professional knowledge. This view is further illustrated by an EFL lecturer when she commented: "It would be a luxury for us to attend a TESOL conference abroad". This finding accords with London's (2011) study in which staff from Vietnamese HEls tend to be undertrained, underpaid and have few opportunities to pursue research.

Dual leadership may also play a role in the paucity of staff's research. As noted in section 1.2, Vietnamese universities are weak in scientific research. To remedy this situation, MoET has recently launched Project 322, now changed to Project 911 to provide scholarships for university lecturers and cadres to go abroad to study with the goal of developing higher education. The aim of the Vietnamese government scholarships is to have 20,000 research-active PhD holders by 2020. Currently, Vietnam has about 24,000 $\mathrm{PhD}$ holders and 9,000 professors and associate professors (Vietnam News Agency, 2012c). However, approximately 70 per cent of these do not do 
research. Instead they prefer managerial positions or high senior positions in government and public offices. When being interviewed by a Tuoi Tre Newspaper reporter, Tran Van Tho emphasised that Vietnam should not confuse a PhD holder with a top-ranking leader. Professor Tho pointed out the disadvantages of this problem have only been seen in Vietnam (Tho, 2014). This shortcoming has resulted in few research publications by Vietnamese PhD holders in comparison with other countries in the Asian region. This is supported by Vietnam being listed in the bottom group of universities in terms of scientific publications (Vietnam News Agency, 2014).

In addition, Vietnam has few universities of international standard and the lack of research contributes to this. Therefore, it is difficult for Vietnamese universities to gain equality with other foreign countries' elite education systems. Rector One shared his perception that one of the challenges universities have to cope with is the ability to implement world-class curricula to enhance training quality.

This Vice-Rector's concern indicated that the Vietnamese university system has developed slowly. An explanation for this slow development of Vietnamese higher education is, according to Tuy (2007), Vietnam's higher education system being heavily influenced by the Soviet academic system, in which universities were mainly teaching institutions whereas research was conducted by research institutions. Valley and Wilkinson (2009) have suggested that this is a reason why Vietnamese academics have poor publication records. The findings of this current study correlate with Valley and Wilkinson (2009) who argue that Vietnamese universities are largely isolated from international knowledge particularly in scientific research. To overcome this, the Government is attempting to build university-based research.

As a result of the above-mentioned constraints, further effort is needed to implement the HERA and build an effective governance framework. This should be a priority in order to reduce the remaining institutional 
shortcomings with special emphasis on autonomy, accountability and regulatory frameworks.

\subsubsection{Section summary}

In short, the findings of this research indicate that organisational barriers that have hindered higher education leaders in decision making include dual leadership, and discrepancies in, and unclear regulations from the MoET and other lines ministries such as the MoF. In order to have sustained improvement in Vietnamese higher education governance and increase international cooperation in training and research development, a shift to increase autonomy and governance reform should be a priority. Despite facing a number of organisational barriers, leadership teams from the two universities discussed their efforts to work more collaboratively to solve the issue of effective curriculum design and delivery.

\subsection{Insufficient staff capability and personal barriers}

Besides organisational barriers such as insufficient institutional autonomy and dual ministerial leadership as discussed in section 7.2, senior leaders and EFL lecturers also face personnel and personal barriers which challenge their participation in Basic English curriculum design and delivery. This section addresses the following question:

- What are the barriers affecting the leadership roles of academic leaders?

\subsubsection{Insufficient staff capability barriers}

One of the staff capability challenges faced by senior leaders is the lack of highly-qualified academic staff and their limited English competence.

\section{Lack of highly-qualified academic staff}

With regard to personnel barriers, the perspectives of senior academic groups are similar to those of EFL lecturers. The challenges which hinder their involvement in curriculum design and delivery relate to the shortage of highly educated staff. This study found that academic leaders from the two universities shared their concern about the shortage of highly-qualified 
teaching staff. A senior leader from University One stated: "The higher education sector is terribly short of highly qualified lecturers and leading experts". It is understood from his comment that key people are needed for the successful design of curricula.

The issue of academic staff lacking qualifications and experience in higher education is due to the expansion of the educational system in recent years, the increasing number of institutions and the escalation in student enrolments (Anh, 2009; London, 2011). The explosion of student enrolments is typical of the world-wide phenomenon where university education has moved from being regarded as elite to being considered as education for the masses. When there is an increase in student enrolments, universities in Vietnam are severely stretched as their faculties are inadequate and staff shortages present huge problems (Clark, 2010). Therefore, the quality of the student learning experience is among the concerns related to the growth in the number of students (Hiep, 2012).

\section{Limitations in staff's professional knowledge, English competence and teaching skills}

Another barrier faced by senior leaders relates to limitations in their staff's professional knowledge, English competence and teaching skills. This lack of knowledge and skills is intrinsically linked to the lecturers' levels of qualifications, as discussed above and is of concern to university leaders in this study. A senior leader from University One stated that many lecturers in his university have "limited professional knowledge, foreign language proficiency and lack the ability to apply IT in their teaching" which makes it difficult to address these shortcomings.

Academic staff in Vietnam's tertiary institutions who teach specialised subjects namely finance, accounting and banking have limited English language competence. A possible explanation for this limitation is that lecturers spend an excessive amount of time teaching which limits their ability to upgrade their professional knowledge. This is in agreement with Clark (2010), who found that the shortage of qualified academics has 
resulted in heavy workloads for lecturers in Vietnam's higher education institutions.

Moreover, EFL lecturers do not have many opportunities to study or attend workshops on English teaching methodology to improve their qualifications. This situation was highlighted by the Dean of the Foreign Languages Faculty from University Two who mentioned that most EFL lecturers have few opportunities to work with foreigners, study, and gain further experience and knowledge. Similar to senior leaders, EFL lecturers also face some barriers including time constraints.

\section{Time constraints in doing research and professional development}

The time constraints EFL lecturers work and live under limit their ability to do research and improve their teaching skills. This is well illustrated in a comment by a lecturer from University One when she talked about her daily activities. Every day, after taking the children to school, Lan comes to university to teach all day. After taking the kids home in the afternoon, she has to teach at her university's foreign language centre in the evening. Therefore, she doesn't have time left for research.

The consequences of an overloaded teaching timetable which leaves little time for EFL's English language development also impacts negatively on the quality and quantity of their research. This is consistent with Anh's (2009) research which found that Vietnamese academics do not have time for research. This is in direct contrast to lecturers in developed countries' universities, where university lecturers teach fewer hours and earn good salaries (Hiep, 2006). By contrast, Vietnamese teachers are poorly paid so they have to work extra time to earn additional money to support their families consequently having to teach extra hours also means there is less time available for lecturers to do their research. Low salaries and unfavourable living and working conditions result in many teachers seeking work in other areas because they cannot live on their basic teaching salaries. Another reason teachers complain about not having the time for professional development is the time consuming unnecessary, extra tasks they must do, 
namely, preparing a myriad of academic documents which contain repetitive information (Vietnam News Agency, 2011a). A number of EFL lecturers also reported they are required to spend time in a class meeting every week as 'course advising teachers' to help solve student issues, including disciplinary matters and making student policy suggestions for the university. These tasks further limit their teaching and research time. As discussed, developing human resources, in quantity and quality, is a big challenge for higher education in Vietnam. This has been further exacerbated by the relatively high ratio of students to a lecturer lecturers/students of around 30:1 (Anh, 2009; Ly, 2010). The high student/teacher ratio and the extra work this involves further limits the time for research and professional development, consequently many EFL lecturers do not meet the English competence framework based on CEFR stipulated in the National Foreign Languages Project 2020 discussed in section 1.2 (Dung, 2008). This is in line with Hung's (2012) study which found that the number of university lecturers who have PhD degrees at Vietnamese HEls is still very small. Thus Vietnam trails behind universities in other countries (London, 2011). These reasons may prevent the universities from designing advanced curricula.

Besides the above barriers senior leaders and teachers face there are also personal demands which impact their professional lives.

\subsubsection{Personal barriers}

The personal barriers that academic leaders and teachers in this study face appear to be gender-related personal barriers. Those relating to males will be discussed then the barriers identified by female staff.

\section{Difficulties in foreign language learning for male academics}

Although they acknowledged the importance of foreign languages, namely English in their professional knowledge and scientific research, most of the male leaders in this study exhibited anxiety about their difficulties learning English. 
This study found that some male academic leaders, from both universities, mentioned the difficulties they have in foreign language learning whereas this was not a significant difficulty for their female counterparts in their leadership roles. The male leaders have difficulties in language learning as reflected by Vice-Rector of University One who mentioned at his age, it would take a long time to achieve fluency in English, for instance. Male leaders commented on their difficulties in learning English and stated this presents a barrier for them as it interferes with their ability to improve the curriculum design and delivery. It appears, from my research, that this is the only personal barrier faced by male university staff. Women, in contrast, have different challenges but unlike the men they did not include learning English among these.

\section{Dual challenges faced by female academic leaders and EFL lecturers}

For female leaders, the issues were quite different. All the female academic leaders, who participated in this study, reported having dual responsibilities. These are academic teaching, running their homes and caring for children and parents-in-law. The roots of these dual responsibilities are imbedded in Confucianism which permeated Vietnamese society during the thousand years of Chinese domination. This continues today according to Ratson, Tong, Maignan, Napier, \& Thang (2006) who state Vietnam shares the cultural origins of Confucianism with China.

In Confucian ideology, men are considered the head of the family and this is manifested in their patriarchal behaviour. The Vietnamese value this traditional ideal of male superiority in the family and consequently they are never expected to contribute to work in the home; whereas women are expected to do all the housework even if they work outside the home. According to Confucian's teachings, Vietnamese women's roles and duties, within the discourse of the patriarchal family, are to serve their husbands and their families by maintaining the housework and bearing children (Frenier \& Mancini, 1996). Further, Vietnamese folklore and literature stereotype these women's roles and place in society. For example, chastity is prized; marriages are arranged; and a married woman has to be faithful to her 
husband. In addition, she is glorified if her husband dies and she remains a widow for the rest of her life (Ashwill \& Diep, 2005; Bich, 1999). Such gendered expectations in Vietnamese society affect females' resolute decisions in their leadership practice at work.

The effects of this patriarchal tradition on Vietnamese women are limited rights and a secondary place in the household. The replies from all the four women academic leaders, in this research, are consistent with the findings of Ngan (2011) which noted that gendered cultural expectations have had significant impacts on women's leadership in higher education. This can be seen in a reflection of a female leader from University Two who noted that being a leader in this cultural milieu inhibited her leadership ability as she felt constrained in her role. She also had the expected responsibilities of being a mother and a housewife. These further impacted on her leadership practice.

This comment by a professional woman is evidence of the imbedded effects of Confucian ethics in the traditional values of the Vietnamese lifestyle (Trinh, 2011). Another possible explanation for this female leader's comments about the individual barriers she and other female leaders encounter may be the ways Vietnamese women are socialised to be gentle and magnanimous. Female EFL lecturers face the same dual challenges as female academic leaders as illustrated by Dong, an EFL teacher from University Two when she comes home she also works hard to fulfil her duties in the house as a mother, a wife, and a housewife. She is very tired by bedtime and "does not have the energy for professional development."

The findings show that these gendered, personal barriers prevent female academic leaders from effectively performing their roles and female EFL lecturers from undertaking professional development and research.

\subsubsection{Section summary}

The lack of highly-qualified academic staff and their limited English competence are the staff capability challenges that senior leaders face. Both senior leaders and EFL lecturers face the gender-related personal barriers 
such as difficulties in foreign language learning for male and dual challenges for female.

The following chart summarises the negative barriers faced by senior leaders and EFL lecturers when solving curriculum issues as discussed in section 7.2 and 7.3. The first negative factor is an organisational barrier due to the impact of the dual leadership from the two ministries and the resulting lack of autonomy. The second is the staff's capability including the lack of qualified staff and their limitations in teaching skills and English competence which are challenges for the leadership teams. The last factor which also hinders collaborative leadership in the Basic English curriculum design and delivery is the different personal barriers faced by male senior leaders, female academic leaders and EFL lecturers. These factors are summarised in figure 7.2 below.

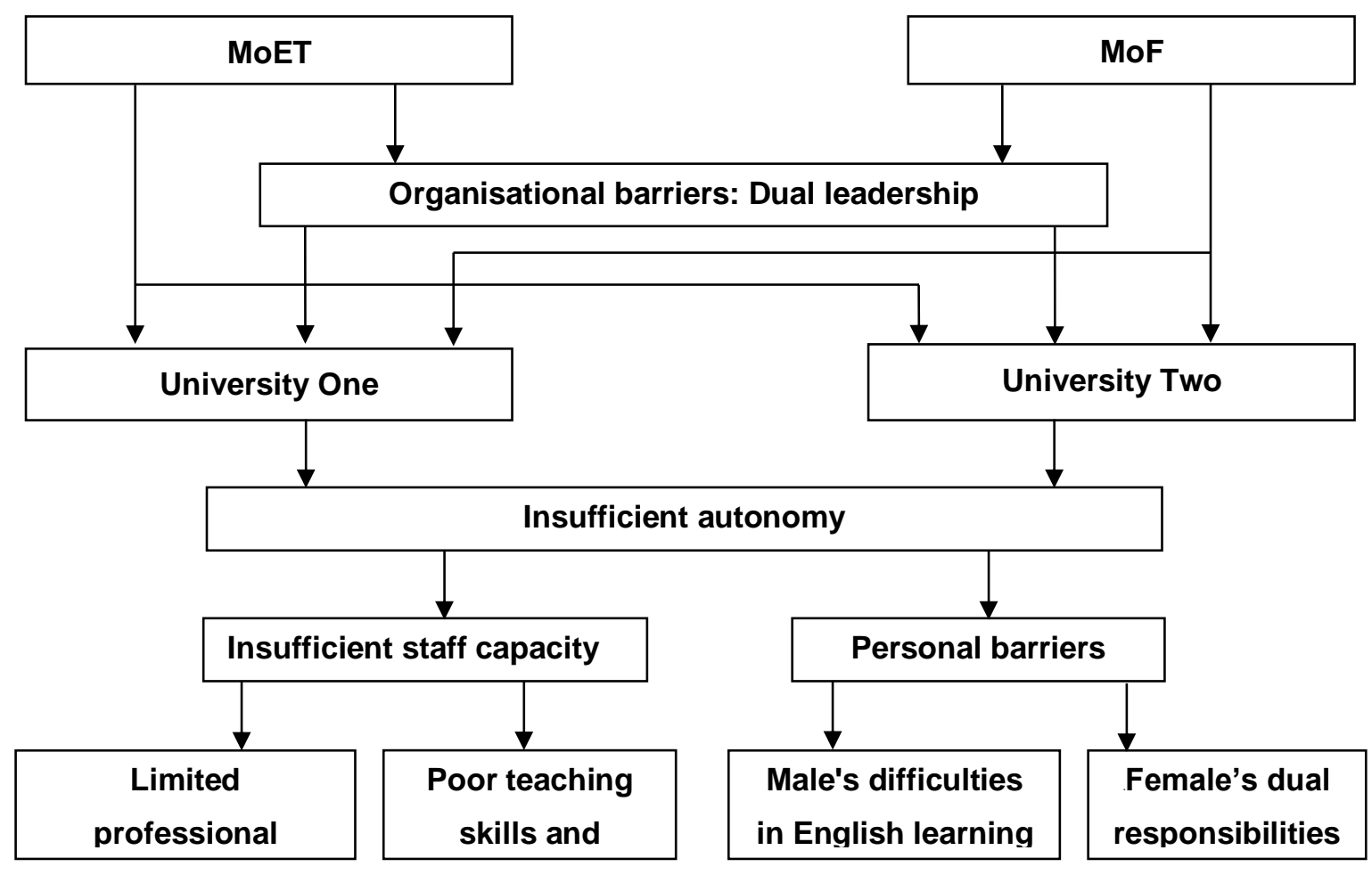

Figure 7.2: Barriers affecting the two leadership teams 


\subsection{Collaborative leadership at different levels within the two universities}

In this section collaborative leadership will be explored within the context of the two research questions as below:

- In what ways do collaborative leadership practices positively impact on the Basic English curriculum design and delivery?

- How do academic leaders promote the Basic English curriculum delivery?

\subsubsection{Building relational trust with colleagues and partners}

One effective way to work in collaboration with colleagues and partners is to build relationships and highly value all the people involved. This study's findings show academic leaders from University One and University Two believe they share power and work collaboratively in curriculum design and delivery. In the following sub-sections, the views of senior leaders and EFL lecturers on the levels of their collaboration in curriculum design and delivery will be addressed.

Senior leaders interviewed for this study described their efforts to build relationships with staff by trusting and valuing them. This is illustrated in Rector One's comment: "Being leaders requires us to be good listeners to our colleagues". He viewed himself as a very good listener who respects his colleagues' thoughts and the sharing of ideas. In addition to evaluating his colleagues' contribution, this Rector also tried to mobilise local experts and scientists with seasoned experience in their specialised fields, for instance, officials of Finance, Treasury, Customs Departments, or leaders of the People Committee of the district and the province.

It is clear from the data that listening to senior and junior colleagues' opinions is seen by this leader as valuable for leadership practice. Rector One's comment also indicated that he believed an effective strategy of leadership is to learn from, and share experiences with, other colleagues and expert government officials who have in-depth knowledge of processes, procedures and expectations of workplaces and have specialised expertise in their fields. 
Rector One says this is important because of its relevance to the workplace. This rector's view is supported by Harris' (2008) study which found that there is increasing evidence to support a strong relationship between distributed patterns of leadership and better student outcomes. The more involved the staff are, the better outcomes students will have. According to Harris (2008), it will also be helpful to provide the creative spaces and platforms for dialogue and discussion with staff within the school and offer staff opportunities to lead and build leadership capacity. These perceptions of senior leaders about collaboration in curriculum design and delivery were also supported by their EFL lecturers, whose thoughts on this will be explored later in this section.

In a curriculum meeting I observed which was chaired by Vice-Rector One of Teaching and learning, I did not see senior leaders spending a lot of time listening to their colleagues. In this meeting attended by a representative of the Scientific and Research department and the teachers in the English department, Vice-Rector One spent most of the time talking about the importance of English in the National Foreign Languages Project 2020. This is imperative as he continued talking, because it will ensure graduates will communicate more effectively in English and attain B1 - CEFR which they must achieve to graduate. The meeting focused on a new course design for students to achieve B1 and the internal C1-examination the EFL teachers need to take in relation to the project 2020. During the meeting, many of them were quiet and listened to their Vice-Rector. There were only a few comments from EFL lecturers, as there was little opportunity to express their views. Further, they acknowledged his directive by promising to try to improve their professional learning. There was a small amount of time set aside at the end for the lecturers to comment. Some of the teachers voiced their opinions about the challenges they faced such as their heavy teaching loads which leave little time to up-skill, their low salaries and lack of support from the university and the Ministries. Besides this, some of the teachers also mentioned the barriers they face when teaching a large class of students with varying levels of English. These barriers were explored in chapter Five. 
There were no concrete solutions about how to resolve these challenges. Another teacher offered her suggestion about "adding more listening and speaking drills when designing the intensive English course" with the aim to help students improve communicative skills to meet the language requirement for graduates as mentioned earlier. Her comment was evaluated and responded to positively by the chairman, who stated that communicative skills will be given more emphasis in the upcoming intensive course.

Vice-Rector Two agreed with his counterpart at University One, about the importance of listening and believed he gives equal importance to listening to his staff's leadership ideas. He said he highly values their input and arranges many opportunities to gather and share ideas with them. Further, he acknowledges the important role of lecturers in his university and particularly elicits their thoughts about the university's strategic, long, and short term goals.

Observations were unable to be conducted in University Two due to many of the EFL lecturers preparing to go to Singapore for a short training course. Therefore, I have no evidence of whether the leader implemented these beliefs or not. The findings suggest that another effective way to work in collaboration with staff across his university is that leaders encourage colleagues to participate in curriculum design by respecting their ideas and assigning them jobs. This can help senior leaders to promote the Basic English curriculum design and delivery. It may be assumed, because of the hierarchical nature of Vietnamese society, that teachers have little say in the curriculum tasks their leaders allocate to them. However, the concept of working in groups or teams was also approved of by the Rector of University Two who expressed the necessity of learning from the former leaders' experience as well as his subordinates, and he also thought about how to convince and encourage all staff to mutually implement the political tasks set up by the university.

It can be understood from Rector Two's comment that highly-positioned leaders in government agencies or organisations are required to be Party 
members. Consequently, senior leaders are always cognizant of their political responsibilities and must think about or consider what they should do to reflect the prevailing political points of view. Besides being aware of their political responsibilities, it can be clearly seen the senior leaders put an emphasis on their approaches to leading his/her university including being willing to learn from past and current colleagues. Rector Two suggested that leadership is shared across the university because many senior leaders appear to trust their staff. An example of sharing responsibility is in the response of Rector One who said that he always hosts discussions among the members of the Board of Rectors about job assignments and leadership activities. He also has these discussions with colleagues, especially the university's leaders. Finally, he "delegates tasks very clearly and lead under the principle 'Collective leads and individuals perform' which results in maximising colleagues' responsibilities."

It can be seen from the principle above that Rector One's viewpoint might be related to the idea of the collective spirit of Vietnamese people. It also has a link with the previous political point of view given by Rector Two in terms of Communist ideology in Vietnam. This is consistent with Thang's (2013) study which found that in collective cultures, people's relationships are very close, they tend to be more considerate and responsible for each other's well-being and especially emphasise loyalty and respect for members of the groups.

As I was only able to observe one curriculum meeting it is difficult to know whether the communication pattern I observed is similar in University Two. However, it could be assumed from both Rectors' comments that they recognise the importance of listening to colleagues but as noted in the University One meeting, where the Rector spoke throughout, it could be assumed that listening to colleagues is still aspirational. This could also be supported by the fact that few lecturers spoke at this meeting. The following section will explore collaboration between leaders and heads of faculties. 


\subsubsection{The role of collaborative leadership}

The data from this study showed that leadership teams view collaborative leadership in designing curriculum as playing a crucial role in both universities. An illustration of this is provided by the Vice-Rector of University Two mentioned that he not only "directly participates in designing and composing curricula for some subjects but also collaborates with the specialists of the faculties and departments." As can be seen from the ViceRector's response, he believes he cooperates with his academic staff across the university.

This way of working in a collective team may stem from collectivism in Confucian ideology which is in line with Ratson et al. (2006) who found that collectivism is reflected in Vietnamese moral philosophy. Accordingly, people believe that merit acquired through virtuous deeds is later passed onto their future generations. People are advised to follow the Vietnamese saying "If the father's generation eats salt, the children's generations are thirsty for water." This saying is embedded in Vietnamese people's psyche and is manifested in the moral values they have to pursue in life. These values are also inherent in 'collectivism' which outlines the responsibilities and obligations people should fulfil for their families, succeeding generations and communities (Thang, 2013).

In community organisations and business contexts, it has recently been accepted that people are required to work collaboratively (Humphreys, 2013). Therefore, in higher education, collaboration and cross-sector communication is also very necessary to increase understanding of institutional goals and practices. The Vietnamese proverb says "Một cây làm chẳng nên non, ba cây chụm lại thành hòn núi cao" which can be translated into "Together we can change the world". This saying represents the consolidated spirit of the Vietnamese people. It has been suggested in the literature that collectivism affects the Vietnamese people's behaviours and approaches (Ratson et al., 2006; Thang, 2013). 
Academic leaders from both universities support collaboration and emphasise the role of collaborative relationship in curriculum design, renewal and delivery. This emphasis can be illustrated in the Rector Two's reflection about the process in curriculum design. When designing a curriculum, there is a council in which he is the president who puts forward guidelines and orientations to design curriculum for every specific major. The final design of the curriculum will be sent to the faculties and departments for feedback, and then the council will host a meeting. The Rector will be the one who "makes the final decision on the curriculum"

After explaining the procedures in designing curricula, Rector Two also noted that to ensure a good curriculum, they send it to internal and external reviewers for assessment. Moreover, as the head of the university, the Rector is the one with the full responsibility of finalising the curriculum once approved by the MoET. This approval by the MoET may affect the collaboration in curriculum issues because of its centrally-controlling curriculum design.

Rector One also expressed his perspective about curriculum design and delivery, emphasising the importance of 'using practical cadres to assess the curriculum' because the cooperation of these experienced people in curriculum issues will assist better curriculum design. An explanation of cadre is found in the Great Soviet Encyclopedia (Prokhorov, 1979), which defines the term 'cadre' as a basic/permanent staff of trained, qualified workers in enterprises, institutions, the party, the trade unions, and public organisations engaged in some area of work. In the Vietnamese context, that the term 'cadre' is given preference here may be due to the fact that the Vietnamese university system was influenced by the Soviet Union and is a Communist country as discussed earlier. In a broad sense, cadres means all permanent staff members and they are evaluated and placed in workplaces according to their political and practical qualities. The policy of the Communist Party of the former Soviet Union with regard to cadres is aimed at promoting talented, politically aligned, educated, and professionally trained personnel. Further, practical cadres are understood as officials who currently work in businesses 
or government organisations and master practical knowledge in the workplaces.

Rector One also said that lecturers who teach specific subjects at university should be the ones playing a very important role in deciding the curricula. It can be inferred that this experienced Rector trusts the potential of his academic staff to have analytical and foreseeable competence to design a curriculum. Rector One continued, in a changing world, it is difficult for universities to always follow businesses' needs therefore he emphasised the lecturers' role in anticipating the professional knowledge they should include in the curriculum to provide their students with skills and expertise they can apply in practical work after their graduation. In addition, he shared his perception that building curriculum is the main responsibility of academics within the university, so senior academics as well as teaching staff have to work together to foresee the disciplines to provide students with a basic theoretical framework they can use and apply in their future workplaces.

The views of EFL lecturers regarding collaboration in curriculum design and delivery will be discussed in the following section.

\subsubsection{EFL lecturers' collaboration in curriculum design and delivery}

The findings reveal another level of collaboration in curriculum design and delivery in that senior leaders and EFL lecturers appear to work collaboratively to solve the issue of curriculum renewal and delivery. As mentioned in section 5.5, the question put to the teachers asked for their perspectives on curriculum design and delivery and, although there were some significant comments about design, most teachers offered their views on curriculum delivery only as this is possibly of greater concern to them. That few EFL lecturers offered their thoughts on curriculum design is an interesting finding. This could be partly explained by the fact that curriculum frameworks are determined by the MoET, as discussed in the introduction chapter. The MoET's directives, therefore, restrict teachers' input into curriculum design. Nevertheless, they are given some leeway and co-operate within these limitations. The response of Truc, an EFL teacher from 
University One, revealed that every six months she and her colleagues have a department meeting chaired by the Dean during which they discuss problems arising during the teaching process or adjusting the curriculum to be more relevant for each major.

These comments suggest that Truc works collaboratively with her departmental colleagues in curriculum design and implementation and dealing with issues which arise during teaching periods. Further, all department members discuss the teaching timetable and the teaching content to solve issues in a timely manner, e.g inappropriate teaching timetables. Truc explained more about the teaching content timetable, saying that every teacher has suggestions about the teaching content of their subject in each semester. However, during their teaching, if they find something inappropriate, they have some flexibility to make alterations.

Similarly, Xuan, an EFL lecturer from University Two emphasised the necessity of team work in designing and altering the curriculum. Xuan's reply showed she often has meetings with her colleagues to amend, or compile a new curriculum for new majors at her university. Changes to, or the introduction of, new majors are strategies used by universities in Vietnam to attract more students and thus more fees. In addition, new majors attract extra funding from the MoF, on instructions from the MoET. These extra funding sources enable the universities to improve their facilities, or employ more teachers and/or purchase teaching resources.

However, EFL lecturers report that senior leaders have the final say in curricula design and delivery. An illustration of this is seen in the response of Mai, a teacher from University One who highly appreciated the role of the leaders in her university as they play an important role in curricula orientation, design and delivery and make the final decisions on everything, especially on the curriculum.

Mai's comment highlighted the significant and important roles of senior leaders of her university in terms of curriculum design and delivery. In the Vietnamese context, as a Communist nation, the Vietnamese junior staff 
usually follow the slogan 'Party leads and the people take control' as a result their leaders play decisive roles in curriculum design in universities. In reality, teachers have some flexibility when they teach although the curriculum is designated by the MoET. For instance, when the teachers find their teaching content inappropriate, they can bring it to their faculty meeting and obtain consensus on the changes from the whole faculty. The faculty dean writes a report stating the reasons for the amendments. These suggestions will be sent to the scientific research department and then forwarded to the ViceRector in charge of teaching and learning. When he or she has checked it, the Rector will host a meeting where he or she will finalise and approve the changes in the curriculum for the next semester. As a consequence, the lecturers have a secondary role in the curriculum design.

Interestingly, Lan, another EFL lecturer from University One had a contrary perspective and stressed the crucial role of teachers of English in curriculum design. Lan thought that teachers are those who master professional knowledge whereas leaders are managers. Therefore teachers should be encouraged to have more flexibility in decision making in all areas of the curriculum.

As can be seen clearly from this female lecturer's comment she believes EFL lecturers have a greater knowledge of students' levels of English competence and learning styles and considers they could make a valuable contribution to curriculum design. As stated earlier, lecturers play a secondary role in curriculum design and delivery, therefore, it can also be inferred from her comments that EFL lecturers would like to have more autonomy in curriculum design and delivery.

\subsubsection{Positive factors enhancing collaborative leadership}

The following figure summarises some positive factors identified in the research such as building relational trust with academic staff and partners, emphasising the importance of collaborative leadership and working in collaboration with colleagues across the university. These are considered to be effective ways to enhance collaborative leadership in the Basic English 
curriculum design and delivery in Vietnamese higher education contexts. (See figure 7.3)

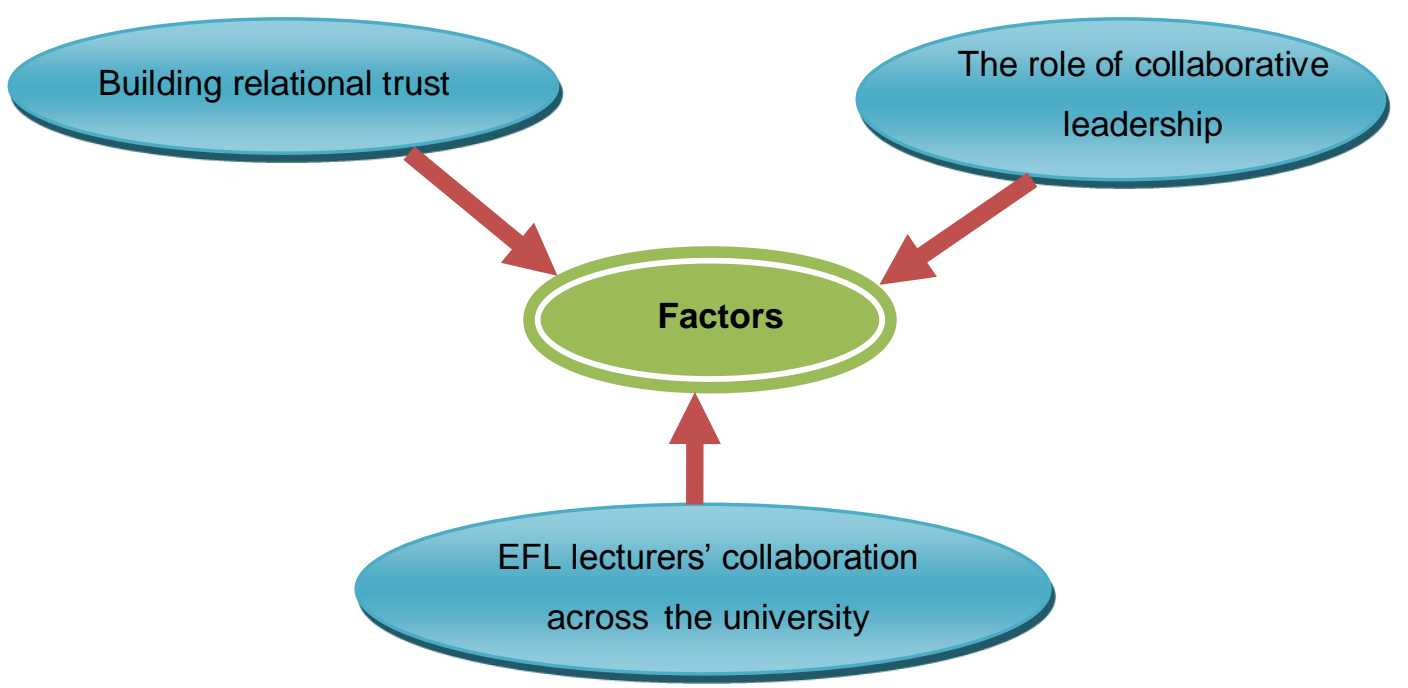

Figure 7.3: Factors enhancing collaborative leadership

This section discussed the participants' perceptions about the opportunities for collaborative leadership between the leadership teams and EFL lecturers in curriculum design and delivery. The building of relational trust and highly valuing academic staff are perceived to be among effective ways for leaders to have a positively impact on the Basic English curriculum design and delivery. Further, highlighting the role of collaborative leadership in the Basic English curriculum design and delivery is seen as contributing to students' learning outcomes.

\subsection{Synthesis of the university leaders' perspectives on the effectiveness of the Basic English curriculum}

This section discusses the perspectives of the stakeholders, in this study, concerning the effectiveness of the Basic English curriculum and barriers faced by graduates. Some stakeholders questioned the effectiveness of the Basic English curriculum in preparing students for the requirements of the labour market and global market. The perspectives of these interested parties will be explored in answer to the research question: 
- What are the perspectives of the stakeholders about the effectiveness of the Basic English curriculum design and delivery? In the first sub-section, the perspectives of senior leaders on the lack of resources, international integration, graduates' barriers and funding will be reported. The perspectives of EFL lecturers will be explored in the second sub-section.

\subsubsection{The leaders' perspectives}

This section presents the perspectives of senior leaders in explaining the inadequacies of the universities namely resources and the resulting challenges graduates face in the workplace in relation to the effectiveness of the Basic English curriculum.

\section{Senior leaders' perspectives on lack of resources}

The reasons given by senior leaders for graduates' failing to respond to the workplace requirements included the training institutions' shortages of facilities, staff and practical resources for teaching and learning. An example of these shortages is clearly seen in the response by an academic leader from the training department in University One when she indicated that professional practice in her university faces many issues because the university lacks practical labs due to the limited infrastructure.

A possible explanation for this situation might be that public universities lack sufficient funding from the State. This is consistent with Valley and Wilkinson's (2009) study which highlighted the financial shortages in the Vietnamese higher education system. Further, the authors reported other results of their surveys which showed as many as 50 Vietnamese university graduates are unable to find jobs in the areas of their majors. What is more, the evidence from Valley and Wilkinson's study revealed that "the disconnection between the classroom and the need of the market is large" (p.1.).

A reason for this disconnection could be that the universities have difficulty finding practical workplace experience for students. This difficulty was also noted by the Rector of University Two when he explained the difficulties that 
he faced at work. After finishing all compulsory subjects in their major at the university, all students must have a probation period in enterprises. However, at present, many enterprises in Vietnam are facing many difficulties and challenges and find it difficult to take on probationers. This results in students' ineffective practicing outcomes.

It can be inferred from Rector Two's response that when students are unable to gain probationary positions, his university has difficulty in providing the necessary training due to the university's inadequate infrastructure. The outcome of this, in his opinion, is the low quality of work-based practice.

Another reason for the inadequate infrastructure is the explosion in the demand for university education. To meet this demand the MoET has allowed many more universities to be built. Despite this growth, the new and the established universities are still unable to cope with the influx of students. Limited infrastructure results in the lack of practicum opportunities for students. Moreover, shortages of teaching staff and limited basic curricula disadvantaged students' learning Finance, Accounting, Banking, etc. As a consequence, students' subject knowledge and soft skills do not meet the requirements expected of graduates in the workplace. This is in line with Chi's (2011) report which showed new school graduates lack both professional knowledge and skills.

Senior leaders also expressed disquiet about these issues and their impact on graduates' preparedness to meet the needs of the labour force and global integration. For example, Vice-Rector One indicated that Vietnam has integrated with other countries in the region and in the world. Nevertheless, this integration has its challenges. According to the Vice-Rector One, tertiary education in Vietnam has been lagging behind other countries' education systems in the region and in the world.

It can be deduced from Vice-Rector One's comment that the Vietnamese university system has developed slowly. Hence, it is difficult to catch up with other countries' elite education systems. These challenges, in his opinion, face his university and most of the universities in Vietnam. This view is 
supported by Valley and Wilkinson (2009) who argue Vietnamese universities are largely isolated from international knowledge particularly in scientific research.

\section{Senior leaders' perspectives on HEls' international integration}

Several leaders from University One discussed their concerns regarding education integration with other advanced education systems in the region and in the wider world. For example, the Deputy Manager of the Training Department from University One particularly chose learning and teaching foreign languages to highlight the regional difference as the key part of the problem. The challenge of the Basic English curriculum she had recently coped with was to meet the English language demands of international economic integration. This is especially pertinent in all English speaking companies including those in the Central and Highlands region of Vietnam.

It can be implied from this academic leader's comment that universities in regional Vietnam have severe shortages of staff, especially a shortage of English speaking staff and facilities which hinder the university's training quality and as a consequence, affect the economic growth of these regions. One of the reasons for this could be that universities are not providing graduates with effective English skills, as mentioned earlier by the employers interviewed. While this academic leader focused on the regional difficulties in learning and teaching English, Vice-Rector Two shifted to the challenges his university faces when dealing with curriculum design and delivery to meet the task of global economic integration. Vice-Rector Two shares a very similar viewpoint about how to meet the global economic demands when he indicated that Vietnam's education system is on its way to join the AEC in the region as mentioned earlier and the global integration. However, this ViceRector is concerned about rankings of Vietnamese universities in the world. That education in Vietnam trails other countries can be inferred from the following table. Unfortunately, the two universities in this study have not been ranked. However, within a year, a higher ranking has been achieved for two of Vietnam's universitities. 
Table 7.1: Rankings of Vietnam National universities Adapted from (QS top universities, 2014)

\begin{tabular}{|l|l|l|}
\hline \multicolumn{1}{|c|}{ Institutions } & 2013 rank & 2014 rank \\
\hline VIETNAM NATIONAL UNIVERSITY, X university & $201-250$ & $161-170$ \\
\hline VIETNAM NATIONAL UNIVERSITY - HO CHI MINH CITY (VNU-HCM) & $300+$ & $191-200$ \\
\hline
\end{tabular}

Other than the two universities in the table, the University of Science and Technology of Hanoi trails both and was rated in the 251-300 group in 2014. The University of Economics in Ho Chi Minh City (UEH) is among the top 1,000 business schools in the world (Eduniversal, 2013). The statistics reveal that Vietnamese tertiary institutions rank relatively lowly in the Asian region and the world mainly because of their low quality of research. This poor research record may be due to budget shortages, academic staff's limited English proficiency, research method deficiencies and long teaching hours (Tuoitre, 2012). There was agreement between both universities, in this study, that Vietnam's higher education institutions lack significant international connections which could be another reason they are lagging behind the world's modern education systems. To overcome this disadvantage, Vietnamese universities must improve their strategies to move forward and compete with other universities.

Vietnam is still a developing country. Thus one of the government's important missions is to innovate the education system completely and fundamentally to integrate it into the global economy. In addition, this integration can assist in improving people's standards of living and developing the country to keep up with neighbouring and other countries in the world (Trong, 2013).

Innovation of the country's education systems could contribute to universities better preparing students to meet the demands of global integration, including their competence in English. Low levels of English are suggested as a possible barrier facing graduates in meeting the demands of global integration, as noted by a senior university leader and supported by a faculty Dean from University One. Rector One also added regional differences as 
another challenge his university faces with regard to his rural students' poor English competence.

\section{Senior leaders' perspectives on graduates' barriers}

One of the explanations from a senior leader is that the barriers to graduates meeting the demands of global economic integration are due to students' limited English competence. Students' limited English ability appears to be particularly problematic for rural students. A Faculty Dean at University One explained the difficulty she has faced in curriculum issues is that her students' level of proficiency in English is of a poorer standard than that of urban students who have more contact with English. Most of the students, at her university, originate from rural areas and have a very limited knowledge of English, so the curriculum at the university is challenging for them.

Her comment highlights the challenges teachers encounter when they teach a large class of students with different levels of English. The varying levels of English competence in this teacher's class may be explained by the fact that there is a shortage of teachers and teaching aids in some rural and mountainous regions of Vietnam. Also, her high school students have only three years English instruction before they continue their study at universities. As a consequence, their English competence is not at the same levels as those who live in urban areas and spend four years learning English at lower high school and three years at upper high school.

Furthermore, the Vietnamese Government's initiative of reducing tuition fees for students from the ethnic, mountainous and remote areas to encourage them to go to university has increased the number of rural students in universities. Rural students' professional knowledge of their majors such as finance, banking and accounting.is limited in comparison to their urban counterparts. In addition, rural and remote students have to support themselves by working part-time and therefore have less time for study.

\section{Senior leaders' perspectives on funding}

The discrepancies between students' English competence and professional knowledge are not the only challenges faced by universities in Vietnam. 
Funding, as briefly touched on earlier, is another challenge. Although university Two is located in a big city, it has similar constraints in sources of revenue as University One, situated in a small city. The Rector from University Two, for instance, stated that financial resources to serve training activities play a very crucial role, the budget for training is very modest, and the limited amount of money available is distributed to all public universities by the State budget.

It is clear from the data that the funding given by the State is insufficient for universities to expand their campuses, upgrade their infrastructure and train their staff to serve teaching needs. The academic leaders also indicated they are unable to provide their students with effective practical workplace experience which hinders students from strengthening their professional development and their English capabilities. However, improving training quality for better student outcomes to meet the needs of society and global integration seem problematic because the universities' inadequate funding is unlikely to be addressed in the near future.

Another factor contributing to low quality training is the tension between the expectations of the curriculum and the limited teaching hours. This shortcoming is illustrated by a faculty Dean from University Two when he complained that the time limit for teaching is too short and the requirements of the Basic English curriculum are too high and inappropriate for students, especially for those from remote and mountainous regions.

This Dean's comment supports Hang's (2011) view that the English curriculum framework is still stipulated by the MoET with limited hours whereas the content is vast. At present many examinations are conducted in English whereas it is recommended English be taught as a skill subject. Moreover, the imbalance between students' English levels from region to region may also affect the quality of teaching and cause challenges for teachers. 


\subsubsection{EFL lecturers' perspectives}

The EFL lecturers' perceptions of the barriers faced by graduate students which result in their poor English are in line with their colleagues and senior leaders as reported in previous sub-sections. However, as they are faced with these challenges daily their comments are especially pertinent.

EFL lecturers generally agreed they find it challenging when teaching students with varying English language levels. An example of this is seen in this statement from Hoa, an EFL lecturer from University One. Hoa revealed that students come from many different areas, hence, their English competence varies. This leads to a big difference in the English language skills between students from rural and urban areas.

As noted, geographical differences impact students' English language competence and these differences are further exacerbated by differences in income levels. Although Vietnam has made huge developmental and economic strides including raising the standards of living for many, mainly in urban areas, the country remains principally an agricultural nation and the disparity of wealth is noticeable in the economic status of the majority of farmers who continue to be impoverished. These factors result in students from the economically disadvantaged areas being poorly prepared for university study. This lack of preparedness for study in all disciplines, but particularly in English, is further aggravated in the remote, mountainous and island regions. Students in these remote areas do not study English until high school where they have only three years of English instruction before enrolling in junior colleges or universities. A significant cohort among these are from the ethnic minority communities and have had no English instruction before studying at university (VNA, 2012a). Because of the shortage of teachers in remote areas, the MoET has allowed students from these areas to take history, geography or chemistry instead of English in the national high school graduation examination each year. This further inhibits these students' successful achievement at university. 
Another reason students have limited English competence is large classes. Xuan, a lecturer from University Two commented that in some classes, there are over 45 students so it very difficult for lecturers to divide students into groups to practice speaking and listening. Moreover, the time limit in the curriculum prevents lecturers from organising many group work activities.

Time is relevant here as many students are hesitant to speak as they are shy and afraid of making mistakes and it often takes some time to encourage them to try. Tuyet (2013b) also observed students' lack confidence when speaking English. Furthermore, Xuan's comment implied that the curriculum is heavily theoretical and inappropriate. This is in line with Le and Barnard's (2009) study showing the curricula at HEls in Vietnam is still heavily focused on theory and lacks verbal communicative practice.

\subsubsection{Section summary}

Overall, the results of the study indicated that the Basic English curriculum is not effective and leads to graduates' lack of English communicative skills as mentioned in chapter 6 by the employers and graduates. The university leaders in this study claimed that they do not get enough autonomy from the Ministries while the employers claimed that the universities do not do their jobs well enough to serve students. They also express their views on other challenges that graduates face in the workplace such as limited professional knowledge and soft skills. Dual leadership and insufficient autonomy has resulted in negative barriers as discussed in 7.3.3. Therefore, senior leaders and EFL lecturers should work together to redesign the curriculum to have more communicative skill focus which will enhance students' language skills to meet the requirements of the workplace. The following figure shows the cause and effects of ineffective Basic English curriculum in this study. 


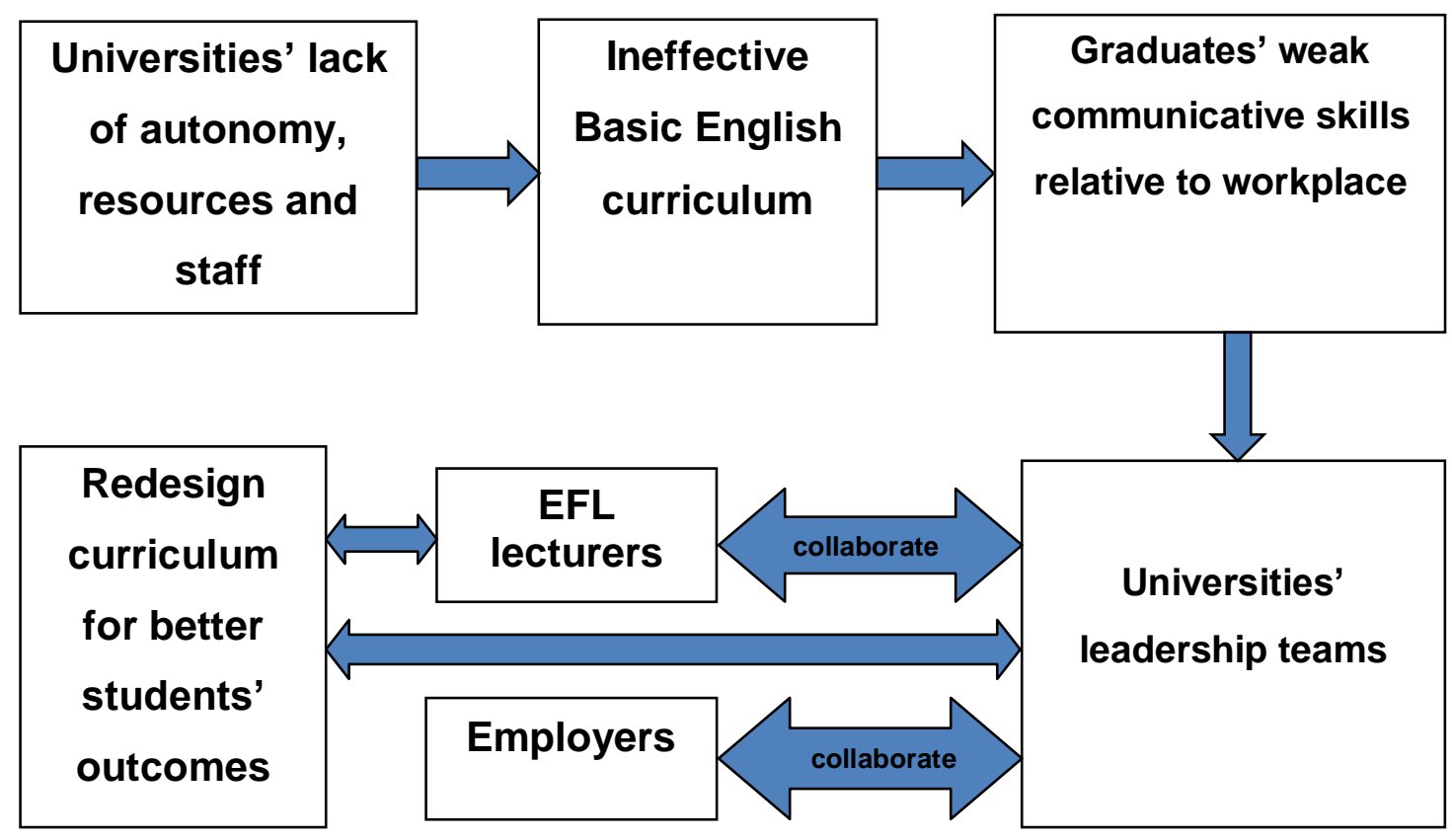

Figure 7.4: Causes and effects of the Basic English curriculum

\subsection{Chapter summary}

This chapter presented a synthesis of the different perspectives of the stakeholders, including the views of senior leaders and EFL lecturers concerning the effectiveness of the Basic English curriculum. Although the views of employers and graduates about the English language barriers facing graduates were discussed in section 6.4, they are also relevant here. Several similarities and differences became apparent. First, the similarities are clear, as all the stakeholders agreed that graduates are limited in English communicative skills. Senior leaders and EFL lecturers share similar personal barriers in terms of difficulties in language learning for males and dual responsibilities for females. Both employers and graduates linked the effectiveness of the Basic English curriculum to the communication challenges the graduates face with co-workers and customers in their workplaces. Senior leaders concurred but did not specify the Basic English curriculum as the cause of the graduates' challenges but noted that the barriers were caused by the great shortages of staff and resources, while 
another difference was highlighted by the EFL lecturers who saw students' different levels of English language in large classes as the main cause of the barriers.

The chapter also discussed dual and collaborative leadership which affected the role of leadership in curriculum design activities. However, there is evidence of hierarchal power and the senior leaders espoused claims of distributed and collaborative leadership approaches, were not matched by what EFL lecturers reported and by my observation. Therefore, there is a mismatch between what senior leaders said and what was actually happening. These leadership practices discussed are aligned with the literature review in chapter 2 and provide a strategy addressing the research questions. Therefore, the findings of this study are important as they have implications for the leadership teams at universities in Vietnam. Aspects of leadership such as dual and collaborative leadership need to be addressed in order to promote collaboration among staff to enhance the effectiveness of the Basic English curriculum. In view of Vietnam's economic development requirements in the globalisation era, collaboration within and between universities and businesses is necessary to ensure qualified graduates for the country's internal growth and to compete successfully internationally in the near future.

Research implications and conclusion will be explored in the final chapter. 


\section{Chapter 8: RESEARCH IMPLICATIONS AND CONCLUSION}

\subsection{Chapter overview}

This study has investigated the role of leadership in supporting and promoting the Basic English curriculum design and delivery in two selected Vietnamese universities. As noted earlier, educational leadership has attracted the attention of many researchers internationally, however this field has received little attention in Vietnam, especially in the higher education sector. Academic leadership impacts directly on student learning (Gardiner, 2002). Leaders in HEls need to develop management and leadership skills that can ensure high-quality learning experiences for each student. Moreover, leadership is necessary to effect change (Oliver \& Hyun, 2010), and in the context of this study, leadership has the potential to improve the design and delivery of the Basic English curriculum to ensure students can communicate effectively in English in the workplace. The role of leadership in making the Basic English curriculum more relevant and useful for graduate students is of particular importance in the Vietnamese university context.

The research was guided by an interpretivist/ constructivist theoretical framework as it aimed to elicit and understand how research participants construct their practices and shared meanings in curriculum design and delivery. Using this approach, I interacted with participants to construct an understanding and interpretation of the leadership role of each participant in the natural setting, at the two selected universities (Creswell, 2008). Moreover, I assume that knowledge is constructed within participants' minds and that is "subjective, personal, and unique" (Cohen et al., 2007, p. 7). The interpretive/constructivist research paradigm is consistent with my study as one of my foci was to explore the meaning that people bring to leadership situations in universities. To gain these understandings $I$, as the researcher, played an active part in constructing the interpretation of the data gathered. A qualitatively-focused intrinsic case-study design was developed because it could help solicit information and gather data that provide answers to explore how academic leaders promote the Basic English curriculum design and delivery in 
the Vietnamese university context. The qualitative case study approach, as discussed earlier, fits with the interpretive/constructivist paradigm (Stake, 2008). Accordingly, this research set out to answer the question:

- What is the role of leadership in supporting and promoting the Basic English curriculum design and delivery at two selected Vietnamese universities?

This final chapter comprises five sections: first, a summary of the study, focusing on the research questions; second, the implications of the findings, focusing on university leadership practices and policies; third, the research limitations, based on my reflections on this study; fourth, suggestions for future research; and finally my concluding arguments.

\subsection{Summary of the findings}

This research focused on the perspectives of four different stakeholders: senior leaders, EFL lecturers, employers and graduates. It involved an interpretative/ constructivist intrinsic case study with both qualitative and quantitative data sources. Three main methods of data collection were adopted, consisting of interviews (individual and focus groups); an observation; and online questionnaires. University senior leaders and EFL teachers from two chosen Vietnamese public universities participated. In addition, several employers who recruit graduates from the two universities contributed their insights, as did recent graduates. In addition to these data sources, university documents (such as annual university reports, university discipline and regulations, and university statutes) were collected to enable better understanding of the policy and institutional environment of these two Vietnamese universities.

Several key aspects of leadership roles were highlighted in this study. First, leadership in curriculum design and delivery was practised by leaders and EFL lecturers in this study. The findings showed that leadership is practised at different levels. Although their responsibilities differ, senior leaders and EFL lecturers have similar viewpoints in some areas, sharing similar personal barriers and emphasising the role of leadership in curriculum design and 
delivery. The senior leaders are responsible at the macro-level and the EFL lecturers at the micro-level. Senior leaders have the final say on what is taught but in order to have effective leadership in curriculum design and delivery, EFL lecturers need to be empowered to participate in curriculum design.

Second, being controlled by MoET and MoF puts the two universities under dual ministerial leadership which causes a range of issues for universities to manage. This study found that leadership in curriculum design and delivery would be more efficient if the impact of dual leadership was minimised and the universities were given more autonomy. This would allow university leaders to have more control over making decisions related to the expanding of infrastructure, updating teaching facilities and providing adequate support for lecturers to pursue professional development. The findings showed that organisational barriers have hindered the leadership teams from the two universities in decision making due to dual leadership, including unclear regulations from MoET and other line ministries such as the MoF. Moreover, the resulting lack of autonomy has limited university leaders' abilities to execute their power and effectively implement their responsibilities.

Third, successful leadership in curriculum design and delivery requires sufficient funding and resources, and favourable support for staff's professional development. The findings showed that senior leaders face staff capacity barriers which challenge the leaders' role in the Basic English curriculum design. These barriers are highlighted through the concerns of the senior leaders from both universities regarding the lack of highly-qualified staff with the professional knowledge necessary for effective curriculum design and delivery. The shortage of highly qualified staff and the resulting limitations of professional knowledge, English competence and teaching skills are additional concerns for senior leaders. EFL lecturers also face barriers. Time constraints are a major factor as overloaded teaching timetables seriously limit time to do research and pursue professional development. 
Fourth, leadership in curriculum design and delivery in Vietnamese higher education contexts appears to be affected by cultural values and gender differences. The findings provided evidence that leadership practices in Vietnam were influenced by Confucian values. These cultural values are reinforced in the political and administrative hierarchical structures which influence the senior leaders' leadership practices. In addition, the leadership practices were also found to be embedded in and shaped by other cultural values such as collectivism and moral values.

The study also showed that the personal barriers academic leaders and EFL lecturers face vary according to gender. Some male academic leaders from both universities, reported difficulties in foreign language learning, whereas female leaders did not mention foreign language acquisition as an obstacle for them in terms of their leadership roles. Instead, female leaders and EFL lecturers faced dual responsibilities. Beside their leadership and teaching responsibilities, they also have to run their homes and care for their children and parents-in-law. Such gendered expectations in Vietnamese society, within the discourse of the patriarchal family under Confucian teachings, affect females' time to fulfil their academic and leadership responsibilities and also their resolution in decision making in their leadership practices at work.

Furthermore, the participants suggested that collaboration is necessary for successful leadership as discussed in section 7.4. This includes working with colleagues and external business leaders whose input, regarding the requirements of business, would ensure better curriculum design. Specifically, collaboration would be developed by building relational trust with colleagues and partners, listening to the ideas of staff, and highlighting the role of collaborative leadership in curriculum design, renewal and delivery.

In addition, different perspectives among the stakeholders concerning the barriers facing graduates also emerged from the findings. The employers cited lacks in professional knowledge, English and soft skills, whereas graduates linked the lack of effectiveness of the Basic English curriculum to the communication challenges they face in their workplace. Senior leaders at 
the universities explained that the challenges faced by graduates in the workplace resulted from the inadequacies of the universities themselves, including staff shortages, facilities and resources. However, EFL lecturers reported the main cause of such challenges was the students' diverse levels of English within their large classes.

\subsection{Potential contributions of the study}

The goals of this study were: to identify the relationship between leadership at different levels and curriculum issues; to critically analyse leadership roles in the Basic English curriculum design and delivery in two selected universities; and to examine perceptions of stakeholders such as employers, graduates, academic leaders and EFL lecturers about the effectiveness of the Basic English curriculum design and delivery.

This study is one of the first works with a central focus on the role of leadership from different stakeholders' perspectives on curriculum design and delivery in a Vietnamese context. There are few detailed and comprehensive studies of curriculum leadership in Vietnamese universities. Therefore, the study may provide valuable information for policy makers, university leaders, curriculum developers and EFL lecturers to clarify the role of academic leadership in the Vietnamese university context in terms of theory, policy, and practice.

The leadership literature is presently dominated by Western perspectives. Therefore, it may not always be applicable or appropriate to Eastern contexts. Accordingly, my thesis argues that the leadership literature needs to take into consideration cultural factors such as Confucian philosophy. Confucian values and gender differences together create more challenges for female leaders in practising their roles. The ways leaders' exercise leadership may contribute to understandings of how to improve the quality of educational leadership practices not only in Vietnamese universities but may also be of significance to other countries' higher education contexts where are strongly influenced by Confucian ideology. 
Theoretical implications of this study include an understanding of how leadership at all levels in Vietnamese higher education impacts on curriculum design and delivery. The original contributions of the thesis lie in its central focus on the role of leadership from different stakeholders' perspectives. The research has brought insights for senior leaders looking to create successful collaborations with their colleagues and partners in curriculum design and renewal and provided guidance to enhance educational leadership practices in the two chosen institutions. Different perspectives of leadership roles and practices in curriculum design and delivery at both universities provide valuable information for policy makers, university leaders, curriculum developers and EFL lecturers. In particular, this thesis makes a number of important contributions to our understanding of academic leadership in the Vietnamese university context. First, the leadership literature needs to take into consideration cultural factors such as Confucian philosophy in the Vietnamese context because Confucian philosophy appears to have a huge influence on senior leaders' perceptions of leadership. Vietnamese society is "a highly bureaucratic and hierarchical structure" in which age and seniority is accorded with wisdom (Dung, 2012, p.7). Therefore, the hierarchical structure and power distance has inevitably influenced senior leaders' leadership practices as revealed in this study. From the observation data, it appeared that lecturers respect their leader's seniority and power so many of them kept quiet and listened to him during meetings. It is obvious that power distance and hierarchical structures prevent academic staff from contributing their ideas in solving the curriculum issues.

Second, gender differences and Confucian values together create more challenges for female leaders in practising their roles. In line with Lan (2012), this study demonstrates that female leaders face challenges in their academic leadership practices due to culturally-determined gender expectations. Therefore, this study has provided insights into the influences of cultural values on senior leaders' perceptions of performing their roles in curriculum design and delivery at Vietnamese tertiary education level. 
Third, distributed leadership and collaborative leadership could be two effective leadership approaches to dealing with curriculum issues in Vietnamese higher education contexts. This research highlighted the importance of distributed leadership in emphasising collectivism rather than individualism (Bolden, Petrov, and Gosling, 2009) as discussed in section 2.4.2. Therefore, distributed leadership in curriculum design and delivery could be an effective approach in the Vietnamese (i.e collective) society. This study is supported by Gardiner's (2002) view that academic leaders should: actively engage in a balanced curriculum and give excellent academic advice to students; ensure active involvement of students in all their study components; and provide support and development. This study provides further support for the role of collaborative leadership in curriculum design and delivery (Humphreys, 2013). The findings revealed that senior leaders and EFL lecturers appear to work collaboratively to solve the issue of curriculum renewal and delivery as discussed in section 7.4.3.

The ways that participants' exercise leadership contributes to understandings about how to improve the quality of educational leadership practices not only in Vietnamese universities but may also be of significance to other countries' higher education contexts are also strongly influenced by Confucian ideology. In summary, the results of this research study have contributed to the understanding of the role of leadership in curriculum design and delivery in Vietnamese universities especially in relation to effective leadership and the importance of promoting and supporting the Basic English curriculum design and delivery. This study will be useful not only in the Vietnamese context but also in other countries teaching Basic English curriculum as a second or foreign language.

\subsection{Policy recommendations}

The findings from the research have some implications for policy development in Vietnamese higher education contexts. Leadership in curriculum design and delivery would be more effective if: 


\subsubsection{At the ministry level}

$>$ Ministries should minimise the impact of dual leadership to ensure more autonomy for universities. This would allow university leaders to have more opportunity to perform their roles effectively including expanding their campuses, updating teaching facilities and providing more financial support for lecturers to improve their professional knowledge and English.

Ministries should document clearly defined roles and responsibilities at each level of the education system (from MoET to institutional level) in order to clarify the boundary between the national level autonomy and institutional level autonomy.

> Ministries should increase basic salaries of higher education staff to align with the cost of living and inflation as discussed in section 4.6 so that academics feel comfortable to focus on doing research and improving their professional knowledge. Besides, a programme for non-salary incentives ought to be developed for lecturers (for example, merit-based promotion and more continuting professional development opportunities).

$>\quad$ The leadership teams and ministries should give attention to improving the quality of training to enable Vietnamese universities to compete with other universities in the world. Further, ministries should review the distribution of resources to universities and ensure that existing channels function efficiently. Suitable resources and infrastructures would create an environment conducive to learning for their students so that they can be better equipped with more speaking practice and work-based experience before going into the workplace.

\subsubsection{At the institution level}

> Universities should invest in leadership development by proactively providing learning opportunities and resources for their staff such as leadership and professional development workshops.

> Universities should develop policies to have the curriculum designed and approved by the discipline faculty. This would allow lecturers the 
flexibility to deliver an appropriate curriculum and one of value to their students.

D Besides incentives from the ministries, universities should also develop their own incentive programmes such as offering funding and meritbased promotion for lecturers to encourage them to pursue research and professional development.

Universities could consider launching yearly online surveys to obtain graduates' feedback on the Basic English curriculum design and delivery. This feedback should be given careful consideration and alternations made, if useful to improve the effectiveness of the curriculum.

> Universities should collaborate with businesses in the design and delivery of English curriculum in Finance, Banking, and Accounting. This policy would ensure that the English curriculum would be responsive to the needs of graduates and employers.

$>\quad$ University leaders should develop an awareness of the dual responsibilities expected of academic women. This would involve leaders showing understanding, tolerance and support for the demanding extra duties performed by their female colleagues.

$>\quad$ Lastly, academic leadership at all levels should enhance participation by delegating authority and sharing responsibilities and decision making among heads of departments and faculty members. Effective academic leadership needs to restructure itself toward a department-based system that decreases the multiple levels of decision-making, while increasing the department's autonomy in support of participatory decision making.

\subsection{Practice recommendations}

This research has several practical implications developed from the suggestions made by employers and graduates to university leaders, curriculum developers and teachers. The findings of this study have highlighted the importance of academic leaders and programme developers working together to solve curriculum issues effectively. 


\subsubsection{For university leaders}

University leaders are responsible for leading at the institutional level. Therefore:

> Institutional leaders should be aware of combining top-down and bottom-up leadership approaches in curriculum design and delivery. The distributed model proposed by Scott and others (2008) could be a solution in Vietnamese higher education contexts.

$>$ They should develop their awareness of how all academic staff can make a valuable contribution.

> They should also facilitate more collaborative curriculum meetings to empower lecturers to have more input into curriculum design and delivery and demonstrate their receptiveness to lecturers' feedback and implement their suggestions. This would ensure collaboration across the university to find the common ground to solve curriculum issues.

> A key action in changing the leadership practices for better curriculum design and delivery would be for university leaders to re-apportion teaching hours among the four skills (listening, speaking, reading and writing) to allow more practice for English language instruction.

> Another necessary change is to place students in smaller classes based on their levels of English. This would make classes more manageable and timetabling lessons for each skill would enhance instruction and improve students' acquisition of the English language. Finally, reducing the teaching loads would leave more time for lecturers to prepare, plan, do research and improve their professional knowledge to respond to the requirements of the labour force and global integration.

- Universities should cooperate more with businesses so that graduates can meet enterprise needs. The input by business leaders could be very helpful for curriculum developers to review curriculum to meet the 
requirements of the workplace and enable graduates to adapt more quickly to the work environment.

Universities should provide more funding for English language teachers to access forums to learn and share expertise with domestic and international colleagues and experts in their majors. This would enhance their professional knowledge and thus their ability to provide better quality education.

> Finally, further investment in extending the campuses, purchasing new teaching aids and appropriate resources for teaching should be a priority.

\subsubsection{For curriculum developers}

Curriculum developers should consider redesigning the curriculum to have a more communicative focus. Time spent on grammar and translation should be reduced and more oral work situations should be included to ensure graduates are better prepared for work when they leave university.

$>$ Curriculum should be reviewed and if necessary, revised on a regular basis to better serve the changing needs of both students and society broadly. Redesigning curriculum and the inclusion of oral assessments in examinations would undoubtedly help graduates to develop the English language competence needed in their workplaces.

\subsubsection{For EFL lecturers}

DFL lecturers need to be more proactive in offering their opinions in curriculum meetings so long as they will be listened to.

$>E F L$ lecturers should also establish a self-reinforcing cycle of learning to improve their professional knowledge as part of their appraisal process.

$>$ EFL lecturers should consider methods of classroom activities that encourage more speaking practice. For example, organising 5 or 10 
minute seminars or group discussions to help students improve confidence in communication.

\subsection{Recommendations for future studies}

This research investigated the role of leadership in promoting and supporting the Basic English curriculum design in two selected tertiary institutions. The purposive sampling procedure was applied to gain insight into leadership practices in curriculum design and delivery at the two universities. This data set provided a rich source of information for analysing and identifying the roles of leadership at different levels. This research was clearly limited to the leadership teams at the two selected Vietnamese universities. Although some of the basic concepts may be transferrable to other universities, the interpretive case studies are small-scale and specific to particular cases. Therefore, they cannot be generalised to larger populations of universities in Vietnam or other countries.

There are many potential areas for future research. As this research focused on reviewing the role of leadership in the Basic English curriculum design and delivery in two Vietnamese universities, it would be useful to research a larger sample of different academic disciplines such as humanities, social science, medicine and so on. Similar studies in different regions and involving various taught-disciplines would help to widen the scope and perhaps reveal comparable findings which could broaden and validate the role of leadership in curriculum design and delivery.

More research into evolving the collaborative leadership practice in curriculum issues that is incorporated with academic leadership would also be important. It is also necessary to understand both the impact of dual leadership and distributed leadership in higher education contexts. Such understanding may eventually be extended beyond the Basic English curriculum design and delivery to include a broad suite of other subjects. It would also be interesting to study whether collaborations in curriculum design and delivery requires different leadership styles in relation to developing collaborative efforts. 
From a theoretical perspective, this study may have contributed to a deeper understanding the influence of Confucian ideology on leadership practices in Vietnamese HEls. Although this study has given some understanding of Confucian ideology's influence on leadership practices at the two selected universities, further research on how Confucian ideology affects academic leadership across the whole Vietnamese higher education system should be conducted. Academic leadership in Vietnamese higher education, in this study, reveals a mixture of distributed leadership and collaborative leadership in curriculum design and delivery which can provide insights for other Vietnamese universities. Because of the unique feature of the hierarchical structure of Vietnamese society, it is possible for academic leadership to be more effective if distributed leadership can be combined with collaborative leadership in dealing with curriculum issues.

\subsection{Concluding comments}

Although this study is small, it has contributed some important insights into the role of leadership in curriculum design and delivery at two Vietnamese universities. The findings showed that senior leaders espoused claims of distributed and collaborative leadership approaches but in reality it was not the case as reported by the EFL lecturers and by my observation. As stated in the introductory chapter, the research study has a personal value to me as an EFL lecturer and now as a researcher. Conducting this study has helped me to better understand the relationship between leadership and curriculum issues. It is certain that the knowledge I have gained from doing this study will be very useful for my future research and teaching career. The practical implications addressed in 8.3.3 will be relevant to me when I return to Vietnam to continue teaching. It is also expected that the study findings will contribute to curriculum innovation strategies in the Vietnamese context and also in other countries teaching Basic English curriculum as a second or foreign language.

The findings from the two universities in this study provided evidence that academic leadership in Vietnamese higher education contexts demonstrated 
a combination of distributed leadership and collaborative leadership in curriculum design and delivery. These findings may provide valuable information to other Vietnamese tertiary institutions and to other countries where English is taught as a second language. In order to achieve effective and sustainable academic leadership practices in the Vietnamese higher education system, it is necessary to have institutional autonomy and financial support for resources and professional development. These combined with the collaborative efforts of senior leaders and academic staff will have the potential to markedly improve students' achievement. 


\section{REFERENCES}

Ali, M. M. (2010). Revisiting English language teaching (ELT) curriculum design: How appropriate is Bangladesh higher secondary level National ELT curriculum as a learner-centred one? IIUC Studies, 7 , 283-296.

Anaf, S., Drummond, C., \& Sheppard, A. L. (2007). Combining case study research and systems theory as a heuristic model. Qualitative Health Research, 17(10), 1309-1315.

Anh, H. K. K. (2010). Use of Vietnamese in English language teaching in Vietnam: Attitudes of Vietnamese university teachers. English Language Teaching, 3(2), 119-128.

Anh, T. N. (2009). The internationalization of higher education in Vietnam in the context of East Asian integration: Policies and practice Internationalization, Globalization, and Regionalization of Higher Education (pp. 27-57). Japan: Waseda University.

Anh, V. (2012, February 8). Đổi mới giáo dục đại học Việt Nam - Thực trạng và giải pháp (Innovations in Vietnamese higher education - Problems and solutions), Bao Dien Tu Dang Cong San Viet Nam. Retrieved 11 March from http://www.baomoi.com/Home/GiaoDuc/www.cpv.org.vn/Doi-moiGiao-duc-dai-hoc-o-Viet-Nam--Thuc-trang-va-giai-phap/7842814.epi

Anh, T. N., \& Tho, V. N. (2014). Biến động nhân lực ngành ngân hàng tại Việt Nam- Thực trạng và giải pháp (Fluctuation of banking human resources in Vietnam - Problems and solutions). Retrieved October 29, from http://www.tapchicongsan.org.vn/Home/PrintStory.aspx?distribution=3 0022\&print=true 
Anh, T. P. V. (2014). Autonomy in Vietnam's law of higher education. Paper presented at the The Vietnam education dialogue: Higher education reforms Ho Chi Minh City, Vietnam.

Ashwill, M. A., \& Diep, T. N. (2005). Vietnamese today: A guide to a national at a crossroads. Yarmouth: Intercultural Press.

Avolio, J. B., Walumbwa, O. F., \& Weber, J. T. (2009 ). Leadership: Current theories, research, and future directions. The Annual Review of Psychology, 60, 421-449.

Barnett, R. (1997). Towards a higher education for a new century. London: Institute of Education, University of London.

Barnett, R., \& Coate, K. (2005). Engaging the curriculum in higher education Buckingham SRHE \& Open University Press.

Barry, D. (1991). Managing bossless team: Lessons in distributed leadership. Organizational Dynamics, 20(1), 31-47.

Bell, B., \& Baker, R. (1997). Curriculum development in science: Policy-topractice and practice-to-policy. In B. Bell \& R. Barker (Eds.), Developing the science curriculum in Aotearoa New Zealand (pp. 117). Auckland: Longman.

Bendikson, L., Robinson, V., \& Hattie, J. (2012). Principal instructional leadership and secondary school performance. SET Research Information for Teachers, 1, 2-8.

Bennett, N., Crawford, M., \& Cartwright, M. (2003). Effective educational leadership. Thousand Oaks, CA: Sage.

Bennett, N., Wise, C., Woods, A., P., \& Harvey, A. J. (2003). Distributed Leadership: A review of literature. UK: National College for School Leadership. 
Berg, L. B. (2004). Qualitative research methods for the social sciences $\left(5^{\text {th }}\right.$ ed.). Boston: Pearson Education, Inc.

Bich, V. P. (1999). Vietnam. The Vietnamese family in change: The case of Red River Delta. Richmon, Surrey: Curzon Press in cooperation with The Nordic Institute of Asian Studies, Vietnam in transition series, Bibliography, Index.

Bijandi, M. S., Nazari, K., Pourrajab, M., \& Mahdinezhad, M. (2011). Role of a dynamic educational leader on teaching and learning in higher education. Paper presented at the International Conference on Sociality and Economics Development IPEDR.

Blackwell, J. P. (2003). Student learning: Education's field of dreams. Phil Delta Kappan, 84(5), 362-367. doi: 10.1177/003172170308400508

Bolden, R. (2011). Distributed leadership in organizations: A review of theory and research. International Journal of Management Reviews, 13, 251 269. doi: $10.1111 /$ j.1468-2370.2011.00306.x

Bolden, R., Gosling, J., O'Brien, A., Peters, K., Ryan, M., \& Haslam, A. (2012). Academic leadership: Changing conceptions, identities and experiences in UK higher education. London, UK: Leadership Foundation for Higher Education.

Bolden, R., Petrov, G., \& Gosling, J. (2008a). Developing collective leadership in higher education Research and development series $\left(1^{\text {st }}\right.$ ed., pp. 1-88). London, UK: Centre for Leadership Studies, University of Exeter.

Bolden, R., Petrov, G., \& Gosling, J. (2008b). Tension in higher education leadership: Towards a multi-level model of leadership practice. Higher Education Quarterly, 62(4), 358-376. doi: 10.1111/j.14682273.2008.00398.x 
Bolden, R., Petrov, G., \& Gosling, J. (2009). Distributed leadership in higher education: Rhetoric and reality. Educational Management Administration and Leadership, 37(2), 257-277. doi: $10.1177 / 1741143208100301$

Boyatzis, E. R. (1998). Transforming qualitative information: Thematic analysis and code development Thousand Oaks: CA: Sage.

Braun, V., \& Clarke, V. (2006). Using thematic analysis in psychology. Qualitative Research in Psychology, 3(2), 77-101. doi: 10.1191/1478088706qp063oa

Briggs, A., Coleman, M., \& Morrison, M. (2012). Research methods in educational leadership and management $\left(3^{\text {rd }}\right.$ ed.). London: Sage.

Brown, P. (2004). Strategic capability development in the higher education sector. The International Journal of Educational Management, 18(7), 436-445.

Brungardt, C. L. (1998). The new face of leadership: Implications for higher $\begin{array}{lllll}\text { education. } & \text { Retrieved } & 25 & \text { February } & 2014\end{array}$ http://www.nwlink.com/ donclark/leader/lead edu.html

Bryman, A. (1988). Quality and quantity in social research. London: Routledge.

Bryman, A. (2007). Effective leadership in higher education: A literature review. Studies in Higher Education, 32(6), 693-710. doi: 10.1080/03075070701685114

Burgoyne, J., Mackness, J., \& Williams, S. (2009). Baseline study of leadership development in higher education Research and Development Series. London, UK: Leadership Foundation for Higher Education.

Burns, M. J. (2010). Leadership. New York: HarperCollins. 
Burton, L. J., \& Dowling, D. (2005). In search of the key factors that influence student success at university. Paper presented at the 28th HERDSA Annual Conference: Higher Education in a Changing World (HERDSA 2005), Sydney, Australia.

Bush, T. (2003). Theories of educational leadership and management ( $3^{\text {rd }}$ ed.). London: Sage.

Canh, V. L., \& Barnard, R. (2009). Curriculum innovation behind closed classroom doors: A Vietnamese case study. Prospect: An Australian Journal of TESOL, 24(2), 1-14.

Cardno, C. (2012). Managing effective relationships in education. London: Sage.

Carson, J. B., Tesluk, P. E., \& Marrone, J. A. (2007). Shared leadership in teams: An investigation of antecedent conditions and performance. Academy of Management Journal, 50(5), 1217-1234.

Chang, I. (2011). A study of the relationships between distributed leadership, teacher academic optimism and student achievement in Taiwanese elementary schools. 31(5), 491-515. doi: $10.1080 / 13632434.2011 .614945$

Charmaz, K. (2006). Constructing grounded theory: A practical guide through qualitative analysis. London: Sage.

Chi, K. (2011, 22 December). University graduates lack necessary skills for works, VietnamNet English. Retrieved 18 February 2012 from http://english.vietnamnet.vn/fms/education/16558/universitygraduates-lack-necessary-skills-for-works.html

Clark, N. (2010, August 1). Higher education in Vietnam: Student growth, faculty shortages and international partnerships, World Education News \& Reviews. Retrieved 24 February 2012 from 
http://wenr.wes.org/2010/08/wenr-julyaugust-2010-practicalinformation/

Cleveland-Innes, M., \& Sangra, A. (2010). Leadership in a new era of higher distance education. In M. Cleveland-Innes \& D. Garrison (Eds.), An introduction to distance education: Understanding teaching and learning in a new era (pp. 227-246). New York: Routledge.

Coaldrake, P., \& Stedman, L. (1999). Academic work in the twenty-first century: Changing roles and practices Occasional Paper Series, 1-35.

Cohen, L., Bunker, A., \& Ellis, R. (2007). Exploring the role of unit coordinators. Paper presented at the The HERDSA Conference, Adelaide, South Australia.

Cohen, L., Manion, L., \& Morrison, K. (2007). Research methods in education $\left(6^{\text {th }}\right.$ ed.). New York: Routledge.

Cohen, W. (2013, 28 December) Four myths about "heroic leadership".

Retrieved 31 December 2013

http://www.processexcellencenetwork.com/lean-six-sigma-businesstransformation/columns/heroic-leadership-it-may-not-be-what-youthink/

Conger, J. A., \& Pearce, C. L. (2003). Shared leadership. Thousand Oaks, CA: Sage.

Couper, M. P. (2000). Web-based surveys: A review of issues and approaches. Public Opinion Quarterly, 64, 464-494.

Creswell, W. J. (2003). Research design: Qualitative, quantitative, and mixed methods approaches $\left(2^{\text {nd }}\right.$ ed.). CA: Sage.

Creswell, W. J. (2008). Educational research: Planning, conducting, and evaluating quantitative and qualitative research ( $3^{\text {rd }}$ ed.). New Jersey: Pearson Prentice Hall. 
Creswell, W. J. (2009). Research design: Qualitative, quantitative and mixed methods approaches ( ${ }^{\text {rd }}$ ed.). CA: Sage.

Creswell, W. J. (2012). Qualitative inquiry and research design: Choosing among five apporaches ( $3^{\text {rd }}$ ed.). London: Sage.

Creswell, W. J. (2014). Research design: Qualitative, quantitative, and mixed methods approaches $\left(4^{\text {th }}\right.$ ed.). CA: Sage.

Creswell, W. J., \& Plano Clark, V. L. (2011). Designing and conducting mixed methods research $\left(2^{\text {nd }}\right.$ ed. $)$. CA: Sage

Currie, J., \& Vidovich, L. M. (2009). The changing nature of academic work. New York: Routledge

D'Agostino, F., \& O'Brien, M. (2010). Articulating curriculum leadership in higher education: An examination of the knowledge, expertise, role and dilemmas of the sequence of study convenor Closing the gap in curriculum leadership. Brisbane, Australia: Australian Learning and Teaching Council.

Davis, H., \& Jones, S. (2014). The work of leadership in higher education management. Journal of Higher Education Policy and Management, 36(4), 367-370. doi: 10.1080/1360080X.2014.916463

Debowski, S., \& Blake, V. (2004). The development needs of higher education academic leaders in encouraging effective teaching and learning. Paper presented at The 13th Annual Teaching Learning Forum, Perth: Murdoch University.

http://sn.curtin.edu.au/tl//tlf2004/debowski.html

Del Favero, M. (2006a). Disciplinary variation in preparation for the academic dean role. Higher Education Research \& Development, 25(3), 277292. 
Denzin, N. K., \& Lincoln, Y. S. (2000). Introduction: the discipline and practice of qualitative research Handbook of qualitative research $\left(2^{\text {nd }}\right.$ ed., pp. 1-28). London: Sage.

Denzin, N. K., \& Lincoln, Y. S. (2005). Introduction: The discipline and practice of qualitative research In N. K. Denzin \& Y. S. Lincoln (Eds.), The Sage handbook of qualitative research ( $3^{\text {rd }}$ ed., pp. 1-32). Thousand Oaks, CA: Sage.

Dillman, D. A. (2007). Mail and internet surveys: The tailored design method 2007 update with new internet, visual, and mixed-mode guide. Hoboken, New Jersey: John Wiley \& Sons.

Dimmock, C., \& Walker, A. (2005). Educational leadership: Culture and diversity. Thousand Oaks, CA: Sage.

Dinham, S. (2005). Principal leadership for outstanding educational outcomes. Journal of Education Administration, 43(4), 338-356.

Doan, H. D. (2005). Moral education or political education in the Vietnamese educational system? Journal of Moral Education, 34(451-463).

Drath, W., McCauley, C., Palus, C., Van, V. E., O'Connor, P., \& McGuire, J. (2008). Direction, alignment, commitment: Towards a more integrative ontology of leadership. The Leadership Quarterly, 19(6), 635-653.

Du, N. N. (2013). The influence of distributed leadership on teacher organisational comitment: Initial evidence from Vietnam. ARECLS, 10, 69-90.

Dung, T. M. T. (2012). Developing middle leadership in a Vietnamese university - Perceptions and practices: A case study from the Mekong Delta. (Unpublished Master Thesis), University of Waikato, New Zealand. 
Eddy, P. L. (2003). Sensemaking on campus: How community college presidents frame change. Community College Journal of Research and Practice, 27(6), 453-471.

Eduniversal. (2013). The best 1,000 Business schools in 154 countries in 2013. Retrieved 25 June 2014 from http://www.eduniversalranking.com/about

Elmore, R. F. (2000). Building a new structure for school leadership. Washington, DC: The Albert Shanker Institute.

Estermann, T., \& Nokkala, T. (2009). University autonomy in Europe (pp. 1 48). Brussels, Belgium: European University Association.

Estermann, T., Nokkala, T., \& Steinel, M. (2011). University autonomy in Europe II- The scorecard (pp. 1-84). Brussels, Belgium: European University Association.

Fidler, B. (1997). School leadership: Some key ideas. School Leadership and Management, 17(1), 23-37.

Firestone, A. W, \& Wilson. L. B. (1985). Using bureaucratic and cultural linkages to improve instruction: The principals' contribution. Educational Administration Quarterly, 21(1), 7-30.

Fletcher, J. K. (2004). The paradox of postheroic leadership: An essay on gender, power, and transformational change. The Leadership Quarterly, 15, 647-661.

Fontana, A., \& Frey, J. H. (2005). The interview: from neutral stance to political involvement. In N. K. Denzin \& Y. S. E. Lincohn (Eds.), The Sage handbook of qualitative research (pp. 695-729). Thousand Oaks, CA: Sage.

Fosberg, R. H., \& Nelson, M. R. (1999). Leadership structure and firm performance. International Review of Financial Analysis, 8(1), 83-96. 
Frenier, M. D., \& Mancini, K. (1996). Vietnamese women in a Confucian setting: The causes of the initial decline in the status of East Asian women. In K. Barry. (Ed.), Vietnam's women in transition (pp. 21-37). New York: Martin's Press, Inc.

Fry, G. W. (2009). Higher education in Vietnam. In Y. Hirosata \& Y. Kitamura (Eds.), The political economy of educational reforms and capacity development in Southeast Asia (pp. 237-261). London, England: Springer.

Fullan, M. (2006). Turnaround leadership. Thousand Oaks, CA: Sage.

Fullan, M. (2007). Educational leadership. San Francisco, CA: Jossey-Bass.

Fullan, M., \& Scott, G. (2009). Turnaround leadership for higher education. San Francisco, CA: Jossey-Bass.

Gaff, J. G., \& Ratcliff, J. (1997). Handbook of the undergraduate curriculum A comprehensive guide to purposes, structures, practices, and change. San Francisco: Jossey-Bass.

Galli, D. J. (2011). Organisational management in the non-profit performing arts: Exploring new models of structure, management, and leadership. (Unpublished Master Thesis), University of Oregon, Oregon, USA.

Gardiner, L. F. (2002). Research on learning and student development and its implications. In R. M. Diamond (Ed.), Field Guide to Academic Leadership (pp. 89-110). San Francisco, CA Jossey-Bass.

General Statistics Office of Vietnam. (2011). University and college education. $\quad$ Retrieved 6 April 2012 from: http://www.gso.gov.vn/default en.aspx?tabid=474\&idmid=3\&ltemID $=1$ $\underline{2699}$

Gibbs, E. (2005). Leadership next: Changing leaders in a changing culture. Leicester: Inter-Varsity Press. 
Gmelch, W. H. (2004). The department chair's balancing acts New Directions for Higher Education, 126, 69-84.

Gosling, J., Bolden, R., \& Petrov, G. (2009). Distributed leadership: What does it accomplish? Leadership, 5(3), 299-310.

Gottfridsson, A. (2013). Dual leadership: An example of how leadership might be shared in a non-profit organisation. (Unpublished Master Thesis), University of Gothenburg, Gothenburg, Sweden. (N.2013.50)

Grant, D. \& McLarty, R. (2004) Business basics. Hanoi: Thanh Nien Publishing House.

Grint, K. (2005). Leadership: Limits and possibilities. Basingstoke: Palgrave Macmillan.

Gronn, P. (2002). Distributed leadership as a unit of analysis. The Leadership Quarterly, 13(4), 423-451.

Gronn, P. (2009). From distributed to hybrid leadership practice. In A. Harris (Ed.), Distributed leadership: Different perspectives (pp. 197-217). Milton Keynes: Springer.

Gropello, E. D., Thomas, C. J., Yemenez, E. Y., Chchibber, A., \& Adams, J. W. (2008). Vietnam: Higher education and skills for growth (pp. 1-232). U.S.A: Human Development Department East Asia and Pacific Region.

Gubrium, J. F., \& Holstein, G. A. (2002). Handbook of interview research: Context and method. Thousand Oaks, CA: Sage.

Ha, H. T. T. (2001). Vietnamese women and leadership in the 20th century: Prospects for Vietnamese women leaders in the 21 st century. Kasarinlan: Philippine Journal of Third World Studies, 16(1), 181-198. 
Hang, T. T. T. (2008). Women's leadership in Vietnam: Opportunities and challenges. Journal of Women in Culture and Society, 34(1), 16-21. doi: $10.1086 / 588432$

Hang, T. T. P. (2011). Factors affecting the motivation of Vietnamese technical English majors in their English studies. (Unpublished PhD Thesis), University of Otago, Dunedin, New Zealand.

Harris, A. (2008). Distributed Leadership: According to the evidence. Educational Administration, 46(2), 172-188.

Harris, A. (2009). Distributed leadership: Different perspectives. London: Springer Science+Business Media B.V.

Harris, J., Martin, B. N., \& Agnew, W. (2004). The characteristics, behaviours, and training of effective educational leadership chairs. In D. C. Thompson \& F. E. Campton (Eds.), The changing face(s) of educational leadership. Kansas city, Missouri: The University Council for Educational Administration.

Hayden, M. (2012). Developing a globally integrated higher education system in Vietnam: A nine-point plan. Paper presented at the Vietnamese Higher Education in the Era of Globalization, Ho Chi Minh City, Vietnam.

Hayden, M., \& Thiep, Q. L. (2007). Institutional autonomy for higher education in Vietnam. Higher Education Research and Development, 26(1), 73-85. doi: 10.1080/07294360601166828Hayden, M., \& Thiep, Q. L. (2010). Vietnam's higher education system. In G. Harman, M. Hayden \& N. T. Pham (Eds.), Reforming higher education in Vietnam: Challenges and priorities (pp. 15-30). Netherlands: Springer, Dordrecht. 
Heikkila, A., \& Lonka, K. (2006). Studying in higher education: Students' approaches to learning, self-regulation, and cognitive strategies. Studies in Higher Education, 31(1), 99-117.

Hempsall, K. (2014 ). Developing leadership in higher education: Perspectives from the USA, the UK and Australia. Journal of Higher Education Policy and Management, 36(4), 383-394. doi: 10.1080/1360080X.2014.916468

Henderson, J. G., \& Hawthorne, R. D. (2000). Transformative curriculum leadership. New Jersey: Merrill, Prentice Hall.

Hicks, O. (2007, 8-11 July). Curriculum in higher education in Australia Hello? Paper presented at the Enhancing Higher Education, theory and Scholarship, Proceedings of the 30th HERDSA Annual Conference [CD-ROM], Adelaide.

Hien, V. N. (2014). Thông tư số 01/2014/TT-BGDĐT Ban hành Khung năng lực ngoại ngữ 6 bậc dùng cho Việt Nam (Circular No. 01 / 2014 / TT BGDDT on issuing foreign language competence frame of six levels for Vietnam) Retrieved 20 September 2014, from http://www.moet.gov.vn/?page $=6.10 \& v i e w=5552$

Hiep, H. P. (2006). Researching the research culture in English language education in Vietnam. Teaching English as a second or foreign language, 10(2).

Hiep, P. (2012). New higher education law approved, but sparks criticism. Retrieved June 19, from University World News http://www.universityworldnews.com/article.php?story=201206191115 $\underline{58817}$

Hieu, T. (2011, June 13). Students lack confidence to use English. Retrieved (25 September) from vietnamnews.vn/Talk-AroundTown/212262/Students-lack-confidence-to-use-English.html 
Hoan, P. (2014, October 9). Ngành Tài chính - Ngân hàng: Yếu tiếng Anh sẽ thất nghiệp (Finance - Banking majored students: Lack of English competence leads to unemployment), Dantrinews. Retrieved from http://dantri.com.vn/giao-duc-khuyen-hoc/nganh-tai-chinh-ngan-hangyeu-tieng-anh-se-that-nghiep-983274.htm

Hotho, S., Goldrick, J., \& Work, A. (2008). New perspectives on academic leadership: Moving the research agenda. Academic Leadership: The Online Journal, 6(3).

House, R. J., Hanges, P. J., Javidan, M., Dorfman, P. W., \& Gupta, V. (2004). Leadership, culture, and organizations: The GLOBE study of 62 societies. Thousand Oaks, CA: Sage.

Humphreys, D. (2013). Deploying collaborative leadership to reinvent higher education for the twenty-first century. Peer Review 15(1) 4-6.

Hung, D. N. (2012, Sep 27). Giáo dục Việt Nam bệnh đã quá nặng, cẫn được giải phẫu (Seriously "sick"- Vietnamese education system needs to be operated on), Giao Duc Retrieved 18 November 2012 from http://giaoduc.net.vn/Giao-duc-24h/Giao-duc-Viet-Nam-benh-da-quanang-can-duoc-giai-phau/230319.gd

Hung, N. (2013, December 28). Phó Thủ tướng Vũ Đức Đam: Đào tạo Đại học đang có vấn đề (Deputy Prime Minister Vu Duc Dam: Training in Vietnamese higher education is facing challenges), Dantri. Retrieved 14 January 2014 from http://dantri.com.vn/giao-duc-khuyen-hoc/phothu-tuong-vu-duc-dam-dao-tao-dai-hoc-dang-co-van-de-821047.htm

Hung, S. N. (2012). Vietnam's Higher Education Law. 08/2012/QH13. Retrieved from 5 April 2013 from http://www.chinhphu.vn/portal/page/portal/chinhphu/hethongvanban?cl ass $i d=1 \&$ mode $=$ detail \&document id $=163054$ 
Hung, V. T. (2007, May 14). Giáo dục Việt Nam nên học nền giáo dục nước Mỹ ở điểm nào? (Which lessons should the Vietnamese education system learn from America?), Viet Bao. Retrieved 15 August 2012 from http://vietbao.vn/Giao-duc/Giao-duc-Viet-Nam-nen-hoc-nen-giao-ducnuoc-My-o-diem-nao/55149871/202/

Huong, T. L. P. (2012). The renovation of higher education governance in Vietnam and its impact on the teaching quality at universities Tertiary Education and Management, 18(3), 289-308. doi: $10.1080 / 13583883.2012 .675350$

Huong, T. T. T. (2010). How do Vietnamese students prepare for study in English- speaking universities overseas? VNU Scientific Journal Social Science and Humanity, 26, 230-237.

Huu, T. (2012, November 19). Vietnam, Switzerland boost educational ties, Vietnam Plus. Retrieved 27 December 2012 from http://en.vietnamplus.vn/Home/VN-Switzerland-boost-educationalties/20129/28707.vnplus

Huyen, L. (2012, December 10). College grads lack teamwork, communication skills Tuoi Tre. Retrieved 16 January 2013 from http:/tuoitrenews.vn/education/4962/college-grads-lack-teamworkcommunication-skills

Huyen, T. P. (2008). Higher education in Vietnam: A look from labour market angle. Hanoi: Vietnam Development Forum.

Jackson, J. F. L. (2004). Toward a business model of executive behavior. The Review of Higher Education, 27(3), 409-427.

Jackson, N., \& Lund, H. (2000). Benchmarking for higher education. New York: Taylor \& Francis, Inc.

Jefferies, S. (2000). A literature review exploring a meaning for the term 'curriculum leadership'. Waikato Journal of Education, 6, 133-142. 
Johnson, B., \& Christensen, L. (2008). Educational research: Quantitative, qualitative and mixed approaches. Thousand Oaks, CA: Sage.

Jones, S., Hadgraft, R., Harvey , M., Lefoe, G., \& Ryland, K. (2014). Evidence-based benchmarking framework for a distributed leadership approach to capacity building in learning and teaching Office for Learning and Teaching. Sydney, Australia.

Jones, S., Harvey, M., \& Lefoe, G. (2014). A conceptual approach for blended leadership for tertiary education institutions. Journal of Higher Education Policy and Management, 36(4), 418-429. doi: 10.1080/1360080X.2014.916469

Jones, S., Harvey, M., Lefoe, G., \& Ryland, K. (2014). Synthesising theory and practice: Distributed leadership in higher education. Educational Management Administration \& Leadership, 1-17. doi: 10.1177/1741143213510506

Jones, S., Lefoe, G., Harvey, M., \& Ryland, K. (2012). Distributed leadership: a collaborative framework for academics, executives and professionals in higher education. Journal of Higher Education Policy and Management, 34(1), 67-78. doi: 10.1080/1360080X.2012.642334

Joyce, P., \& O'Boyle, C. (2013). Sustaining academic leadership in higher education. In C. O'Farrell \& A. Farrell (Eds.), Emerging issues III: From capacity building to sustainability (pp. 69-81). Athlone.

Kennedy, D. (1995). Another century's end: Another revolution for higher education. Change, 27(3), 8-10.

Knight, P. T., \& Trowler, P. R. (2001). Departmental leadership in higher education. Philadelphia: Open University Press.

Kocolowski, D. M. (2010). Shared leadership: Is it time for a change? Emerging Leadership Journeys, 3(1), 22-32. 
Koivunen, N. (2007). The processual nature of leadership discourses. Scandinavian Journal of Management, 23(3), 285-305. doi: 10.1016/j.scaman.2007.05.006

Ladyshewsky, R., \& Jones, S. (2007). Academic leadership and the course coordinator: 'King pin' in the quality process'. Paper presented at the Evolution and Renewal in Quality Assurance, Hobart, Australia.

Lan, T. N. D. (2012). Vietnamese women in academic leadership experiences of mid-level women leaders in universities and colleges in the Mekong Delta. (Unpublished PhD Thesis), Michigan State University, The U.S.

Lauckner, H., Paterson, M., \& Krupa, T. (2012). Using constructivist case study methodology to understand community development processes: Proposed methodological questions to guide the research process. The Qualitative Report, 17, 1-22.

Le, T. C. N. (2005). From passive participant to active thinker - A learnercentred approach to material development. English Teaching Forum, 43(3), 2-9.

Leithwood, K. \& Poplin, S. M. (1992). The move toward transformational leadership Educational Leadership, 49(5), 8-13

Lincoln, Y. S., \& Guba, E. G. (1985). Naturalistic inquiry. Newbury Park, CA: Sage.

London, D. J. (2011). Education in Vietnam: Historical roots, recent trends (pp. 1-56). Singapore: Institute of South East Asian Studies.

Long, T. N. (2013). Integrating culture into Vietnamese university EFL teaching: A critical ethnography study. (Unpublished PhD Thesis), Auckland University of Technology, Auckland, New Zealand. 
Ly, T. P. (2010). Vietnamese students deserve a better quality education. http://lypham.net/joomla/index.php?option=com content\&task=view\&i $\underline{\mathrm{d}=203 \& \text { Itemid }=2}$

Ly, T. T., Marginson, S., Hoang, D., Quyen, D., Truc, L., Thao, V., ... Huong, $\mathrm{H}$. (2014). Higher education in Vietnam: Flexibility, mobility and practicality in the global knowledge economy. Basingstoke: Palgrave Macmillan.

MacBeath, J., Oduro, G. K. T., \& Waterhouse, J. (2004). Distributed leadership in action: A study of current practice in schools. Nottingham: National College for School Leadership.

Mackenzie, N., \& Knipe, S. (2006). Research dilemmas: Paradigms, methods and methodology. Issues In Educational Research, 16(2), 193-205.

Mahdinezhad, M., Suandi, B. T., Silong, D. A., \& Omar, B. Z. (2013). Transformational, transactional leadership styles and job performance of academic leaders. International Education Studies, 6(11).

Mai, T. (2015, January 18). Theory-heavy university curricula cannot produce highly qualified workers, Vietnamnet. Retrieved 19 February from http://www.vietnambreakingnews.com/2015/01/theory-heavyuniversity-curricula-cannot-produce-highly-qualified-workers/

Marginson, S., \& Sawir, E. (2006). University leaders' strategies in the global environment: A comparative study of Universitas Indonesia and the Australian National University. Higher Education Policy, 52, 343-373. doi: 10.1007/s10734-004-5591-6

Marshall, S. J. (2006). Issues in the development of leadership for learning and teaching in higher education. Occasional paper. Carrick Institute for Learning and Teaching in Higher Education. Australia. Retrieved 17 August 2012 from http://www.altc.edu.au/resource-issuesdevelopment-leadership-learning-macquarie-2008 
Marshall, S. J., Orrell, J., Cameron, A., Bosanquet, A., \& Thomas, S. (2011). Leading and managing learning and teaching in higher education. Higher Education Research and Development, 30(2), 87-103.

Mason, J. (2004). Mixing methods in a qualitatively driven way. Qualitative Research, 6(1), 9-25.

Mayes, T., Morrison, D., Mellar, H., Bullen, P., \& Oliver, M. (2009). Transforming higher education through technology-enhanced learning. York, England: Higher Education Academy.

McCaffery, P. (2010). The higher education manager's handbook: Effective leadership and management in universities and colleges. London: Routledge.

McDonald, J., Holt, D., Nagy, J., Cohen, L., Campbell-Evans, G., Chang, P., . . . \& Atkinson, K. (2010). Coalface subject coordinators - The missing link to building leadership capacities in the academic supply chain Literature review/Occasional Paper. Deakin University and Australian Learning and Teaching Council.

McKenzie, K., Gow, K., \& Schwietzer, R. (2004). Exploring first-year academic achievement through structural equation modelling. Higher Education Research and Development, 23(1), 95-112.

McMaster, M. (2014). Learning to lead: a practitioner perspective. Journal of Higher Education Policy and Management, 36(4), 430-439. doi: 10.1080/1360080X.2014.916470

Merriam, B. S. (2002). Introduction to qualitative research Qualitative research in practice (pp. 3-17). San Francisco: Jossey-Bass.

Mertens, M. D. (2005). Research methods in education and psychology: Integrating diversity with qualitative and qualitative approaches $\left(2^{\text {nd }}\right.$ ed.). Thousand Oaks, CA: Sage. 
Middlehurst, R. (1993). Leading academics. Buckingham, UK: SRHE Open University.

Middlehurst, R., Goreham, H., \& Woodfield, S. (2009). Why research leadership in higher education? Exploring contributions from the UK's leadership foundation for higher education. Leadership, 5(3), 311-329. doi:10.1177/174271500337763

Middlehurst, R., \& Woodfield, S. (2007). Responding to the internationalisation agenda: Implications for institutional strategy and practice Research Report for UK: The Higher Education Academy.

Mikhalak, W. M., \& Luan, P. V. (2009). US - Vietnam education task force. Hanoi: MoET.

Minh, L. L. (2014). Thinking globally, prospering regionally-ASEAN economic community 2015. Jakarta, Indonesia: The ASEAN Secretariat.

Ministry of Education and Training, MoET. (2003a). Decision No 06/2003/QD-BGDDT on promulgating the curriculum for foreign languages (English and French) at professional high schools.

Ministry of Education and Training, MoET (2006a). Instruction on teaching and learning foreign languages No 9893/BGDĐT-GDTrH dated September 6th, 2006. Ministry of Education and Training, MoET. (2009). Báo cáo sự phát triển của hệ thống giáo dục đại học, các giải pháp đảm bảo và nâng cao chất lượng đào tạo. (Report on the development of higher education system and solutions for quality assurance and improvement). Hanoi: MoET.

Montez, J. M., Wolverton, M., \& Gmelch, W. H. (2003). The roles and challenges of deans. Review of Higher Education, 26(2), 241-266.

Mukherji, P., \& Albon, D. (2010). Research methods in early childhood: An introductory guide. London: Sage. 
Mutch, C. (2005). Doing educational research: A practitioner's guide to getting started. Wellington, New Zealand: NZCER Press.

Nahavandi, A. (2012). The art and science of leadership (6 $6^{\text {th }}$ ed.). New Jersey: Pearson Prentice Hall.

Nation, I. S. P., \& Macalister, J. (2010). Language curriculum design. London: Routledge.

Neumann, R., Parry, S., \& Becher, T. (2002). Teaching and learning in their disciplinary contexts: A conceptual analysis. Studies in Higher Education, 27(4), 405-417. doi: 10.1080/0307507022000011525

Ngan, T. T. L. (2011). How does culture impact on women's leadership in higher education? A case study in Vietnam. (Unpublished Master Thesis), University of Waikato, New Zealand.

Nhan, T. N. (2008). Quyết định số 1400/QĐ-TTg ngày 30/9/2008 của Thủ tướng Chính phủ phê duyệt Đề án "Dạy và học ngoại ngữ trong hệ thống giáo dục quốc dân, giai đoạn 2008-2020"(Decision No. 1400 /QD-TTg dated 30/9/2008 of the Prime Minister approving the project "Teaching and learning foreign languages in the national education system for the period 2008-2020". Retrieved 25 July 2013, from Chinhphu portal page http://www.chinhphu.vn/portal/page/portal/chinhphu/hethongvanban?cl ass $i d=1 \&$ page $=18 \&$ mode $=$ detail\&document $i d=78437$

Northouse, P. G. (2007). Leadership: Theory and practice $\left(4^{\text {th }}\right.$ ed.). Thousand Oaks, CA: Sage.

Northouse, P. G. (2013). Leadership: Theory and practice (6 $6^{\text {th }}$ ed.). Thousand Oaks, CA: Sage.

Nunan, D. (1998a). Second language teaching and learning. Boston: Heinle \& Heinle. 
Nunan, D. (1988b). Syllabus design. UK: Oxford University Press.

O'Donoghue, T., \& Clarke, S. (2010). Leading learning. London: Routledge.

Oduro, K. T. G. (2004 ). Distributed leadership in schools: What English headteachers say about the pull and push factors? Paper presented at The British Educational Research Association Annual Conference, University of Manchester, U.K. http://www.leeds.ac.uk/

Oliver, L. S., \& Hyun, E. (2010). Comprehensive curriculum reform in higher education: Collaborative engagement of faculty and administrators. Journal of Case Studies in Education, 2, 1-20.

Parker, J. (2003). Reconceptualising the curriculum: From commodification to transformation. Teaching in Higher Education, 8(4), 529-543.

Patton, M. (2002). Qualitative research and evaluation methods ( $3^{\text {rd }}$ ed.). Thousand Oaks: Sage.

Pearson Education. (2011). Test comparisons internationally recognized English language exams: How they map to the Common European Framework (CEFR) levels Retrieved 25 September 2013 http://www.versanttest.com/technology/featured/Fact\%20Sheet\%20\%20Versant\%20English\%20comparison\%20to\%20other\%20English\% 20tests.pdf

Percy, A., Scoufis, M., Parry, S., Goody, A., Hicks, M., \& Macdonald, I. (2008). The RED report. Recognition, enhancement, development: The contribution of sessional teachers to higher education Report commissioned by the Australian Learning and Teaching Council.

Phi, N. N., Mai, T. V. \& Ga, V. B. (2014) Thông tư liên tịch hướng dẫn thực hiện một số điều của Nghị định số 49/2010/NĐ-CP ngày 14 tháng 5 năm 2010 của Chính phủ quy định về miễn, giảm học phí, hỗ trợ chi phí học tập và cơ chế thu, sử dụng học phí đối với cơ sở giáo dục thuộc hệ thống giáo dục quốc dân từ năm học 2010 - 2011 đến năm 
học 2014 - 2015 và Nghị định số 74/2013/ND-CP ngày 15 tháng 7 năm 2013 của Chính phủ sửa đổi, bổ sung một số điều của Nghị định số 49/2010/ND-CP (Joint-Joint Circular 49 / 2010 / ND - CP of May 14, 2010 of the Government providing for exemption or reduction of school fees and subsidy for costs of study and fee-collection mechanism, using the tuition fees in institutions of the national education system from the academic year 2010 - 2011 and 2014 2015 and Decree No. 74/2013 / ND - CP of July 15, 2013 of the Government amending and supplementing a number of articles of Decree No. 49 /2010 / ND -CP) Retrieved 12 August 2014 from http://vanban.chinhphu.vn/portal/page/portal/chinhphu/hethongvanban ?mode $=$ detail\&document $\_i d=174496$

Phuong, T. A. L. (2005). Action research in the Vietnam - Australia training project. Teacher's edition, 18, 8-15.

Phuong, T. M. H., \& Berg, D. (2010). Educational leadership challenges: Vietnam's system of higher education. Paper presented at the Asia Leadership Roundtable, Asia Pacific Centre for Leadership and Change, Hong Kong.

Prokhorov, A. (1979). The Great Soviet Encyclopedia. Russia.

QS top universities. (2014, August 27). QS University Rankings: Asia 2014. Retrieved 12 October from http://www.topuniversities.com/universityrankings/asianuniversityrankings/2014\#sorting=rank+region=+country $=138$ + faculty $=+$ stars $=$ false + search $=$

Quan, H. T. (2010, May 23). Chọn đổi mới quản lý làm đột phá là lựa chọn đúng đắn(Innovating management as $\mathrm{a}$ breakthrough is the right choice), Giao duc và Thoi dai Retrieved 8 July 2012 from http://gdtd.vn/channel/2741/201005/Chon-doi-moi-quan-ly-lam-dotpha-la-lua-chon-dung-dan-1927192/ 
Quyen, M. (2013, November 12). Confusing in transitioning full-time training from college to university, Education, Thanhnien, pp. 1-2. Retrieved 26 December 2013 from www.thanhnien.com.vn/pages/20131112/lungtung-dao-tao-lien-thong-chinh-quy.aspx

Ramsden, P. (1998). Learning to lead in higher education. London: Routledge.

Ratson, D. A., Tong, J. T., Maignan, I., Napier, K. N., \& Thang, V. N. (2006). Vietnam: A cross-cultural comparison of upward influence ethics. Journal of International Management, 12(1), 85-105.

Reiss, K. (2007). Leadership coaching for educators. Thousand Oaks, CA: Corwin Press.

Reushle, S., McDonald, J., \& Postle, G. (2009). Transformation through technology-enhanced learning in Australian higher education. In T. Mayes, D. Morrison, H. Mellar, P. Bullen \& M. Oliver (Eds.), Transforming higher education through technology-enhanced learning (pp. 58-71). York, England: Higher Education Academy.

Richards, C. J. (2013). Curriculum approaches in language teaching: Forward, central, and backward design. RELC Journal, 44(1), 5-33. doi: $10.1177 / 0033688212473293$

Runckel, C. (2009). The education system in Vietnam Retrieved 15 August 2012, from http://www.business-inasia.com/vietnam/education system in vietnam.html

Sáfar, A., \& Komos, J. (2008). Revisiting problems with foreign language aptitude. 46(2), 113-116.

Sarvi, J., Dhirathiti, N., Medrano, H., \& Banta, J. S. (2012). Administration and governance of higher education in Asia: Patterns and implications. Manila, Philippines: Asian Development Bank. 
Schwandt, T. A. (2007). The Sage dictionary of qualitative inquiry. Los Angeles: Sage.

Scott, G., Coates, H., \& Anderson, M. (2008). Learning leaders in times of change Final Report, ALTC. Australia: Academic Leadership Capabilities for Australian Higher Education

Sergiovanni, T. J. (1996). Leadership for the schoolhouse. San Francisco: Jossey-Bass.

Shin, J. C., \& Harman, G. (2009). New challenges for higher education: Global and Asia-Pacific perspectives. Asia Pacific Education Review, 1, 1-13. doi: 10.1007/s12564-009-9011-6

Short, G. K. (2002). Inquiry as a stance on curriculum. Retrieved 15 July 2014, from University of Arizona http://www.ibmidatlantic.org/Inquiry as stance.pdf

Sinclair, A. (2007). Leadership for the disillusioned. Thousand Oaks, CA: Sage.

Smith, R. (2005). Departmental leadership and management in chartered and statutory universities: A case of diversity. Educational Management Administration and Leadership, 33(4), 449-464.

Somalingam, A., \& Shanthakumari, R. (2013). The changing role of academic leadership. Educationia Confab, 2(1), 81-89.

Sparks, D., \& Hirsh, S. (1997). A new vision for staff development. Alexandria, VA: Association for Supervision and Curriculum Development.

Spillane, S. J. (2005). Distributed leadership. The Education Forum, 69, 143150. 
Stake, R. E. (1995). The art of case study research. Thousand Oaks, CA: Sage.

Stake, R. E. (2000). Case studies. In K. N. Denzin \& S. Y. Lincohn (Eds.), Handbook of qualitative research (pp. 435-453). Thousand Oaks: Sage.

Stake, R. E. (2005). Qualitative case studies. In N. K. Denzin \& Y. S. Lincohn (Eds.), The Sage handbook of qualitative research ( $3^{\text {rd }}$ ed., pp. 443446). Thousand Oaks, CA: Sage.

Stake, R. E. (2006). Multiple case study analysis. New York: The Guilford Press.

Stake, R. E. (2008). Qualitative case studies. In K. N. Denzin \& S. Y. Lincohn (Eds.), Strategies of qualitative inquiry (pp. 119-149). Los Angeles: Sage.

Sypawka, W. (2008). A study of division deans' in the North Carolina community college system self-perceived leadership style based on Bolman and Deal's four frame theory. (Unpublished PhD thesis), East Carolina University, Greenville, NC.

Teddlie, C., \& Reynolds, D. (2000). The international handbook of school effectiveness research. London, England: Falmer Press.

Thang, D. T. (2013). Confusian values and school leadership in Vietnam. (Unpublished PhD thesis), Victoria University of Wellington, New Zealand.

Thanh, P. (2013). Thị trường vẫn "đói" lao động kỹ thuật cao (The market is still "hungry" for high-tech workers). Retrieved 31 December 2013 http://dantri.com.vn/nghe-nghiep/thi-truong-van-doi-lao-dong-ky-thuatcao-710932.htm 
Thinh, H. D., \& Phuong, T. M. H. (2010). General reform in higher education of Vietnam. Paper presented at the Asia Leadership Roundtable, Asia Pacific Centre for Leadership and Change, Hong Kong.

Tho, T. V. (2014). Đừng nhập nhằng quan chức và tiến sĩ (Do not be ambiguous between officials and PhD holders). Retrieved 17 January from http://tuoitre.vn/Ban-doc/590556/dung-nhap-nhang-quan-chucva-tien-si.html

Thornton, R. K. (2010). The nature of distributed leadership and its development in online environments. In P. Young (Ed.), Leadership in the digital enterprise: Issues and Challenges (pp. 1-14): Hershey PA: IG Global.

Thrash, A. (2012). Leadership in higher education. International Journal of Humanities and Social Science, 2(13), 1-12.

Timperley, H. (2005). Distributed leadership: Developing theory from practice. Journal of Curriculum Studies, 37(4), 395-420. doi: $10.1080 / 00220270500038545$

Toan, V. (2013, March 27). English teaching in Vietnam: Teacher 'reeducation', Tuoitre. Retrieved 20 May 2014 from http://tuoitrenews.vn/education/8231/english-teaching-in-vietnamteacher-reeducation

Trinh, T. N. L. (2011, December 4). Vietnamese traditional family values Vietspring. Retrieved 20 December 2012 from http://www.vietspring.org/values/traditionalval.html

Trinh, T. T. (2012, November 22). FPT university wins three stars, Vietnamnews. Retrieved 6 June 2013 from http://vietnamnews.vn/Economy/233113/fpt-university-wins-three$\underline{\text { stars.html }}$ 
Trong, P. N. (2013). Nghị quyết Hội nghị lần thứ 8, Ban Chấp hành Trung ương khóa XI (Nghị quyết số 29-NQ/TW) về đổi mới căn bản, toàn diện giáo dục và đào tạo, đáp ứng yêu cầu $\mathrm{CNH}-\mathrm{H} Đ H$ trong điều kiện kinh tế thị trường định hướng XHCN và hội nhập quốc tế (Resolution of the 8th Congress by Party General Secretary on innovating completely and fundamentally Vietnamese education system, No.29NQ/TW, Party General Secretary Retrieved 15 February 2014 from http://laodong.com.vn/dang-chinh-phu/ban-hanh-nghi-quyet-ve-doimoi-can-ban-toan-dien-giao-duc-va-dao-tao-146445.bld

Tuckett, A. G. (2005). Applying thematic analysis theory to practice: A researcher's experience. Contemporary Nurse, 19(1), 75-87.

Tuoitre. (2012, October 26). Vietnam education research behind regional standards Tuoitrenews. Retrieved 29 November 2012 from http://tuoitrenews.vn/education/3209/vietnam-education-researchbehind-regional-standards

Tuy, H. (2007). New year, old stories. Tia Sang, Journal of the Ministry of Science and Technology(3-4).

Tuyet, T. T. (2012). Vietnamese higher education and the issue of enhancing graduate employability. Journal of Teaching and Learning for Graduate Employability, 3(1), 2-16.

Tuyet, T. T. (2013). Is the learning approach of students from the Confucian heritage culture problematic? Educational Research for Policy and Practice, 12(1), 57-65.

Tuyet, T. T. (2013). Limitation on the development of skills in higher education in Vietnam. Higher Education, 65(5), 631-644.

Tuyet, T. T. (2013). Factors affecting teaching and learning English in Vietnamese universities. The Internet Journal Language, Culture and Society. 
United Nations Educational, Scientific and Cultural Organisation (2014). Education for all global monitoring report - Teaching and learning: Achieving quality education for all Retrieved 12 May 2015 from http://www.unesco.org/new/en/education/themes/leading-theinternational-agenda/efareport/reports/2013/

Valley, T. J., \& Wilkinson, B. (2009). Vietnamese higher education: crisis and response. Harvard Kennedy School, U.S.A.: Ash Institute from Democratic Governance and Innovation.

Van, T. N. (2007). Foreign language teaching and learning at the University of Engineering and Technology, Vietnam National University. VNU Scientific Journal - Foreign Language, 23, 138-142.

Van, V. H. (2008). Factors affecting the quality of English education at Vietnam National University, Hanoi VNU Scientific Journal - Foreign Language, 24, 22-37.

Van, V. H. (2011). The current situation and issues of the teaching of English in Vietnam 立命館言語文化研究, 22(1).

Varghese, N. V. (2009). Globalization, economic crisis and national strategies for higher education development. France: International Institute for Educational Planning, UNESCO.

Varghese, N. V., Martin, M. (Eds.) (2014). Governance reform in higher education: A study of institutional autonomy in Asian countries Paris, France: Institutional Institute for Education Planning, UNESCO.

Vidyarthi, R. P., Erdogan, B., Anand, S., \& Liden, C. R. (2014). One member, two leaders: Extending leader - Member exchange theory to a dual leadership context. Journal of Applied Psychology, 99(3), 468-483. doi: $10.1037 / \mathrm{a} 0035466$

Vietnam News Agency. (2011, November 14). Teachers complain about overwork, Dantri. Retrieved 27 July 2012 from 
http://www.dtinews.vn/en/news/020/19076/teachers-complain-aboutoverwork.html

Vietnam News Agency. (2011, December 23). Universities need to up teacher training: Experts, Dantri. Retrieved 15 January 2013 from http://www.dtinews.vn/en/news/020/19999/universities-need-to-upteacher-training--experts.html

Vietnam News. (2012a). Local teachers of English not up to standard Retrieved 27 April 2013, from Dantrinews http://www.dtinews.vn/en/news/020/20328/local-teachers-of-englishnot-up-to-standard-.html

Vietnam News Agency. (2012b). Educational system faces crisis. Retrieved 3 October 2013, from Vietnamnews http://vietnamnews.vn/society/230920/educational-system-facescrisis.html

Vietnam News Agency. (2012c). Ngoại giao Việt Nam vươn tới những tầm cao mới (Vietnam's diplomatic relations strives for new height vision). Retrieved 26 August 2013, from http://www.vietnambotschaft.org/ngoai-giao-viet-nam-vuon-toi-nhungtam-cao-moi/

Vietnam News Agency. (2012d). Việt Nam có khoảng 24 ngàn tiến sĩ ( Vietnam has about 24,000 Ph.D. holders). Retrieved 19 August 2013 from Kenhtuyensinh http://kenhtuyensinh.vn/viet-nam-co-khoang-24ngan-tien-si

Vietnam News Agency. (2013, November 23). Vietnam improves English proficiency, Dantrinews. Retrieved 11 January 2014 from http://www.dtinews.vn/en/news/020/32128/vietnam-improves-englishproficiency.html 
Vietnam News Agency. (2014). Three Vietnamese universities in Asia's top 300, Vietnamnews. Retrieved 29 December 2014 from http://vietnamnews.vn/society/254955/vn-universities-listed-in-topasian-schools.html

Voogt, A. D. (2006). Dual leadership as a problem-solving tool in arts organisations. International Journal of Arts Management, 9(1), 73-78.

Walliman, N. (2001). Your research project a step-by-step guide for the first time teacher. London: Sage.

Wiggins, G., \& McTighe, J. (2006). Understanding by design. Upper Saddle River: Pearson Education.

Wiles, J. (2009). Leading curriculum development. Thousand Oaks, CA: Sage.

Wolf, P., \& Hughes, J. C. (2007). Curriculum development in higher education: Faculty-driven processes and practices. New Directions for Higher Education, 112, 1-128.

Wood, R. D. (2004). Leadership behaviors of academic college deans in Mississippi's eight state-supported universities. (Unpublished PhD thesis), The University of Southern Mississippi, U.S.A.

Woolner, P., Thomas, U., Todd, L., \& Cummings, C. (2009). How do visually mediated encounters differ from traditional interviews? Paper presented at the The first International Visual Methods Conference, Leeds, U.K.

Yin, K. R. (1994). Case study research: design and methods (2 ${ }^{\text {nd }}$ ed.). Thousand Oaks: Sage.

Yin, K. R. (2003). Case study research (3 ${ }^{\text {rd }}$ ed.). Thousand Oaks: CA: Sage. 
Yin, K. R. (2009). Case study research: Design and methods ( $4^{\text {th }}$ ed.). Los Angeles: Sage.

Yin, K. R. (2011). Qualitative research from start to finish: The Guilford Press. 


\section{APPENDICES}

Appendix A: Current Basic English curriculum at two universities (for the first semester) adapted from Business Basics by David Grant and Robert McLarty (2004)

\begin{tabular}{|l|l|c|}
\hline \multicolumn{1}{|c|}{$\mathbf{N}^{\mathbf{0}}$} & Content of language teaching & $\begin{array}{l}\text { Amount of } \\
\text { teaching } \\
\text { hours }\end{array}$ \\
\hline $\begin{array}{l}\text { Unit 1: You and your } \\
\text { company }\end{array}$ & Vocabulary and pronunciation & 1 \\
& Language study & 3 \\
& Communication skills & 2 \\
& Practice & 2 \\
\hline Unit 2: Preparing a trip & Vocabulary and pronunciation & 1 \\
& Language study & 2 \\
& Communication skills & 2 \\
& Practice & 2 \\
\hline Unit 3: Away on business & Vocabulary and pronunciation & 1 \\
& Language study & 2 \\
& Communication skills & 2 \\
& Practice & 2 \\
\hline Unit 4: Visiting a company & Vocabulary and pronunciation & 1 \\
& Language study & 2 \\
& Communication skills & 2 \\
& Practice & 3 \\
& Mid-term test & 1 \\
\hline Unit 5: New developments & Vocabulary and pronunciation & 2 \\
& Language study & 2 \\
& Communication skills & 2 \\
\hline Unit 6: Arrangement & Practice & 1 \\
& Vocabulary and pronunciation & 2 \\
& Language study & 2 \\
\hline Total: 6 units & Communication skills & 2 \\
\hline & Practice & 45 \\
& & $(12$ credit \# \\
& & 15 periods) \\
\hline & & \\
\hline
\end{tabular}


Appendix B: Governance, leadership and management of curriculum design and delivery at two selected universities

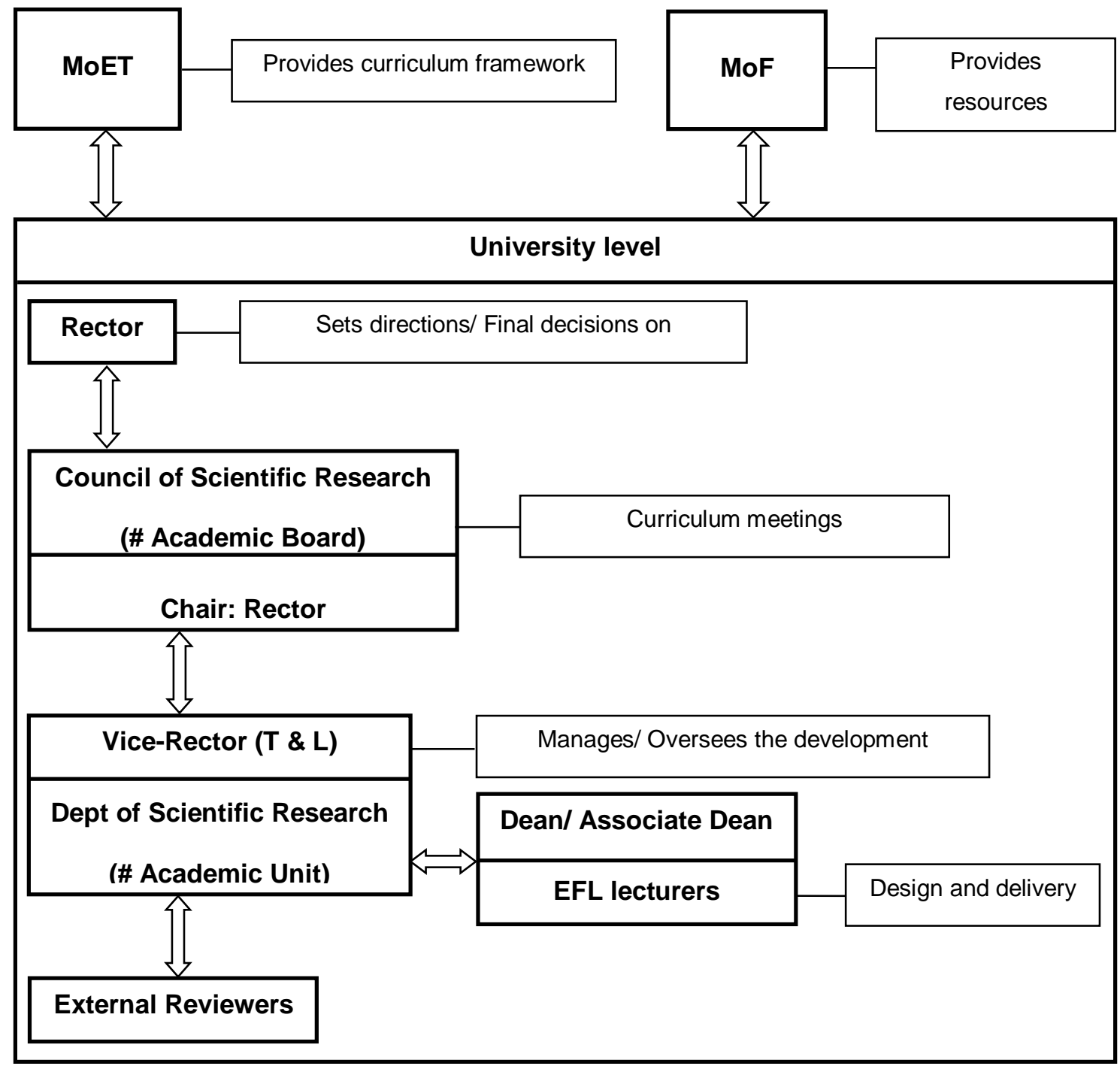




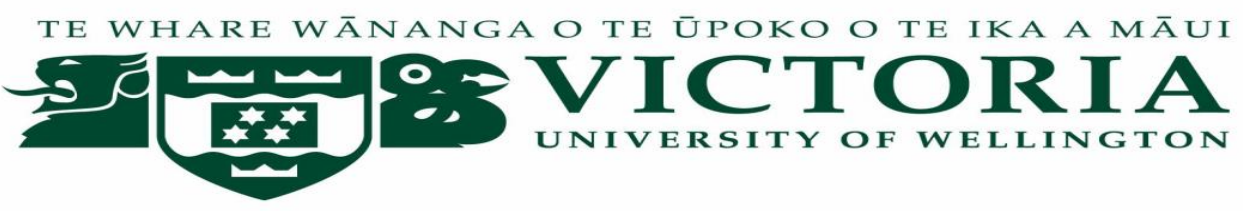

FACULTY OF EDUCATION

\section{Appendix C: Letter to the Rector of University One/ Two (Asking for permission to conduct research)}

Dear Sir or Madam,

I am Tran Thi Bich Thuy, a PhD student at Faculty of Education, Victoria University of Wellington in New Zealand. As part of this degree, I am required to undertake a research project leading to a thesis. I am writing to ask for your permission in order to conduct my research in your university from ....( date).... to .... (date)..... .

The purpose of this study is to explore the role of leadership in promoting and supporting the Basic English curriculum design and delivery at two Vietnamese universities. The research process will be undertaken in the following manner.

- Visiting the university: Initially, I will visit your university to have a meeting with you and representatives of departments to provide further background information about the research;

- Selecting participants: I will invite you (Rector), Vice-Rector(s), Dean/ViceDean of Training Department, Dean/Vice-Dean of Scientific Research and International Relations Department, Dean/Vice-Dean of English Department and six EFL lecturers to participate in the research. Prior to selection, all participants will be fully provided with the necessary information about the research before deciding whether they wish to participate in this study. Their participation is voluntary and they may withdraw from the research at any time without any disadvantage of any kind. 
- Collecting data: I will conduct individual interviews with six academic leaders. Each interview session will take about an hour. EFL lecturers will be invited to join a focus group interview lasting for about one hour. Observations will also be made during scientific meetings about curriculum issues as well as document analysis including the university strategic plan, Basic English curriculum, self-study reports, decisions, agendas or any other items related to teaching and learning Basic English so as to gather supplementary and supportive data for the research.

This research has been assessed and approved by the Human Ethics Committee, Faculty of Education, Victoria University of Wellington, New Zealand, $\mathrm{N}^{0} \mathrm{RM} 19643$. I can assure you that all the identifying information related to the participants and your university will be protected. All the research information will be kept confidential through the use of pseudonyms and the removal of any identifying details. The audio recordings will be kept secure for a period of up to 5 years before being deleted. All research data would be securely stored either/both in password protected files or/and in locked cupboards and will be destroyed either/both using a pager shredder or/and electronically wiped within five years after the completion of the research.

If you have questions about the way the research is being conducted you can contact the Chair of the Victoria University of Wellington Human Ethics Committee, Dr. Allison Kirkman at Allison.Kirkman@vuw.ac.nz. When completed, the doctoral thesis will be submitted to the Victoria University Library and will be online. It is intended that one or more articles about this research topic will be submitted for publication in scholarly journals.

If you are willing to participate could you please sign the consent form and return it to me. If you have any questions or would like to receive further information about the project, please contact me at Thuy.Tran@vuw.ac.nz. You can also contact my supervisors, Dr. Kate Thornton, Senior Lecturer at Kate.Thornton@vuw.ac.nz, Phone $+64-4-4639776$ and/ or Associate 
Professor Catherine Manathunga at Catherine.Manathunga@vuw.ac.nz, Phone: +64-4- 4639719.

Your permission to conduct the research at your university is highly appreciated.

Thank you very much for your support.

Yours sincerely,

Tran Thi Bich Thuy 


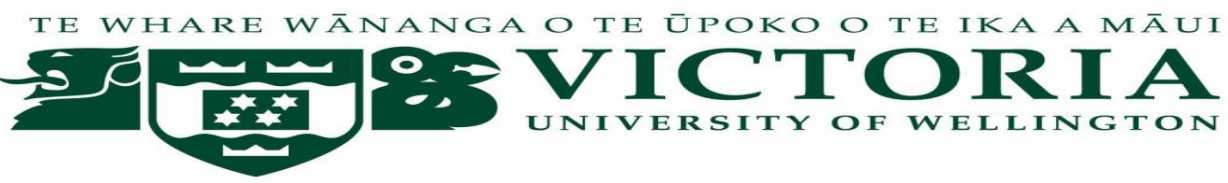

FACULTY OF EDUCATION

Appendix D: INFORMATION SHEET FOR RECTOR OF UNIVERSITY 1/2

Title of project: The role of leadership in promoting and supporting the Basic English curriculum design and delivery at two Vietnamese universities.

I am Tran Thi Bich Thuy, a PhD student at Faculty of Education, Victoria University of Wellington - New Zealand and an EFL lecturer at University of Finance and Accounting - Vietnam. As part of my doctoral study, I am conducting research to examine the role of leadership in promoting the Basic English curriculum design and delivery at two Vietnamese universities. The purpose of this study is to obtain in-depth understanding of leadership role of academic leaders in order to gain insights into how leaders at different levels perform in promoting and supporting the Basic English curriculum design and delivery in the Vietnamese tertiary context.

My study will be conducted in two public university institutions. The research process will be undertaken in the following manner:

Visiting the university: Initially, I will visit each university to have a meeting with you, representatives of some related departments to discuss the research and ask for the permission to conduct the research.

\section{Selecting participants:}

Participants for the interviews: I will meet and invite 6 academic leaders in your university to participate in face-to-face interviews and 6 EFL lecturers for a focus group interview. 


\section{Collecting data:}

Interviews: I will conduct individual interviews with you and six other academic leaders at your university. The six academic leaders will be purposively selected to vary in gender and academic roles. Each interview session will last for about an hour. The interview will be semi-structured and audio-recorded for the purposes of maintaining an accurate record of the participants' responses.

Focus-group interviews: My research involves two focus groups of EFL lecturers. Each focus group which consists of six EFL lecturers from each institution lasts for about an hour. Eligible lecturers are those who have at least two years of teaching Basic English. Similar to face-to-face interview, focus group interviews will be audio-recorded for the purposes of maintaining an accurate record of each participant's words.

Observations: I will conduct an observation of Basic English curriculum meeting of academic leaders and EFL lecturers in each university to gather supplementary data for the research. I will take notes of the discussion during the meeting.

Participants for the online survey: After your permission to access the university data base to get detailed contact of recent graduate students. I will email them and inivte them to participate in my online survey.

All these activities will be done during my data collection from March 2013 to August 2013. If you volunteer to participate in this study, your responses and feedback will be treated confidentially. Your identity will be protected through the use of pseudonym and removal of any identifying details. All research data will be securely stored in password protected files and in locked drawers and will be destroyed within five years after the completion of the research.

When completed, the doctoral thesis will be submitted to the Victoria University Library and will be online. It is intended that one or more articles 
about this research topic will be submitted for publication in scholarly journals.

This research has been accessed and approved by the Victoria University Faculty of Education Ethics Committee, $\mathrm{N}^{0} \mathrm{RM}$ 19643. If you have questions about the way the research is being conducted you may contact the chair of the Victoria University of Wellington Human Ethics Committee, Dr. Allison Kirkman at Allison.Kirkman@vuw.ac.nz

If you have any questions or would like to receive further information about the project, please contact me at Thuy.Tran@vuw.ac.nz. You can also contact my supervisors,

Dr. Kate Thornton, Senior Lecturer at Kate.Thornton@vuw.ac.nz, Phone $+64-4-4639776$ and/ or Associate Professor Catherine Manathunga at Catherine.Manathunga@vuw.ac.nz, Phone: +64-4- 4639719.

Tran Thi Bich Thuy

Signed: 


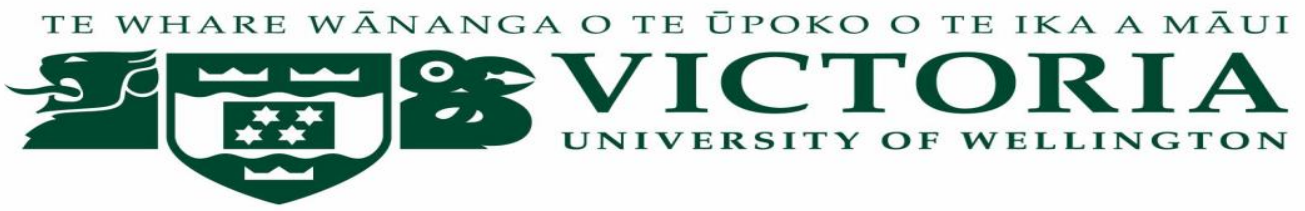

FACULTY OF EDUCATION

\section{Appendix E: CONSENT FORM FOR RECTOR OF UNIVERSITY 1/2 (to conduct the research in his/her university)}

Title of project: The role of leadership in promoting and supporting the Basic English curriculum design and delivery at two Vietnamese universities

Please complete this form if you allow Tran Thi Bich Thuy to conduct her doctoral research at your university. By giving her permission to conduct her study in my university I agree that (please mark each box with a cross $(x)$ to indicate agreement, then sign and date this form):

I I have been given information about this project and discussed the research project with Tran Thi Bich Thuy. I have had an opportunity to ask questions and have them answered to my satisfaction.

I understand what would be required of the participants from this university who take part in individual interviews, focus group interviews, meeting observations.

I understand that my participation in this project is voluntary and the participants may withdraw from it (before data analysis has begun) without having to give reasons or without penalty.

I understand that the university's identity and the participants' identity would be protected and that I may not know the identity of the participants, (or if I do I will keep their identity confidential). 
I understand that all research information would be stored in password protected files and will be destroyed within five years after the completion of the research.

I understand that the data collected from my university will be used for a doctoral thesis and for publication of one or more related articles in scholarly journals, and I consent for it to be used in that manner.

By signing below,

I consent to the researcher conducting her project in this university.

I consent to the researcher having access to relevant documents including the university strategic plan, Basic English curriculum, self-study reports, decisions, agendas or any other items related to teaching and learning Basic English at my university.

I consent to the researcher observing any scientific meetings pertaining to the Basic English curriculum design and delivery policies, mechanisms, and activities in this university. However, the researcher would withdraw from any meeting if requested by the chair (e.g. if the discussion is sensitive).

I would like a copy of the summary of findings of this research forwarded to me at the conclusion of the research.

Signed:

Name:

Date:

Email address for summary of findings: 


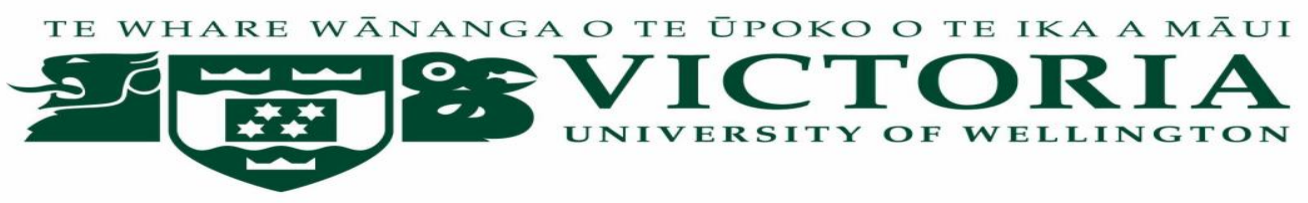

FACULTY OF EDUCATION

\section{Appendix F: CONSENT FORM FOR OTHER ACADEMIC LEADERS}

Title of project: The role of leadership in promoting and supporting the Basic English curriculum design and delivery at two Vietnamese universities

Please complete this form if you would like to participate in Tran Thi Bich Thuy's doctoral research. By taking part in an interview I agree that (please mark each box with a cross $(x)$ to indicate agreement, then sign and date this form):

I I have been given information about this project and discussed the research project with Tran Thi Bich Thuy. I have had an opportunity to ask questions and have them answered to my satisfaction.

I understand that my participation in this project is voluntary. I may withdraw myself (or any information I have provided) from this project (before data analyis has begun) without having to give reasons or without penalty of any sort.

I understand that I will be asked to participate in a semi-structured interview. The interview will last for an hour.

I understand that any information I provide will be kept confidential to the researcher, the supervisors and the person who transcribes the tape recordings of our interview, the published results will not use my name, and that no opinions will be attributed to me in any way that will identify me. 
I understand that all interview data would be stored in password protected files and will be destroyed within five years after the completion of the research.

I understand that I will have an opportunity to check the transcript of the interview and make any corrections within two weeks.

I understand that the data collected from my participation will be used for a doctoral thesis and for publication of one or more articles in scholarly journals, and I consent for it to be used in that manner.

I would like a copy of the summary of findings of this research forwarded to me at the conclusion of the research.

Signed:

Name:

Date:

Email address for summary of findings: 


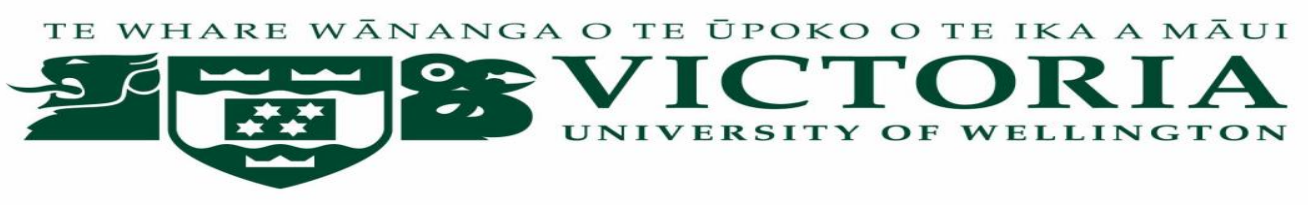

FACULTY OF EDUCATION

\section{Appendix G: INTERVIEW QUESTIONS FOR ACADEMIC LEADERS}

Section A:

Could you please introduce a bit about yourself? (position, qualifications, responsibilities, year in current position?)

Section B:

1. How long have you been in your position?

2. What preparation/ experience have you had for your leadership journey?

3. What is your role and responsibility in curriculum design and delivery?

4. In what ways are you currently involved in the leadership of curriculum design and delivery?

5. What leadership challenges have you faced when dealing with curriculum issues in recent times?

6. In what ways is leadership practice shared in your university?

7. What is the impact of collaborative leadership in curriculum design in your university?

8. What are the barriers that impact on your leadership roles? Both organisational and individual)

9. How do you deal with these challenges? 


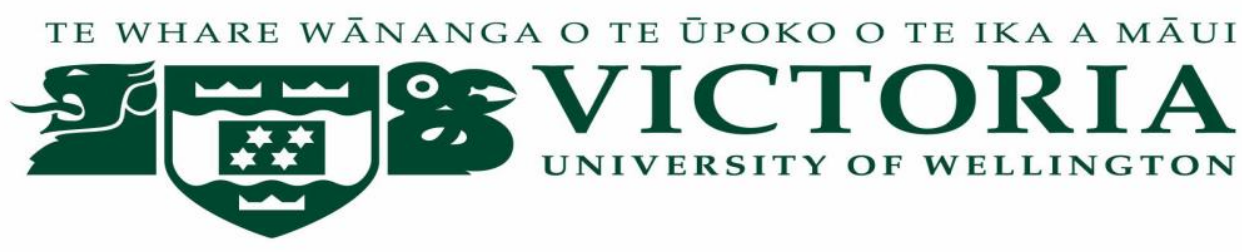

FACULTY OF EDUCATION

\section{Appendix H: CONSENT FORM FOR ELF LECTURERS}

Title of project: The role of leadership in promoting and supporting the Basic English curriculum design and delivery at two selected Vietnamese universities

Please complete this form if you would like to participate in Tran Thi Bich Thuy's doctoral research. By taking part in a focus group interview, I agree that (please mark each box with a cross $(x)$ to indicate agreement, then sign and date this form):

I have been given information about this project and discussed the research project with Tran Thi Bich Thuy. I have had an opportunity to ask questions and have them answered to my satisfaction.

I understand that my participation in this project is voluntary. I may withdraw myself (or any information I have provided) from this project (before data analysis has begun) without having to give reasons or without penalty of any sort.

I understand that I will be asked to participate in a focus group interview. The interview will last for an hour.

I understand that any information I provide will be kept confidential to the researcher, the supervisors and the person who transcribes the tape recordings of our interview, the published results will not use my name, and that no opinions will be attributed to me in any way that will identify me.

I understand that I will keep confidential all information discussed in the focus group interview. 
I I understand that all interview data would be stored in password protected files and will be destroyed within five years after the completion of the research.

$\square$ I understand that I will have an opportunity to check the transcript of the focus group interview and make any corrections within two weeks.

$\square$ I understand that the data collected from my participation will be used for a doctoral thesis and for publication of one or more articles in scholarly journals, and I consent for it to be used in that manner.

$\square \quad$ I would like a copy of the summary of findings of this research forwarded to me at the conclusion of the research.

Signed:.

Name:

Date:.

Email address for summary of findings: 


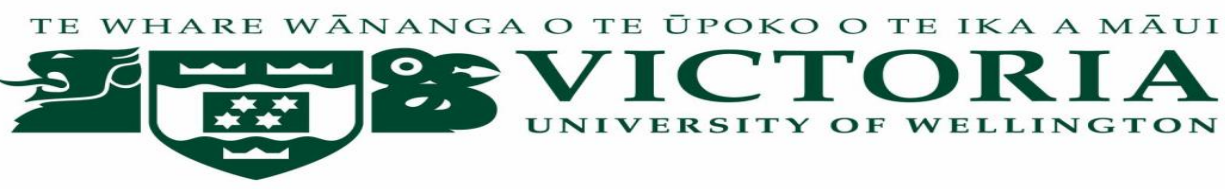

FACULTY OF EDUCATION

\section{Appendix I: Interview questions for EFL lecturers}

\section{Section A: Warm-up questions}

Could please introduce a bit about yourself? (How long have you been teaching at university?/ What's your role and responsibility?)

\section{Section B: Focus group interview questions}

1. In what ways do you work with your colleagues to design the English curriculum?

2. How is this work supported (resources/ professional development)?

3. Who decides what is taught and how is taught?

4. How often do you discuss the content of the subject with the subject coordinator?

5. The literature says that collaboration across the university is very important in curriculum design and delivery. In your opinion, how might it be improved?

6. What's your perception of the role of university leaders relating to curriculum issues?

7. If you could propose some recommendations to the Rector board and senior leaders, what would you recommend to improve the leadership performances relating to curriculum design and delivery in your university? 
FACULTY OF EDUCATION

\section{Appendix J: CONSENT FORM FOR COMPANY DIRECTORS}

Title of project: The role of leadership in promoting and supporting the Basic English curriculum design and delivery at two Vietnamese universities

Please complete this form if you would like to participate in Tran Thi Bich Thuy's doctoral research. By taking part in an interview I agree that (please mark each box with a cross $(x)$ to indicate agreement, then sign and date this form):

1 I have been given information about this project and discussed the research project with Tran Thi Bich Thuy. I have had an opportunity to ask questions and have them answered to my satisfaction.

I understand that my participation in this project is voluntary. I may withdraw myself (or any information I have provided) from this project (before data analysis has begun) without having to give reasons or without penalty of any sort.

I understand that I will be asked to participate in a semi-structured interview. The interview will last for thirty minutes.

I understand that any information I provide will be kept confidential to the researcher, the supervisors and the person who transcribes the tape recordings of our interview, the published results will not use my name, and that no opinions will be attributed to me in any way that will identify me. 
I understand that all interview data would be stored in password protected files and will be destroyed within five years after the completion of the research.

I understand that I will have an opportunity to check the transcript of the interview and make any corrections within two weeks.

I understand that the data collected from my participation will be used for a doctoral thesis and for publication of one or more articles in scholarly journals, and I consent for it to be used in that manner.

I would like a copy of the summary of findings of this research forwarded to me at the conclusion of the research.

Signed:

Name:

Date:

Email address for summary of findings: 


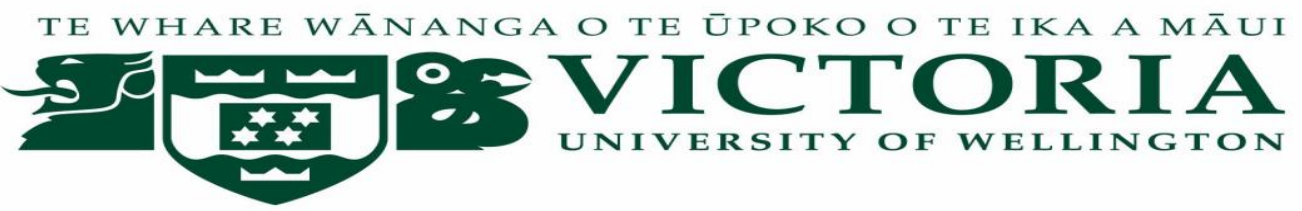

FACULTY OF EDUCATION

\section{Appendix K: INTERVIEW QUESTIONS FOR COMPANY DIRECTORS}

\section{Section A:}

Could you please introduce a bit about yourself and your company (position/time in your position/ type of company, ect.?)

\section{Section B:}

1. What do you think of new employees' English language competence when they begin at your workplace?

2. What skills do you think that they are relatively good at? (i.e Listening, Speaking, Reading, Writing)

3. What skills do you think that they need to reinforce? (i.e Listening, Speaking, Reading, Writing?)

4. What recommendations do you wish to send to university curriculum designer or leader?

5. What additional professional development does your company offer new employees? What do you find they still need to learn?

6. In what ways could universities and businesses collaboratively work about language skills that job applicants need in the workplace so that the university's curriculum design and delivery will be implemented more effectively? 


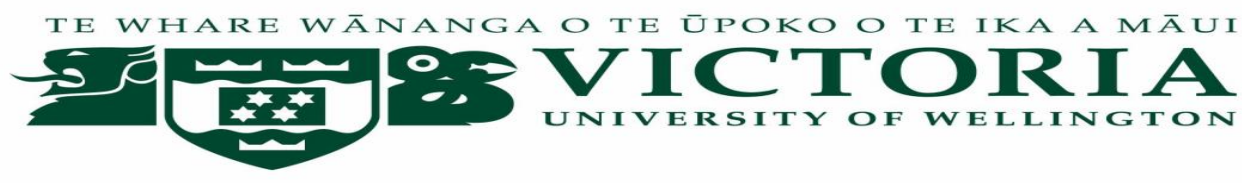

FACULTY OF EDUCATION

\section{APPENDIX L: LETTER TO THE MEETING CHAIRMAN AT UNIVERSITY $1 / 2$}

\section{(Asking for permission to observe the curriculum meeting)}

Dear Sir or Madam,

I am Tran Thi Bich Thuy, a PhD student at Faculty of Education, Victoria University of Wellington in New Zealand. As part of this degree, I am required to undertake a research project leading to a thesis. I am writing to ask for your permission in order to observe a scientific meeting organised in your university regarding the Basic English curriculum issues.

The purpose of this study is to explore the role of leadership in promoting and the Basic English curriculum design and delivery at two Vietnamese universities. The research process will be undertaken in the following manner.

Observations will also be made during scientific meetings about curriculum issues to gather supplementary and supportive data for the research. Before the meeting, I will contact all the participants to explain and invite them to participate in my study. They are asked to sign the consent form to show their voluntary participation and return it to me before the meeting starts.

This research has been assessed and approved by the Human Ethics Committee, Faculty of Education, Victoria University of Wellington, New Zealand, $\mathrm{N}^{0} \mathrm{RM}$ 19643. I can assure you that all the identifying information related to the participants and your university will be protected. All the research information will be kept confidential through the use of pseudonyms 
and the removal of any identifying details. The audio recordings will be kept secure for a period of up to 5 years before being deleted. All research data would be securely stored either/both in password protected files or/and in locked cupboards and will be destroyed either/both using a pager shredder or/and electronically wiped within five years after the completion of the research.

If you have questions about the way the research is being conducted you can contact the Chair of the Victoria University of Wellington Human Ethics Committee, Dr. Allison Kirkman at Allison.Kirkman@vuw.ac.nz. When completed, the doctoral thesis will be submitted to the Victoria University Library and will be online. It is intended that one or more articles about this research topic will be submitted for publication in scholarly journals.

If you are willing to participate could you please sign the consent form and return it to me.If you have any questions or would like to receive further information about the project, please contact me at Thuy.Tran@vuw.ac.nz. You can also contact my supervisors, Dr. Kate Thornton, Senior Lecturer at Kate.Thornton@vuw.ac.nz, Phone + +64-4-463 9776 and/ or Associate Professor Catherine Manathunga at Catherine.Manathunga@vuw.ac.nz, Phone: + 64-4- 4639719.

Your permission to observe the meeting relating to the Basic English curriculum issues at your university is highly appreciated.

Thank you very much for your support.

Yours sincerely,

Tran Thi Bich Thuy 


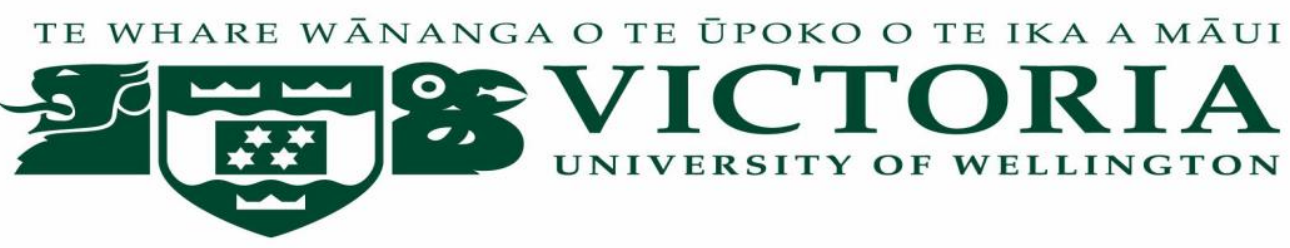

FACULTY OF EDUCATION

Appendix M: CONSENT FORM FOR MEETING PARTICIPANTS

Title of project: The role of leadership in promoting and supporting the Basic English curriculum design and delivery at two Vietnamese universities

By giving Tran Thi Bich Thuy permission to observe the meeting that I am one of the attenders, I agree that (please mark each box with a cross $(x)$ to indicate agreement, then sign and date this form):

I have been given information about the purpose of the observation and discussed this with Tran Thi Bich Thuy. I have had an opportunity to ask questions and have them answered to my satisfaction.

I understand what would be observed during the meeting that I am attending.

I understand that the university's identity and each attendant's identity will be protected. I will not divulge the identity of the attendants in the meeting.

I understand that any information I provide during the meeting will be kept confidential to the researcher, and the supervisors. The published results will not use my name, and that no opinions will be attributed to me in any way that will identify me. 
I understand that I will have an opportunity to check the summary of what will have been observed and make any corrections within two weeks.

I understand that all research information would be stored in password protected files and will be destroyed within five years after the completion of the research.

I understand that the data collected from the meeting observation will be used for a doctoral thesis and for publication of one or more related articles in scholarly journals, and I consent for it to be used in that manner.

By signing below,

I give Tran Thi Bich Thuy permission to come and audio-record at the meeting

I give Tran Thi Bich Thuy permission to be at the meeting but I do not want her to record my contribution

I would rather not to be observed at the meeting

I would like a copy of the summary of findings of this research forwarded to me at the conclusion of the research.

Signed:

Name:

Date

Email address for summary of findings: 
FACUTY OF EDUCATION

\section{Appendix N: GREETINGS AND ONLINE SURVEY FOR GRAUDATES FROM UNIVERSITY 1/2}

Greetings,

I am Tran Thi Bich Thuy, PhD student at Facuty of Education, Victoria University of Wellington in New Zealand. As part of this degree, I am required to undertake a research project leading to a thesis.

You are invited to participate in an anonymous survey that explores your perceptions of the effectiveness of the Basic English curriculum design and delivery which you had learnt before you left university. The survey will take approximately 15 minutes to complete. It is part of a wider research study exploring the role of leadership in promoting the Basic English curriculum design and delivery at two selected Vietnamese universities. Results of this study will be included in publications and presentations and will contribute to a greater understanding of the role of leadership in curriculum design and delivery in the Vietnamese higher education context.

By completing this survey you are consenting to participate in the research. Participation in this survey is optional and your responses will not be identified.

To complete the survey please click on the link ...... below. Survey responses must be received by ....(date)... to be included in the research study.

All data collected will be kept confidential and secure and will be destroyed 5 years after the conclusion of the project. This project has been assessed and approved by the Victoria University of Wellington Faculty of Education's Human Ethics Committee on 4 March 2013, N RM 19643.

If you have questions, please feel free to contact me at thuy.tran@vuw.ac.nz for further information. If you have any questions about the ethical issues 
associated with this research you may contact Dr. Allison Kirkman at Allison.Kirkman@vuw.ac.nz, Chair of the Victoria University of Wellington Human Ethics Committee.

Thank you very much.

Tran Thi Bich Thuy

PhD student

School of Education

Victoria University of Wellington, New Zealand

\section{Online survey}

\section{Part I:}

1. Your gender: Male

Female

2. Your age:

- $22-26$

- 27-31

- 32-36

3. Which university did you attend?

University A

University B

4. Describe your current area of work

- Accounting -

- Finance

- Banking

- Others (please specify)

\section{Part II: Questionnaire}




\begin{tabular}{|c|c|c|c|c|c|}
\hline \multirow{2}{*}{ Questions } & \multicolumn{5}{|c|}{ Rating scale } \\
\hline & $\begin{array}{l}\text { Strongly } \\
\text { agree }\end{array}$ & Agree & Neutral & Disagree & $\begin{array}{l}\text { Strongly } \\
\text { disagree }\end{array}$ \\
\hline $\begin{array}{l}\text { 1. The Basic English curriculum } \\
\text { is in accordance with the } \\
\text { training objectives. } \\
\text { (See on www......edu.vn/ } \\
\text { /www......edu.vn) }\end{array}$ & & & & & \\
\hline $\begin{array}{l}\text { 2.The structure of the Basic } \\
\text { English curriculum (in terms of } \\
\text { Listening, Speaking, Reading, } \\
\text { Writing) is flexible to facilitate } \\
\text { the learning of students. }\end{array}$ & & & & & \\
\hline $\begin{array}{l}\text { 3.The content of the Basic } \\
\text { English curriculum is relevant to } \\
\text { your practical work. }\end{array}$ & & & & & \\
\hline $\begin{array}{l}\text { 4. The content of the Basic } \\
\text { English curriculum is easily } \\
\text { understood by students. }\end{array}$ & & & & & \\
\hline $\begin{array}{l}\text { 5.Knowledge gained from the } \\
\text { course ensured that I was } \\
\text { confident in my ability to find to } \\
\text { find a job. }\end{array}$ & & & & & \\
\hline $\begin{array}{l}\text { 6. The total amount of credit } \\
\text { hours between theory and } \\
\text { practice was appropriate. }\end{array}$ & & & & & \\
\hline $\begin{array}{l}7 . I \text { am satisfied with the } \\
\text { lecturers' teaching and different }\end{array}$ & & & & & \\
\hline
\end{tabular}




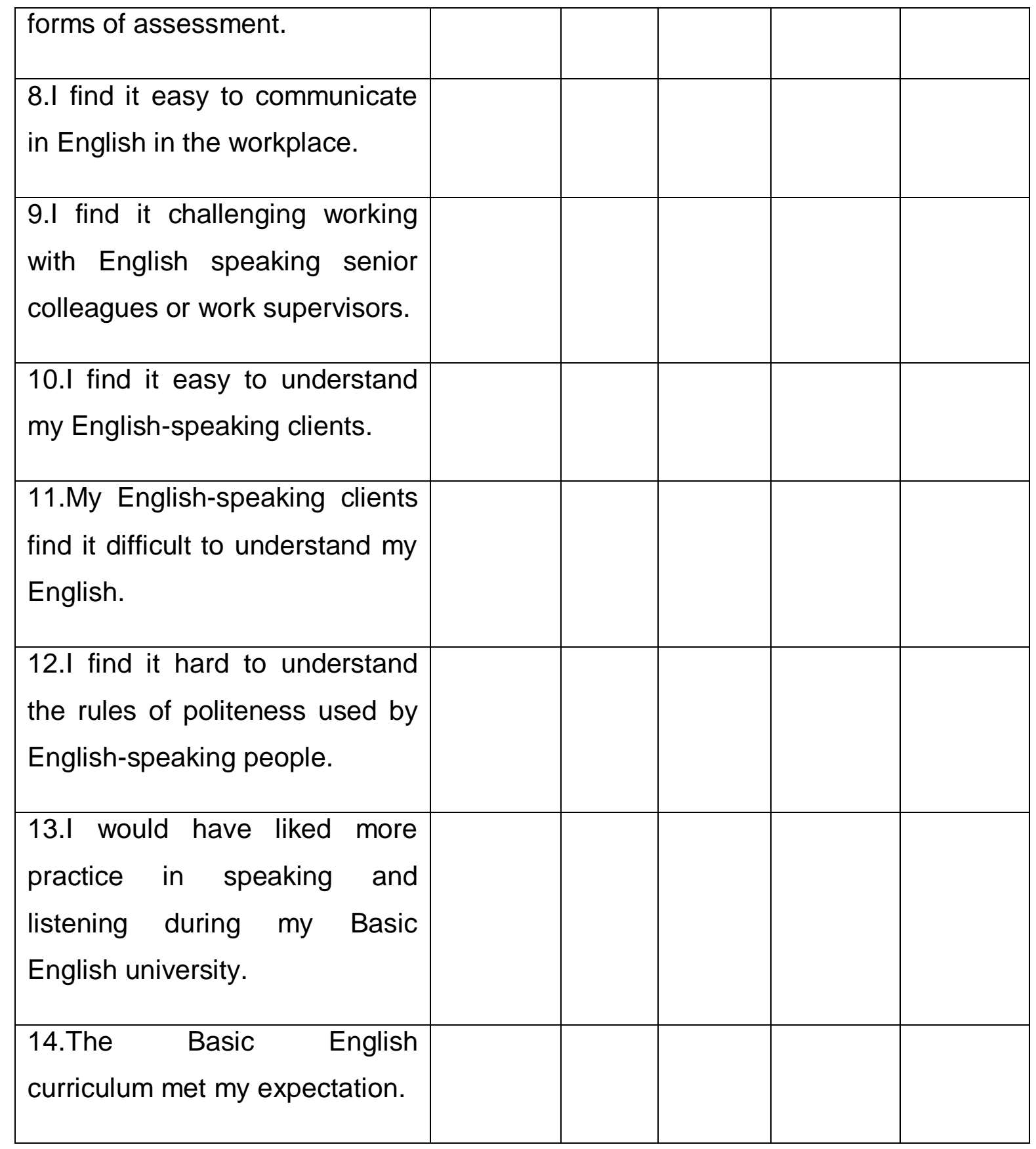




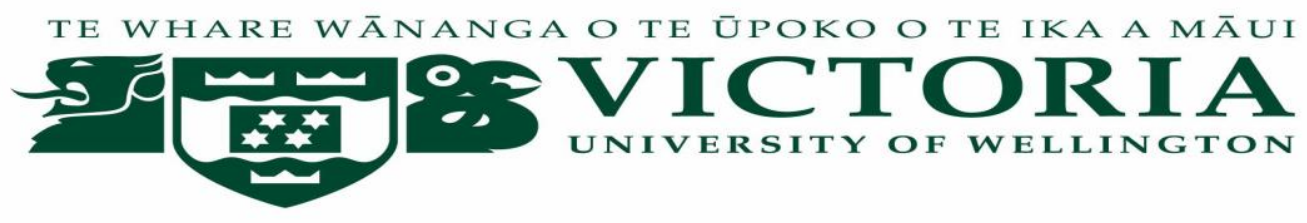

FACULTY OF EDUCATION

\section{Appendix M: Transcription and/or translation Confidentiality Agreement}

Title of project: The role of leadership in promoting and supporting the Basic English curriculum design and delivery at two Vietnamese universities

I, ............................, transcriber and/ or translator, individually, do hereby agree to maintain full confidentiality in regards to any and all audiotapes or written documentation received from Tran Thi Bich Thuy related to her research study titled The role of leadership in promoting the Basic English curriculum design and delivery at two selected Vietnamese university institutions. Furthermore, I agree:

1. To hold in strict confidence the identification of any individual that may be inadventently related during the transcription of audio-taped or live oral interviews, or in any associated documents;

2. To not disclose any information received for profit, gain, or otherwise;

3. To not make copies of any audio tapes or computerised files of the transcribed interview texts, unless specially requested to do so by Tran Thi Bich Thuy;

4. To store all study-related audiotapes and materials in a safe, secure location as long as they are in my possession; 
5.To return all audiotapes and study-related documents to Tran Thi Bich Thuy in a complete and timely manner.

6. To delete all electronic files containing study-related documents from my computer hard drive and any backup devices.

For Transcriber/ Translator:

Address:

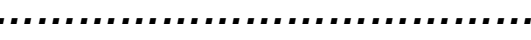

Telephone:

Email:

I am aware that I can be held legally liable for any breach of this confidentiality agreement, and for any harm incurred by individuals if I disclose identifiable information contained in the audiotapes and or/ paper files to which I will have access. I am further aware that if any breach of confidentiality occurs, I will be fully subject to the stipulation of Vietnamese laws on notarization No: 82/2006/QH11 about the translation version is verified at the Justice office of Vietnam.

Transcriber/ Translator's name:

Transcriber/ Translator's signature:

Transcriber/ Translator's title( if applicable):

Date:
For researcher: Tran Thi Bich Thuy

Address: R103, Postgraduate House

31 Campbell street, Karori

Wellington, New Zealand

Telephone: + 64-4-4635233 Ext.9851

Email: Thuy.Tran@vuw.ac.nz 